CENTRO UNIVERSITÁRIO FEI

LAERCIO RIBEIRO DA SILVA JUNIOR

MÉTRICAS COGNITIVAS PARA ANÁLISE DE PROFICIÊNCIA EM XADREZ BASEADAS EM SINAIS DE ELETROENCEFALOGRAMA E MOVIMENTOS OCULARES

São Bernardo do Campo 

LAERCIO RIBEIRO DA SILVA JUNIOR

\section{MÉTRICAS COGNITIVAS PARA ANÁLISE DE PROFICIÊNCIA EM XADREZ BASEADAS EM SINAIS DE ELETROENCEFALOGRAMA E MOVIMENTOS OCULARES}

Tese de Doutorado, apresentada ao Centro Universitário FEI para obtenção do título de Doutor em Engenharia Elétrica. Orientada pelo Prof. Dr. Carlos Eduardo Thomaz.

São Bernardo do Campo 
Silva Junior, Laercio Ribeiro da.

Métricas Cognitivas para Análise de Proficiência em Xadrez

Baseadas em Sinais de Eletroencefalograma e de Movimentos

Oculares / Laercio Ribeiro da Silva Junior. São Bernardo do

Campo, 2021.

132 p. : il.

Tese - Centro Universitário FEI.

Orientador: Prof. Dr. Carlos Eduardo Thomaz.

1. Xadrez. 2. Eletroencefalografia. 3. Eye-tracking. 4.

Reconhecimento de padrão. I. Thomaz, Carlos Eduardo, orient. II.

Título.

Elaborada pelo sistema de geração automática de ficha catalográfica da FEI com os dados fornecidos pelo(a) autor(a). 
Título do Trabalho: Métricas cognitivas para análise de proficiência em xadrez baseadas em sinais de eletroencefalograma e movimentos oculares.

Área de Concentração: Processamento de Sinais e Imagens

Orientador: Prof. Dr. Carlos Eduardo Thomaz

Data da realização da defesa: $26 / 02 / 2021$

\section{ORIGINAL ASSINADA}

Avaliação da Banca Examinadora

O aluno fez uma apresentação oral de 35 minutos. A seguir, foi arguido por cada um dos membros da banca, tendo respondido aos questionamentos de forma satisfatória. A banca sugeriu alterações de melhoria no texto (versão final). Ao final, o aluno foi aprovado por unanimidade.

São Bernardo do Campo, 26 / 02 / 2021.

\section{MEMBROS DA BANCA EXAMINADORA}

Prof. Dr. Carlos Eduardo Thomaz

Profa Dra Paula Dornhofer Paro Costa

Prof. Dr. Wilson da Silva

Prof. Dr. André Mascioli Cravo

Prof. Dr. Ivandro Sanches
Ass.:

Ass.:

Ass. :

Ass.:

Ass. :

A Banca Examinadora acima-assinada atribuiu ao aluno o seguinte:

APROVADO $\bigotimes$

REPROVADO

\section{VERSÃO FINAL DA TESE}

ENDOSSO DO ORIENTADOR APÓS A INCLUSÃO DAS RECOMENDAÇÕES DA BANCA EXAMINADORA
Aprovação do Coordenador do Programa de Pós-graduação

Prof. Dr. Carlos Eduardo Thomaz 

Aos meus pais. 



\section{AGRADECIMENTOS}

Agradeço aos meus pais pelo incentivo e total apoio que me foi dado.

Agradeço ao meu orientador Prof. Dr. Carlos Eduardo Thomaz, pelo apoio, motivação, pelas sugestões, pelas aulas ministradas, pelas oportunidades dadas e por acreditar no meu trabalho.

Aos meus pais, Laercio e Regina, pelo amor, incentivo, ensinamentos e apoio desde sempre.

Aos meus irmãos, Kaique e Marrary, pelas conversas e momentos de descontração.

À minha esposa, Viviane, pelo incentivo e por estar sempre ao meu lado.

Aos professores do Centro Universitário da FEI pelo incentivo e pelas aulas ministradas:

Prof. Dr. Ivandro Sanches, Prof. Dr. Plinio Thomaz Aquino Junior, Prof. Dr. Raul Cesar Gouveia Fernandes e Prof. Dr. João Chang Júnior

Agradeço à CAPES pela bolsa de estudos de doutorado. 

A felicidade é uma experiência ligada à sabedoria. Roberto Shinyashiki 



\section{RESUMO}

O jogo de xadrez tem atraído o interesse de vários trabalhos acadêmicos em áreas distintas do conhecimento científico. Nesses trabalhos, a discriminação entre proficientes e nãoproficientes se dá, essencialmente, por métricas relacionadas ao Rating ELO, ao tempo dedicado à prática do xadrez ou em testes baseados na acurácia e tempo de resposta dos voluntários. Nenhuma dessas métricas considera explicitamente como os indivíduos pensam ou pensaram, de fato, durante as jogadas para, então, investigar se os sinais cognitivos desses voluntários seguem padrões que permitam classificá-los em níveis de proficiência automaticamente. O objetivo principal desta tese é analisar a proficiência de um enxadrista por meio de sua ativação cerebral (sinais de eletroencefalografia) e movimentos oculares em determinados estímulos relacionados ao jogo de xadrez. Mais especificamente, objetiva-se: (1) adquirir e interpretar sinais cognitivos de enxadristas com diferentes níveis de proficiência para reconhecer possíveis padrões cognitivos durante jogadas específicas de xadrez; (2) implementar métodos estatísticos para interpretar, analisar e classificar os sinais cognitivos de enxadristas com diferentes níveis de proficiência; (3) separar e classificar jogadores de xadrez de acordo com seu nível de proficiência por meio de seus sinais cerebrais e movimentos oculares; 4) ranquear o nível de proficiência de enxadristas e compará-lo com a métrica tradicional de ranqueamento baseado em acurácia e tempo de resposta. Experimentos foram realizados em uma tela de computador envolvendo 51 questões relacionadas ao jogo de xadrez, separadas nas seguintes 5 categorias: (1) reconhecimento de peças e posicionamento; (2) reconhecimento de situações de xeque; (3) reconhecimento de situações de xeque-mate; (4) possibilidade de xeque-mate em um lance; e (5) conhecimento de jogadas e possibilidade de captura de peças. Um total de 32 voluntários contribuíram para esses experimentos, dentre os quais participaram jogadores profissionais de xadrez com rating ELO (4 voluntários), professores de xadrez (4), crianças em idade escolar que eram competidoras de um campeonato de xadrez estadual (4) e voluntários que não tinham prática contínua em xadrez (20). Os resultados experimentais mostram que é possível separar enxadristas em grupos de proficiência por meio de sinais cognitivos capturados durante respostas de questões deste jogo. Mais do que isso, a métrica tradicional de quantificação de proficiência apresentou acurácia média de até 73,3\%, enquanto que as métricas propostas aqui atingiram acurácias médias de até $87,5 \%$ e $98,9 \%$ para os sinais de eletroencefalografia e movimentos oculares, respectivamente. Acredita-se que os resultados desta tese revelam o potencial dos sinais cognitivos em traduzir e 
compreender melhor a proficiência humana em xadrez, com especial destaque para os padrões mais discriminantes dos movimentos oculares.

Palavras-chave: Xadrez. Eletroencefalografia. Eye-tracking. Reconhecimento de padrão. 


\begin{abstract}
Chess game has attracted the interest of many academic works in distinct areas of scientific knowledge. In these works, the discrimination between proficient and non-proficient is essentially due to metrics related to the ELO Rating, the time dedicated to the practice of chess or tests based on volunteer's accuracy and response time. None of these works takes into account explicitly how the person thinks or thought de facto during the plays to then investigate if the cognitive signals of these volunteers follow patterns that to automatically classify them into proficiency levels. The aim of this thesis is to analyze chess players proficiency by their brain activation (electroencephalography signals) and eye movement in specific stimuli related to chess game. More specifically, it is intended: (1) to acquire and interpret cognitive signals from chess players with different levels of proficiency to recognize possible cognitive patterns during specific chess plays; (2) to implement statistical methods to interpret, analyze and classify cognitive signals of chess players with different proficiency levels; (3) to separate and classify chess players according to their proficiency level through their brain signals and eye movements; (4) to rank chess players' proficiency level and compare it with the ranking metric based on accuracy and response time. Experiments have been carried out in a computer screen involving 51 questions related to the chess game, separated into the following 5 categories: (1) object recognition and positioning; (2) possibility of check; (3) possibility of check-mate; (4) possibility of check-mate in one move and; (5) rule retrieval and possibility of pieces capture. A total of 32 volunteers contributed to these experiments, including professional chess players with ELO rating (4 volunteers), chess teachers (4), schoolchildren who competed in a state chess championship (4), and volunteers who did not have continuous chess practice (20). The results of these experiments show that it is possible to separate chess players into groups of proficiency by their cognitive signals obtained during answers from question of this game. More than that, the traditional metric to quantify proficiency presented accuracy up to $73,3 \%$, while the proposed metrics reached has mean accuracy up to $87,5 \%$ and $98,9 \%$ for the electroencephalography and eye movements, respectively. We believe that the results from this thesis reveal the potential of cognitive signals to translate and understand better human proficiency in chess, with an emphasis on the most discriminating patterns of eye movements.
\end{abstract}

Keywords: Chess. Electroencephalography. Eye-tracking. Pattern Recognition. 



\section{LISTA DE ILUSTRAÇÕES}

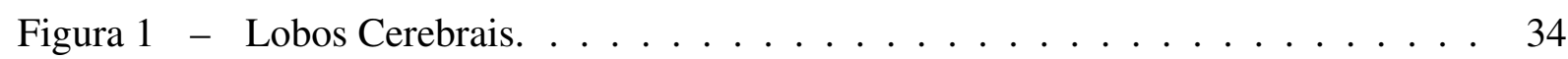

Figura 2 - Lobo frontal e região pré-frontal. . . . . . . . . . . . . . 34

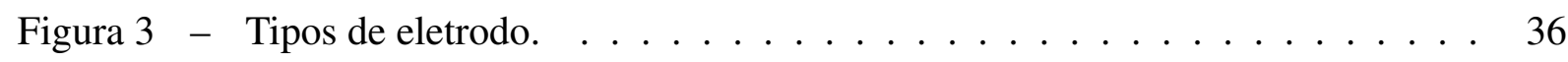

Figura 4 - Atividade Sináptica. . . . . . . . . . . . 37

Figura 5 - Formas de onda das bandas delta, teta, alfa beta e gama. . . . . . . . 38

Figura 6 - Posicionamento dos eletrodos no sistema internacional 10-20. . . . . . . 39

Figura 7 Imagem formada na retina. . . . . . . . . . . . 40

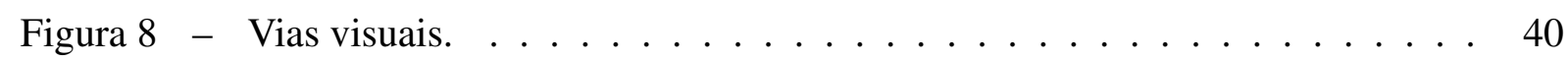

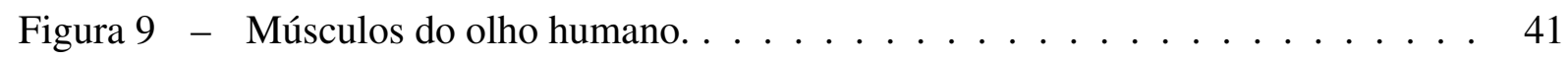

Figura 10 - Brilho da córnea com diferentes fixações. . . . . . . . . . . . . . 42

Figura 11 - Diagrama de funcionamento da VOG. . . . . . . . . . . . . . . . 43

Figura 12 - Equipamento OpenBCI. . . . . . . . . . . . . 58

Figura 13 - Toucas de eletrodos para EEG. . . . . . . . . . . . . . 58

Figura 14 - Posicionamento dos eletrodos. . . . . . . . . . . . . . 59

Figura 15 - Equipamento Tobii Pro TX300 . . . . . . . . . . . . . . 60

Figura 16 - Exemplo de ruído e artefato no sinal de EEG . . . . . . . . . . . . . 62

Figura 17 - Exemplo de sintetização dos canais de EEG. . . . . . . . . . . . 63

Figura 18 - Interpolação dos sinais de movimentos oculares. . . . . . . . . . . . 68

Figura 19 - Filtragem dos sinais de movimentos oculares. . . . . . . . . . . . 69

Figura $20-$ Montagem do heatmap. . . . . . . . . . . . . 70

Figura 21 - Remoção do background. . . . . . . . . . . . . . 71

Figura 22 - Transformação de uma imagem em RGB para tons de cinza. . . . . . . . . 72

Figura 23 - Sequência dos experimentos. . . . . . . . . . . 78

Figura 24 - Exemplo de questão e seu respectivo tabuleiro. . . . . . . . . . . . . 79

Figura 25 - Realização dos experimentos por um voluntário. . . . . . . . . . . . 80

Figura 26 - Escala de cor para heatmaps e mapas cerebrais. . . . . . . . . . . . 86

Figura 27 - Categoria 1. . . . . . . . . . . . . 87

Figura 28 - Classificação de Volke e eye-tracking para questão 36 . . . . . . . . . 88

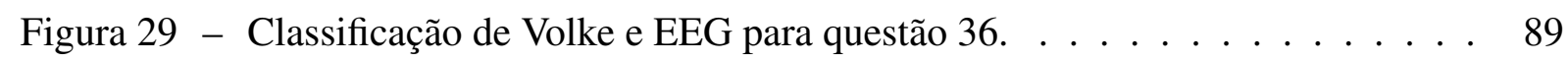

Figura 30 - Classificação de eye-tracking e EEG para questão 36 . . . . . . . . . . . . 90

Figura 31 - Heatmaps e mapas cerebrais para a questão 36 . . . . . . . . . . . . 91 
Figura $32-$ Categoria $2 \ldots \ldots \ldots \ldots 3$

Figura 33 - Classificação de Volke e eye-tracking para questão 23. . . . . . . . . . . . 94

Figura 34 - Classificação de Volke e EEG para questão 23. . . . . . . . . . . . . . 95

Figura 35 - Classificação de eye-tracking e EEG para questão 23 . . . . . . . . . . . . 97

Figura 36 - Heatmaps e mapas cerebrais para a questão 23 . . . . . . . . . . . . 98

Figura 37 - Categoria 3. . . . . . . . . . . . . . . . 99

Figura 38 - Classificação de Volke e eye-tracking para questão 39 . . . . . . . . . . . 100

Figura 39 - Classificação de Volke e EEG para questão 39. . . . . . . . . . . . . . . . 102

Figura 40 - Classificação de eye-tracking e EEG para questão 39 . . . . . . . . . . . 103

Figura 41 - Heatmap e mapas cerebrais para a questão 39. . . . . . . . . . . . . 104

Figura 42 - Categoria $4 \ldots \ldots \ldots \ldots$. . . . . . . . . . . . . . . . . . . . .

Figura 43 - Classificação de Volke e eye-tracking para questão 37. . . . . . . . . . . 107

Figura 44 - Classificação de Volke e EEG para questão 37 . . . . . . . . . . . . . 108

Figura 45 - Classificação de eye-tracking e EEG para questão 37. . . . . . . . . . . . 109

Figura 46 - Heatmap e mapas cerebrais para a questão $37 . \ldots \ldots$. . . . . . . 110

Figura 47 - Categoria $5 \ldots \ldots \ldots \ldots \ldots \ldots \ldots$

Figura 48 - Classificação de Volke e eye-tracking para questão 48. . . . . . . . . . . 113

Figura 49 - Classificação de Volke e EEG para questão 48. . . . . . . . . . . . . . . . 114

Figura 50 - Classificação de eye-tracking e EEG para questão 48 . . . . . . . . . . . 115

Figura 51 - Heatmaps e mapas cerebrais para a questão 48 . . . . . . . . . . . 116 


\section{LISTA DE TABELAS}

Tabela 1 - Resumo do estado da arte. . . . . . . . . . . . . 55

Tabela 2 - Correlação entre eletrodos e áreas de Brodmann. . . . . . . . . . . . . 59

Tabela 3 - Categorias do questionário de classificação. . . . . . . . . . . 78

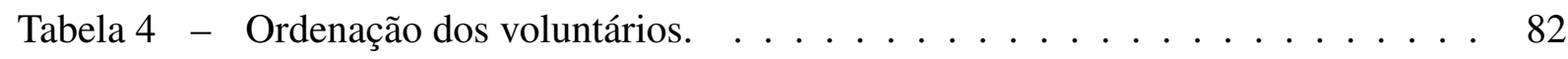

Tabela 5 - Classificação da métrica tradicional dos grupos de treinamento, por categoria. 83

Tabela 6 - Classificação do hiperplano EEG pelo método SIPD dos grupos de treinamento, por categoria. . . . . . . . . . . . . . 83

Tabela 7 - Classificação do hiperplano EEG pelo método SIPD dos grupos de teste, por categoria. . . . . . . . . . . . . . . . 83

Tabela 8 - Classificação do hiperplano EEG pelo método PSD dos grupos de treinamento, por categoria. . . . . . . . . . . . . . . . . 83

Tabela 9 - Classificação do hiperplano EEG pelo método PSD dos grupos de teste, por categoria. . . . . . . . . . . . . . . . . . . . 84

Tabela 10 - Classificação do hiperplano eye-tracking dos grupos de treinamento, por categoria. . . . . . . . . . . . . . . . . . 84

Tabela 11 - Classificação do hiperplano eye-tracking dos grupos de teste, por categoria. 84 



\section{LISTA DE ALGORITMOS}

Algoritmo 1 - Algoritmo para extração de características dos sinais cerebrais pelo método SIPD. . . . . . . . . . . . . . . . . 65

Algoritmo 2 - Algoritmo para extração de características dos sinais cerebrais pelo método PSD . . . . . . . . . . . . . . . . . 66

Algoritmo 3 - Algoritmo para extração de características dos movimentos oculares . . . 72 



\section{LISTA DE ABREVIATURAS}

EEG Electroencephalography - Encefalografia (Electroencephalography)

EOG Electro-oculography - Eletro-oculografia (Electro-oculography)

ERP Event-Related Potential - Potencial Evocado (Event-Related Potential)

fMRI Functional Magnetic Resonance Imaging - Ressonância Magnética Funcional (Functional Magnetic Resonance Imaging)

ICA Independent Components Analysis - Análise de Componentes Independentes (Independent Components Analysis)

IFCN International Federation of Clinical Neurophysiology - Federação Internacional de Neuro-fisiologia Clínica (International Federation of Clinical Neurophysio$\log )$

LDA Linear Discriminant Analysis - Análise Discriminante Linear (Linear Discriminant Analysis)

MEG Magnetoencephalography - Magnetoencefalografia (Magnetoencephalography)

MRI Magnetic Resonance Imaging - Ressonância Magnética (Magnetic Resonance Imaging)

PCA Principal Components Analysis - Análise de Componentes Principais (Principal Components Analysis)

PET Positron Emission Tomography - Tomografia por Emissão de Pósitron (Positron Emission Tomography)

PSD Power Spectral Density - Densidade Espectral de Potência (Power Spectral Density)

SIPD Sistema Inteligente de Processamento Distribuído (Sistema Inteligente de Processamento Distribuído)

SPECT Single Photon Emission Computadorized Tomography - Tomografia Computadorizada por Emissão de Fóton Único (Single Photon Emission Computadorized Tomography)

VOG Video-oculography - Vídeo-oculografia (Video-oculography) 



\section{LISTA DE SÍMBOLOS}

$c_{i, j} \quad$ correlação entre dois canais distintos

$h\left(c_{i}\right) \quad$ entropia de um canal $i$

$h\left(c_{i, j}\right)$ entropia da correlação entre dois canais distintos

$H_{s} \quad$ proficiência em xadrez do voluntário $s$

$k \quad$ tamanho da janela para filtrar os dados

$m$ número de componentes principais, cujo auto-valores são não-nulos

$n \quad$ número de eletrodos

$P_{i} \quad$ valor $i$ ausente contíguo no vetor

$P_{j} \quad$ valor $j$ no vetor de pontos

$P_{j-n} \quad$ valor da enésima posição anterior no vetor

$P_{n} \quad$ valor $n$ do ponto imediatamente seguinte aos pontos ausentes

$P_{s} \quad$ valor $s$ do ponto imediatamente anterior aos pontos ausentes

$Q_{j} \quad$ ordenação de um mesmo conjunto de $N$ participantes determinado por seu $V_{s}$ ou $H_{s}$

$R_{j} \quad$ ordenação de um mesmo conjunto de $N$ participantes determinado por seu $V_{s}$ ou $H_{s}$

$R T_{m} \quad$ tempo de resposta médio de todos os participantes em todas as questões

$R T_{s} \quad$ tempo médio de resposta do voluntário $s$

$W \quad$ vetor de pesos 



\section{SUMÁRIO}

$1 \quad$ INTRODUÇÃO $\ldots \ldots \ldots \ldots$

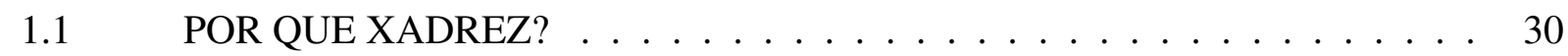

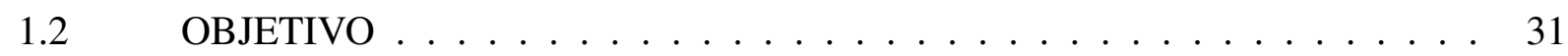

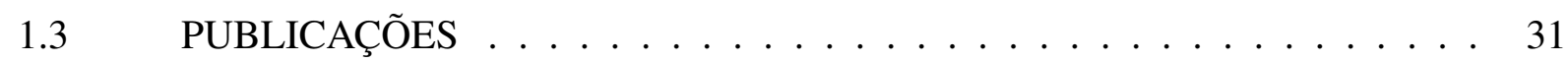

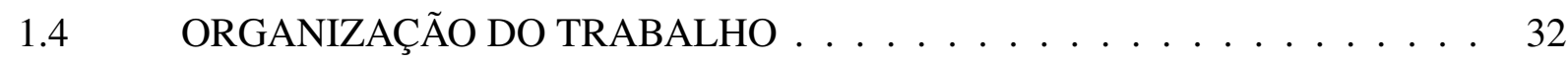

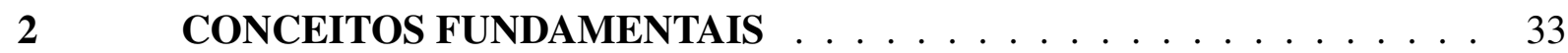

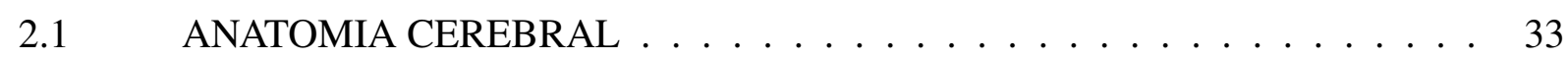

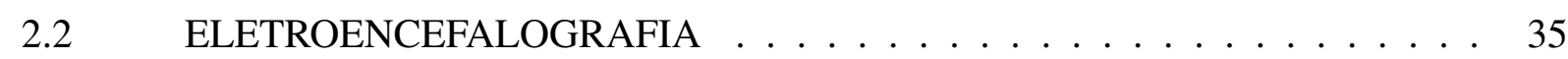

2.3 O OLHO HUMANO . . . . . . . . . . . . . . . . . . . . . . . . . . 39

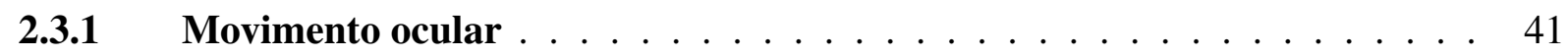

2.4 VÍDEO-OCULOGRAFIA $\ldots \ldots \ldots \ldots \ldots \ldots \ldots \ldots \ldots$

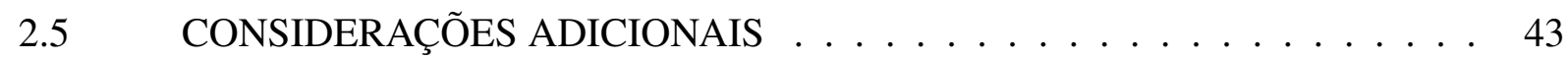

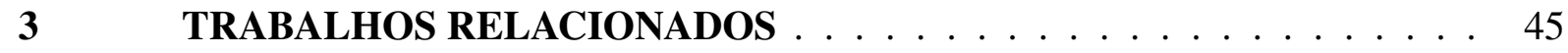

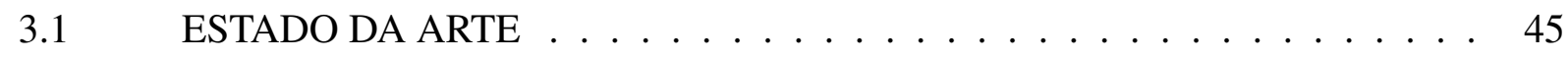

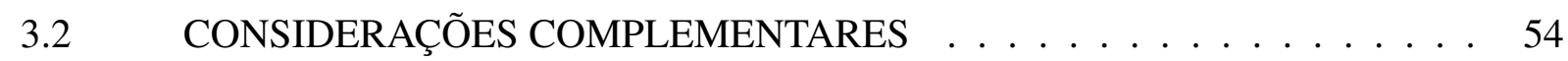

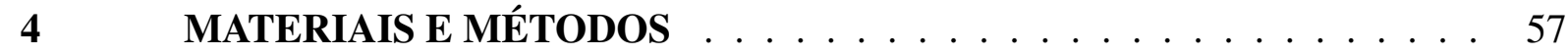

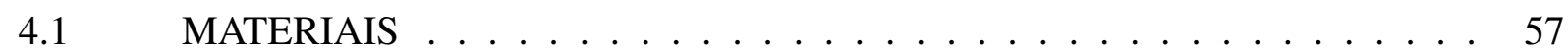

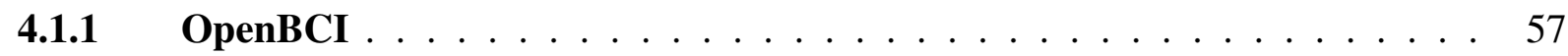

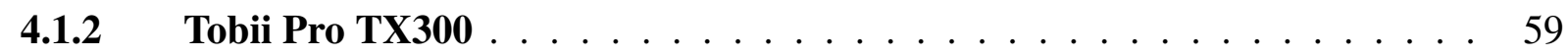

4.1.3 Considerações adicionais $\ldots \ldots \ldots \ldots \ldots$

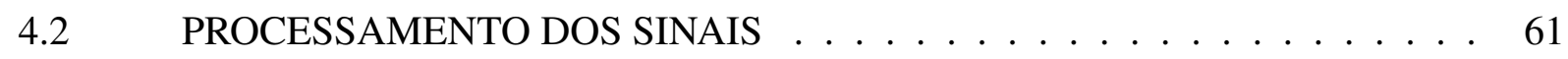

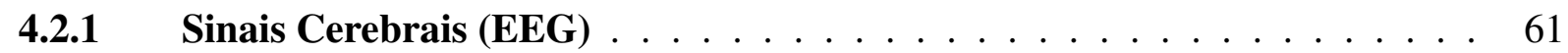

4.2.1.1 Sistema Inteligente de Processamento Distribuído . . . . . . . . . . . . . . 62

4.2.1.2 Densidade espectral de potência . . . . . . . . . . . . . . . . . 65

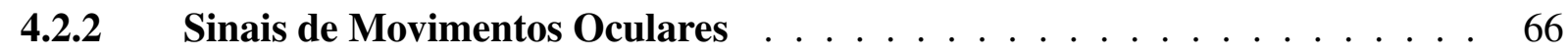

4.3 MÉTRICAS DE AVALIAÇÃO DE PROFICIÊNCIA . . . . . . . . . . . 71

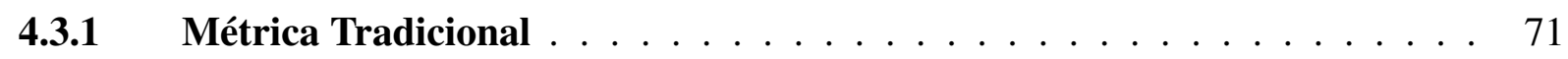

4.3.2 Métricas Cognitivas . . . . . . . . . . . . . . . . . . . . 73

4.3.3 Comparação entre as métricas . . . . . . . . . . . . . . . . 75

5 EXPERIMENTOS E RESULTADOS . . . . . . . . . . . . . . . . . 77

5.1 TAREFAS E ESTÍMULOS $\ldots \ldots \ldots \ldots \ldots \ldots$ 
$5.2 \quad$ PARTICIPANTES $\ldots \ldots \ldots \ldots \ldots \ldots \ldots$

$5.3 \quad$ VALIDAÇÃO DAS MÉTRICAS . . . . . . . . . . . . . 81

5.4 COMPARAÇÃO ENTRE MÉTRICAS DE CLASSIFICAÇÃO . . . . . . . . 85

5.4.1 Categoria 1: Reconhecimento de peças e posicionamento . . . . . . . . . 86

5.4.2 Categoria 2: Reconhecimento de situações de xeque . . . . . . . . . . . . 92

5.4.3 Categoria 3: Reconhecimento de situações de xeque-mate . . . . . . . . . . 98

5.4.4 Categoria 4: Possibilidade de xeque-mate em um lance . . . . . . . . . . . 104

5.4.5 Categoria 5: Conhecimento de jogadas e possibilidade de captura de peças 110

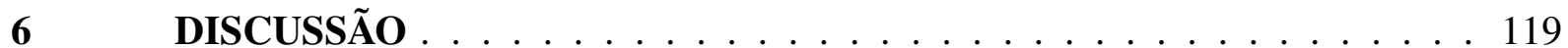

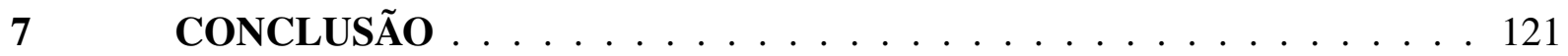

REFERÊNCIAS . . . . . . . . . . . . . . . . . . . . . 124 




\section{INTRODUÇÃO}

O jogo de xadrez tem atraído o interesse de vários trabalhos acadêmicos em áreas distintas do conhecimento científico, devido ao seu ambiente compacto e controlado para questionamentos sobre o raciocínio humano. Tais áreas incluem trabalhos em neurociência, cognição, psicologia perceptiva, processamento de sinais e visão computacional (NICHELLI et al., 1994; ONOFRJ et al., 1995; AMIDZIC et al., 2001; AMIDZIC; RIEHLE; ELBERT, 2006; CAMPITELLI; GOBET; PARKER, 2005; BILALIĆ et al., 2010, 2011b,a; KRAWCZYK et al., 2011; DUAN et al., 2012a, 2012b, 2014; HÄNGGI et al., 2014; MAYELI; RAHMANI; AARABI, 2018; VOLKE et al., 2002; WRIGHT et al., 2013; ROCHA, F. et al., 2016).

Nas áreas de neurociência e cognição, vários estudos têm sido realizados nas últimas décadas em relação às diferentes ativações cerebrais entre jogadores proficientes ${ }^{1}$ e não-proficientes ${ }^{2}$ em xadrez. Essas ativações cerebrais são medidas por equipamentos de magnetoencefalografia (AMIDZIC et al., 2001; AMIDZIC; RIEHLE; ELBERT, 2006), Positron Emission Tomography (PET) (NICHELLI et al., 1994), Single Photon Emission Computed Tomography (SPECT) (ONOFRJ et al., 1995), ressonância magnética (CAMPITELLI; GOBET; PARKER, 2005; BILALIĆ et al., 2010, 2011b,a; KRAWCZYK et al., 2011; DUAN et al., 2012a, 2012b, 2014; HÄNGGI et al., 2014; MAYELI; RAHMANI; AARABI, 2018) e eletroencefalografia (EEG) (VOLKE et al., 2002; WRIGHT et al., 2013; ROCHA, F. et al., 2016), entre outros. Analogamente, estudos sobre movimentos oculares em jogos de xadrez têm sido publicados, mostrando diferenças no padrão de fixações de olhares entre proficientes e não-proficientes, evidenciando que enxadristas com maior proficiência ${ }^{3}$ fixam seus olhares em regiões mais importantes do tabuleiro e, consequentemente, têm desempenho superior nesse tipo de tarefa (SILVA JUNIOR et al., 2018; SHERIDAN; REINGOLD, 2015; REINGOLD; SHERIDAN, 2011; BLIGNAUT; BEELDERS; SO, 2008; REINGOLD et al., 2001).

Contudo, a discriminação entre proficientes e não-proficientes nesses estudos é, essencialmente, relacionada ao Rating $\mathrm{ELO}^{4}$, ao tempo dedicado à prática do xadrez ou em testes baseados na acurácia e tempo de resposta dos voluntários. Nenhuma dessas métricas considera, explicitamente, como os indivíduos pensam ou pensaram, de fato, durante as jogadas

\footnotetext{
${ }^{1}$ A palavra proficiente é uma tradução livre da palavra expert em inglês.

${ }^{2}$ A palavra não-proficiente é uma tradução livre da palavra novice em inglês.

${ }^{3}$ A palavra proficiência é uma tradução livre da palavra expertise em inglês. Segundo Ericsson et al. (2018), expertise se refere à características, habilidades e conhecimento que distinguem os experts dos novices e pessoas menos experientes.

${ }^{4}$ Sistema de ranqueamento profissional em torneios de xadrez criado por Arpad Elo (ELO, 1978).
} 
para, então, investigar se os sinais cognitivos desses voluntários seguem padrões que permitam classificá-los automaticamente em níveis de proficiência.

Portanto, o desenvolvimento desta tese é motivado pelo interesse em entender o mecanismo humano de abstração mental (conhecimento implícito) neste processo de aprendizagem e codificação de informação relevante (reconhecimento de padrões) e pela possibilidade de contribuir com o conhecimento existente na área de processamento de sinais cognitivos por meio da realização de experimentos e da análise da ativação cerebral e movimentos oculares para a solução de problemas em xadrez.

\subsection{POR QUE XADREZ?}

O xadrez, devido suas características para realização de experimentos controlados, tem sido utilizado para determinar diferenças cognitivas entre sujeitos com maior e menor proficiência nessa área. Por esses motivos, ao invés de se mensurar proficiência por meio de acurácia em tarefas relacionadas ao jogo de xadrez, uma abordagem voltada para a determinação e predição de proficiência por meio de técnicas estatísticas e de mineração de dados se faz condizente e possível.

Especificamente, o xadrez como ambiente de experimentos científicos, tem vantagens como: facilidade de transferir as informações para o ambiente matemático ou linguagens computacionais; flexibilidade, que permite a utilização de diferentes tarefas e estímulos relacionados ao xadrez; existência de um grande histórico de partidas que pode ser utilizado para análises estatísticas; e possibilidade de trabalhar com jogadores com diferentes níveis de habilidade para analisar o processo cognitivo (GOBET, 1998).

Para pesquisas em percepção cognitiva, outro fato importante é a comunicação entre enxadristas sobre seus pensamentos através de análises de partidas já realizadas. Fato relevante, já que é muito difícil as pessoas verbalizarem seus pensamentos (SAARILUOMA, 1995).

Outra vantagem do uso do xadrez é o método de separação entre os possíveis voluntários da pesquisa. Os enxadristas são separados em grupos de acordo com sua proficiência na área utilizando a ferramenta ELO, mundialmente utilizada, fazendo com que experimentos realizados nesse campo possam ser replicados utilizando-se os mesmos parâmetros (GOBET, 1998). 
Adicionalmente, estudos mostram que a prática do jogo de xadrez para estudantes de diferentes idades melhora a habilidade dos mesmos em resolver problemas matemáticos, além de aumentar as habilidades meta-cognitivas (KAZEMI; YEKTAYAR; ABAD, 2012). Por ser uma plataforma que oferece grande complexidade devido à quantidade de possibilidades a serem realizadas no jogo, o xadrez é um ambiente explorado para experimentos de mapeamento cerebral cognitivo (SAARILUOMA, 1995), como os que serão descritos nesta tese.

\subsection{OBJETIVO}

O objetivo principal desta tese é analisar a proficiência de enxadristas por meio de suas ativações cerebrais e movimentos oculares em determinados estímulos relacionados ao jogo de xadrez. Mais especificamente, pretende-se:

a) adquirir e interpretar sinais cognitivos de enxadristas com diferentes níveis de proficiência para reconhecer possíveis padrões cognitivos durante jogadas específicas de xadrez;

b) implementar métodos estatísticos para interpretar, analisar e classificar os sinais cognitivos de enxadristas com diferentes níveis de proficiência;

c) separar e classificar jogadores de xadrez de acordo com seu nível de proficiência por meio de seus sinais cerebrais e movimentos oculares;

d) ranquear esse nível de proficiência de enxadristas e compará-lo com a métrica tradicional de ranqueamento baseado em acurácia e tempo de resposta.

\subsection{PUBLICAÇÕES}

Parte dos materiais, métodos, experimentos e resultados desta tese estão publicados em:

L. R. S. Junior and C. E. Thomaz. Visual perception ranking of chess players. In proceedings of the 17th International Conference on Image Analysis and Recognition, ICIAR 2020, Springer LNCS, pp. 307-315, Povoa de Varzim, Portugal, June 24th-26th 2020.

L. R. S. Junior and C. E. Thomaz. A multivariate correlation assessment of chess proficiency using brain signals. In proceedings of the XV Workshop de Visao Computacional, WVC 2019, pp. 10-15, IEEE CS Press, Sao Bernardo do Campo, Sao Paulo, Brazil, September 9th-11 2019. 
L. R. S. Junior, F. H. G. Cesar, F. T. Rocha and C. E. Thomaz. A combined eye-tracking and EEG analysis on chess moves, IEEE Latin America Transactions, vol. 16, no. 5, pp. 12881297, May 2018.

L. R. S. Junior, F. H. G. Cesar, F. T. Rocha and C. E. Thomaz. EEG and eye movement maps of chess players. In proceedings of the 6th International Conference on Pattern Recognition Applications and Methods, ICPRAM 2017, pp. 434-441, Porto, Portugal, 24th-27th February 2017.

\subsection{ORGANIZAÇÃO DO TRABALHO}

Este trabalho está dividido em 7 capítulos. No Capítulo 2, são explicados os conceitos fundamentais nos quais a presente tese se baseia. No capítulo seguinte, de número 3, são mostrados estudos relacionados ao trabalho proposto. A seguir, no Capítulo 4, são descritos os materiais e métodos propostos nesta tese. Logo em seguida, no Capítulo 5, são relatados os experimentos e os resultados obtidos. No Capítulo 6, é apresentada uma discussão acerca dos resultados. Por fim, no Capítulo 7, é feita a conclusão da presente tese e são apresentados possíveis trabalhos futuros a serem desenvolvidos. 


\section{CONCEITOS FUNDAMENTAIS}

Este capítulo apresenta os principais conceitos gerais que são abordados nesta tese e está dividido em cinco seções: anatomia cerebral, eletroencefalografia, o olho humano, vídeooculografia e considerações adicionais. Na primeira seção são descritos o cérebro e as principais funções dos lobos cerebrais. Na seção seguinte, são descritas, sucintamente, a técnica e o funcionamento da eletroencefalografia. Em seguida, são abordadas as principais partes da anatomia do olho e do movimento ocular. Na outra seção, apresenta-se a técnica de vídeo-oculografia. Por fim, na última seção deste capítulo, são feitas considerações a respeito do conteúdo apresentado.

\subsection{ANATOMIA CEREBRAL}

O cérebro é o local do corpo humano onde originam-se o processamento consciente do pensamento, funções intelectuais, armazenamento e recuperação da memória, e onde determinamse reações do organismo e padrões motores complexos (MARTINI; TIMMONS; TALLITSCH, 2009; GUYTON; HALL; GUYTON, 2006).

O cérebro pode ser dividido em dois hemisférios. Na camada mais externa de cada hemisfério encontra-se o córtex cerebral, região em que são realizadas atividades elétricas espontâneas, que podem ser detectadas colocando-se eletrodos em sua superfície ou no próprio crânio (eletroencefalografia, (EEG)) (KANDEL et al., 2014; GAZZANIGA; IVRY; MANGUN, 2009; MACHADO; CAMPOS, 2005).

O córtex cerebral também pode ser dividido em quatro lobos cerebrais. Esses lobos têm seus nomes derivados dos ossos com os quais se relacionam. São eles: lobo frontal, lobo temporal, lobo parietal e lobo occipital. Cada um dos lobos contém áreas funcionais que não são precisamente definidas, pois os limites contém considerável superposição, sendo que cada lobo pode exercer diversas funções (MARTINI; TIMMONS; TALLITSCH, 2009; MACHADO; CAMPOS, 2005). A Figura 1 mostra a separação dos lobos cerebrais, analisado por meio de uma vista sagital do cérebro.

O lobo frontal tem participação na movimentação dos músculos responsáveis pelos movimentos oculares e de outros músculos do corpo de forma voluntária, desempenha funções no aprendizado, memória a curto prazo e raciocínio, além de envolver, por exemplo, a área de 
Figura 1 - Lobos Cerebrais.

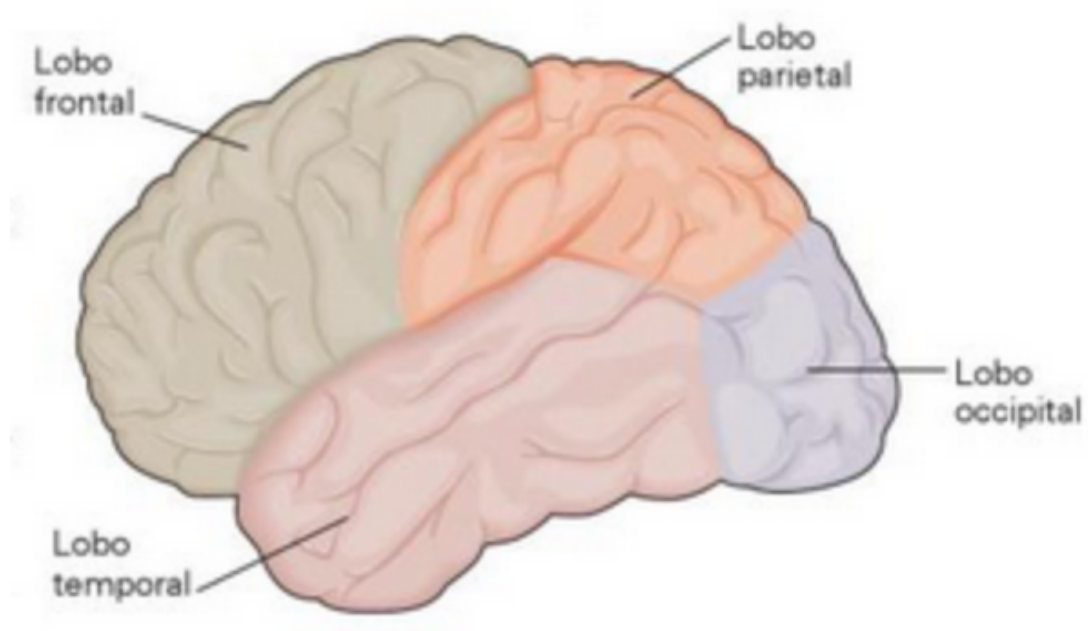

Fonte: Autor “adaptado de"Kandel et al., 2014, p.9

Broca, área essencial para articulação da fala. O lobo frontal tem duas subdivisões principais: córtex motor e córtex pré-frontal ${ }^{1}$ (MARTIN, 2014; GAZZANIGA; IVRY; MANGUN, 2009; KAY; TASMAN; LIEBERMAN, 2002; DE OLIVEIRA, 2001).

O córtex motor tem como principal função o controle consciente dos músculos esqueléticos, enquanto o córtex pré-frontal, localizado anteriormente às áreas motoras e pré-motoras, desempenha funções comportamentais como cognições, emoções e pensamento, além de ser importante para atenção, motivação e resolução de problemas (MARTIN, 2014; KAY; TASMAN; LIEBERMAN, 2002). A Figura 2 mostra a região pré-frontal e o lobo frontal.

Figura 2 - Lobo frontal e região pré-frontal.

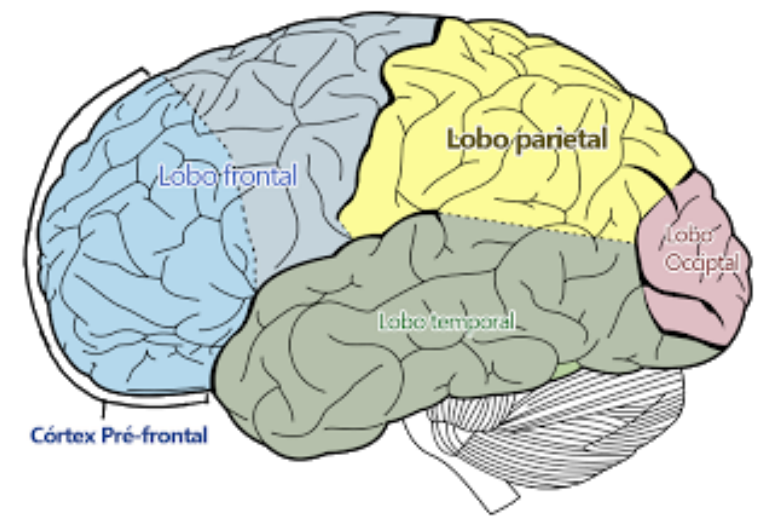

Fonte: Hennemann, 2012

\footnotetext{
${ }^{1}$ Em neuroanatomia, o prefixo "pré" significa "na frente de".
} 
O lobo temporal tem relação com a percepção de estímulos como o olfato e a audição, relaciona-se com as emoções e memória juntamente com o lobo frontal e sistema límbico, e envolve, por exemplo, a área de Wernicke, importante para o reconhecimento e interpretação da palavra (MARTIN, 2014; MARTINI; TIMMONS; TALLITSCH, 2009; KAY; TASMAN; LIEBERMAN, 2002; DE OLIVEIRA, 2001).

O lobo parietal, também conhecido como área somestésica, está relacionado com a percepção do tato, dor, vibração, pressão, temperatura e paladar. A parte inferior do lobo parietal é próxima às áreas de Broca e área de Wernicke relacionando-se com as mesmas (MARTINI; TIMMONS; TALLITSCH, 2009; KAY; TASMAN; LIEBERMAN, 2002; DE OLIVEIRA, 2001).

O lobo occipital se liga diretamente ou indiretamente aos órgãos visuais, relacionandose com a percepção de estímulos visuais, fazendo com que seja possível identificar forma, tamanho e cor de objetos (MARTIN, 2014; MARTINI; TIMMONS; TALLITSCH, 2009; DE OLIVEIRA, 2001).

Além da separação do córtex cerebral em lobos, também é possível separá-lo de acordo com a microanatomia dos tipos de células, como essas se organizam e laminação cortical, ou seja, de acordo com sua citoarquitetura. Essas separações são chamadas de áreas de Brodmann (MARTIN, 2014; KANDEL et al., 2014; MARTINI; TIMMONS; TALLITSCH, 2009; MACHADO; CAMPOS, 2005).

\subsection{ELETROENCEFALOGRAFIA}

Eletroencefalografia (EEG) é um método não invasivo utilizado tanto para área medicinal para estudo e diagnóstico de várias doenças neurológicas e neuropsiquiátricas, quanto para pesquisas científicas para medir as atividades elétricas geradas pelas estruturas cerebrais (FONTES; FUKUJIMA; CARDEAL, 2007; SÖRNMO; LAGUNA, 2005; TEPLAN, 2002). Essa técnica consiste em eletrodos que são posicionados no escalpo do indivíduo captando funcionalmente a atividade cortical de forma ininterrupta (GAZZANIGA; IVRY; MANGUN, 2009; FONTES; FUKUJIMA; CARDEAL, 2007; TEPLAN, 2002).

Dentre os tipos de eletrodos existentes, pode-se separá-los em três tipos: escalpo, cortical e de profundidade. O eletrodo cortical recebe esse nome quando é posicionado diretamente na superfície do córtex cerebral. O eletrodo de profundidade é uma técnica invasiva e utilizada 
em casos específicos de diagnóstico clínico, por exemplo, epilepsia. O eletrodo de escalpo é o mais comumente utilizado, tanto para pesquisas científicas quanto para exames clínicos, por ser não-invasivo (SANEI; CHAMBERS, 2013).

Dentre os eletrodos de escalpo existem, basicamente, dois tipos: disco de cloreto de prata $(\mathrm{AgCl})$ e eletrodo seco (CASSON, 2019). O eletrodo de disco de cloreto de prata requer a aplicação de um gel condutor, que deve ser aplicado por uma pessoa especializada, para garantir a qualidade do sinal adquirido. Já o eletrodo seco é mais rápido e fácil de ser configurado e não precisa da aplicação de gel condutor (CASSON, 2019). A Figura 3a mostra um exemplo de eletrodo de disco de cloreto de prata e a Figura 3 b um exemplo de eletrodo seco.

Figura 3 - Tipos de eletrodo.

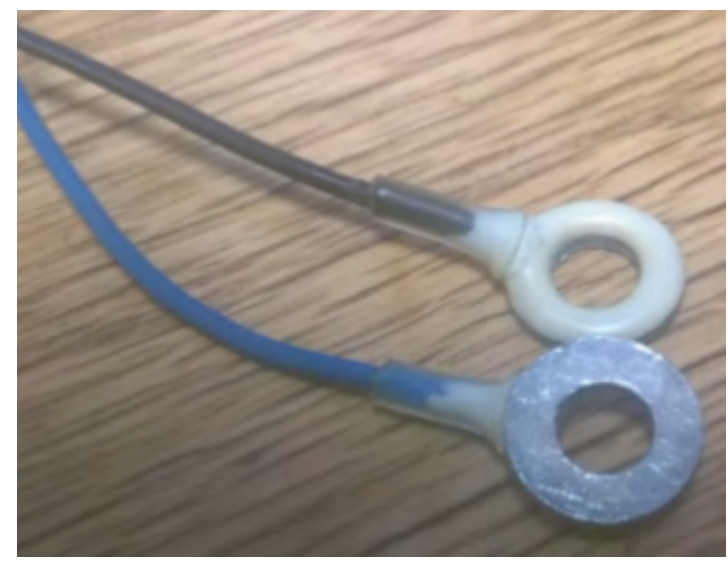

(a) Eletrodo de disco de cloreto de prata.

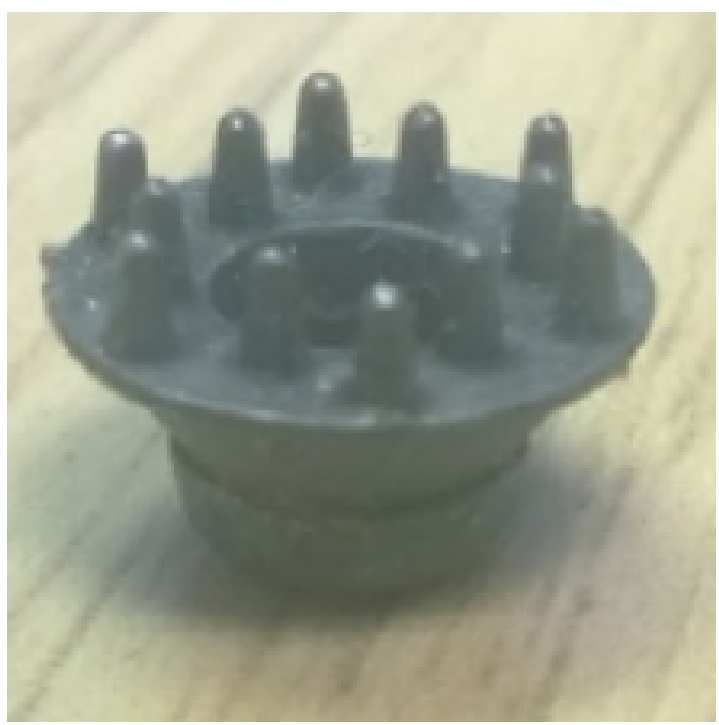

(b) Eletrodo seco.

Autor "adaptado de" Casson, 2019

A atividade elétrica que o EEG mede é gerada pelos neurônios localizados nas regiões próximas ao córtex cerebral (SÖRNMO; LAGUNA, 2005; PURVES, 2004). Essa atividade elétrica ocorre quando há a transmissão de informação de um neurônio para outro, chamada de sinapse (SÖRNMO; LAGUNA, 2005). A sinapse realizada por um único neurônio não pode ser medida no escalpo devido as grossas camadas de tecido existentes, porém milhares de neurônios trabalham juntos e quase simultaneamente, fazendo com que seja possível medir o sinal elétrico gerado pelo cérebro de forma síncrona (SÖRNMO; LAGUNA, 2005; PURVES, 2004). A Figura 4 ilustra as camadas onde estão os neurônios e os eletrodos.

Em geral, os sinais elétricos medidos no escalpo têm aproximadamente $100 \mu \mathrm{V}$ de amplitude e frequência variando entre $0,5 \mathrm{~Hz}$ e $40 \mathrm{~Hz}$. Para análise desses sinais, essa faixa de 
Figura 4 - Atividade Sináptica.

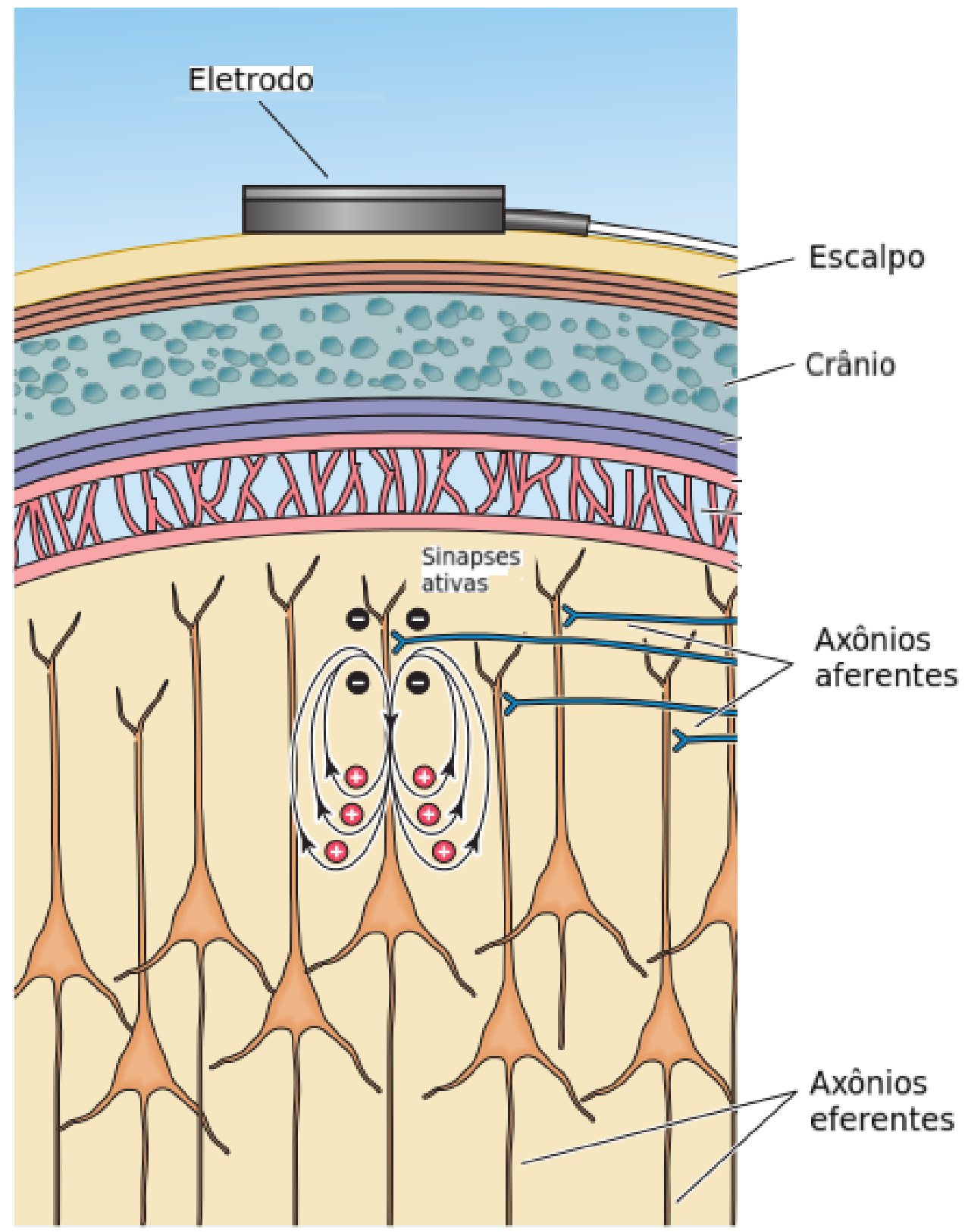

Fonte: Autor “adaptado de" Purves, 2004, p.669

frequência é separada em cinco bandas, sendo essas: delta, teta, alfa, beta e gama (SÖRNMO; LAGUNA, 2005). A banda delta com intervalo entre $0,5 \mathrm{~Hz}$ e $4 \mathrm{~Hz}$ é associada ao estado de sono profundo. A banda teta, que varia entre $4 \mathrm{~Hz}$ e $8 \mathrm{~Hz}$, é relacionada a estados específicos do sono e meditação. A banda alfa, com frequência entre $8 \mathrm{~Hz}$ e $13 \mathrm{~Hz}$, tem o estado mental associado à leitura e relaxação. A banda beta varia entre $13 \mathrm{~Hz}$ e $30 \mathrm{~Hz}$ e é correlacionada à concentração e atenção. Já a banda gama abrange as frequência acima de $30 \mathrm{~Hz}$ e é ligada ao estado mental de excitação e pico de desempenho (MÜLLER-PUTZ; RIEDL; C WRIESSNEGGER et al., 2015; 
SÖRNMO; LAGUNA, 2005). A Figura 5 ilustra as formas de onda de cada uma dessas bandas de frequência.

Figura 5 - Formas de onda das bandas delta, teta, alfa beta e gama.

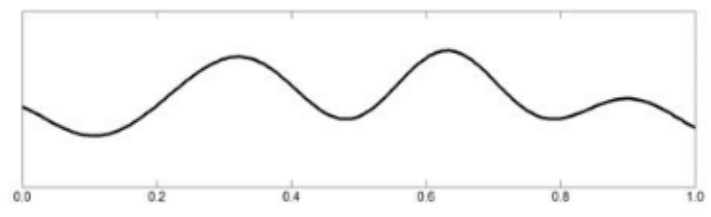

(a) Delta.

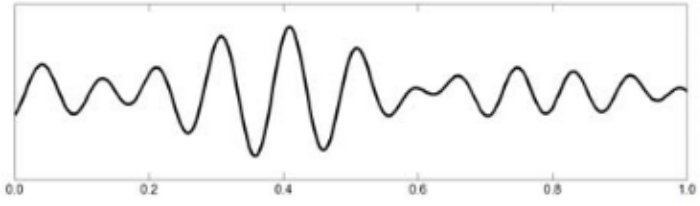

(c) Alfa.

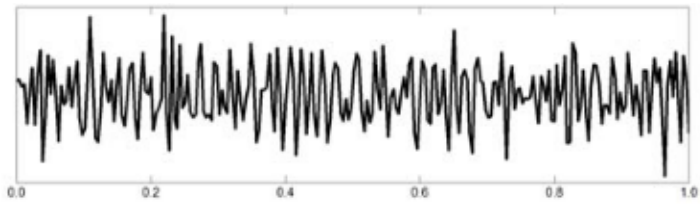

(e) Gama.

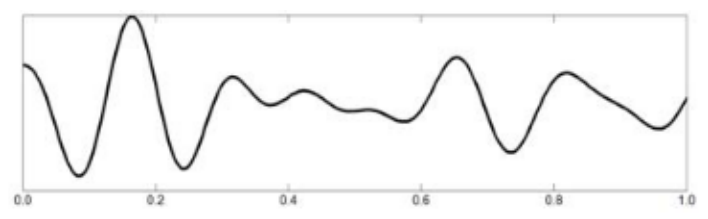

(b) Teta.

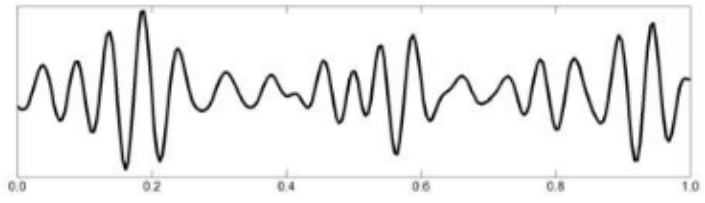

(d) Beta.

Fonte: Autor “adaptado de” Müller-Putz, Riedl, C Wriessnegger et al., 2015

Para a medição desses sinais elétricos, o posicionamento dos eletrodos mais utilizado para o EEG é chamado 10-20, que foi padronizado pela Federação Internacional de Neurofisiologia Clínica (IFCN), em 1958. Nesse posicionamento, a área do escalpo é dividida em distâncias proporcionais para localização dos eletrodos fazendo com que todas as áreas do cérebro estejam cobertas (FONTES; FUKUJIMA; CARDEAL, 2007; TEPLAN, 2002; JASPER, 1958).

Esses eletrodos recebem nomes de acordo com sua localização em cada um dos lobos cerebrais: temporal $(T)$, frontal $(F)$, central $(C)$, parietal $(P)$, occipital $(O)$ e uma numeração de acordo com o lado do cérebro em que se encontra: números ímpares para o lado esquerdo e números pares do lado direito, além das letra (z) para designar eletrodos localizados na linha média e a letra (p) para designar eletrodos localizados na região polar. Os eletrodos A1 e A2 são colocados nos lóbulos das orelhas que servem como pontos de referência (FONTES; FUKUJIMA; CARDEAL, 2007; TEPLAN, 2002; JASPER, 1958). A Figura 6 demonstra a posição dos eletrodos e suas medidas.

O EEG mostra a atividade elétrica global do cérebro e, por isso, tem limitações como uma ferramenta para análise cerebral cognitiva (GAZZANIGA; IVRY; MANGUN, 2009). Por 
Figura 6 - Posicionamento dos eletrodos no sistema internacional 10-20.
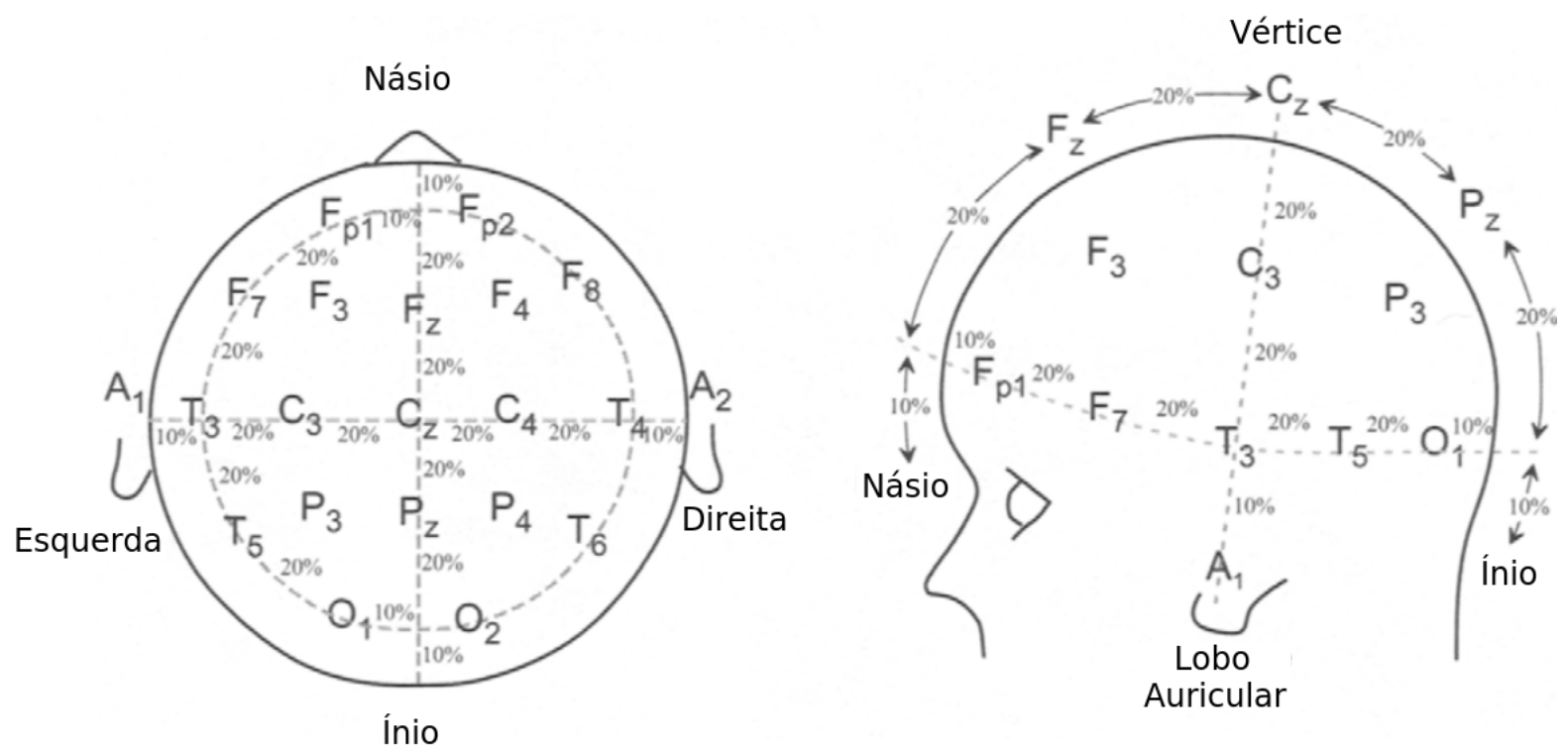

Fonte: Autor Autor "adaptado de" Sörnmo e Laguna, 2005

outro lado, comparando-se o EEG com outras técnicas de imagens cerebrais, existe a vantagem da alta resolução temporal e portabilidade para além do ambiente clínico e laboratorial (CASSON, 2019). Normalmente, a análise dos sinais de EEG é feita a partir da resposta de uma determinada tarefa, chamado de potencial evocado ou ERP (Event-Related Potential) que é o sinal elétrico referente somente ao estímulo externo realizado, com precisão temporal e mostrando como a atividade neural se altera ao longo do tempo (GAZZANIGA; IVRY; MANGUN, 2009; PICTON et al., 2000).

\subsection{O OLHO HUMANO}

Dentre os cinco sentidos que são inerentes ao ser humano, a visão é considerada a de maior dependência humana (MARTINI; TIMMONS; TALLITSCH, 2009). O processo da visão pode ser resumido da seguinte maneira: a luz chega através da pupila dos olhos e forma uma imagem de ponta-cabeça na retina; posteriormente, essa imagem é transformada em neuro sinais que são transportados para o cérebro e lá interpretados (DUCHOWSKI, A., 2017). A Figura 7 mostra um exemplo de como uma imagem é formada na retina.

Além da retina, outra região muito importante do olho é a córnea. A córnea é a parte externa que cobre o olho e reflete a luz e que, apesar de não ser a única parte do olho que tem a propriedade de reflexão, é a que tem o maior brilho. Por este motivo é utilizada como referência 
Figura 7 - Imagem formada na retina.

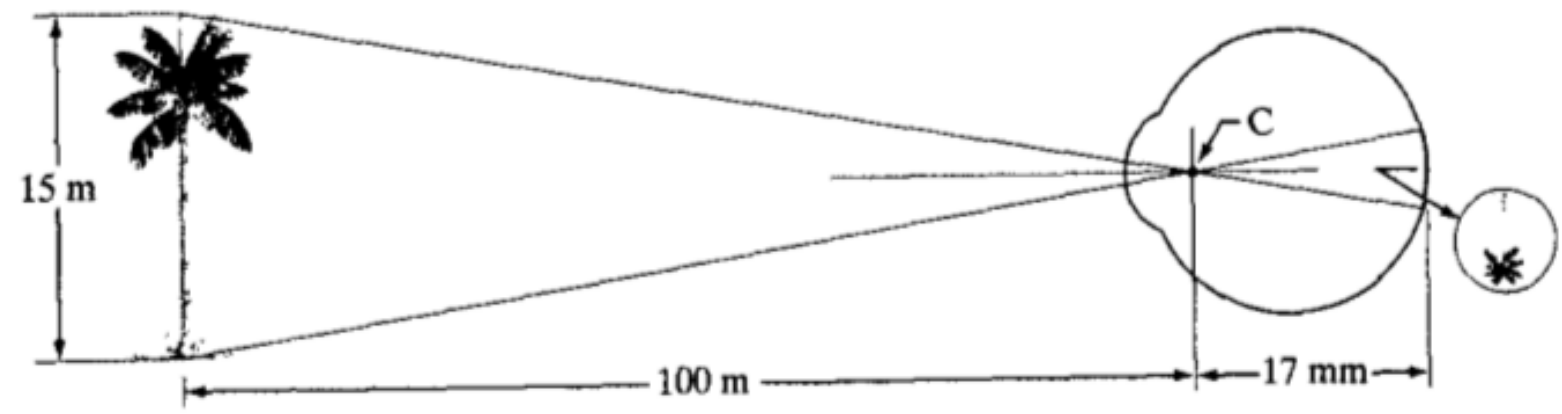

Fonte: Autor "adaptado de" Gonzalez e Woods, 2008, p.38

para estimar o ponto de fixação do olhar, bem como para o rastreamento do movimento ocular (HOLMQVIST et al., 2011).

Como visto anteriormente neste capítulo, as principais vias de comunicação entre uma imagem capturada pelos olhos ligam-se até o córtex visual, localizado no lobo ocipital, que é a região responsável pelos processamentos básicos do contorno dos objetos. A Figura 8 exibe essas vias visuais.

Figura 8 - Vias visuais.

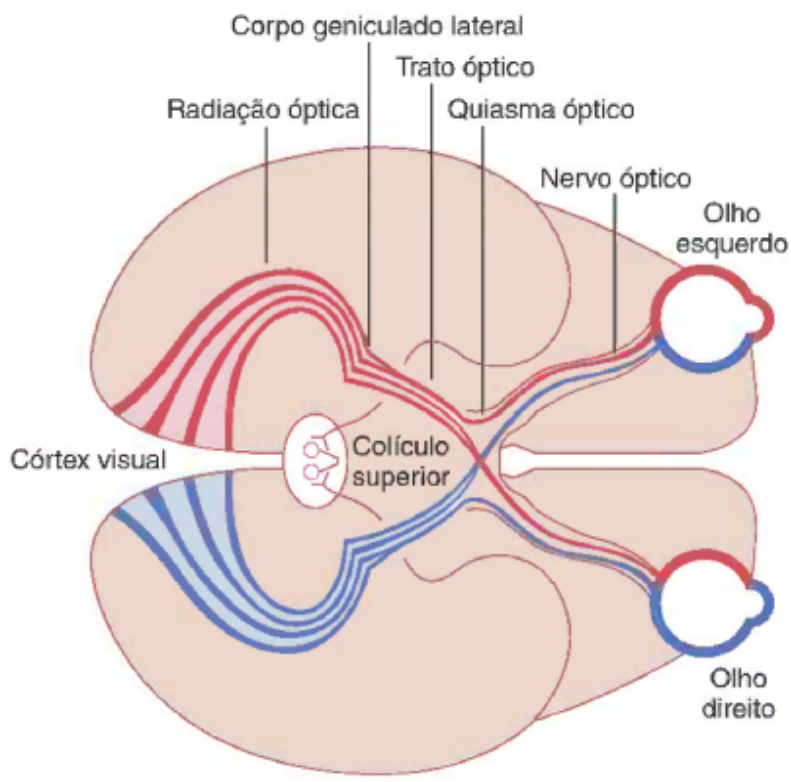

Fonte: Autor "adaptado de" Guyton, Hall e Guyton, 2006, p.659 


\subsubsection{Movimento ocular}

Segundo Porterfield (1759), o movimento ocular pode ser dividido em interno e externo. O movimento ocular interno compreende os movimentos que ocorrem com algumas partes do olho, como a iris e o cristalino, ou quando existe um movimento de todo o olho, transformando sua forma natural esférica para uma forma achatada ou oblonga. O movimento ocular externo se refere aos movimentos dos músculos dos olhos que mudam sua situação e sentido. Esses músculos são: inferior, superior, medial e lateral (músculos retos); inferior e superior (músculos oblíquos) (WADE; TATLER, 2005). A Figura 9 ilustra os músculos do olho humano.

Figura 9 - Músculos do olho humano.

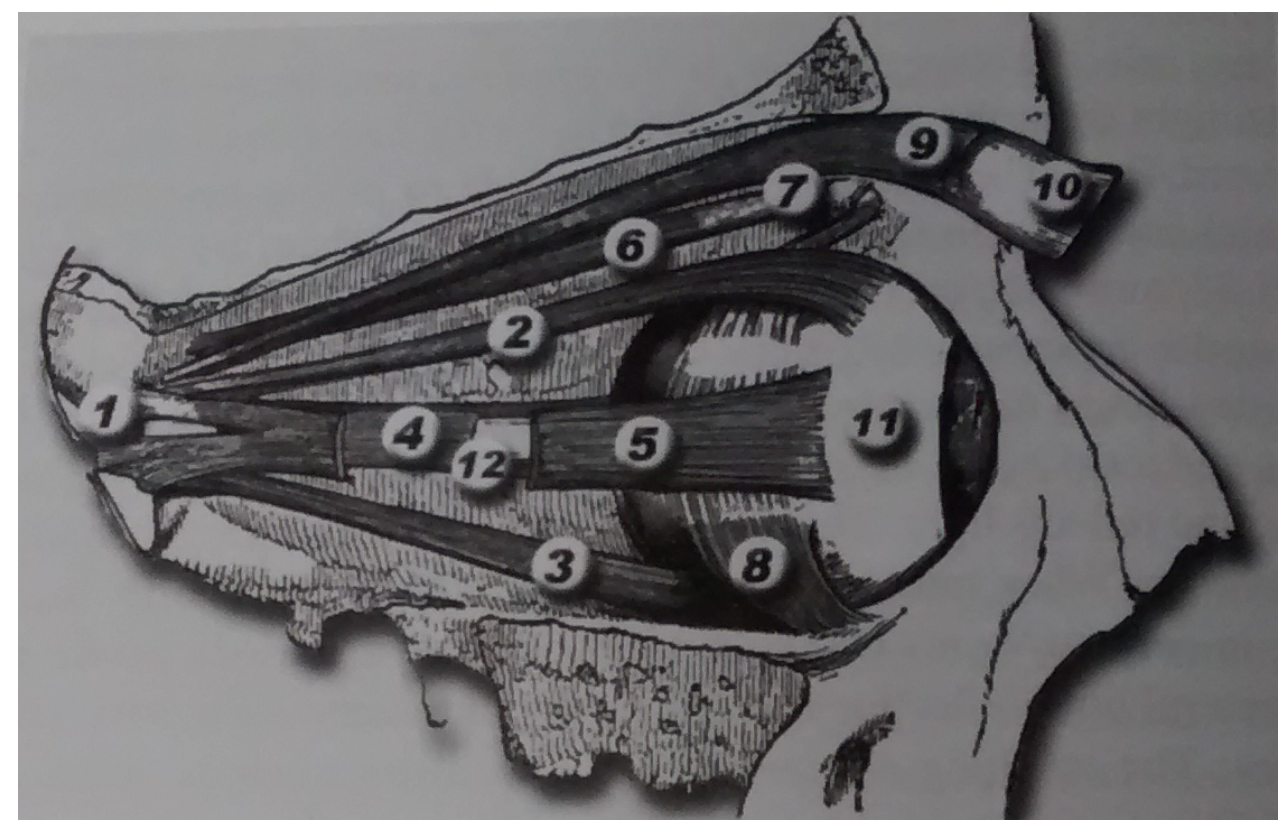

Fonte: Autor "adaptado de" Holmqvist et al., 2011, p.32

Legenda: (2)-(3) geram os movimentos verticais, (4)-(5) geram os movimentos horizontais, (7)-(8) geram o movimento torcional e (9)-(10) controlam a pálpebra.

Apesar de se estudar o movimento ocular, os resultados apresentados são mostrados, na maioria das vezes, quando os olhos estão parados, movimentos chamados de fixação e sacada (HOLMQVIST et al., 2011). Fixação é o termo utilizado para designar o período de tempo no qual o olho permanece parado com a atenção voltada para algum ponto. Sacada é um movimento muito rápido do olho entre uma fixação e outra. É, na verdade, o movimento mais rápido que o corpo humano pode produzir (DUCHOWSKI, A., 2017; HOLMQVIST et al., 2011). 


\subsection{VÍDEO-OCULOGRAFIA}

Assim como o EEG, a vídeo-oculografia (VOG) ou videonistagmografia também é uma técnica não invasiva e, atualmente, é a técnica de rastreamento de movimentos oculares mais utilizada em relação a outras técnicas de rastreamento ocular (CHENNAMMA; YUAN, 2013; DUCHOWSKI, A., 2017; EGGERT, 2007). Isso se deve ao rápido avanço do processamento de dados, aumento da robustez dos algoritmos, redução de preço e aumento dos campos de aplicação (CHENNAMMA; YUAN, 2013; EGGERT, 2007).

A VOG, com uma câmera, utiliza o princípio da emissão de raios infravermelhos em direção aos olhos, produzindo um brilho na córnea, chamado de reflexão da córnea que é usado como referência para estimar o ponto de fixação - já que a diferença entre a pupila e brilho produzido na córnea é constante (GAUR; JARIWALA, 2014; CHENNAMMA; YUAN, 2013). A Figura 10 mostra as diferentes posições de fixação do olhar e a posição da reflexão da córnea.

Figura 10 - Brilho da córnea com diferentes fixações.
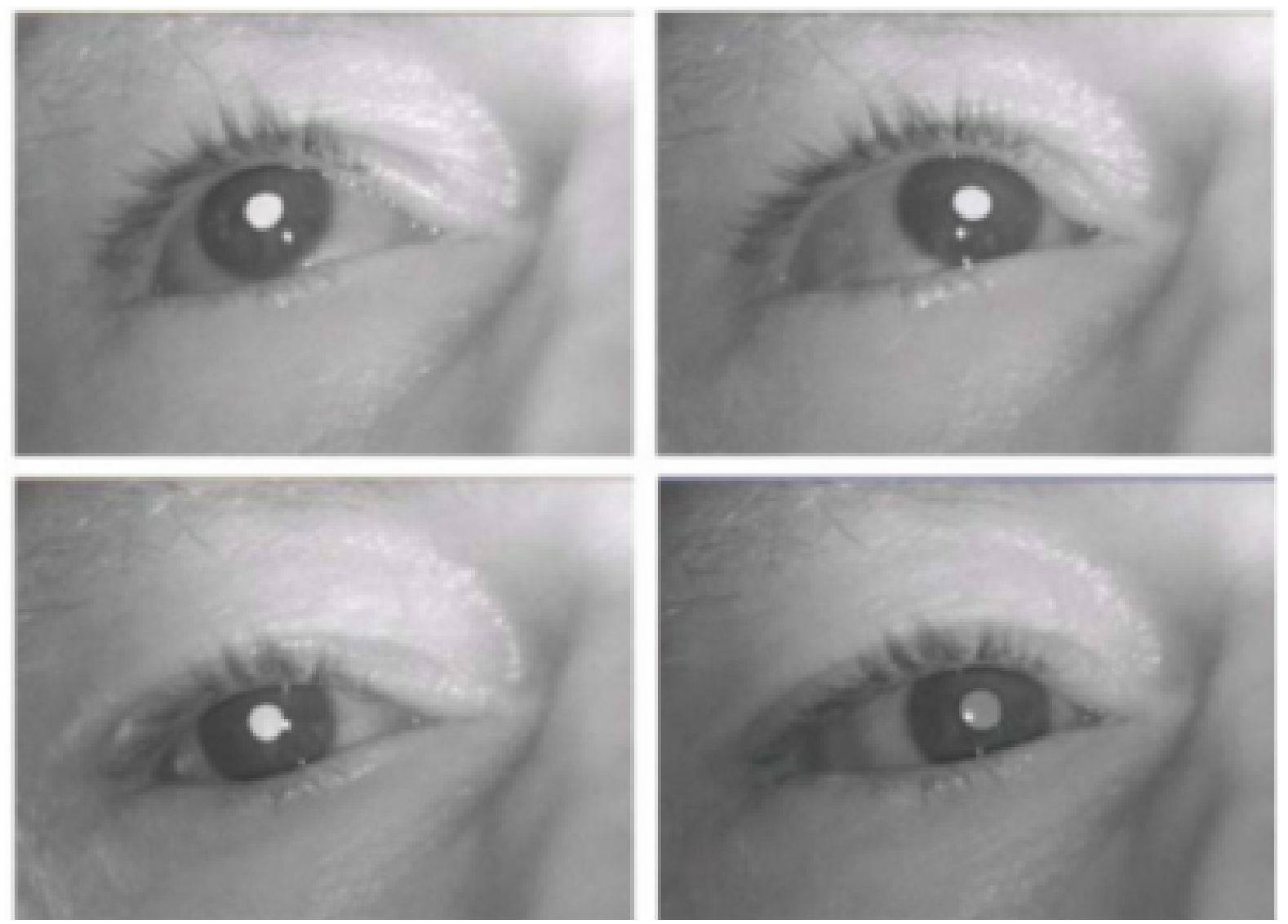

Fonte: Autor "adaptado de" Gaur e Jariwala, 2014

A partir dos raios infravermelhos emitidos e refletidos pela córnea, a captação dos movimentos oculares se dá por meio de sensores infravermelhos colocados em óculos especiais, 
máscara ou câmera (CHENNAMMA; YUAN, 2013; GANANÇA; CAOVILLA; GANANÇA, 2010). Para melhorar a precisão da captação dos movimentos oculares, é comum serem utilizadas várias fontes emissoras de raios infravermelhos (CHENNAMMA; YUAN, 2013). A Figura 11 mostra o diagrama de funcionamento da técnica VOG utilizando apenas uma câmera.

Figura 11 - Diagrama de funcionamento da VOG.

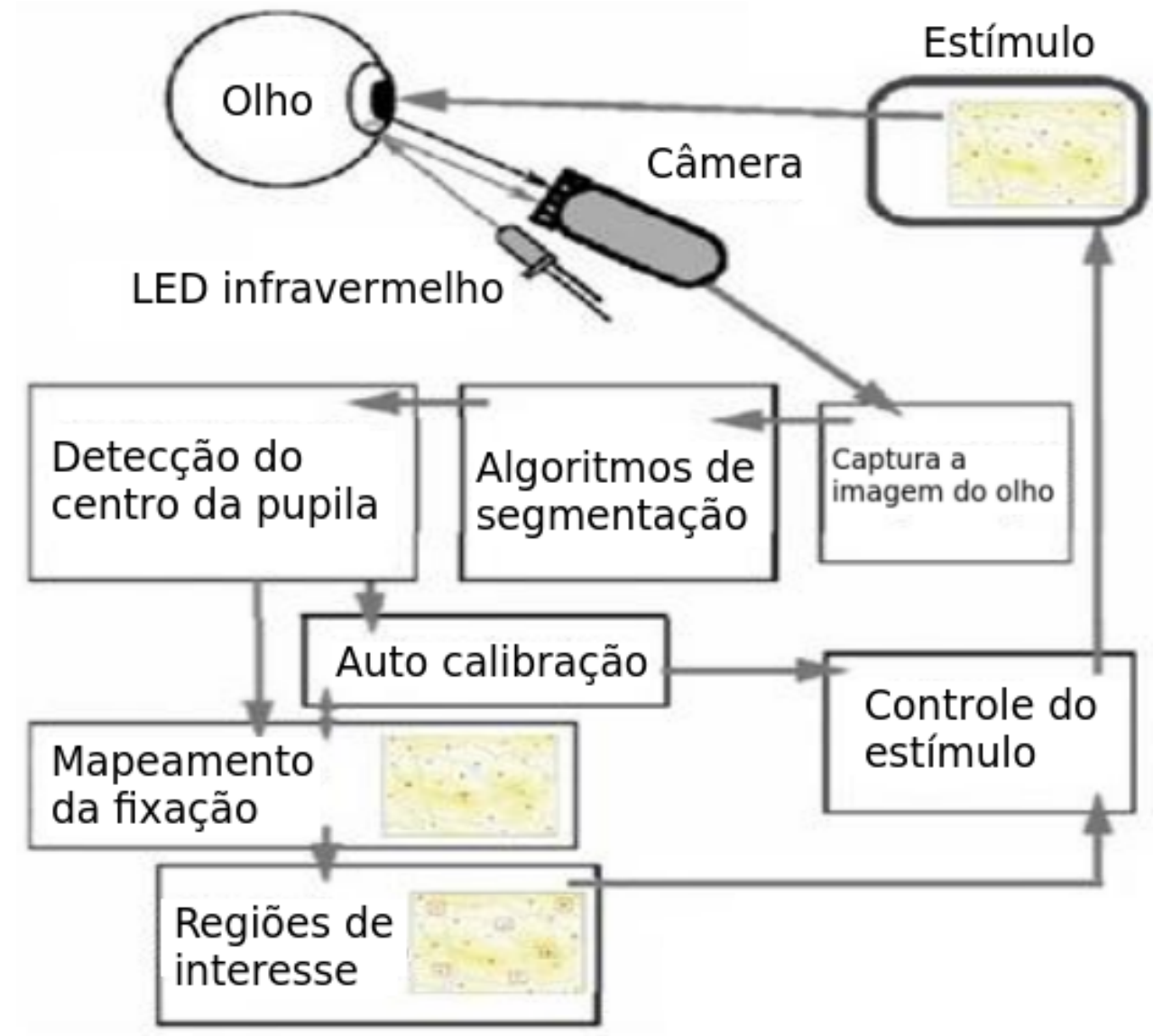

Fonte: Autor "adaptado de" Gaur e Jariwala, 2014

\subsection{CONSIDERAÇÕES ADICIONAIS}

Este capítulo apresentou a fisiologia básica do cérebro e do olho, em que serão analisados as ativações cerebrais e os movimentos oculares, respectivamente. Além disso, o princípio de funcionamento das técnicas de aquisição de sinais cognitivos utilizadas nesta tese também foi descrito.

Para que o voluntário da pesquisa se sinta o mais próximo possível do ambiente do xadrez, as técnicas de EEG e VOG foram escolhidas levando-se em consideração suas caracte- 
rísticas técnicas para as futuras análises dos dados que serão realizadas, bem como o conforto do usuário com relação à realização dos experimentos. 


\section{TRABALHOS RELACIONADOS}

Este capítulo descreve, sucintamente, os principais trabalhos relacionados ao tema em questão e está dividido em duas seções: estado da arte e considerações complementares. Na próxima seção, do estado da arte, são descritos, mais especificamente, experimentos realizados tendo o xadrez como aplicação e que utilizaram técnicas de mapeamento cerebral ou técnicas de rastreamento do movimento ocular para aquisição de sinais, bem como os trabalhos pioneiros na área. Na seção seguinte são feitas considerações em relação ao estado da arte.

\subsection{ESTADO DA ARTE}

Um dos trabalhos pioneiros na área de cognição no ambiente de xadrez foi realizado por de Groot (CHARNESS, 1992). Em 1946, De Groot (1978) realizaram experimentos com enxadristas de diferentes níveis, os quais deveriam olhar para uma posição no tabuleiro de xadrez, memorizá-la e, posteriormente, recriar a posição antes vista. Os principais resultados dessa pesquisa mostraram que enxadristas com titulação de grande mestres ${ }^{1}$ obtiveram melhores resultados que enxadristas de outros níveis.

Outro trabalho importante na área de cognição envolvendo o xadrez foi o trabalho de Chase e Simon (CHARNESS, 1992). Nesse trabalho, Chase e Simon (1973) contaram com a participação de um mestre em xadrez, um jogador classe $\mathrm{A}^{2}$ e um jogador iniciante para realizar tarefas similares às propostas por de Groot, em que os participantes analisavam uma posição do jogo de xadrez, memorizavam e tentavam reproduzir a mesma posição posteriormente. Chase e Simon (1973) concluíram que um mestre não era superior a um novato na tarefa de reproduzir posições de xadrez aleatórias. Essa constatação desafiava a visão de que os grandes mestres possuíam capacidade de memória superior.

Segundo o trabalho de Silva et al. (2010), a primeira pesquisa envolvendo xadrez e rastreamento ocular foi realizada por Tikhomirov e Poznyanskaya (1966). Para a realização do experimento, Tikhomirov e Poznyanskaya (1966) gravaram o registro dos movimentos oculares de um mestre em xadrez utilizando o método de filmagem, por meio de uma câmera. Por meio

\footnotetext{
${ }^{1}$ Titulação de mestre internacional requer que o jogador tenha no mínimo 2400 de rating Elo. Além disso, deve ter, ao menos, três normas em competições de Mestres Internacionais nas quais tenham competido, no mínimo, dois estrangeiros, além de ter conseguido obter o "rating performance" adequado.

${ }^{2}$ Titulação classe A requer que o jogador tenha rating Elo ente 1800 e 2000
} 
desse método foi possível mensurar o tempo que o enxadrista gastou em cada parte do tabuleiro, bem como a ordem das fixações.

No início da década de 90, Chabris e Hamilton (1992) efetuaram um experimento com 16 jogadores de xadrez com níveis de mestres. Desses, 4 participaram da escolha dos estímulos e 12 do teste, somente o teste consistia em mostrar aos participantes vários diagramas de xadrez por um período de tempo e, posteriormente, pedir que esses mesmos participantes reconstruíssem o que havia sido mostrado enquanto os pesquisadores anotavam a ordem em que a reconstrução era feita, mesmo expeimento realizado por Chase e Simon (1973) em 1973. Com esse experimento, Chabris e Hamilton (1992) concluíram que o hemisfério direito do cérebro teve melhor desempenho para identificar um único chunk ${ }^{3}$ enquanto que o hemisfério esquerdo teve melhor desempenho para identificar múltiplos chunks com tamanhos equivalentes.

Em 1994, utilizando a técnica de neuroimagem PET, Nichelli et al. (1994) realizaram um experimento envolvendo 10 enxadristas que já tinham, pelo menos, 4 anos de experiência em xadrez e participavam constantemente de torneios na área. Utilizando-se de um computador que mostrava um diagrama de xadrez, foram apresentadas 4 tipos de questões: reconhecimento de peças, discriminação espacial, conhecimento de regras e possibilidade de xeque-mate em um lance. Cada uma das tarefas realizadas mostrou diferentes áreas de ativação do cérebro: a tarefa de discriminação espacial mostrou ativação na área dorsal parieto-occipital; a tarefa de conhecimento de regras mostrou ativação nas regiões medial, lateral e inferior do lobo temporal; a tarefa de possibilidade de xeque-mate em um lance mostrou ativação do lado direito na área pré-frontal e na junção parieto-occipital.

No ano seguinte, Onofrj et al. (1995) efetuaram o primeiro experimento utilizando a técnica de SPECT e xadrez como ambiente de estudo. O experimento contou com 5 jogadores de xadrez com rating ELO acima de 1800 que foram colocados diante de um problema complexo de xadrez e, após 15 minutos de análise, chegaram à resposta correta. Esse estudo mostrou que existe uma ativação na região não-dominante do lobo frontal e na região não-dominante do lobo temporal quando enxadristas especialistas estão resolvendo problemas complexos de xadrez.

No início dos anos 2000, Amidzic et al. (2001) utilizaram a técnica de magnetoencefalografia (MEG) e realizaram um experimento envolvendo 20 enxadristas, sendo 10 grandes mestres e 10 amadores, em que os sujeitos da pesquisa jogavam uma partida de xadrez contra o computador. Com os resultados, foi possível verificar que os jogadores amadores tiveram

\footnotetext{
${ }^{3}$ Chunk é um termo utilizado em neurociência cognitiva em que unidades individuais de informação estão estruturadas em unidades maiores para melhorar o desempenho da memória.
} 
maior ativação na área medial do lobo temporal, enquanto que os grandes mestres mostraram maior ativação nas área dos lobos frontal e parietal, o que, segundo Amidzic et al. (2001), está relacionado ao fato de que os grandes mestres confiam mais em sua memória remota do que na memória recente.

Em 2001, Reingold et al. (2001) investigaram as diferenças entre jogadores de xadrez principiantes, intermediários e experientes, analisando-se a extensão visual dos mesmos por meio de um equipamento de eye-tracking. Diferentes estímulos foram apresentados aos participantes, sendo esses: identificar qual peça foi alterada entre dois quadros que continham situações reais de jogo, identificar qual peça foi alterada entre dois quadros que continham posições randômicas de peças de xadrez e analisar uma situação de xeque em uma situação real de jogo. Com esse estudo, Reingold et al. (2001) mostraram que enxadristas experientes conseguem extrair mais informações em suas fixações na cena. De modo que, tarefas de identificação de situação de xeque, demonstraram que precisam de menos fixações para analisar a relação entre as peças.

Nesse mesmo ano, Charness et al. (2001) realizaram experimento envolvendo enxadristas somente com rating ELO, sendo 12 participantes entre 1600 a 1923 pontos e 12 participantes entre 2200 e 2350 , em que os movimentos oculares dos voluntários foram analisados enquanto solucionavam 5 tarefas relacionadas ao xadrez. Esse experimento mostrou que jogadores com maior proficiência responderam às questões de forma mais rápida e com mais acurácia, além de uma proporção maior de fixações entre as peças do que em uma única peça, mostrando que esses jogadores analisam a configuração da codificação do xadrez ao invés das peças individualmente.

Em 2002, Volke et al. (2002) realizaram experimentos com 39 enxadristas de diferentes níveis de proficiência em xadrez usando o EEG como ferramenta de análise, em que foram apresentadas 4 diferentes tipos de questões, nas quais cada variação seguinte continha os elementos da questão anterior, adicionando-se mais um novo elemento. Os resultados mostraram que as áreas essenciais para a realização das tarefas apresentadas em jogadores com maior proficiência mudam da parte anterior para a parte posterior e mostram maior conexão entre várias áreas do córtex cerebral, enquanto que jogadores com menor proficiência em xadrez apresentam menor conexão entre as áreas do córtex cerebral.

No ano seguinte, em 2003, Atherton et al. (2003) estudaram as áreas do cérebro que são ativadas para realização de 3 tarefas relacionadas ao xadrez. Os estímulos apresentados 
foram: diagrama do tabuleiro de xadrez sem peças, diagrama com peças em posições aleatórias e diagrama representando uma situação de jogo. Para realização do experimento foi utilizada a técnica de fMRI e 7 voluntários principiantes em xadrez participaram da pesquisa. Nesse trabalho, Atherton et al. (2003) analisaram os resultados da subtração entre as tarefas envolvendo diagrama com peças em posições aleatórias e com representação de jogo, mostrando que, em geral, houve ativação em ambos os hemisférios dos lobos frontal, parietal e occipital. Esse resultado foi comparado com outros encontrados no jogo Go, que tem os fundamentos semelhantes ao do xadrez em relação ao esforço cognitivo, o que indicou similaridades entre os resultados.

Em 2005, Campitelli, Gobet e Parker (2005) utilizaram fMRI para analisar as áreas de ativação do cérebro em enxadristas profissionais e principiantes, sendo 2 enxadristas com rating ELO e 14 principiantes, a fim de entender as diferenças em testes de memória que envolviam estímulos relacionados ao xadrez ou não. Os resultados mostraram as diferenças das ativações cerebrais entre os estímulos apresentados, tal que enxadristas principiantes mostraram diferenças de ativações cerebrais nas áreas do lobos frontal e temporal, além da área posterior em ambos os hemisférios, enquanto que, em jogadores com maior proficiência, não houve diferença de ativação do cérebro entre as diferentes tarefas.

Dois anos mais tarde, em 2007, Campitelli et al. (2007) investigaram principalmente a localização do domínio específico dos chunks de memória a longo prazo. Esse experimento contou com a participação de 5 voluntários com raking ELO entre 1550 e 2200, que foram apresentados a 4 tipos de tarefas distintas. A análise foi feita a partir dos dados coletados por meio do uso de um equipamento de fMRI. Com este estudo, Campitelli et al. (2007) propuseram que enxadristas ativam os chunks de memória a longo prazo no lobo temporal quando expostos às tarefas relacionadas ao xadrez e que há ativação na área dorso-lateral, pré-frontal e no lobo parietal em tarefas relacionadas à memória.

No ano seguinte, Blignaut, Beelders e So (2008) estudaram o padrão de fixação de enxadristas utilizando um equipamento de eye-tracking por meio da técnica de video-oculografia. Neste experimento, 75 voluntários com rating ELO responderam a três diferentes categorias de questões envolvendo xadrez enquanto seus movimentos oculares foram capturados. Os principais resultados mostraram que enxadristas com maior proficiência conseguiram perceber mais que um quadrado do tabuleiro por fixação e levaram menos tempo para analisar um quadrado do que enxadristas com menor proficiência. 
Em outro experimento utilizando as técnicas de fMRI e eye-tracking, Bilalić et al. (2010), em 2010, compararam as diferenças entre enxadristas experientes e principiantes, sendo 8 experientes e 15 principiantes, que foram submetidos a tarefas de reconhecimento de padrão e reconhecimento de objetos. Analisando-se os resultados obtidos com eye-tracking, foi possível mostrar que jogadores de xadrez com maior proficiência olhavam para as partes mais relevantes da cena, enquanto que jogadores com menor proficiência olhavam para toda a cena para obter a mesma solução. Analisando-se os resultados obtidos com fMRI, notou-se uma ativação maior em diversas áreas em tarefas relacionadas ao xadrez. Em contrapartida, não houve diferenças em tarefas que não eram relacionadas ao jogo.

Utilizando-se as mesmas técnicas, no ano seguinte, Bilalić et al. (2011a) compararam novamente diferenças entre jogadores de xadrez principiantes e experientes. Esse experimento contou com a participação de 16 enxadristas, sendo 8 experientes e 8 principiantes, que realizaram tarefas de reconhecimento de formas de objetos, reconhecimento de objetos relacionados ao xadrez e funções de objetos relacionados ao xadrez. A análise dos movimentos oculares mostrou que enxadristas com maior proficiência precisaram de menos fixações nos objetos para reconhecê-los e, consequentemente, realizaram as tarefas mais rapidamente do que os enxadristas com menor proficiência, porém essa diferença não existiu quando a tarefa não era relacionada com objetos de xadrez. As imagens de fMRI revelaram ativação do lado esquerdo do lobo temporal e parte lateral do lobo parietal, e ativação equivalente no hemisfério direito somente nos enxadristas com maior proficiência.

Nesse mesmo ano de 2011, Bilalić et al. (2011b) estudaram as diferenças entre enxadristas principiantes e experientes na Fusiform Face Area (FFA), área relacionada ao reconhecimento de faces. Utilizando-se fMRI, os voluntários da pesquisa foram submetidos a tarefas de reconhecimento de objetos, algumas envolvendo objetos relacionados ao xadrez e outras não. Com esse experimento, Bilalić et al. (2011b) mostraram que a área do FFA é mais ativada em enxadristas mais experientes, tanto em tarefas relacionadas quanto não-relacionadas com proficiência em xadrez, o que pode ser algo que ajude os jogadores com maior proficiência a terem melhores resultados em relação a percepção visual.

Em 2011, assim como Bilalić et al. (2011b), Krawczyk et al. (2011) estudaram a diferença na ativação na FFA entre jogadores de xadrez principiantes e experientes. O grupo de voluntários foi composto por 6 enxadristas com rating ELO e 6 enxadristas principiantes que foram submetidos a estímulos que envolviam ou não características relacionadas ao xadrez. As 
ativações do cérebro foram capturadas por um equipamento de fMRI e, ao contrário do resultado encontrado por Bilalić et al. (2011b), Krawczyk et al. (2011) mostraram que não há seletividade entre xadrez e outras formas de estímulo. Porém, em estímulos relacionados a situações reais de um jogo de xadrez, os enxadristas principiantes tiveram maior ativação no lobo parietal.

No ano seguinte, Duan et al. (2012a) realizaram um experimento com enxadristas com diferentes níveis de proficiência para estudar as diferenças no núcleo caudado, área relacionada com o aprendizado e associação de estímulos recebidos, utilizando-se a técnica de fMRI. Nesse experimento, Duan et al. (2012a) verificaram que enxadristas com maior proficiência têm um volume menor de massa cinzenta no núcleo caudado bilateral e melhor conexão com o Default Mode Network (DMN, rede neural do cérebro que, normalmente, é ativada em situação de repouso) em atividades espontâneas oscilatórias.

Nesse mesmo ano de 2012, Duan et al. (2012b) estudaram novamente a diferença entre jogadores de xadrez experientes e principiantes, analisando-se o DMN através das imagens geradas por fMRI, em que os voluntários foram submetidos a tarefas relacionadas ao xadrez. A análise foi feita durante e após o período de realização da tarefa. Com esse experimento encontrou-se uma supressão robusta do DMN durante a realização de uma tarefa relacionada ao xadrez e maior conexão entre o DMN e o núcleo caudado em situação de repouso em enxadristas com maior proficiência, que pode estar relacionada com melhor desempenho desse grupo em comparação com os enxadristas com menor proficiência.

Mais recentemente, em 2013, Wright et al. (2013) realizaram experimento com EEG e ERP em que 28 voluntários, sendo 14 experientes e 14 novatos, foram submetidos a estímulos relacionados com o xadrez, como reconhecimento de peças e conhecimento de situações de xeque, para comparação das diferenças entre os grupos de participantes. Comparando-se os resultados do experimento, Wright et al. (2013) verificaram que no grupo de enxadristas com maior proficiência houve aumento na componente N2 em tarefas em situação de xeque e aumento na componente P3 em tarefas de reconhecimento de peças, que pode ter ligação com melhor desempenho deste grupo em reconhecimento de padrões, o que comprova os resultados encontrados por Bilalić et al. (2011a).

Neste mesmo ano, em 2013, Rennig et al. (2013) deram continuidade aos trabalhos de Bilalic et. al. publicados em 2010, 2011 e 2012. Com a análise desses dados nas regiões de interesse, Rennig et al. (2013) exploraram a hipótese de que habilidades de processamento visual superiores para tarefas complexas e altamente familiares (especialista) estão fortemente 
associadas a habilidades aprimoradas de integração visual, que no caso do xadrez: especialistas olham para o tabuleiro como um todo enquanto iniciantes olham as peças individualmente.

Em 2014, Duan et al. (2014) investigaram a diferença na conectividade de toda rede neural entre enxadristas principiantes e experientes. Para este experimento, Duan et al. (2014) utilizaram a técnica de fMRI com a participação de 40 voluntários, sendo 20 jogadores experientes e 20 jogadores principiantes. Neste experimento, Duan et al. (2014) apuraram que a conectividade funcional em enxadristas com maior proficiência é maior entre as regiões dos gânglios basais, tálamo, lobo temporal e algumas áreas do lobo parietal, sugerindo que a proficiência em xadrez influencia nas redes de conexões ligadas ao aprendizado e memória.

Nesse mesmo ano, Hänggi et al. (2014) realizaram experimento utilizando a técnica de ressonância magnética envolvendo 40 voluntários, sendo 20 enxadristas experientes e 20 enxadristas principiantes, para determinar diferenças morfológicas entre esses 2 grupos. Ao contrário dos resultados encontrados por Duan et al. (2012a), Hänggi et al. (2014) não encontraram diferenças no núcleo caudado entre enxadristas com maior proficiência e o grupo de controle, porém verificaram uma diminuição da massa cinzenta e aumento da média de dilatação dentro de dois agrupamentos do lado superior esquerdo do fascículo longitudinal.

No ano seguinte, em 2015, Sheridan e Reingold (2015) estudaram a diferença dos movimentos oculares entre enxadristas iniciantes e experientes, por meio da técnica VOG, para analisar os focos de atenção em áreas relevantes e irrelevantes para solução das tarefas. Esse estudo contou com a participação de 41 jogadores de xadrez, sendo 17 experientes com rating ELO variando entre 1876 e 2580 e 24 iniciantes sem rating ELO. Os principais resultados mostram que jogadores experientes revelaram uma rápida diferenciação entre as regiões do tabuleiro de xadrez que eram relevantes e irrelevantes para a definição da melhor jogada.

Em 2016, Fabio Rocha et al. (2016) compararam as diferenças entre jogadores de xadrez iniciantes e experientes utilizando a técnica de EEG para obtenção dos sinais cerebrais, analisando-se esses sinais 2 segundos antes da tomada de decisão através do método proposto por Fabio Rocha et al. (2005). Os resultados desse experimento foram apresentados em mapas cerebrais codificados em cores, que mostraram que enxadristas com maior proficiência tiveram maior ativação na área frontal do cérebro, área relacionada ao planejamento e tomada de decisão, enquanto que enxadristas com menor proficiência apresentaram maior ativação cerebral nas áreas relacionadas à leitura lexical, o que pode remeter ao momento de leitura da questão para analisar qual a resposta correta a ser dada. 
Comparando-se a habilidade em xadrez por meio do rating ELO e testes de meta-análise, Burgoyne et al. (2016) verificaram, ainda em 2016, a correlação entre essas duas métricas. Ao todo, informações de 1779 voluntários foram coletadas de 19 estudos realizados anteriormente. A conclusão dessa análise evidencia que existe uma correlação positiva e estatisticamente significativa entre as métricas utilizadas, representando numericamente a relação entre proficiência em xadrez e habilidade cognitiva realizada por testes de QI.

Em 2018, Mayeli, Rahmani e Aarabi (2018) utilizaram os dados adquiridos anteriormente por Li et al. (2015) para analisar a diferença da substância branca do cérebro entre enxadristas profissionais e iniciantes por meio da técnica de DMRI (Diffusion MRI - ressonância magnética ponderada por difusão). Os resultados de Mayeli, Rahmani e Aarabi (2018) mostraram diferenças nessa substância branca entre os dois grupos em diversas áreas, além de correlação entre elas, porém não foram encontradas diferenças em relação a idade, sexo e tempo de estudo entre os grupos.

Neste mesmo ano, Fuentes et al. (2018) analisaram os sinais cerebrais adquiridos por meio do EEG e a taxa de variação cardíaca de um único enxadrista profissional quando o mesmo jogava uma partida de xadrez contra uma engine de xadrez. Os resultados obtidos revelaram um aumento da proporção na região dos eletrodos Fz e Pz nas bandas de frequência alfa e theta, respectivamente, quando comparadas as situações pré-jogo e pós-jogo. Esse resultado pode estar relacionado ao aumento de esforço cognitivo.

No ano seguinte, em 2019, Villafaina et al. (2019) utilizaram o EEG como ferramenta de mapeamento cerebral e verificaram a ativação cerebral de 14 enxadristras com rating ELO em duas modalidades do jogo de xadrez: jogo relâmpago e rápido. Seus resultados mostraram que houve aumento da atividade de ondas thetas nas áreas central e parietal durante o jogo relâmpago. Além disso, o hemisfério direito do cérebro apresentou, ligeiramente, maior ativação do que o hemisfério esquerdo em ambas as modalidades do jogo.

Neste mesmo ano, Fuentes-García et al. (2019) utilizaram o EEG e a taxa de variação cardíaca como métricas para investigar como o coração e o cérebro reagem quando um enxadrista joga contra um computador e quando joga contra outro enxadrista, métodos utilizados também em 2018 por Fuentes et al. (2018). Esse experimento contou com a participação de 27 voluntários e, como resultado, verificou-se que enxadristas que não são familiarizados com o ambiente virtual apresentaram maior atividade das ondas thetas quando os mesmos foram submetidos a esse ambiente. A taxa de variação cardíaca mostrou resultados semelhantes com 
o EEG, em que houve aumento quando enxadristas não familiarizados com o ambiente virtual foram submetidos a esse ambiente.

Em outro experimento, utilizando rede neural convolucional, Louedec et al. (2019) estudaram a possibilidade de prever os pontos de atenção visual de enxadristas. Para essa análise foram utilizados dados de experimentos anteriores que contaram com jogadores experientes e intermediários com rating ELO, e jogadores iniciantes sem rating ELO. Esse trabalho não mostrou resultados conclusivos em relação à previsão dos pontos de atenção visual, porém apresentou possibilidades de ser uma boa métrica para esse tipo de análise.

Em 2020, Fuentes-García et al. (2020) verificaram por meio do EEG a variação da potência nas frequências alfa, beta e theta de enxadristas em jogos de xadrez contra um computador com diferentes níveis de dificuldade de acordo com o rating ELO de cada participante. Cada participante, em um total de 14, jogou partidas contra o computador em três níveis: $75 \%, 100 \%$ e $125 \%$ de seus respectivos rating ELO. Notou-se aumento de potência na banda de frequência alfa conforme aumentava a dificuldade das partidas para o grupo que venceu, enquanto que a potência nas bandas de frequência alfa e beta diminui conforme aumentava a dificuldade das partidas que o grupo que perdeu.

No ano passado, em 2020, Pereira et al. (2020) estudaram especificamente a área do córtex pré-frontal de enxadristas proficientes por meio da técnica FNIRS (Functional Nearinfrared Spectroscopy - Espectrografia Funcional de Infravermelho Próximo). Ao todo, 30 voluntários participaram desse estudo, sendo 15 adolescentes e 15 adultos, aos quais foram apresentadas tarefas de diferentes níveis de complexidade. Os principais resultados revelaram que as ativações na área do córtex pré-frontal, em ambos os grupos, foram maiores conforme mais difícil era a tarefa apresentada.

Ainda no ano passado, Ouellette et al. (2020) analisaram imagens de fMRI de 29 enxadristas proficientes e 29 não-proficientes disponibilizadas em uma base de dados pública. Por meio dessa análise, Ouellette et al. (2020) verificaram que dez regiões do córtex cerebral dos enxadristas proficientes são mais finas do que de enxadristas não-proficientes. Essas regiões são relacionadas às áreas de: processamento da visão, atenção, memória de trabalho e episódica, imagens mentais e região do córtex pré-frontal. Outra constatação é de que não houve regiões mais espessas dos enxadristas proficientes quando comparados aos não-proficientes. 


\subsection{CONSIDERAÇÕES COMPLEMENTARES}

Este capítulo apresentou as principais pesquisas realizadas nas últimas décadas que estão dentro do escopo deste trabalho. A quantidade de artigos encontrados na literatura mostra a importância do tópico que vem sendo estudado e também como ainda são necessários novos experimentos nessa área, principalmente que investiguem o mecanismo humano de abstração mental.

Os trabalhos anteriores revelam números relativamente baixos de voluntários para a realização de experimentos. Em sua maioria, a quantidade de voluntários não foi superior a 20. Outra característica comum se refere à forma como os experimentos foram conduzidos, utilizando-se do sistema de perguntas e respostas.

O estado da arte mostra também a evolução das técnicas de mapeamento cerebral utilizadas desde meados da década de 1990. Inicialmente, as técnicas utilizadas eram PET e SPECT, ambas sendo invasivas. Logo em seguida, a partir dos anos 2000, essas técnicas invasivas deixaram de ser utilizadas nessa área de pesquisa, sendo substituídas pelas técnicas de MRI e fMRI, principalmente. Apesar dessas novas técnicas de mapeamento cerebral serem não-invasivas, ambas requerem locais específicos para funcionamento, retiram os voluntários de seu local natural de realização das atividades e são de difícil acesso para realização de experimentos científicos. Algumas pesquisas foram realizadas utilizando o EEG como técnica para aquisição de sinais cerebrais, sendo não-invasiva e ecologicamente correta (ROCHA, A. F. d. et al., 2017), porém o sinal é suscetível a ruído e apresenta resolução espacial menor que as outras técnicas.

Já a técnica de eye-tracking, utilizada em todos os trabalhos anteriores, foi baseada na técnica VOG, mais utilizada atualmente devido aos avanços tecnológicos recentes (EGGERT, 2007; CHENNAMMA; YUAN, 2013). Em relação às técnicas de aquisição de sinais cognitivos, somente os trabalhos de Bilalić et al. (2010) e Bilalić et al. (2011b) utilizaram técnicas de mapeamento cerebral e rastreamento ocular de forma sincronizada, sendo que os demais trabalhos utilizaram apenas uma técnica de aquisição de sinais cognitivos. A Tabela 1 resume os trabalhos que foram apresentados neste capítulo.

Para que o voluntário da pesquisa se sinta o mais próximo possível do ambiente do xadrez e, consequentemente, os sinais cognitivos obtidos sejam os mais próximos à situação real do jogo, as técnicas de EEG e VOG foram escolhidas para realização dos experimentos 
Tabela 1 - Resumo do estado da arte.

\begin{tabular}{c|c|c|c}
\hline \multirow{2}{*}{ Técnica } & \multicolumn{3}{|c}{ Anos } \\
\cline { 2 - 4 } & $1991-2000$ & $2001-2010$ & 2011-atual \\
\hline PET & 1 & - & - \\
\hline SPECT & 1 & - & - \\
\hline MEG & - & 1 & - \\
\hline EEG & - & 1 & 7 \\
\hline fMRI & - & 4 & 7 \\
\hline VOG & - & 4 & 2 \\
\hline MRI & - & - & 1 \\
\hline fNIRS & - & - & 1 \\
\hline
\end{tabular}

Fonte: Autor

que serão mostrados a seguir. Mais do que isso, apesar do EEG apresentar ruído em seu sinal e menor resolução espacial, limitações que podem ser atenuadas, possui também portabilidade e alta resolução temporal. Já a técnica VOG, além de apresentar maior conforto para o usuário, é a que apresenta maior taxa de aquisição de dados.

Resultados apresentados por Silva Junior et al. (2018) e Junior e Thomaz (2020) revelam diferenças entre os processos cognitivos entre enxadristas com maior e menor proficiência em jogadas específicas. Essas diferenças, tanto nas ativações cerebrais quanto nos movimentos oculares, podem explicar o melhor desempenho de enxadristas com maior proficiência no âmbito do jogo. Portanto, a ideia de aplicar uma técnica que separe enxadristas em grupos de proficiência por meio de seus sinais cognitivos, e mais do que isso, mensure essa proficiência, se faz plausível nesse contexto, e será detalhada nos capítulo seguintes. 



\section{MATERIAIS E MÉTODOS}

Este capítulo apresenta os materiais utilizados para realização dos experimentos e está dividido em três seções: materiais, processamento de sinais e métricas de avaliação de proficiência. Na primeira seção, são descritos os equipamentos utilizados, separados de acordo com os biossinais adquiridos. Na seção seguinte, são explicados os processamentos desses mesmos biossinais. Na ultima seção, é apresentada uma métrica tradicional para mensurar proficiência e a métrica de proficiência baseada em sinais cognitivos.

\subsection{MATERIAIS}

Os materiais utilizados para os experimentos serão divididos de acordo com os sinais cognitivos adquiridos: sinais cerebrais e de movimentos oculares. As subseções seguintes descrevem os materiais utilizados na execução dos experimentos propostos.

\subsubsection{OpenBCI}

Dentre os diversos equipamentos de EEG disponíveis no mercado, o OpenBCI foi escolhido devido a suas características técnicas, como: ferramenta aberta (opensource), frequência de amostragem de até $2000 \mathrm{~Hz}$ e captura dos sinais elétricos cerebrais por meio de 16 canais de EEG de forma simultânea; além de características não-técnicas como: portabilidade e conectividade com os tipos de eletrodos encontrados comercialmente. A Figura 12 mostra esse equipamento.

$\mathrm{Na}$ aquisição dos sinais cerebrais foram utilizadas duas toucas de tamanhos diferentes para melhor adquirir os sinais elétricos cerebrais conforme o tamanho da circunferência cranial do voluntário utilizando-se eletrodos de cloreto de prata $(\mathrm{AgCl})$ posicionados de acordo com o sistema internacional 10-20 (TEPLAN, 2002; JASPER, 1958). A Figura 13 mostra as toucas que foram utilizadas para realização dos experimentos.

Nos experimentos realizados, foram adquiridos os sinais elétricos de dezesseis canais, posicionados de forma a abranger a maior parte possível do cérebro, são eles: Fp1, Fp2, F3, F4, F7, F8, T3, T4, T5, T6, C3, C4, P3, P4, O1 e O2, além dos eletrodos A1 e A2 posicionados nos lóbulos auriculares, que foram utilizados como referência de potencial elétrico (TEPLAN, 
Figura 12 - Equipamento OpenBCI.
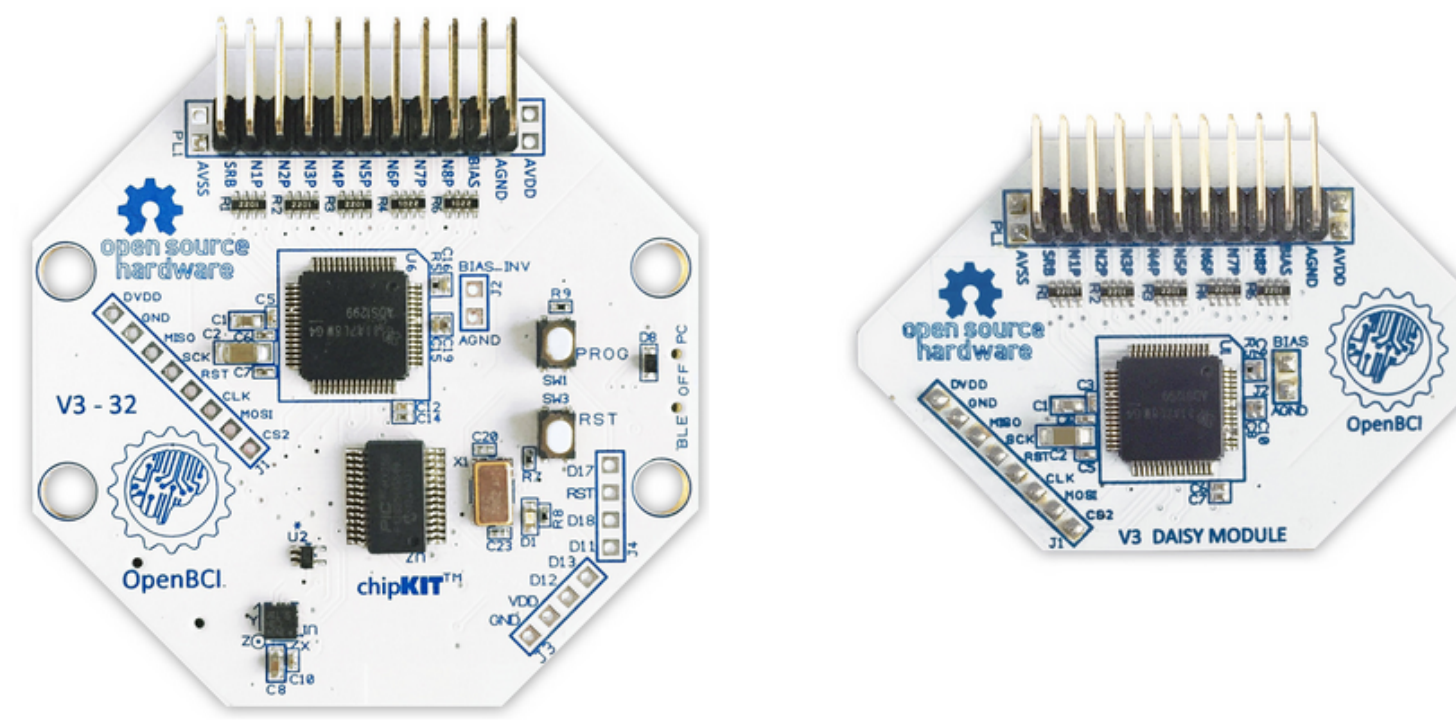

Fonte: OpenBCI, 2021

Figura 13 - Toucas de eletrodos para EEG.

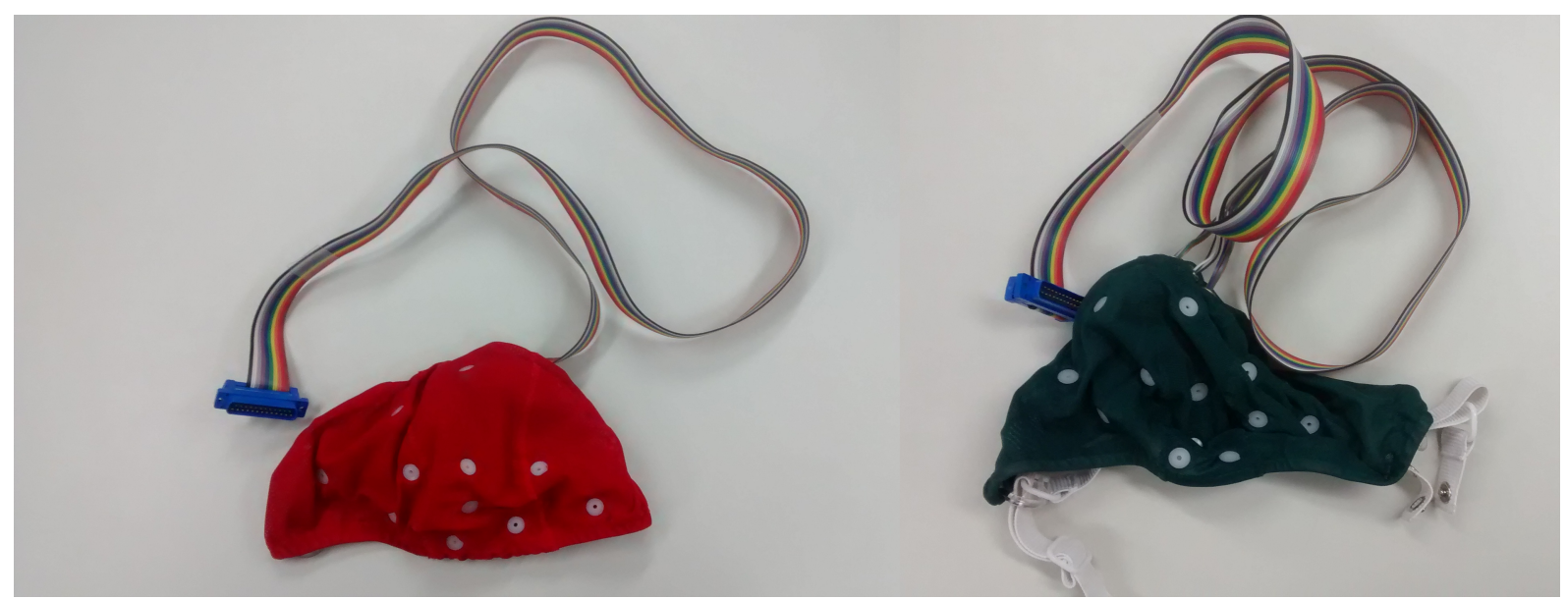

Fonte: Autor

2002; JASPER, 1958). A Figura 14 mostra o sistema 10-20 convencional que foi utilizado como referência para o posicionamento dos eletrodos, evidenciando na cor laranja os eletrodos utilizados nos experimentos.

Para as análises que serão descritas a seguir, serão exploradas as áreas de Brodmannm (BRODMANN, 1909) — por esse motivo, é importante correlacionar as posições dos eletrodos no sistema 10-20 com tais áreas. A Tabela 2 mostra a associação entre elas segundo Homan (1988) e Koessler et al. (2009). 
Figura 14 - Posicionamento dos eletrodos.
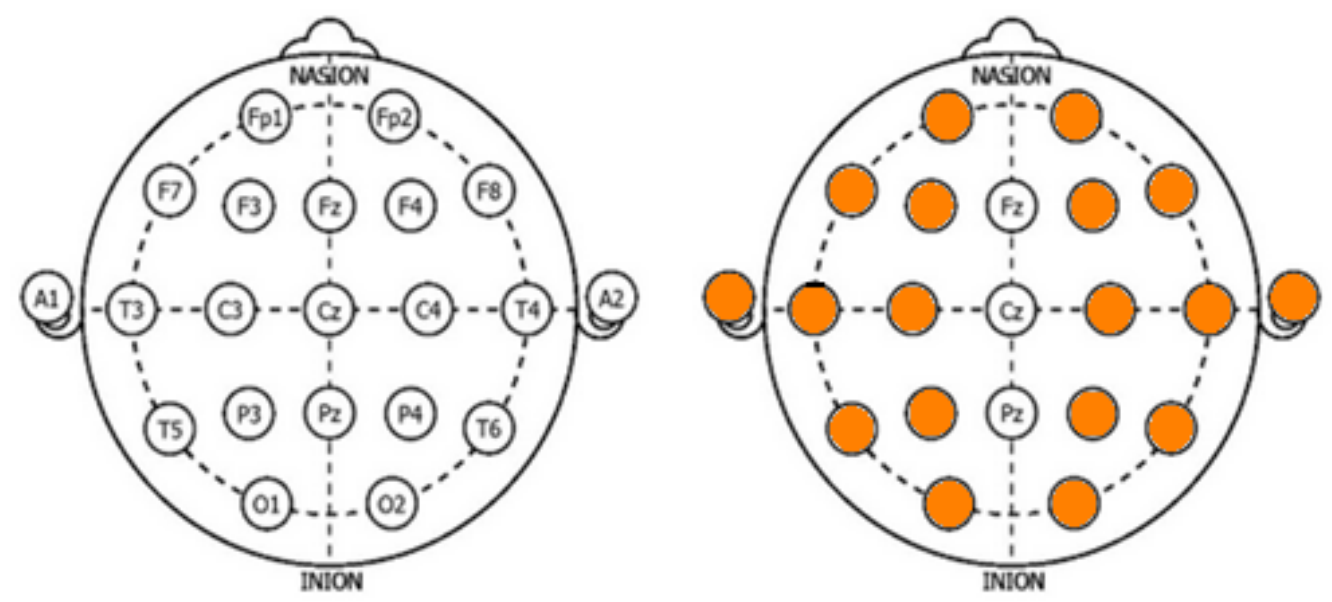

Fonte: Autor "adaptado de" Teplan, 2002

Tabela 2 - Correlação entre eletrodos e áreas de Brodmann.

\begin{tabular}{c|c}
\hline Eletrodos & Áreas de Brodmann \\
\hline Fp1 & BA10 \\
\hline Fp2 & BA10 \\
\hline F3 & BA8 \\
\hline F4 & BA8 \\
\hline F7 & BA45 \\
\hline F8 & BA45 \\
\hline T3 & BA21 \\
\hline T4 & BA22 \\
\hline T5 & BA37 \\
\hline T6 & BA19,37,39 \\
\hline C3 & BA4 \\
\hline C4 & BA4 \\
\hline P3 & BA19 \\
\hline P4 & BA7 \\
\hline O1 & BA18 \\
\hline O2 & BA18
\end{tabular}

Fonte: Autor

\subsubsection{Tobii Pro TX300}

Dentre os equipamentos de rastreamento ocular ocular disponíveis no mercado que utilizam a video-oculografia como técnica de captação dos movimentos oculares, o equipamento Tobii Pro TX300 foi escolhido para o presente trabalho. Esse equipamento possui características técnicas como: frequência de amostragem de $300 \mathrm{~Hz}$, latência total menor que $10 \mathrm{~ms}$ e 
monitor de 23" que é acoplado ao dispositivo de rastreamento ocular. Além de características não-técnicas: portabilidade e facilidade de calibração. A Figura 15 mostra esse equipamento.

Figura 15 - Equipamento Tobii Pro TX300.

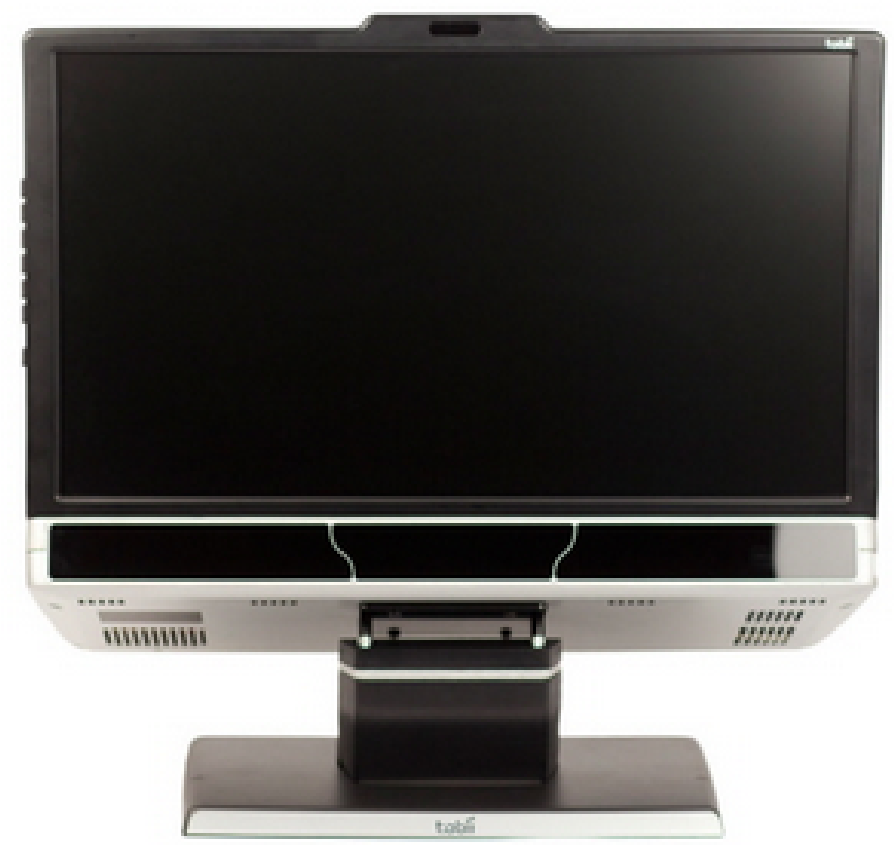

Fonte: Tobii Pro, 2021

\subsubsection{Considerações adicionais}

Para captura dos sinais, foi utilizado o software CHESSLAB desenvolvido no laboratório de processamento de sinais e imagens da FEI (CESAR; ROCHA; THOMAZ, 2015) e um computador notebook com processador Intel Core i7 com 8GB de memória RAM, para armazenar os sinais de EEG provenientes do equipamento OpenBCI de forma simultânea aos sinais de movimentos oculares proveniente do equipamento Tobii TX 300. Todos os participantes tiveram seus olhares calibrados por meio de uma ferramenta disponibilizada pelo fabricante do equipamento TobiiTX 300, antes da atividade. Previamente e durante o teste, os sinais de EEG foram analisados visualmente por meio da interface gráfica do software OpenBCI. 


\subsection{PROCESSAMENTO DOS SINAIS}

\subsubsection{Sinais Cerebrais (EEG)}

Os dados originais obtidos através do OpenBCI não possuem qualquer tipo de préprocessamento e, portanto, o fabricante recomenda que, antes de qualquer análise, filtre-se o sinal. Então, primeiramente, foi aplicado um filtro passa alta com frequência de corte de $0.5 \mathrm{~Hz}$ para retirar o nível DC apresentado no sinal elétrico devido ao componente eletrônico presente no equipamento OpenBCI. Posteriormente, o sinal passou por um filtro passa baixa com frequência de corte de 50Hz, que segundo Gazzaniga, Ivry e Mangun (2009) essa frequência de corte é, normalmente, a frequência máxima de funcionamento do cérebro. Aplicou-se também um filtro rejeita-faixa de $60 \mathrm{~Hz}$ para remover possíveis ruídos referentes à frequência da rede elétrica nacional. Para todas as etapas foram utilizados filtros butterworth digitais, alterando-se apenas as configurações e frequências de corte para cada caso (TEPLAN, 2002).

Após essa primeira etapa de filtragem, obtém-se os sinais cerebrais provenientes de cada voluntário. Porém esse sinal possui ruídos e artefatos adicionais, sinais que são provenientes de fonte que não seja o cérebro, obtidos juntamente com as ativações cerebrais, e que precisam ser removidos para posterior análise. A técnica ICA (Independent Component Analysis) é a mais utilizada para isso (SUBHA et al., 2010; ZHANG et al., 2015).

O princípio de funcionamento do ICA para filtragem de sinais de EEG é que, por meio de filtros espaciais, encontre-se uma matriz que, multiplicada à matriz de dados originais, obtenhase os sinais de EEG sem ruídos (ZHANG et al., 2015). A remoção desses artefatos é baseada em treinamentos realizados de forma anterior para classificação de ruídos e artefatos, porém diferentes estímulos proporcionam diferentes sinais de EEG. Para garantir que a remoção de artefatos não remova informações que podem ser importantes para análises futuras, os ruídos e artefatos foram removidos manualmente neste trabalho. A Figura 16 mostra um exemplo dos ruídos e artefatos, nesse caso o artefato é uma piscada, marcado na cor vermelha e que, posteriormente, são removidos do sinal.

Como o objetivo principal deste trabalho é analisar a proficiência de enxadristas por meio de suas ativações cerebrais e movimentos oculares em determinados estímulos relacionados ao jogo de xadrez, faz-se necessário que ambos os sinais cognitivos sejam correspondentes 
Figura 16 - Exemplo de ruído e artefato no sinal de EEG.

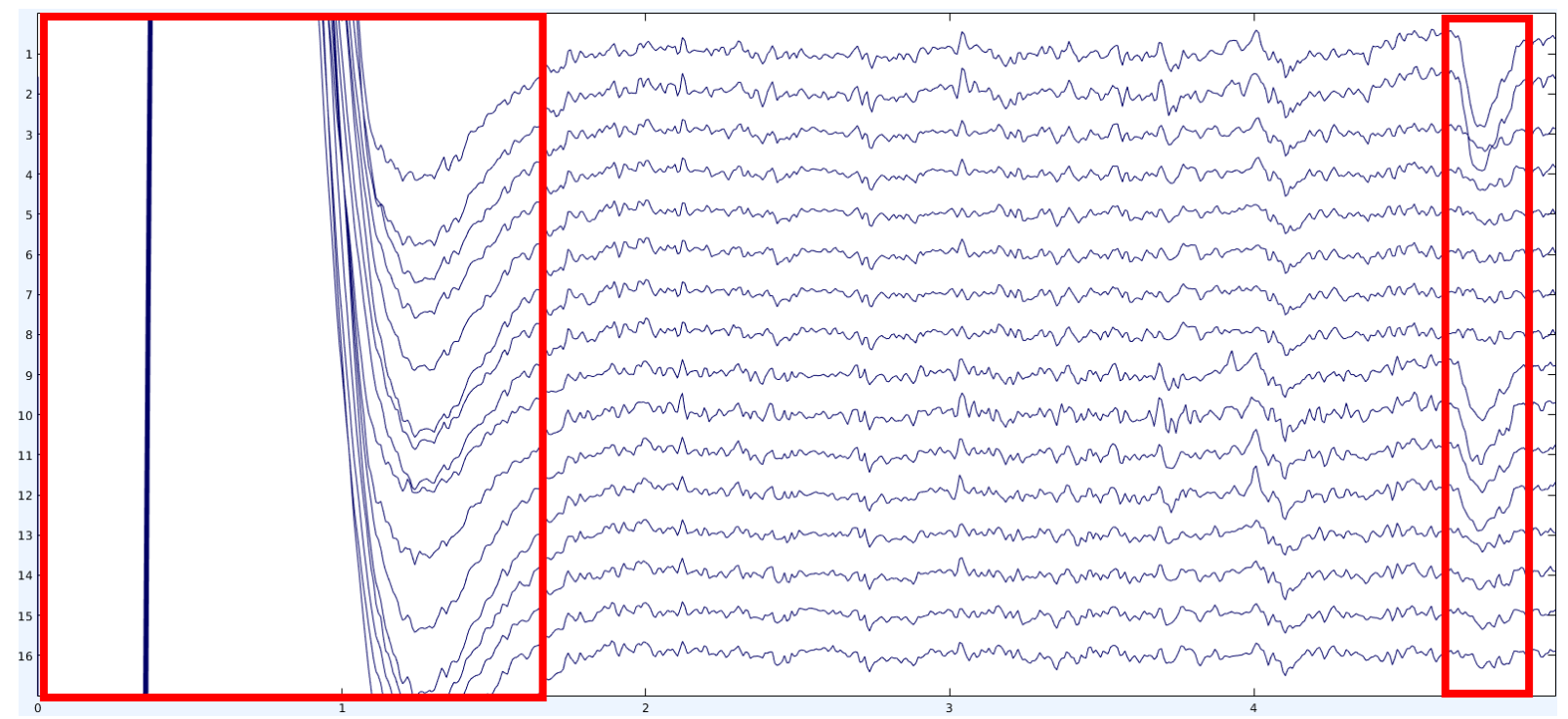

Fonte: Autor

em relação à tomada de decisão dentro da configuração do experimento proposto, conforme detalhado no capítulo anterior.

Por esse motivo, a técnica SIPD (Sistema Inteligente de Processamento Distribuído) anteriormente proposta por Fabio Rocha et al. (2016), bem como a técnica PSD (Power Spectral Density - Densidade Espectral de Potência) anteriormente abordada por Fuentes et al. (2018) e Fuentes-García et al. (2020), serão exploradas neste trabalho, visto que ambas podem ser relacionadas aos sinais de ativação cerebral. Os fundamentos dessas duas técnicas são explicados nas subseções seguintes.

\subsubsection{Sistema Inteligente de Processamento Distribuído}

Nessa abordagem, os sinais obtidos por meio do EEG são analisados como um Sistema Inteligente de Processamento Distribuído (SIPD) (ROCHA, F. et al., 2005, 2016). Nesse sistema, considera-se que os sinais cerebrais conectam-se em padrões para uma determinada atividade (ROCHA, F. et al., 2016). Essa teoria ainda aborda que uma pessoa gasta menos energia quando são utilizados os agentes mais adequados para a solução da tarefa do que utilizando-se agentes não relacionados à tarefa específica (ROCHA, F. et al., 2016).

Para o cálculo da conexão entre os eletrodos, logo após a filtragem do sinal e remoção de artefatos, o processamento dos sinais eletroencefalográficos foi realizado pelo método proposto por Fabio Rocha et al. (2005), que sintetiza, a cada 2 segundos antes da tomada de decisão, 
a comunicação entre os agentes neurais especializados nas soluções das jogadas por meio da variação da atividade elétrica registrada por cada um dos eletrodos do EEG. A Figura 17 ilustra um exemplo dessa sintetização para 16 canais de EEG variando, simultaneamente, ao longo do tempo.

Figura 17 - Exemplo de sintetização dos canais de EEG.

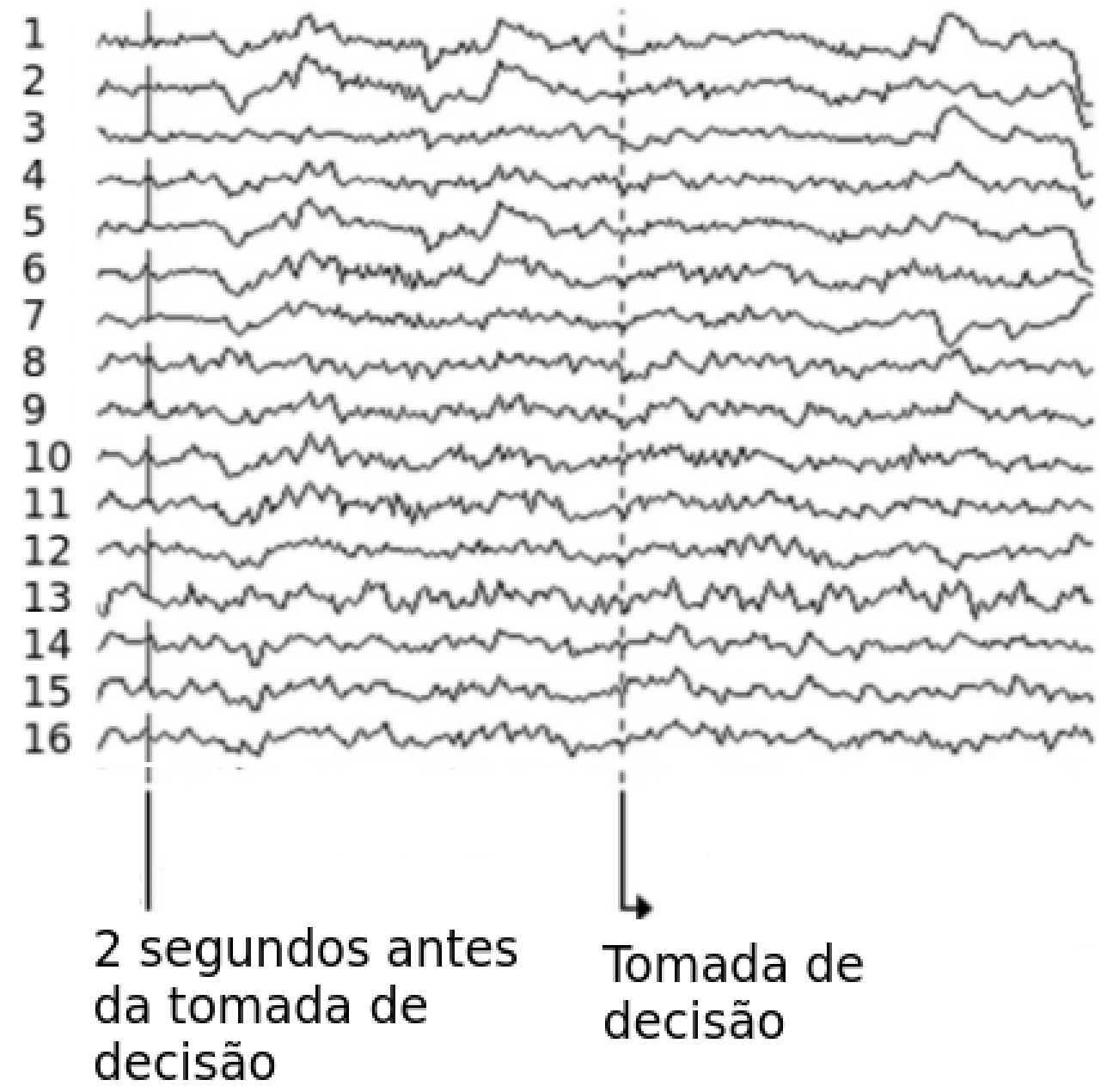

Fonte: Autor "adaptado de" Fabio Rocha et al., 2016

Para sintetização, são calculados os coeficientes de correlação linear dos valores de amplitude elétrica registrados por cada um dos eletrodos com relação aos demais. Para tal, adotouse aqui a correlação de Pearson por ser um teste paramétrico (ROCHA, F. et al., 2016). Após o cálculo de correlação, seus resultados são utilizados para realizar o cálculo de entropia entre os canais. A Equação (1) mostra como é realizado o cálculo com base na fórmula de entropia de Shannon (SHANNON, 1949):

$$
h\left(c_{i, j}\right)=-c_{i, j} \log _{2} c_{i, j}-\left(1-c_{i, j}\right) \log _{2}\left(1-c_{i, j}\right),
$$


em que $c_{i, j}$ é o módulo da correlação entre dois canais distintos. A Equação (1) mostra que se a correlação entre dois canais for igual a 1 ou igual a 0 , a entropia será igual a 0 . Por outro lado, se a correlação for igual a 0.5 , a entropia será máxima, igual a 1 , indicando a possibilidade da atividade elétrica de cada eletrodo estar associada à atividade elétrica de cada um dos demais, ou seja:

$$
\begin{aligned}
& h\left(c_{i, j}\right) \rightarrow 1, \text { se } c_{i, j} \rightarrow 0.5 \\
& h\left(c_{i, j}\right) \rightarrow 0, \text { se } c_{i, j} \rightarrow 1 \text { ou } c_{i, j} \rightarrow 0
\end{aligned}
$$

Analogamente, a entropia da correlação média de cada eletrodo pode ser calculada de acordo com a Equação (2),

$$
h\left(\bar{c}_{i}\right)=-\bar{c}_{i} \log _{2} \bar{c}_{i}-\left(1-\bar{c}_{i}\right) \log _{2}\left(1-\bar{c}_{i}\right),
$$

em que,

$$
\bar{c}_{i}=\frac{1}{(n-1)} \sum_{j=1}^{n-1} c_{i, j},
$$

e $n$ é a quantidade de eletrodos. Neste trabalho, $n=16$.

O fluxo de informação no eletrodo é dado pelo somatório das diferenças entre a entropia de correlação média e as entropias desse eletrodo com os demais canais, ou seja,

$$
h\left(c_{i}\right)=\sum_{j=1}^{n}\left(h\left(\bar{c}_{i}\right)-h\left(c_{i, j}\right)\right) .
$$

Essa informação sintetizada de cada eletrodo para cada voluntário pode ser agora representado por um vetor de tamanho $1 \times 16$, em que 1 representa o participante e 16 a quantidade de eletrodos, sendo que esse vetor representa a extração de características dos sinais de EEG pelo método SIPD.

Como o objetivo desta tese é interpretar sinais cognitivos de enxadristas com diferentes níveis de proficiência, cria-se, então, uma matriz de dados com as informações provenientes dos voluntários classificados como proficientes e não-proficientes. A Equação (11) mostra essa matriz de dados. 


$$
\mathbf{X}=\left[\begin{array}{c}
\mathbf{x}_{\mathbf{1}} \\
\mathbf{x}_{\mathbf{2}} \\
\vdots \\
\mathbf{x}_{\mathbf{N}}
\end{array}\right]=\left[\begin{array}{ccc}
x_{11} & \ldots & x_{1 n} \\
x_{21} & \ldots & x_{2 n} \\
\vdots & \vdots & \vdots \\
x_{N 1} & \ldots & x_{N n}
\end{array}\right]
$$

em que $N$ é o número de voluntários e $n$ é o número de eletrodos $(n=16)$.

O Algoritmo 1 descreve, sucintamente, os passos para geração dos sinais cerebrais pelo método SIPD.

Algoritmo 1 - Algoritmo para extração de características dos sinais cerebrais pelo método SIPD.

1 Entrada: Dados adquiridos pelo equipamento de EEG

2 Filtragem dos sinais

3 Remoção dos ruídos e artefatos

4 para cada tomada de decisão faça

5 Sintetizar os dados 2 segundos antes da tomada de decisão

6 fim

7 para cada canal faça

8 Realizar cálculo da correlação de Pearson

9 Realizar cálculo de entropia

10 fim

11 Saída: Vetor com a extração de características dos sinais cerebrais pelo método SIPD

\subsubsection{Densidade espectral de potência}

Sinais de EEG são não-Gaussianos, não estacionários e de natureza não linear e aleatória, não existindo, consequentemente, a aplicação direta da transformada de Fourier (SUBHA et al., 2010; DINIZ; SILVA; NETTO, 2014). Para poder calcular os sinais de EEG, utilizou-se a função PSD (Power Spectral Density - Densidade Espectral de Potência), que descreve como a potência de um sinal é distribuída com a frequência (DINIZ; SILVA; NETTO, 2014). Segundo Unde e Shriram (2014), o cálculo do PSD é dado pela transformada de Fourier da função de autocorrelação do sinal de EEG, conforme Equação 6:

$$
S\left(e^{j W}\right)=\frac{1}{2 \pi M}\left|\sum_{m=1}^{M} x_{n} e^{-j w n}\right|^{2},
$$

em que $S\left(e^{j W}\right)$ é o PSD, $M$ é a quantidade de sinais amostrados no domínio da frequência, e $x_{n}$ é o sinal de EEG de um canal. 
Após o cálculo do PSD, a informação da potência é separada em bandas de acordo com a faixa de frequência: delta, teta, alfa, beta e gama. Essa separação em bandas tem como resultado a energia do sinal de EEG amostrado na frequência. Como o objetivo é que cada eletrodo forneça um único valor de informação para análise posterior, calculou-se aqui a média da potência amostrada na frequência, conforme Equação 7:

$$
p\left(c_{i}\right)=\frac{\sum_{m=1}^{M} S\left(e^{j W}\right)}{M},
$$

em que $p\left(c_{i}\right)$ é a média da potência do sinal de cada um dos eletrodos.

Assim como na abordagem SIPD, essa média representa a informação de cada eletrodo para cada voluntário e a representação de um participante com a informação proveniente de todos os eletrodos é um vetor 1x16. O Algoritmo 2 descreve, sucintamente, os passos para geração dos sinais cerebrais pelo método PSD.

Algoritmo 2 - Algoritmo para extração de características dos sinais cerebrais pelo método PSD.

1 Entrada: Dados adquiridos pelo equipamento de EEG

2 Filtragem dos sinais

3 Remoção dos ruídos e artefatos

4 para cada canal faça

5 Realizar cálculo da PSD

6 Separar as bandas de frequência

7 Calcular a média da potência do sinais por banda

8 fim

9 Saída: Vetor com a extração de características dos sinais cerebrais pelo método PSD

\subsubsection{Sinais de Movimentos Oculares}

Diferentemente dos sinais de eletroencefalografia descritos na seção anterior, o estado da arte que envolve o estudo de movimentos oculares e xadrez aborda a quantidade, área e tempo de fixação dos participantes. Neste trabalho, as fixações também serão o ponto de estudo dos movimentos oculares, porém agora com o objetivo de servir como uma métrica cognitiva para analisar a proficiência de enxadristas.

Para isso, a primeira etapa de pré-processamento dos dados de movimentos oculares adquiridos é eliminar os sinais dos voluntários com $40 \%$ ou menos na captura desses sinais. Logo em seguida, é realizada a interpolação de informações incompletas, que consiste em interpolar 
os valores ausentes para não prejudicar os cálculos subsequentes, uma vez que considerar a coordenada $(0,0)$ como parte do movimento dos olhos poderia introduzir erros nos cálculos para determinar as fixações. A Equação (8) descreve a fórmula de interpolação linear utilizada para esse fim:

$$
P_{i}=P_{s}+i \cdot \frac{\left(P_{n}-P_{s}\right)}{(n-s)}
$$

onde $P_{i}$ representa os valores ausentes contíguos no vetor, $P_{s}$ é o valor do ponto imediatamente anterior aos pontos ausentes, $P_{n}$ é valor do ponto imediatamente seguinte aos pontos ausentes com $1<i<n-s-1$, sendo $n$ e $s$ valores dos vetores $P_{s}$ e $P_{n}$.

Essa interpolação só é aplicada quando o vetor de pontos ausentes é inferior a $60 \mathrm{~ms}$ (aproximadamente 20 amostras no dispositivo de rastreamento ocular utilizado). Uma interpolação em um vetor muito grande pode gerar fixações inexistentes. O tempo de $60 \mathrm{~ms}$ é um tempo muito próximo ao tempo de uma piscada (50ms em média) (CESAR, 2016), assim, de maneira conservadora, apenas pequenas falhas são corrigidas (CESAR, 2016; CESAR; ROCHA; THOMAZ, 2015). A Figura 18 mostra um exemplo dessa interpolação.

Em seguida, são filtrados os ruídos gerados pelo próprio equipamento, bem como os micro movimentos dos olhos ou da cabeça. A existência desses ruídos pode prejudicar a detecção de eventos como o da fixação do olhar, pois é preciso detectar a inércia nos movimentos oculares e os ruídos podem gerar falsos movimentos. Por isso, utilizou-se como método de filtragem uma média móvel ponderada linearmente de forma decrescente, com tamanho de janela igual a 20 (CESAR, 2016; CESAR; ROCHA; THOMAZ, 2015). A Equação (9) mostra o método de filtragem utilizado e a Figura 19 exibe um exemplo dessa interpolação.

$$
P_{j}=\frac{1}{\sum_{n=0}^{k} W_{n}} \cdot \sum_{n=0}^{k} P_{j-n} \cdot W_{n},
$$

onde $P_{j}$ é um valor no vetor de pontos, $W$ é vetor de pesos, $k$ é o tamanho da janela e $P_{i-n}$ é o valor da enésima posição anterior no vetor (quando $\mathrm{n}=0, P_{i-n}$ será igual a $P_{i}$ ). Neste caso, $k=20$ e $W$ é linearmente decrescente. A Figura 19 mostra um exemplo de filtragem.

Depois que os dados dos movimentos oculares foram pré-processados, é utilizado um algoritmo que detecta as fixações a partir da identificação da inércia dos movimentos oculares em uma determinada localização, chamado de detecção por dispersão (DUCHOWSKI, A. T., 2002; SALVUCCI; GOLDBERG, 2000). Esse algoritmo necessita de dois parâmetros para definir as fixações: o limiar de espaço que indica a dispersão máxima aceitável para considerar 
Figura 18 - Interpolação dos sinais de movimentos oculares.

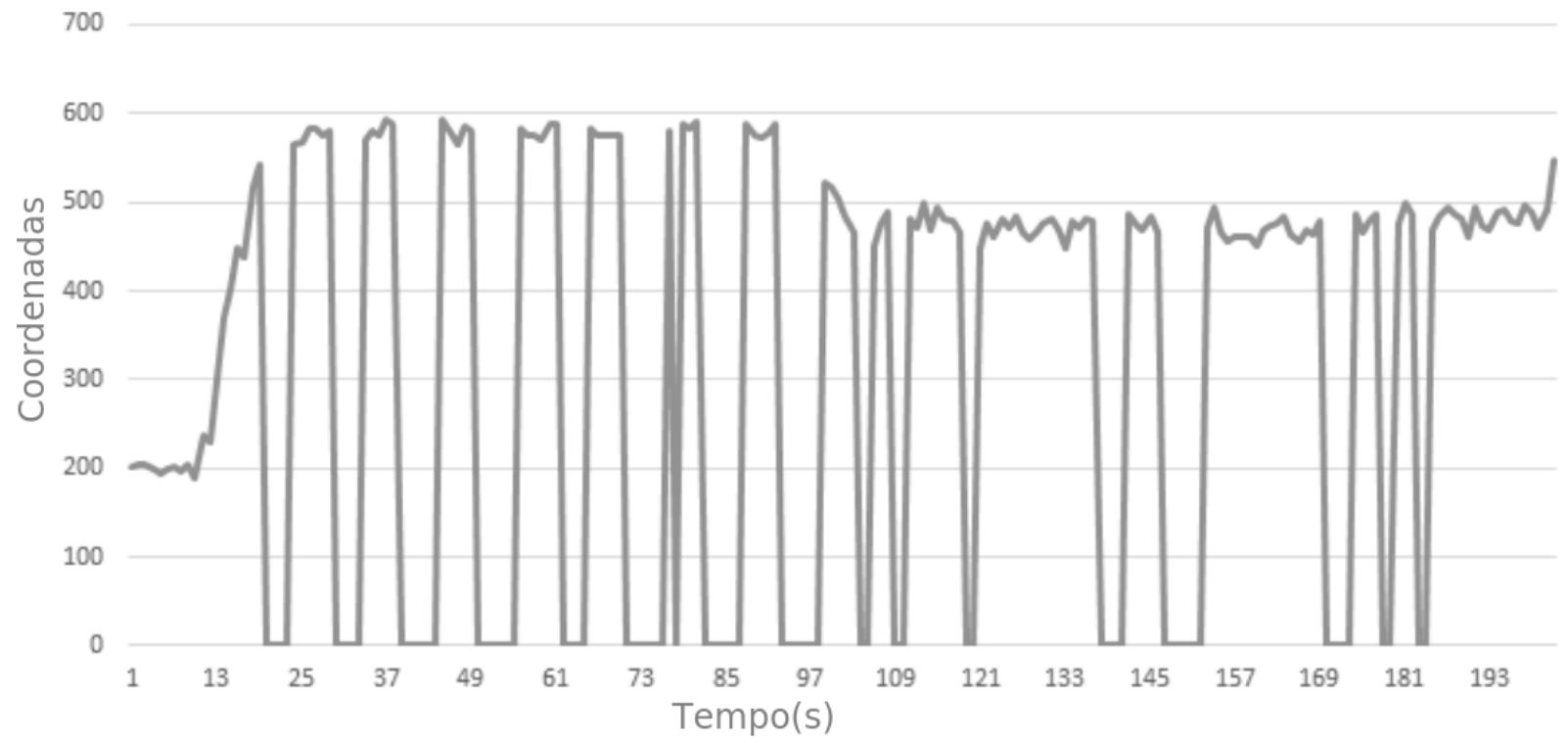

(a) Sinal original.

700

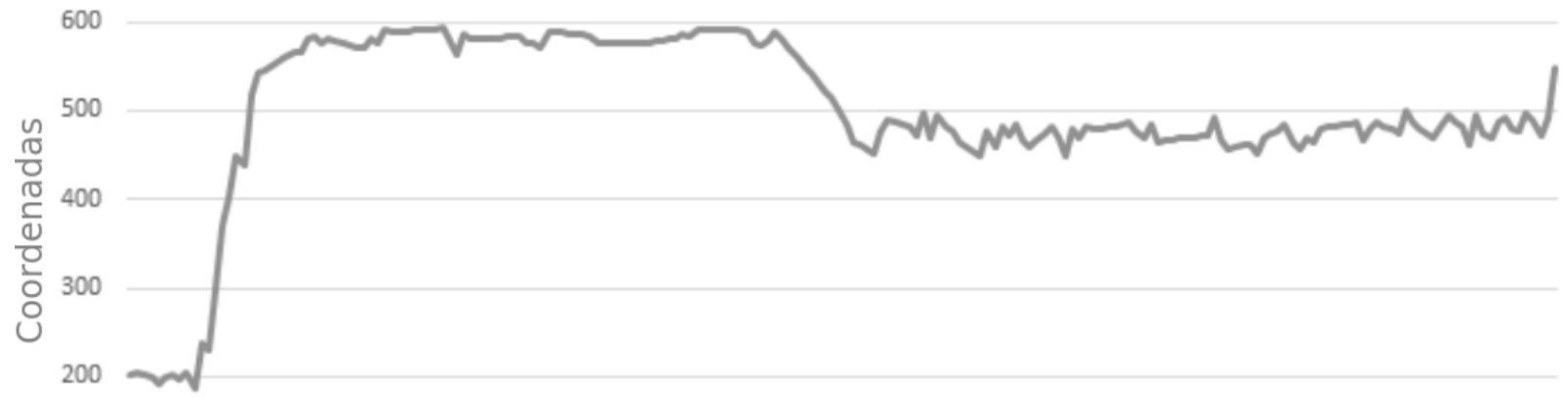

100

0

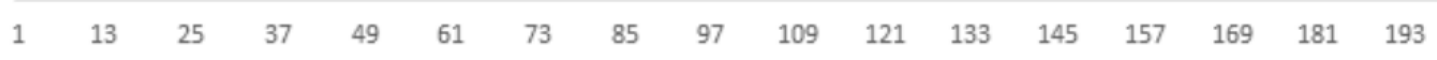

(b) Sinal interpolado.

Autor "adaptado de" Cesar, 2016

um ponto como pertencente a uma fixação; e o limiar de tempo, que indica o tempo mínimo para considerar um conjunto de pontos como uma fixação. Esses valores foram configurados iguais a 120 pixels e 120ms, respectivamente (CESAR, 2016; CESAR; ROCHA; THOMAZ, 2015).

A partir desse ponto, o software CHESSLAB automaticamente calcula os heatmaps para cada uma das questões dos experimentos. Para isso, é criada uma matriz quadrada (matriz de pontos) com o mesmo tamanho da imagem original (800x800 pixel), que recebe a soma de pontos de exposição a partir das fixações de um participante. Outra matriz é gerada, cujos valores 
Figura 19 - Filtragem dos sinais de movimentos oculares.

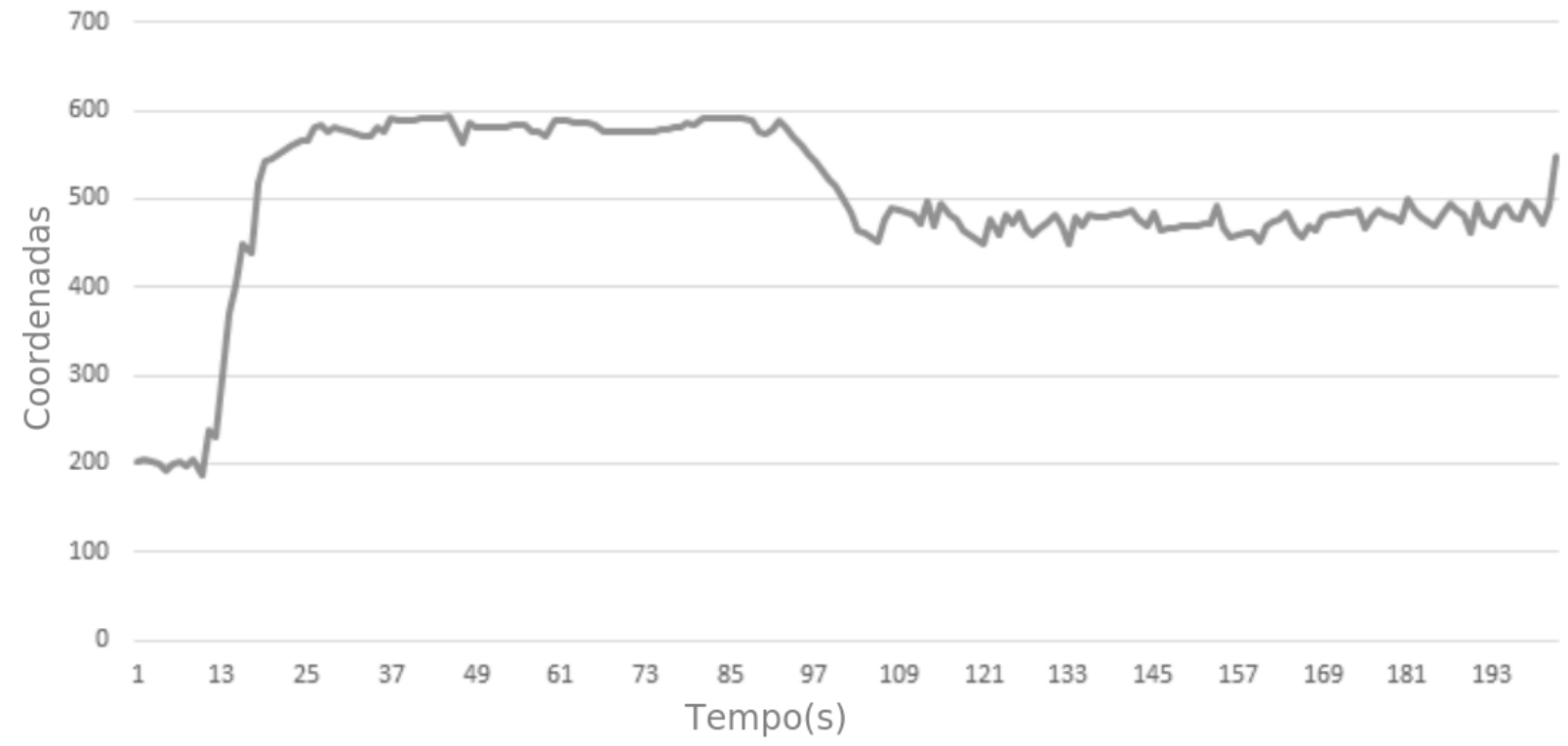

(a) Sinal interpolado.

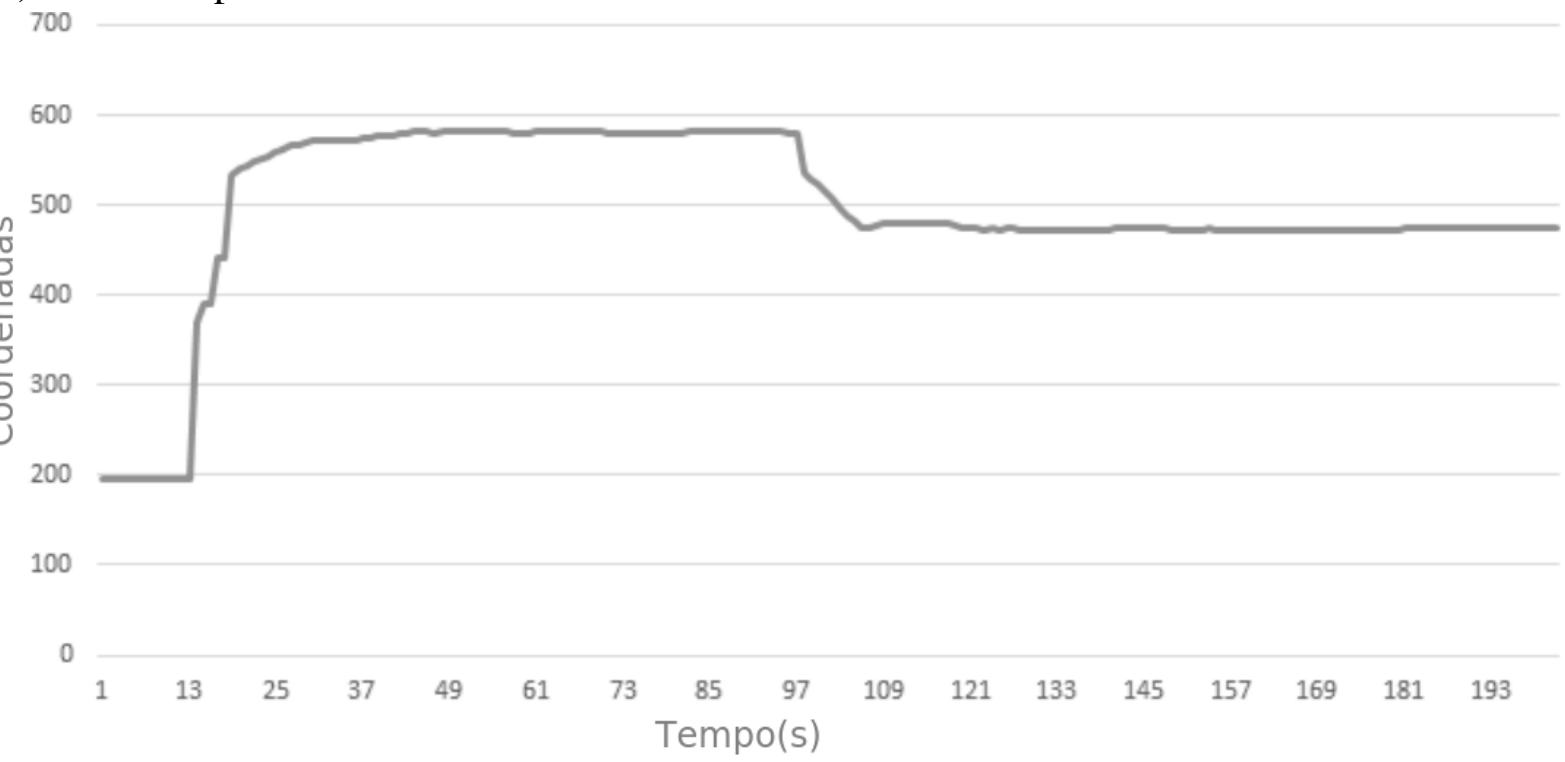

(b) Sinal filtrado.

Autor "adaptado de" Cesar, 2016

são preenchidos através de uma função gaussiana. O preenchimento da matriz de pontos se dá pela sobreposição centralizada da matriz da máscara no ponto de cada fixação. Os valores originais da máscara de pontos são somados pelos valores contidos na matriz da máscara ponderados pela duração da fixação (CESAR, 2016). A Figura 20 exibe como o heatmap é inserido no diagrama apresentado ao voluntário.

Como a saída do software CHESSLAB possui o heatmap e o diagrama de forma conjunta, é necessário remover do background de cada uma das imagens para analisar apenas o foco de atenção dos voluntários. Para isso, é feita a subtração do diagrama com o heatmap 
Figura 20 - Montagem do heatmap.

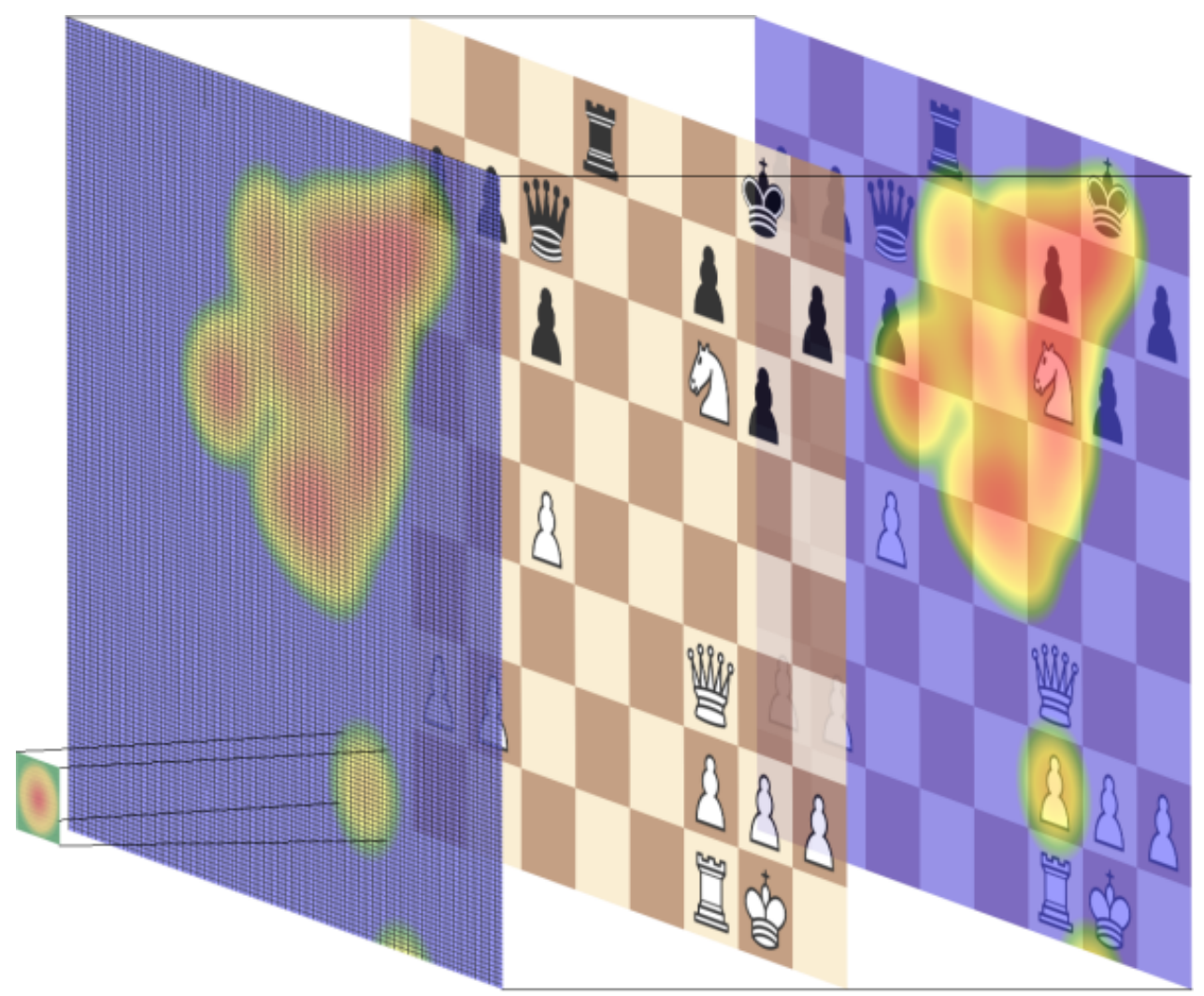

Fonte: Autor "adaptado de" Cesar, 2016

(Figura 21a) pela imagem original do diagrama (Figura 21b), obtendo-se, então, uma imagem de 800x800 com apenas o foco de atenção dos voluntários (Figura 21c) conforme Figura 21.

Essa imagem com o foco de atenção está no tom de cores RGB (Red Green Blue - Vermelho Verde Azul) possuindo, assim, três dimensões. Para as futuras análises não é necessário que as informações provenientes do heatmap possuam três dimensões, então essa imagem foi transformada para tons de cinza para se tornar uma imagem com duas dimensões. Para essa transformação, assumiu-se que os pontos de maior fixação na cor vermelha seriam transformados para o valor 255 na escala de tons de cinza, enquanto a cor verde foi transformada para o valor 64. As outras cores variaram dentro limite inferior e superior de acordo com a escala de cor adotada para construção dos heatmaps. A Figura 22 apresenta o resultado dessa transformação.

O Algoritmo 3 descreve, sucintamente, os passos para geração do vetor de características dos movimentos oculares. 
Figura 21 - Remoção do background.

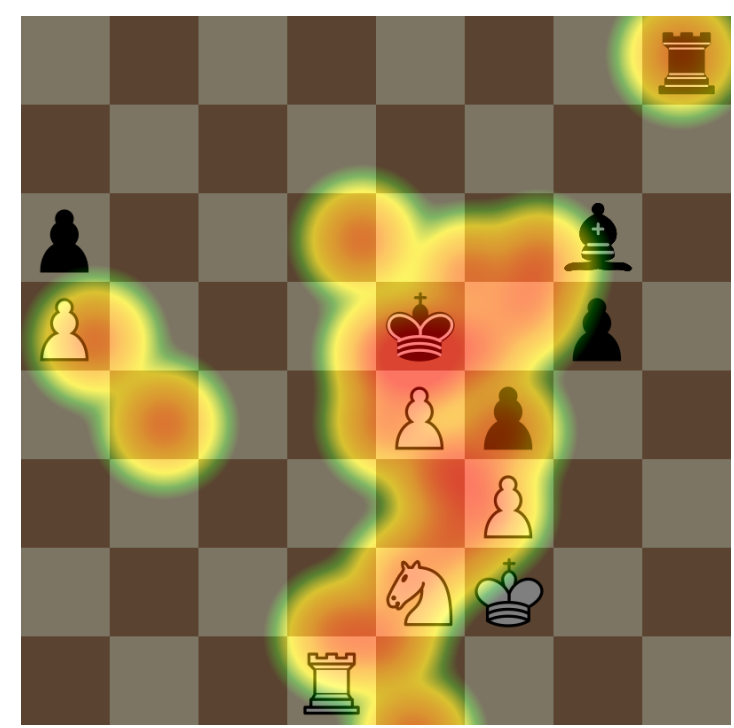

(a) Diagrama com heatmap.

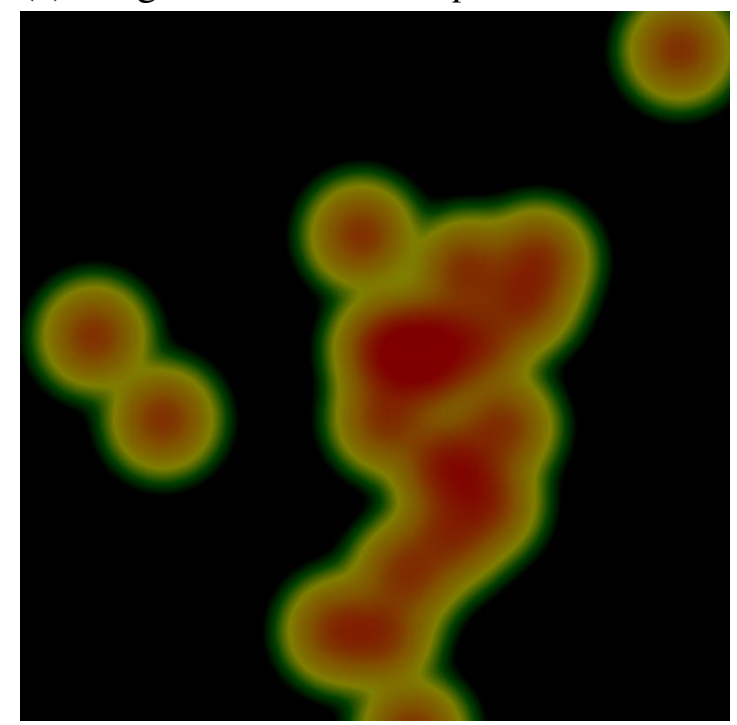

(c) Foco de atenção sem background.

Fonte: Autor

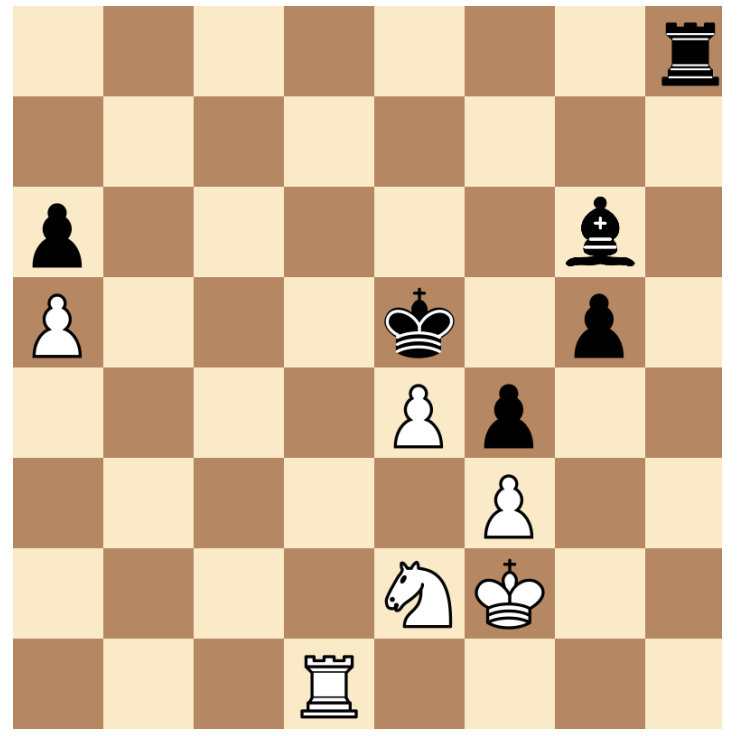

(b) Diagrama original.

\subsection{MÉTRICAS DE AVALIAÇÃO DE PROFICIÊNCIA}

\subsubsection{Métrica Tradicional}

Uma abordagem para quantificar proficiência em jogadores de xadrez é a métrica baseada em acurácia e tempo de resposta proposta por Volke (VOLKE et al., 2002). Nessa abordagem, considera-se que quanto mais respostas corretas forem respondidas no menor tempo possível, maior será a experiência do enxadrista, gerando como resultado um rating numérico 
Figura 22 - Transformação de uma imagem em RGB para tons de cinza.

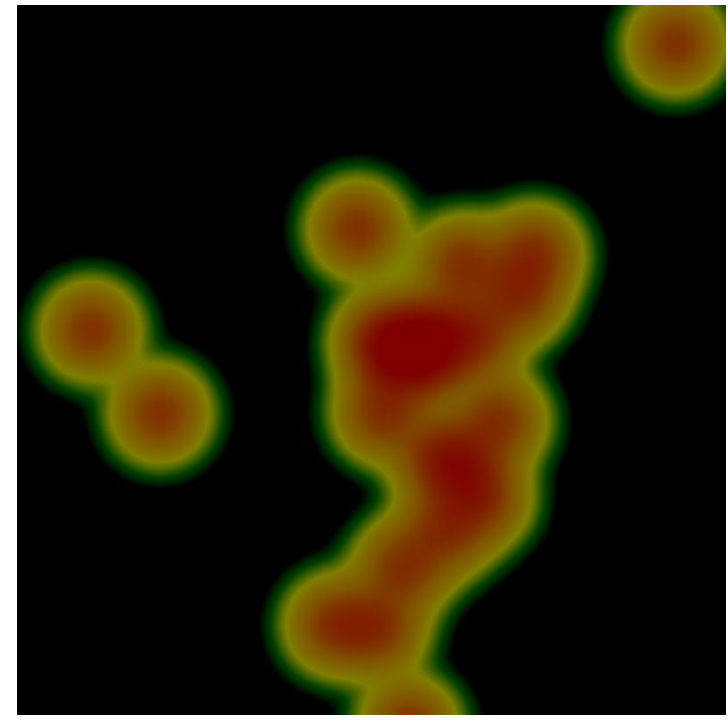

(a) Heatmap em RGB.

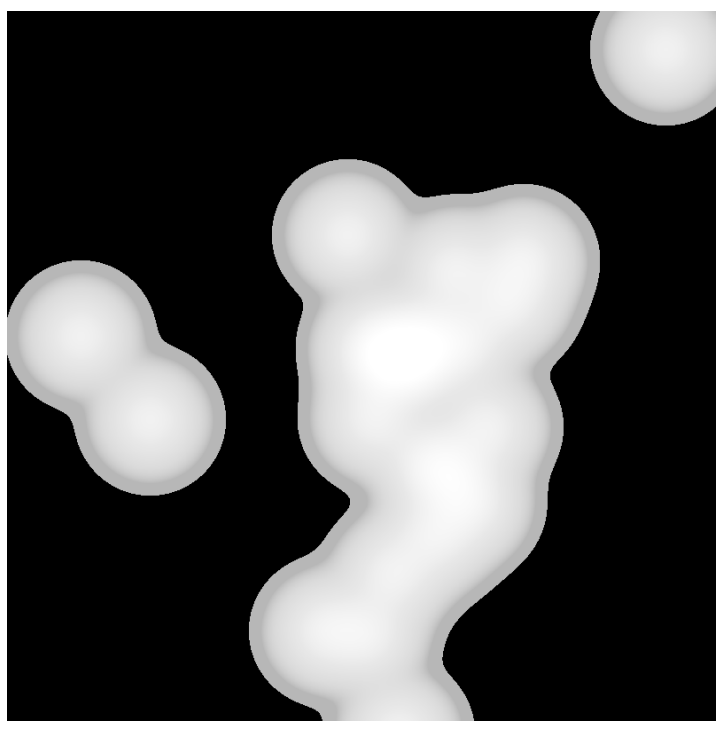

(b) Heatmap em tons de cinza.

Fonte: Autor

Algoritmo 3 - Algoritmo para extração de características dos movimentos oculares

1 Entrada: Dados adquiridos pelo equipamento de rastreamento ocular

2 se Vetor de pontos ausentes < 60ms então

3 Interpolação linear

4 fim

5 Aplicação da Média Móvel Ponderável

6 Detecção das fixações

7 Máscara de pontos

8 Mapa de atenção visual

9 Remoção do background da imagem

10 Transformação do mapa em RGB para tons de cinza

11 Saída: Heatmap em tons de cinza com a extração de características dos movimentos oculares

baseado no desempenho individual. A Equação 10 mostra como é calculada a proficiência por essa abordagem:

$$
V_{s}=\left(N_{\text {correct }}-\frac{N T}{2}\right) \cdot \frac{R T_{m}}{R T_{s}}
$$

em que $V_{s}$ é a proficiência de cada voluntário, $N_{\text {correct }}$ é o número de respostas corretas, $N T$ é o número total de questões, $R T_{m}$ é o tempo de resposta médio de todos os participantes em todas as questões e $R T_{s}$ é o tempo médio de resposta de cada voluntário da pesquisa. 
Esse teste de proficiência se mostra eficaz para experimentos baseados em pergunta e resposta, como a maioria dos experimentos vistos no capítulo 3, pois leva em consideração não somente a acurácia da resposta, como também o tempo gasto relativamente para fornecê-la.

De acordo com a proficiência $V_{s}$, conforme descrito na Equação 10, é possível separar os voluntários em grupos de acordo com sua proficiência, ordenados do maior para o menor em quartis estatísticos. Os voluntários foram separados em: proficiente (primeiro quartil), nãoproficiente (quarto quartil) e intermediário (segundo e terceiro quartis). O primeiro e quarto quartis foram selecionados para as análises posteriores com o objetivo de realçar as diferenças entre os voluntários proficientes e não-proficientes.

\subsubsection{Métricas Cognitivas}

Nas seções anteriores foram detalhadas as técnicas de processamento de sinais cerebrais (EEG) e de processamento de sinais oculares. Como resultado desses processamentos, tem-se agora vetores que representam os sinais cerebrais, bem como heatmaps em tons de cinza que representam os movimentos oculares de cada voluntário.

Para quantificar as características cognitivas entre os grupos de enxadristas proficientes e não proficientes, é proposto aqui tratar cada vetor de características dos sinais cerebrais e cada heatmap em tons de cinza de características dos movimentos oculares como um padrão em um espaço n-dimensional, fazendo com que este seja um problema de estatística multivariada.

Para analisar os sinais cerebrais, cria-se, então, uma matriz de dados com as informações provenientes dos voluntários classificados como proficientes e não-proficientes. A Equação (11) mostra essa matriz de dados.

$$
\mathbf{X}_{\mathbf{E E G}}=\left[\begin{array}{c}
\mathbf{x}_{\mathbf{1}} \\
\mathbf{x}_{\mathbf{2}} \\
\vdots \\
\mathbf{x}_{\mathbf{N}}
\end{array}\right]=\left[\begin{array}{ccc}
x_{11} & \ldots & x_{1 n} \\
x_{21} & \ldots & x_{2 n} \\
\vdots & \vdots & \vdots \\
x_{N 1} & \ldots & x_{N n}
\end{array}\right]
$$

em que $N$ é o número de voluntários e $n$ é o número de eletrodos $(n=16)$.

Já o heatmap em tons de cinza agora pode ser apresentado como uma matriz com duas dimensões. Para que cada heatmap de cada voluntário seja representado como uma informação, cada uma das linhas foram concatenadas sequencialmente em um único vetor, fazendo 
com que a informação de cada heatmap de cada voluntário seja agora representado por um vetor $x=\left[x_{1}, x_{2}, \ldots, x_{k}\right]^{T}$. Esse vetor representa a extração de características dos movimentos oculares. Nessa concatenação, torna-se matematicamente inviável processar essa quantidade de dados. Para diminuir a dimensionalidade, foi utilizado o PCA (Principal Component Analysis - Análise de Componentes Principais) em que a dimensionalidade foi reduzida para o número de componentes principais, cujos auto-valores são não-nulos (FUKUNAGA, 2013). Posteriormente, após a aplicação do PCA, assim como foi feito com os sinais de EEG, esses dados serão tratados como uma matriz em um espaço multi-dimensional, como descrito na Equação (12):

$$
\mathbf{X}_{\text {Eye-tracking }}=\left[\begin{array}{c}
\mathbf{x}_{\mathbf{1}} \\
\mathbf{x}_{\mathbf{2}} \\
\vdots \\
\mathbf{x}_{\mathbf{N}}
\end{array}\right]=\left[\begin{array}{ccc}
x_{11} & \ldots & x_{1 m} \\
x_{21} & \ldots & x_{2 m} \\
\vdots & \vdots & \vdots \\
x_{N 1} & \ldots & x_{N m}
\end{array}\right]
$$

em que $N$ é o número de voluntários proficientes e não proficientes e $m$ é o número de componentes principais, cujo auto-valores são não-nulos.

Como o objetivo é criar uma métrica que consiga mensurar a proficiência de jogadores de xadrez por meio de seus sinais cognitivos e obter como resultado um valor numérico, assim como a métrica tradicional, é proposto aqui utilizar a conhecida técnica LDA (Linear Discriminant Analysis - Análise Discriminante Linear) para alcançar esse objetivo. O LDA é um método supervisionado de estatística multivariada com o objetivo de separar amostras de grupos distintos, maximizando a separação inter-classes e minimizando a variabilidade intraclasses (FUKUNAGA, 2013). O LDA assume implicitamente que as matrizes de covariância de cada classe são iguais, pois a mesma matriz intra-classes é utilizada para todos os grupos.

Primeiramente, calcula-se a matriz inter-classes $\mathbf{S}_{b}$ de acordo com a equação 13:

$$
\mathbf{S}_{b}=\sum_{i=1}^{g} N_{i}\left(\overline{\mathbf{x}}_{i}-\overline{\mathbf{x}}\right)^{T}\left(\overline{\mathbf{x}}_{i}-\overline{\mathbf{x}}\right),
$$

em que $\overline{\mathbf{x}}_{i}$ é o vetor de média de cada classe, $g$ é o número total de classes ou grupos (aqui, $g=2$ ), $N_{i}$ é o número de amostras de treinamento para cada grupo $i$ e o vetor da média $\overline{\mathbf{x}}$ total é dado por:

$$
\overline{\mathbf{x}}=\frac{1}{N} \sum_{i=1}^{g} N_{i} \overline{\mathbf{x}}_{i}=\frac{1}{N} \sum_{i=1}^{g} \sum_{j=1}^{N_{i}} x_{i j}
$$


Já a matriz intra-classes $\mathbf{S}_{w}$ é definida como:

$$
\mathbf{S}_{w}=\sum_{i=1}^{g} \sum_{j=1}^{N_{i}}\left(\mathbf{x}_{j}-\overline{\mathbf{x}}_{i}\right)^{T}\left(\mathbf{x}_{j}-\overline{\mathbf{x}}_{i}\right) .
$$

Calcula-se, então, o vetor $L$, que determina a projeção dos dados em que se maximiza a separação inter-classes e minimiza a variabilidade intra-classes, dado por:

$$
\mathbf{L}=\operatorname{argmax} \frac{\left|\mathbf{P}^{T} \mathbf{S}_{b} \mathbf{P}\right|}{\left|\mathbf{P}^{T} \mathbf{S}_{w} \mathbf{P}\right|} .
$$

Contudo, em problemas com alta dimensionalidade e quantidade de amostras limitadas, $S_{w}$ é singular ou matematicamente instável e não é possível utilizar o LDA padrão para separar os grupos (THOMAZ; KITANI; GILLIES, 2006). Para evitar esse problema, foi utilizado o MLDA (Maximum uncertainty LDA-based). O MLDA considera a questão de estabilizar a matriz $S_{w}$ descrita na Equação (16) com sua versão regularizada (THOMAZ; KITANI; GILLIES, 2006).

Para projetar todos os dados dos voluntários nos hiperplanos mais discriminantes correspondentes, cada amostra é subtraída do vetor de média total e multiplicada pelo valor do MLDA, de acordo com a Equação (17):

$$
H_{s}=\left(\mathbf{x}_{i}-\overline{\mathbf{x}}\right) \mathbf{L}
$$

em que $H_{s}$ é a característica mais discriminante dos dados provindos de cada um dos sinais cognitivos no espaço do MLDA para cada voluntário.

\subsubsection{Comparação entre as métricas}

Os hiperplanos, conforme descrito na seção anterior, descrevem a projeção dos voluntários na dimensão que melhor os separa de acordo com seus sinais cognitivos (ativações cerebrais e movimentos oculares) em proficientes e não proficientes. Além da separação em grupos de proficiência, os hiperplanos descrevem a ordenação na qual a separação foi realizada. Com o objetivo de quantificar as diferenças na ordem de classificação entre a métrica tradicional e as métricas cognitivas, utilizou-se a correlação de Spearman, conforme Equação 18 (PINTO DA COSTA; SOARES, 2005).

$$
\rho=\frac{\sum_{j=1}^{N}\left(R_{j}-\bar{R}\right)\left(Q_{j}-\bar{Q}\right)}{\sqrt{\sum_{j=1}^{N}\left(R_{j}-\bar{R}\right)^{2} \sum_{j=1}^{N}\left(Q_{j}-\bar{Q}\right)^{2}}},
$$


em que $R_{j}$ e $Q_{j}$ representam a ordenação de um mesmo conjunto de $N$ participantes determinado por seu $V_{s}$ ou $H_{s}\left(H_{s}\right.$ pode ser relacionada ao EEG ou eye-tracking). 


\section{EXPERIMENTOS E RESULTADOS}

Este capítulo apresenta os resultados dos experimentos realizados neste trabalho e está dividido em quatro seções: tarefas e estímulos, participantes, validação das métricas cognitivas e comparação entre métricas de classificação. Na primeira seção, serão descritos os experimentos realizados. Na seção seguinte, serão detalhados os participantes e seus respectivos níveis de proficiência. Na terceira seção, será descrita a validação das métricas cognitivas e o desempenho de classificação para cada categoria de questões. Na última seção, serão analisadas as métricas cognitivas de EEG e eye-tracking juntamente com a métrica baseada em acurácia e tempo de resposta em cada uma das categorias, mostrando uma questão como exemplo em cada uma delas.

\subsection{TAREFAS E ESTÍMULOS}

Com o objetivo de analisar a proficiência de enxadristas por meio de suas ativações cerebrais e movimentos oculares e, posteriormente, comparar essa proficiência entre as métricas utilizadas, fez-se necessário utilizar uma plataforma que permitisse a aquisição dos sinais cognitivos de forma síncrona. O software CHESSLAB desenvolvido no Centro Universitário da FEI possui essa característica e, por esse motivo, foi escolhido para realização deste trabalho.

Nesse mesmo software foram elaboradas 51 questões diferentes relacionadas ao jogo de xadrez. Tomando-se como base os trabalhos de Cesar, Rocha e Thomaz (2015) e Fabio Rocha et al. (2016), as questões foram elaboradas para o presente estudo. Foram tomadas precauções na construção do teste sobre o nível de dificuldade das questões, número de questões elaboradas para cada categoria, balanceamento de respostas afirmativas e negativas e entendimento das questões propostas. A Figura 23 exibe a sequência dos estímulos apresentados para os usuários.

As 51 questões apresentadas neste experimento têm o objetivo de analisar o conhecimento dos participantes em diferentes conceitos do jogo de xadrez. A Tabela 3 mostra como as categorias das questões que foram utilizadas nos experimentos foram separadas, onde as categorias 1, 2, 3 e 4 foram propostas por Volke (VOLKE et al., 2002) e a categoria 5 proposta por Nichelli (NICHELLI et al., 1994).

A Categoria 1 mostra questões em que são analisadas a quantidade de peças e a posição das mesmas. Nas questões da Categoria 2, são analisadas as situações em que um dos reis 
Figura 23 - Sequência dos experimentos.

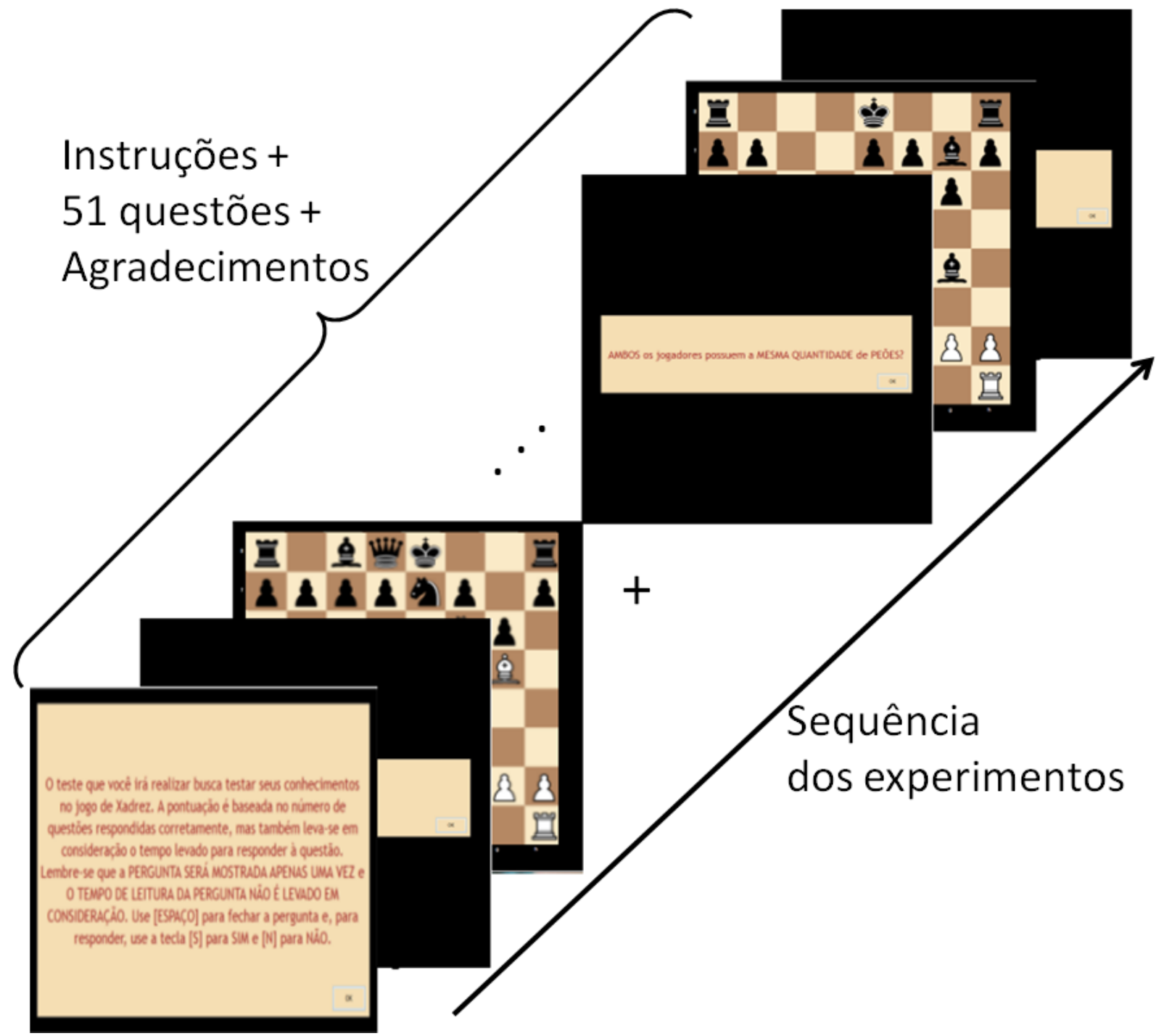

Fonte: Autor

Tabela 3 - Categorias do questionário de classificação.

\begin{tabular}{c|c}
\hline Categoria & Descricão \\
\hline 1 & Reconhecimento de peças e posicionamento \\
\hline 2 & Reconhecimento de situações de xeque \\
\hline 3 & Reconhecimento de situações de xeque-mate \\
\hline 4 & Possibilidade de xeque-mate em um lance \\
\hline 5 & Conhecimento de jogadas e possibilidade de captura de peças \\
\hline
\end{tabular}

Fonte: Autor

encontra-se em condição de xeque. Similar à categoria 2, a Categoria 3 apresenta questões para determinar se um dos reis está em situação de xeque-mate. As questões da Categoria 4 mostram situações em que pode-se terminar uma partida de xadrez colocando o rei adversário em posição de xeque-mate em um lance. Já a Categoria 5 apresenta questões em que há a possibilidade de 
capturar uma peça adversária ou jogadas possíveis de serem executadas de acordo com as regras do xadrez.

Com relação ao sistema de aquisição dos dados, são estabelecidos dois momentos distintos de interação com o usuário. No primeiro momento, o voluntário lê uma pergunta apresentada de forma escrita em um monitor, devendo clicar na barra de espaço quando terminar de ler, compreender e memorizar a questão apresentada. No segundo momento, o tabuleiro de xadrez é apresentado em um monitor com uma configuração de peças coerente com aquela esperada dentro de uma partida, devendo o usuário agora apertar a tecla S para responder "sim" à pergunta ou a tecla N para "não" (CESAR; ROCHA; THOMAZ, 2015). A Figura 24 mostra um exemplo específico de pergunta e seu respectivo tabuleiro de xadrez apresentado ao usuário.

Figura 24 - Exemplo de questão e seu respectivo tabuleiro.
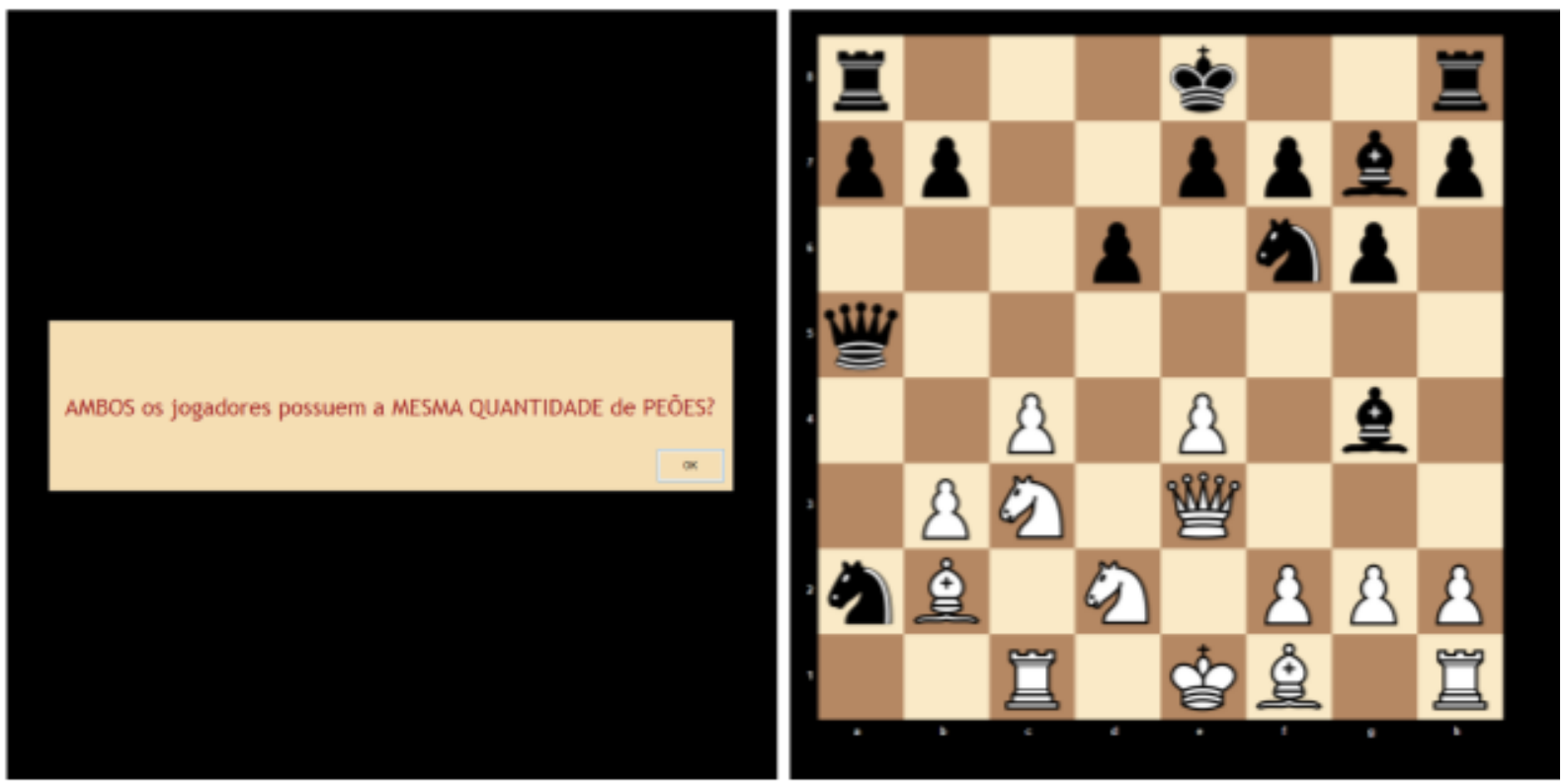

Fonte: Autor "adaptado de" Cesar, Rocha e Thomaz, 2015

Antes do início do teste, o voluntário deve se cadastrar provendo informações sobre o seu nível de escolaridade, idade, área de estudo, gênero, lateralidade e auto-avaliação do nível de proficiência em xadrez, além de receber as instruções verbalizadas de que pode ser gasto o tempo necessário para ler, interpretar e compreender as questões apresentadas, pois o tempo decorrido nessa etapa não é contabilizado. Essas instruções foram apresentadas posteriormente de forma escrita para o voluntário no início dos experimentos.

Como saída do software CHESSLAB é obtida uma planilha de dados contendo informações de cada um dos voluntários para as questões acerca de: acurácia, tempo de início para 
responder a questão e tempo final ao responder a questão. Essas informações são utilizadas para os cálculos de proficiência.

\subsection{PARTICIPANTES}

Uma parte dos experimentos foi realizada em um campeonato de xadrez, sediado pelo Clube Hebraica de São Paulo e organizado pela Xeque \& Mate, onde 404 alunos representando 101 escolas da capital e interior do estado de São Paulo participaram do Campeonato Paulista de Xadrez Escolar. Os participantes eram jogadores experientes de xadrez, professores de xadrez e crianças em idade escolar competidoras do campeonato em questão. Outra parte dos experimentos foi realizada dentro da FEI, em que os voluntários não tinham prática contínua em xadrez, porém tinham conhecimento sobre o jogo. A Figura 25 ilustra um voluntário realizando os experimentos.

Figura 25 - Realização dos experimentos por um voluntário.

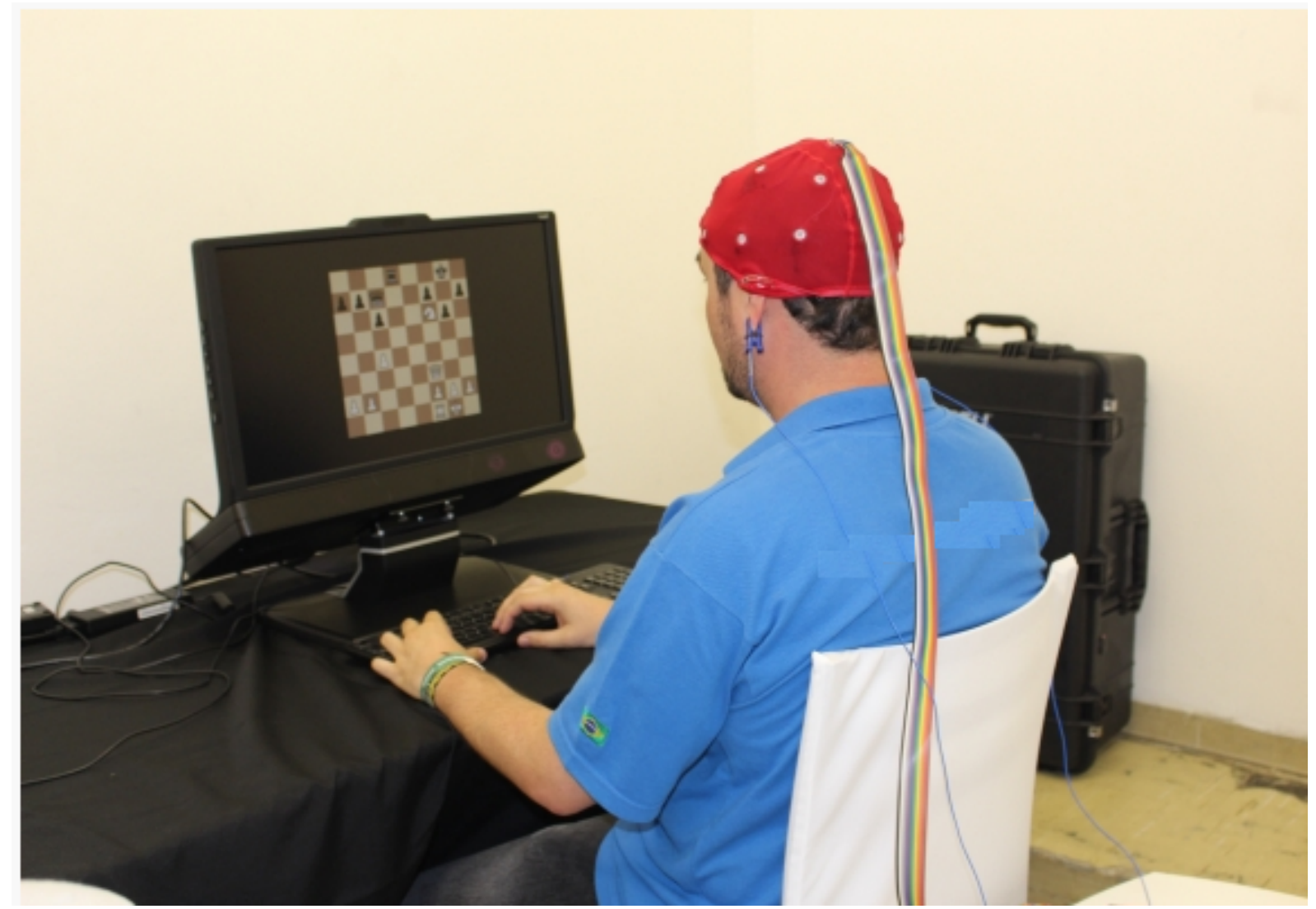

Fonte: Xeque \& Mate, 2011

Ao todo, trinta e dois (32) voluntários participaram dos experimentos (idade média \pm desvio padrão, 27,8 \pm 12,75), em que todos assinaram Termo de Consentimento Livre e Esclare- 
cido. Esses 32 voluntários foram separados em quartis estatísticos de acordo com a proficiência $V_{s}$ calculada pela métrica de Volke, conforme descrito na Equação 10 para todo o teste, envolvendo as 51 questões descritas anteriormente. Os voluntários foram separados em: proficiente (8 voluntários - primeiro quartil), não-proficiente (8 voluntários - quarto quartil) e intermediário (16 voluntários - segundo e terceiro quartis). O primeiro e quarto quartis foram selecionados para as análises posteriores com o objetivo de realçar as diferenças entre os voluntários proficientes e não-proficientes.

A Tabela 4 exibe a quantidade de acertos, tempo total de resposta e rating ELO, caso exista, para cada voluntário. Os voluntários do grupo mais proficiente são realçados pela cor azul e os voluntários do grupo menos proficiente são realçados pela cor vermelha.

A partir dos dados mostrados na Tabela 4 é possível verificar que todos os voluntários que possuíam rating ELO ficaram classificados no grupo de maior proficiência e, em sua maioria, obtiveram uma melhor classificação comparando-se com os demais voluntários que não possuíam rating ELO. Esses resultados indicam que a participação regular em campeonatos de xadrez, assim como o tempo dedicado ao estudo do mesmo, melhora o desempenho em testes nessa área.

\subsection{VALIDAÇÃO DAS MÉTRICAS}

Para verificação da métrica tradicional utilizou-se o método da distância euclidiana mínima de cada amostra com relação à média de cada grupo (proficiente e não-proficiente). Foi calculado para cada uma das categorias a acurácia, precisão, recall e f-measure. A Tabela 5 mostram os resultados para essa métrica.

A Tabela 5 mostra que a precisão da métrica tradicional quando analisada questão à questão tem uma acurácia média de 73,3\% para o grupo de treinamento. Para avaliar a acurácia de classificação das métricas cognitivas, foram utilizadas duas análises: grupo de treinamento e grupo de teste. Para o grupo de treinamento, utilizou-se o mesmo método que para a métrica tradicional. Para o grupo de teste, utilizou-se a técnica leave-one-out devido à quantidade de amostras disponíveis ser pequena (CHEN, 2005) e, assim como foi feito com o grupo de treinamento, foi calculado para cada uma das categorias a acurácia, precisão, recall e $f$-measure. As Tabelas 6 e 7 mostram os resultados do hiperplano discriminante para os sinais de EEG pelo método SIPD de treinamento e teste, respectivamente. 
Tabela 4 - Ordenação dos voluntários.

\begin{tabular}{|c|c|c|c|c|}
\hline Participante & Acertos & Vs & Tempo total de resposta & Rating ELO \\
\hline 5 & 45 & 79,32 & $02 \mathrm{m01s}$ & 1967 \\
\hline 6 & 48 & 34,48 & $08 \mathrm{~m} 14 \mathrm{~s}$ & 1940 \\
\hline 14 & 48 & 29,97 & $10 \mathrm{~m} 49 \mathrm{~s}$ & 1789 \\
\hline 11 & 39 & 28,05 & $07 \mathrm{~m} 18 \mathrm{~s}$ & \\
\hline 13 & 47 & 24,39 & $11 \mathrm{~m} 37 \mathrm{~s}$ & \\
\hline 8 & 42 & 23,77 & $09 \mathrm{~m} 26 \mathrm{~s}$ & 1550 \\
\hline$\overline{33}$ & 40 & 22,17 & $08 \mathrm{~m} 29 \mathrm{~s}$ & \\
\hline 12 & 43 & 20,12 & $10 \mathrm{~m} 15 \mathrm{~s}$ & \\
\hline 10 & 39 & 18,38 & $09 \mathrm{~m} 07 \mathrm{~s}$ & \\
\hline 17 & 40 & 18,26 & $09 \mathrm{~m} 26 \mathrm{~s}$ & \\
\hline 3 & 43 & 18,10 & $09 \mathrm{~m} 26 \mathrm{~s}$ & \\
\hline 16 & 45 & 17,08 & $14 \mathrm{~m} 21 \mathrm{~s}$ & \\
\hline 9 & 47 & 16,36 & $15 \mathrm{~m} 33 \mathrm{~s}$ & \\
\hline 15 & 44 & 16,05 & $14 \mathrm{~m} 10 \mathrm{~s}$ & \\
\hline 31 & 38 & 15,97 & $11 \mathrm{~m} 22 \mathrm{~s}$ & \\
\hline 7 & 41 & 15,33 & $13 \mathrm{~m} 11 \mathrm{~s}$ & \\
\hline 34 & 36 & 13,79 & $08 \mathrm{~m} 59 \mathrm{~s}$ & \\
\hline 21 & 43 & 13,71 & $14 \mathrm{~m} 44 \mathrm{~s}$ & \\
\hline 28 & 39 & 13,60 & $12 \mathrm{~m} 45 \mathrm{~s}$ & \\
\hline 4 & 39 & 13,41 & $07 \mathrm{~m} 54 \mathrm{~s}$ & \\
\hline 19 & 34 & 13,01 & $09 \mathrm{~m} 42 \mathrm{~s}$ & \\
\hline 24 & 41 & 12,49 & $13 \mathrm{~m} 02 \mathrm{~s}$ & \\
\hline 26 & 40 & 12,06 & $14 \mathrm{~m} 01 \mathrm{~s}$ & \\
\hline 22 & 42 & 10,17 & $20 \mathrm{~m} 39 \mathrm{~s}$ & \\
\hline 27 & 34 & 9,20 & $12 \mathrm{~m} 23 \mathrm{~s}$ & \\
\hline 20 & 34 & 8,38 & $12 \mathrm{~m} 30 \mathrm{~s}$ & \\
\hline 18 & 33 & 8,11 & $10 \mathrm{~m} 42 \mathrm{~s}$ & \\
\hline 29 & 38 & 7,67 & $16 \mathrm{~m} 24 \mathrm{~s}$ & \\
\hline 32 & 33 & 7,55 & $11 \mathrm{~m} 13 \mathrm{~s}$ & \\
\hline 30 & 32 & 5,35 & $12 \mathrm{~m} 42 \mathrm{~s}$ & \\
\hline 25 & 29 & 3,51 & $13 \mathrm{~m} 08 \mathrm{~s}$ & \\
\hline 23 & 28 & 2,66 & $14 \mathrm{~m} 19 \mathrm{~s}$ & \\
\hline
\end{tabular}

Fonte: Autor

Os resultados de classificação mostram que o MLDA separa os grupos proficientes e não-proficientes em aproximadamente $86 \%$ dos casos para o grupo de treinamento (Tabela 6). Por outro lado, utilizando-se os dados de teste, somente $46 \%$ foram classificados de maneira correta (Tabela 6) utlizando-se a abordagem SIPD. As mesmas métricas foram utilizadas para a abordagem PSD, analisando-se as bandas de frequência delta, teta, alfa, beta e gama. Os resultados entre essas bandas foram similares. As Tabelas 8 e 9 mostram a classificação para a banda teta, que teve acurácia ligeiramente superior as demais bandas. 
Tabela 5 - Classificação da métrica tradicional dos grupos de treinamento, por categoria.

\begin{tabular}{c|c|c|c|c}
\hline Categoria & Acurácia & Precisão & Recall & F-measure \\
\hline C1 & 0.633 & 0.610 & 0.605 & 0.607 \\
\hline C2 & 0.8 & 0.750 & 0.825 & 0.785 \\
\hline C3 & 0.733 & 0.721 & 0.716 & 0.718 \\
\hline C4 & 0.6 & 0.589 & 0.589 & 0.589 \\
\hline C5 & 0.9 & 0.883 & 0.912 & 0.897 \\
\hline
\end{tabular}

Fonte: Autor

Tabela 6 - Classificação do hiperplano EEG pelo método

SIPD dos grupos de treinamento, por categoria.

\begin{tabular}{c|c|c|c|c}
\hline Categoria & Acurácia & Precisão & Recall & $F$-measure \\
\hline C1 & 0.901 & 0.898 & 0.931 & 0.884 \\
\hline C2 & 0.888 & 0.870 & 0.916 & 0.854 \\
\hline C3 & 0.866 & 0.860 & 0.930 & 0.853 \\
\hline C4 & 0.898 & 0.882 & 0.927 & 0.894 \\
\hline C5 & 0.824 & 0.819 & 0.845 & 0.805 \\
\hline
\end{tabular}

Fonte: Autor

Tabela 7 - Classificação do hiperplano EEG pelo método SIPD dos grupos de teste, por categoria.

\begin{tabular}{c|c|c|c|c}
\hline Categoria & Acurácia & Precisão & Recall & $F$-measure \\
\hline C1 & 0.472 & 0.336 & 0.425 & 0.466 \\
\hline C2 & 0.416 & 0.293 & 0.466 & 0.443 \\
\hline C3 & 0.575 & 0.477 & 0.541 & 0.553 \\
\hline C4 & 0.485 & 0.439 & 0.585 & 0.495 \\
\hline C5 & 0.434 & 0.368 & 0.425 & 0.389 \\
\hline
\end{tabular}

Fonte: Autor

Tabela 8 - Classificação do hiperplano EEG pelo método PSD dos grupos de treinamento, por categoria.

\begin{tabular}{c|c|c|c|c}
\hline Categoria & Acurácia & Precisão & Recall & $F$-measure \\
\hline C1 & 0.778 & 0.652 & 0.725 & 0.686 \\
\hline C2 & 0.754 & 0.642 & 0.724 & 0.680 \\
\hline C3 & 0.783 & 0.665 & 0.730 & 0.696 \\
\hline C4 & 0.789 & 0.665 & 0.732 & 0.697 \\
\hline C5 & 0.742 & 0.639 & 0.721 & 0.677 \\
\hline
\end{tabular}

Fonte: Autor

Para a abordagem PSD, verifica-se que sua acurácia, utizando o MLDA, é de, aproximadamente, $77 \%$ para o grupo de treinamento e, aproximadamente, $44 \%$ para o grupo de teste. 
Tabela 9 - Classificação do hiperplano EEG pelo método PSD dos grupos de teste, por categoria.

\begin{tabular}{c|c|c|c|c}
\hline Categoria & Acurácia & Precisão & Recall & F-measure \\
\hline C1 & 0.453 & 0.336 & 0.463 & 0.389 \\
\hline C2 & 0.405 & 0.329 & 0.422 & 0.443 \\
\hline C3 & 0.461 & 0.415 & 0.458 & 0.369 \\
\hline C4 & 0.472 & 0.419 & 0.486 & 0.450 \\
\hline C5 & 0.399 & 0.288 & 0.401 & 0.335
\end{tabular}

Fonte: Autor

De acordo com os resultados de acurácia, as futuras análises relacionadas aos sinais de EEG são baseadas na abordagem SIPD.

Analogamente, os mesmos critérios foram utilizados para classificação do hiperplano discriminante de eye-tracking utilizando-se o MLDA. As Tabelas 10 e 11 mostram os resultados dessa classificação para os dados de treinamento e de teste, respectivamente.

Tabela 10 - Classificação do hiperplano eye-tracking dos grupos de treinamento, por categoria.

\begin{tabular}{c|c|c|c|c}
\hline Categoria & Acurácia & Precisão & Recall & F-measure \\
\hline C1 & 0.988 & 0.979 & 1 & 0.989 \\
\hline C2 & 0.987 & 0.977 & 1 & 0.988 \\
\hline C3 & 0.994 & 0.995 & 0.995 & 0.995 \\
\hline C4 & 0.989 & 0.983 & 1 & 0.991 \\
\hline C5 & 0.985 & 0.983 & 0.986 & 0.987 \\
\hline
\end{tabular}

Fonte: Autor

Tabela 11 - Classificação do hiperplano eye-tracking dos grupos de teste, por categoria.

\begin{tabular}{c|c|c|c|c}
\hline Categoria & Acurácia & Precisão & Recall & F-measure \\
\hline C1 & 0.618 & 0.661 & 0.657 & 0.654 \\
\hline C2 & 0.670 & 0.677 & 0.757 & 0.712 \\
\hline C3 & 0.608 & 0.654 & 0.703 & 0.673 \\
\hline C4 & 0.476 & 0.505 & 0.523 & 0.509 \\
\hline C5 & 0.562 & 0.600 & 0.559 & 0.573 \\
\hline
\end{tabular}

Fonte: Autor

De acordo com os resultados mostrados nas Tabelas 10 e 11, nota-se que a taxa de acerto na classificação é de, aproximadamente, $99 \%$ e $60 \%$ para os grupos de treino e teste, respectivamente.

Comparando-se os resultados de classificação para ambos sinais cognitivos, verificase que o hiperplano de eye-tracking separou melhor os voluntários do que o hiperplano de 
EEG. Tanto para o EEG quanto para o eye-tracking, a taxa de classificação de cada uma das categorias utilizando-se os dados de teste não é próxima de 1. Por esse motivo, para cada uma das categorias apresentadas nos experimentos será exemplificada uma questão na seção a seguir.

\subsection{COMPARAÇÃO ENTRE MÉTRICAS DE CLASSIFICAÇÃO}

Nesta seção são descritos os resultados das seguintes comparações feitas para as questões de cada uma das categorias: comparação entre a classificação de Volke (considerando-se acurácia e tempo médio de resposta) versus hiperplano de EEG (considerando-se ativações cerebrais); classificação de Volke versus hiperplano de eye-tracking (considerando-se os movimentos oculares); hiperplano de eye-tracking versus hiperplano de EEG.

Para as análises apresentadas a seguir, a classificação de Volke será baseada de questão a questão entre os voluntários que foram separados entre proficientes e não proficientes, ou seja, cada uma das questões tem uma ordenação diferente dependendo da acurácia e tempo de resposta do voluntário, de acordo com a Equação 19:

$$
V_{s}=\left(N_{\text {correct }}-\frac{1}{2}\right) \cdot \frac{R T_{m}}{R T_{s}}
$$

em que $V_{s}$ é a proficiência de cada voluntário para uma questão específica, $N_{\text {correct }}$ é 1 caso o voluntário tenha respondido corretamente à questão e 0 caso contrário, $R T_{m}$ é o tempo de resposta médio de todos os participantes proficientes e não-proficientes para a questão específica e $R T_{s}$ é o tempo de resposta de cada voluntário para a questão específica.

São comparados também os heatmaps dos movimentos oculares e os mapas cerebrais dos voluntários que foram projetados nos extremos e meio dos hiperplanos. Os heatmaps gerados no software CHESSLAB e são apresentados através de uma escala de cor que começa na cor verde, indicando que houve poucas fixações naquele local, passando pelas cores amarelo, laranja e vermelho, cor que indicam várias fixações naquele ponto. Os mapas cerebrais são gerados no software EEGLAB e sua escala de cor inicia na cor azul escuro, sinalizando que houveram poucas ativações naquela área, passando pelas cores, ciano, verde, amarelo, laranja, vermelho até vermelho escuro, indicando que houveram bastante ativações cerebrais. A Figura 26 mostra essas escalas de cores. 
Figura 26 - Escala de cor para heatmaps e mapas cerebrais.

(a) Heatmaps.

(b) Mapas cerebrais.

Fonte: Autor

\subsubsection{Categoria 1: Reconhecimento de peças e posicionamento}

Para a categoria 1, o voluntário analisa a quantidade, o tipo e o posicionamento de peças de xadrez. A Figura 27 mostra o desempenho dos grupos proficientes e não-proficientes com relação à quantidade de acertos e tempo médio de resposta.

A Figura 27a mostra que, para a categoria 1, o grupo de maior proficiência teve 7 ou 8 acertos dentre 8 possíveis para cada questão, enquanto que o grupo de menor proficiência variou a quantidade de acertos por questão. Com relação ao tempo médio de resposta observado na Figura 27b, verifica-se que, no geral, o grupo menos proficiente levou mais tempo para responder às questões apresentadas.

Baseado nas informações fornecidas na Figura 27, são gerados os hiperplanos de EEG e eye-tracking para a questão 36. Para a questão 36, ambos os grupos acertaram 7 questões. A Figura 28 exibe os resultados da classificação de Volke e do hiperplano eye-tracking.

Na classificação de Volke (Figura 28c) nota-se que os voluntários 18, 30 e 32, pertencentes ao grupo não-proficiente encontram-se misturados aos voluntários do grupo proficiente, enquanto que o voluntário 11, pertencente ao grupo proficiente, teve o pior desempenho dentre todos os outros. Já o hiperplano eye-tracking (Figura 28d) separou os grupos sem que houvessem erros entre eles. A correlação de Spearman (Figura 28b) mostra que as duas métricas não têm correlação estatisticamente significante.

A Figura 29 mostra a mesma comparação realizada anteriormente, porém comparandose a classificação de Volke em relação ao hiperplano EEG.

A classificação de Volke (Figura 29c) e o hiperplano EEG (Figura 29d) mostram que os voluntários 20 e 27, não-proficientes, ficaram próximos aos voluntários proficientes na classificação de Volke, enquanto os voluntários 6 e 11, proficientes, ficaram próximos aos voluntários 
Figura 27 - Categoria 1.

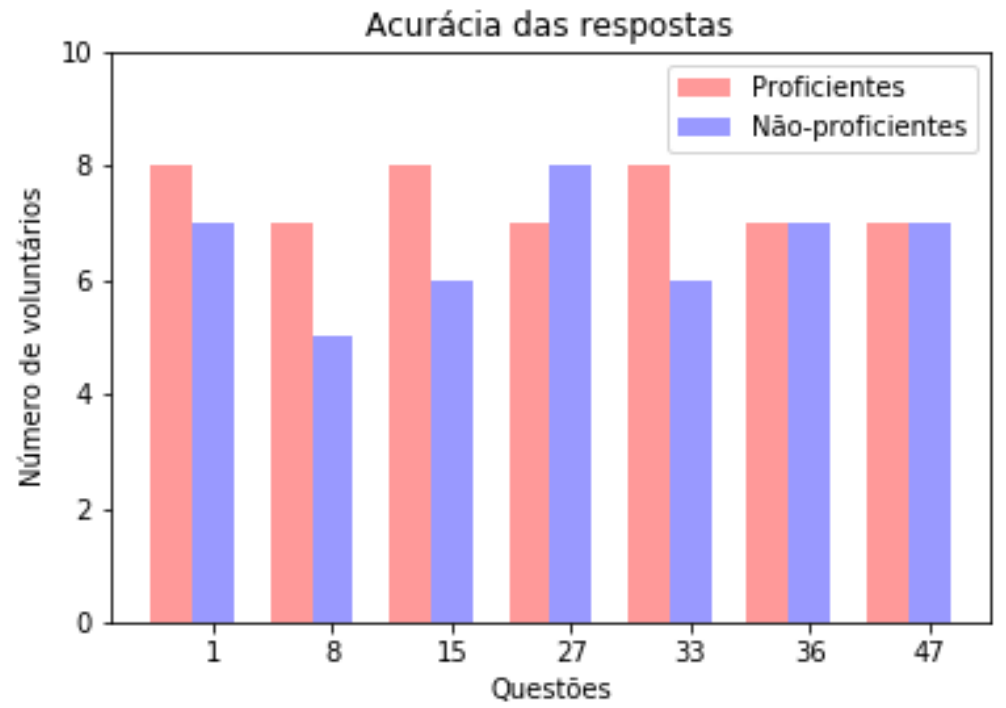

(a) Acurácia das respostas.

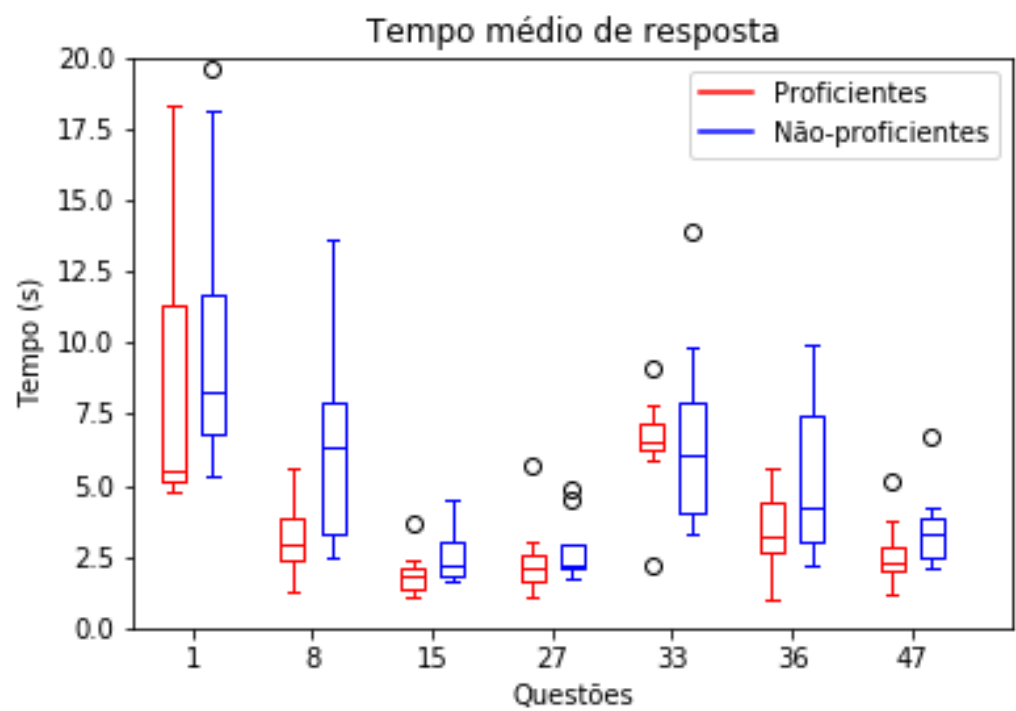

(b) Tempo médio de resposta.

Fonte: Autor

não-proficientes no hiperplano EEG. Ambas as métricas classificaram os voluntários 11 e 23 como sendo os menos proficientes e, apesar dessa concordância, a correlação de Spearman (Figura 29b) entre elas não é estatisticamente significante.

A Figura 30 mostra a comparação entre o hiperplano eye-tracking e hiperplano EEG com os voluntários que são comuns a ambos. 
Figura 28 - Classificação de Volke e eye-tracking para questão 36.

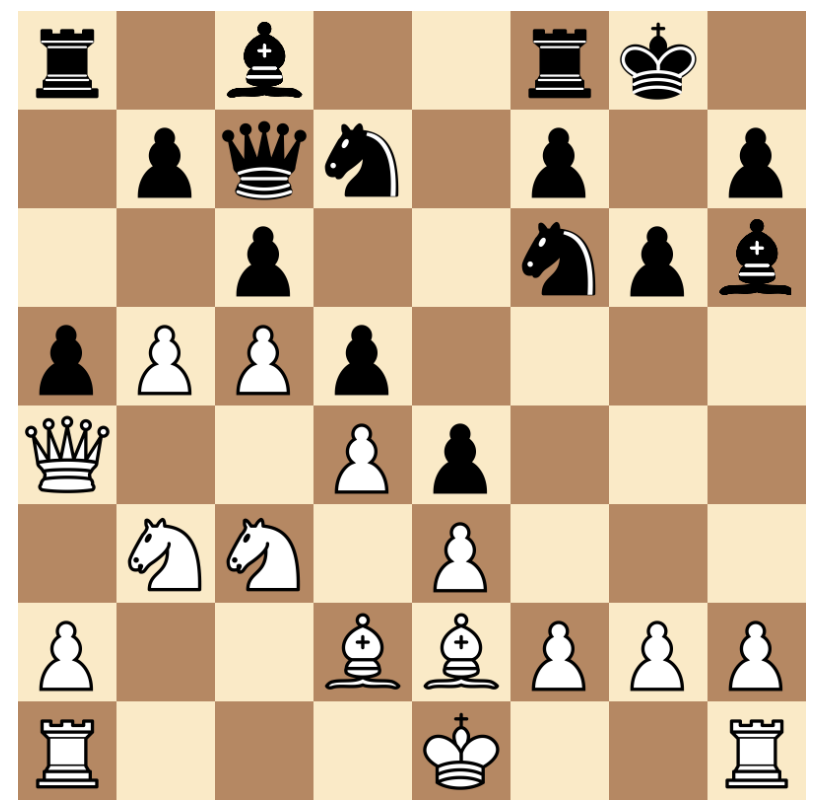

(a) Diagrama da questão 36 - Um BISPO PRETO foi CAPTURADO? (Não).

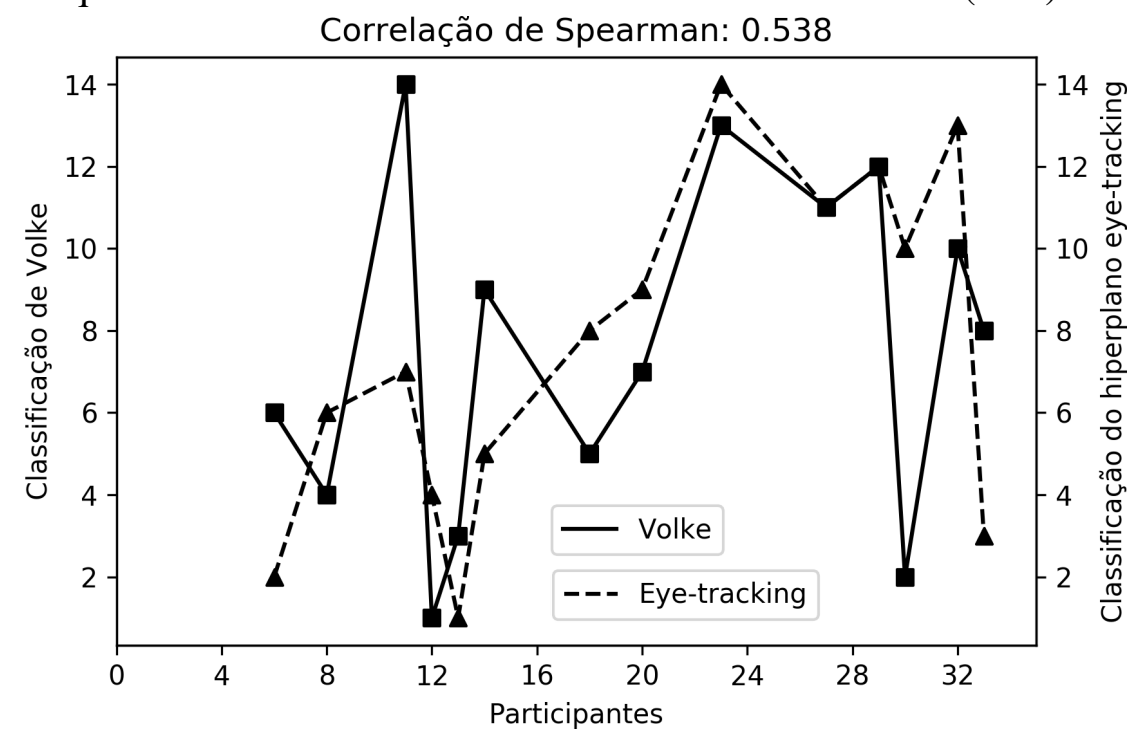

(b) Correlação de Spearman entre hiperplano eye-tracking e classificação de Volke.

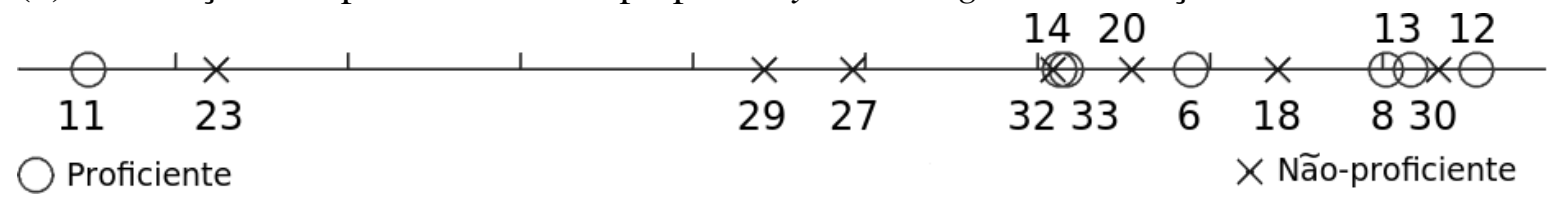

(c) Classificação de Volke.

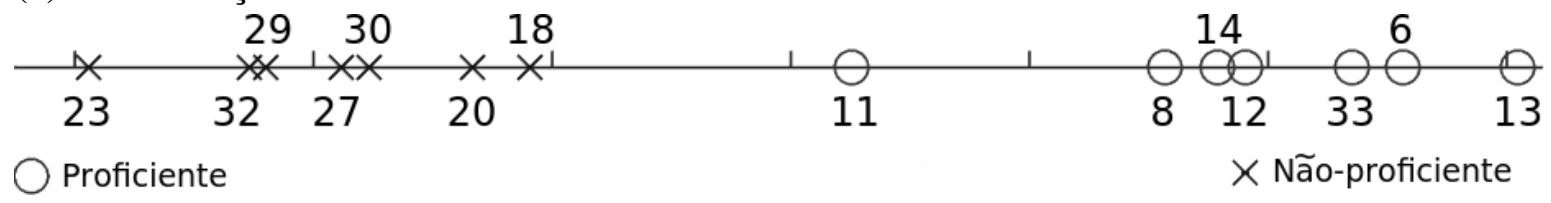

(d) Hiperplano eye-tracking.

Fonte: Autor 
Figura 29 - Classificação de Volke e EEG para questão 36.

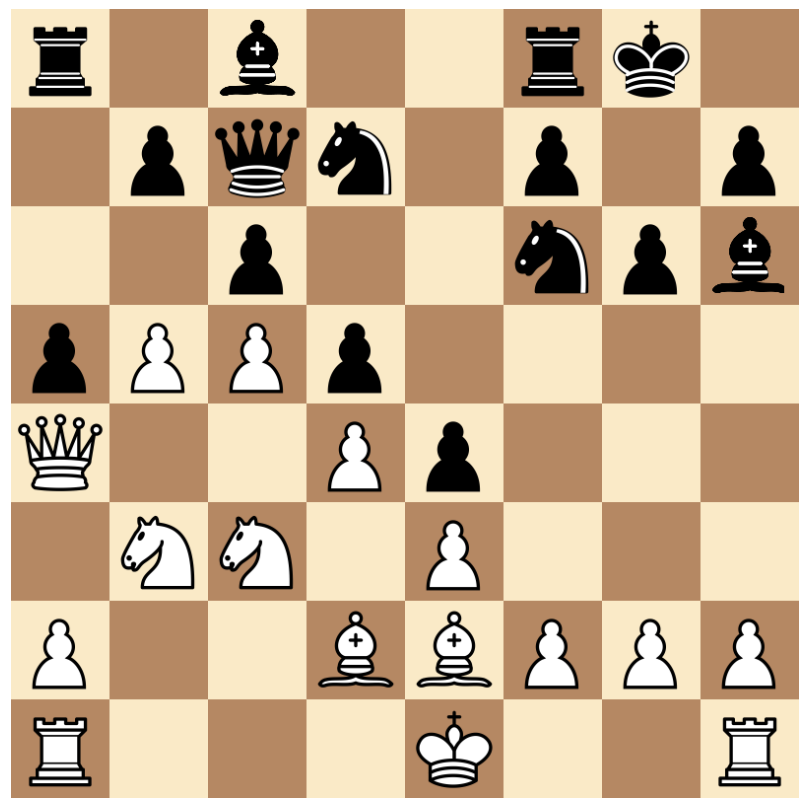

(a) Diagrama da questão 36 - Um BISPO PRETO foi CAPTURADO? (Não).

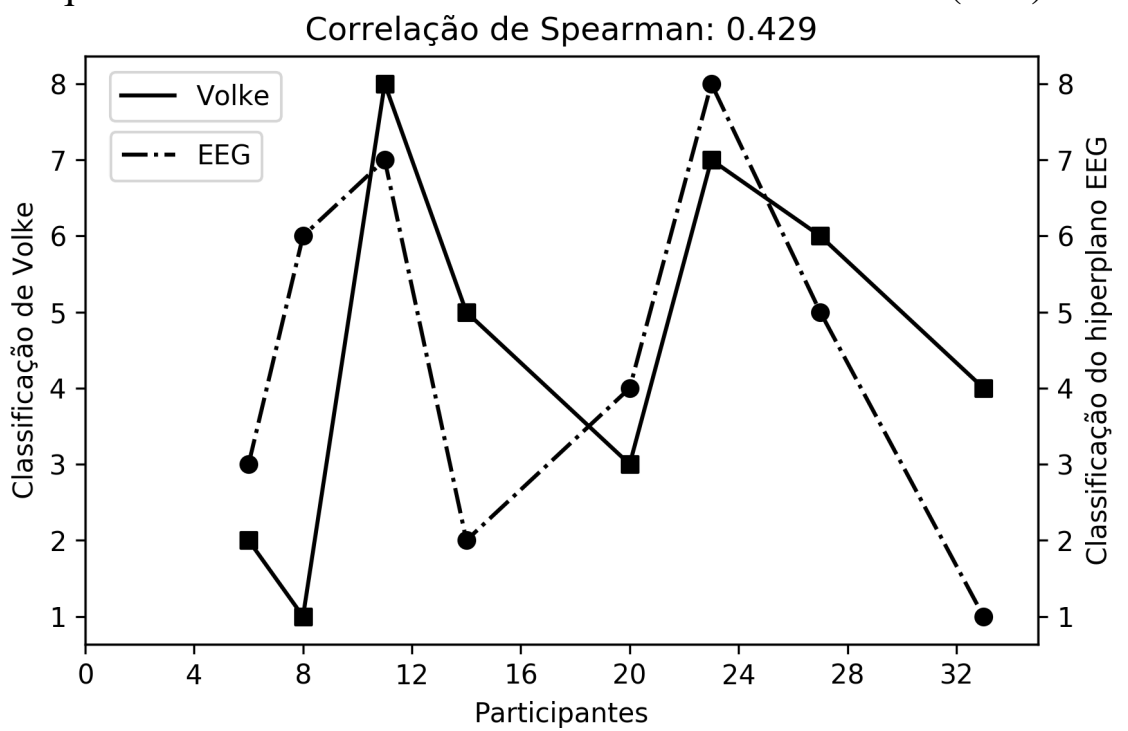

(b) Correlação de Spearman entre hiperplano EEG e classificação de Volke.

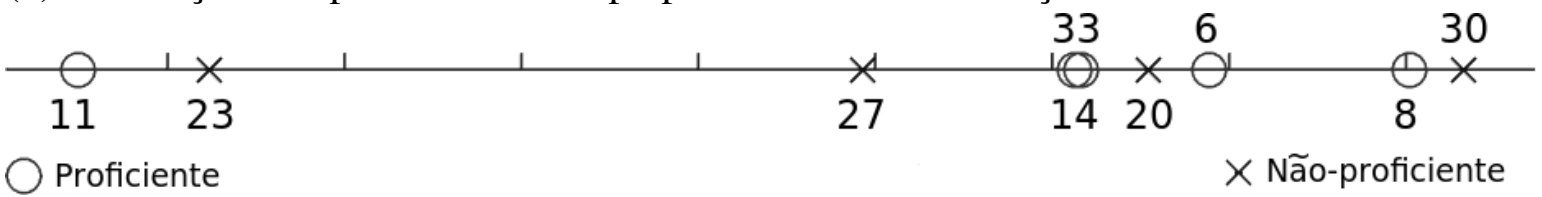

(c) Classificação de Volke.

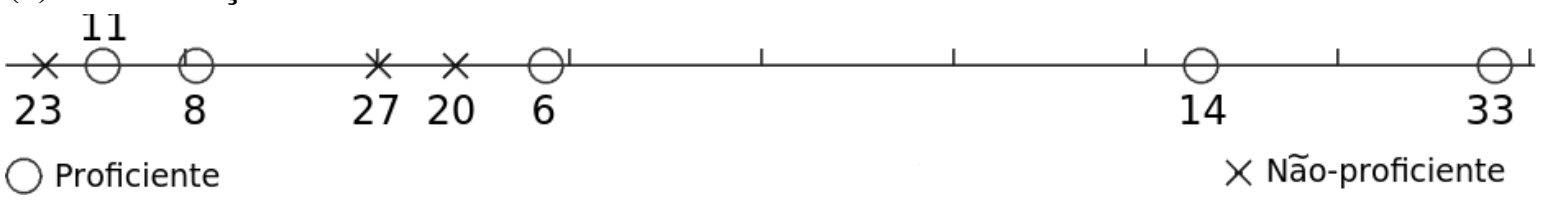

(d) Hiperplano EEG.

Fonte: Autor 
Figura 30 - Classificação de eye-tracking e EEG para questão 36.

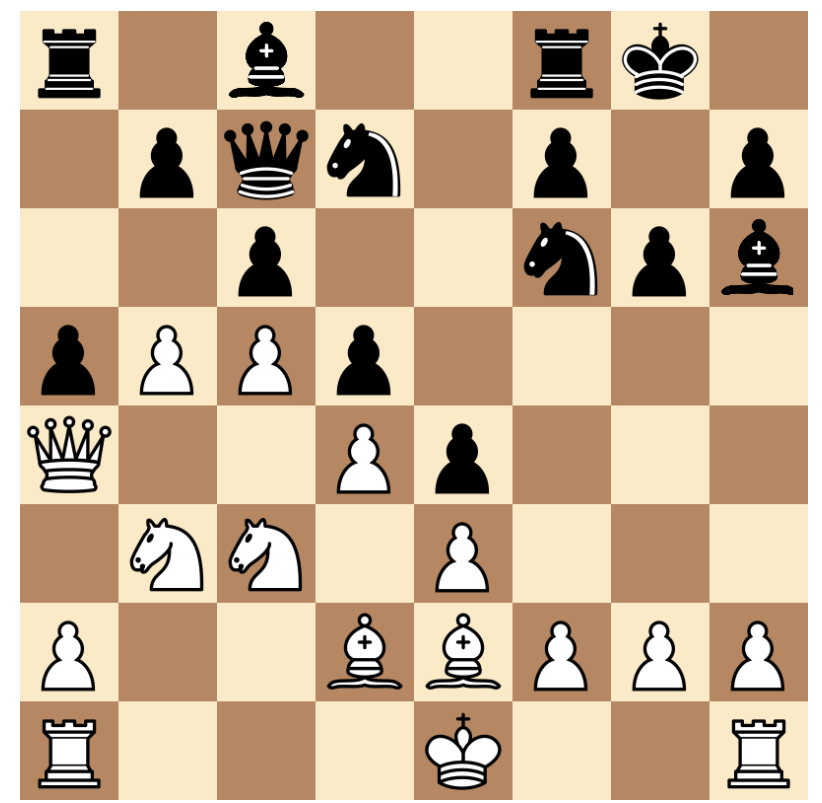

(a) Diagrama da questão 36 - Um BISPO PRETO foi CAPTURADO? (Não).

Correlação de Spearman: 0.738

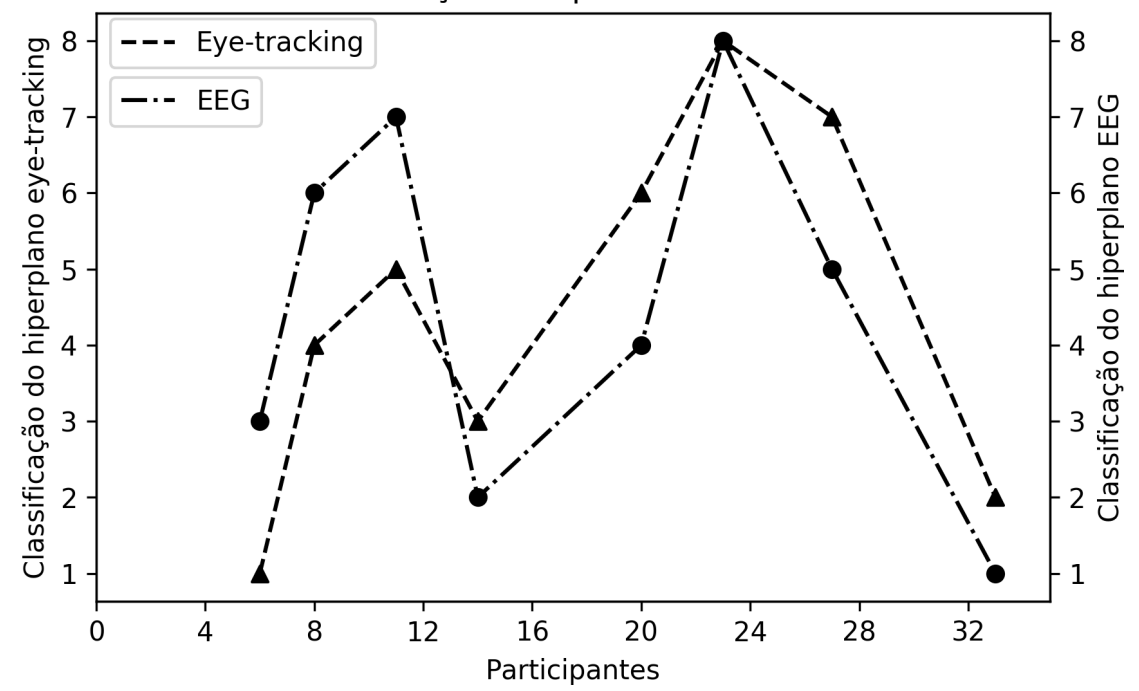

(b) Correlação de Spearman entre hiperplano eye-tracking e EEG.

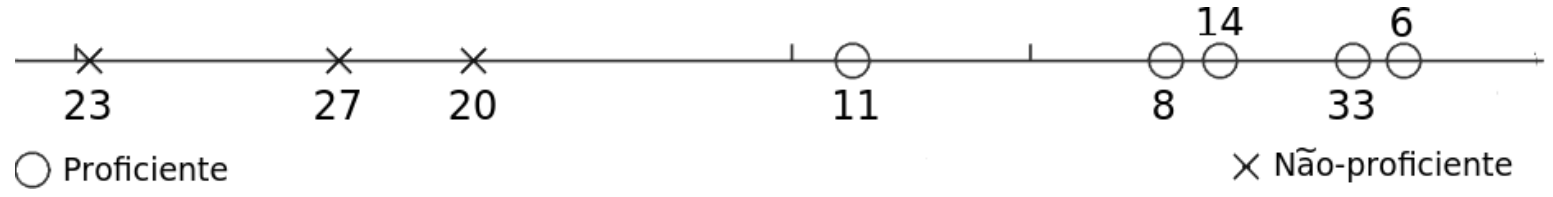

(c) Hiperplano eye-tracking.

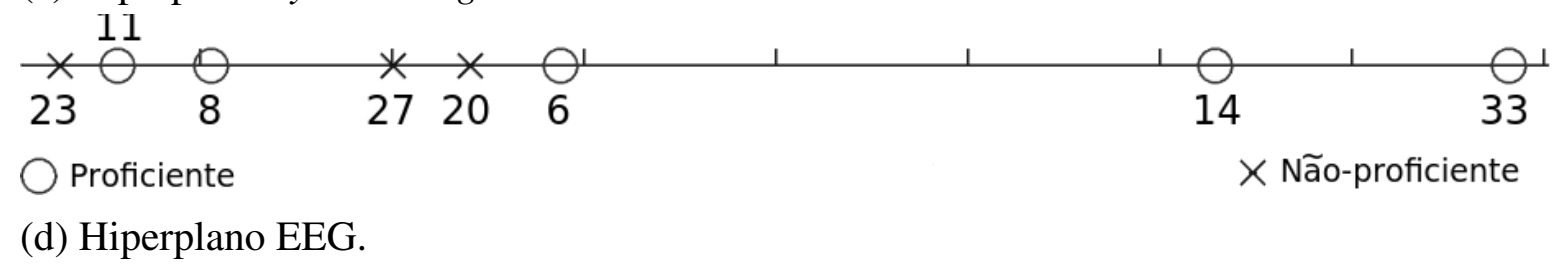

Fonte: Autor 
Comparando-se a classificação entre o hiperplano eye-tracking e o hiperplano EEG, verifica-se que existe uma correlação estatisticamente significante (Figura 30b), apesar de não haver posições iguais para nenhum voluntário.

Para a questão 36, são exibidos na Figura 31 os heatmaps e os mapas cerebrais dos voluntarios 20, 23 e 33. Esses voluntários se encontram na fronteira e nos extremos do hiperplano de eye-tracking, hiperplano que teve maior correlação com a classificação de Volke.

Figura 31 - Heatmaps e mapas cerebrais para a questão 36.

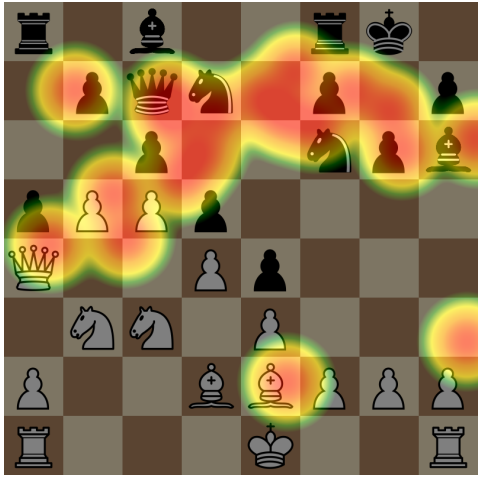

(a) Heatmap do voluntário 23.

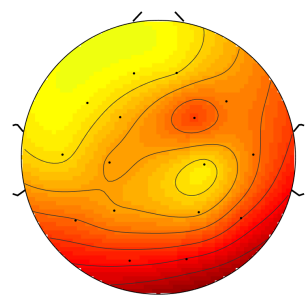

(d) Mapa cerebral do voluntário 23.

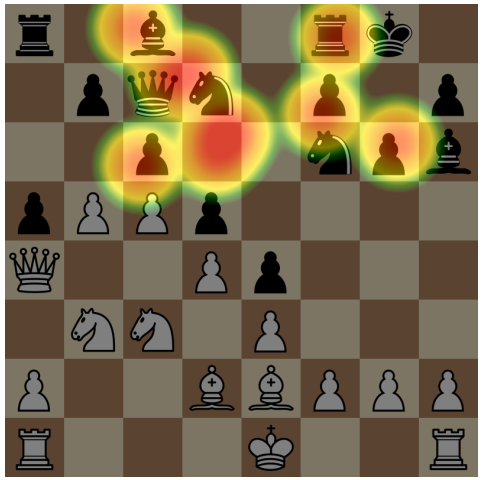

(b) Heatmap do voluntário 20.

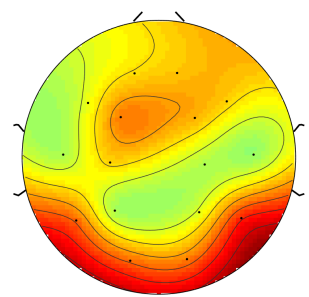

(e) Mapa cerebral do voluntário 20.

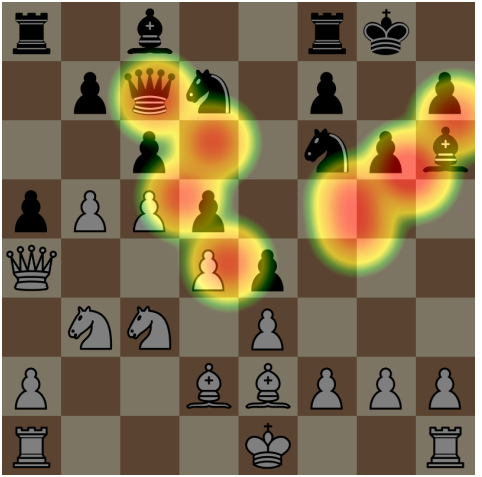

(c) Heatmap do voluntário 33.

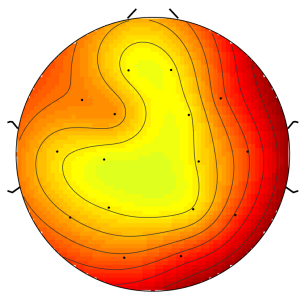

(f) Mapa cerebral do voluntário 33.

Fonte: Autor

Analisando-se os heatmaps, nota-se que o voluntário 23 (Figura 31a) olhou mais para a parte superior do tabuleiro, enquanto o voluntário 20 (Figura 31b) também focou seu olhar na parte superior, porém mais concentrado no centro; e o voluntário 33 (Figura 31c), além de olhar na parte superior central, olhou também na parte superior direita, duas áreas das quais encontram-se as peças perguntadas na questão 36.

Para os mapas cerebrais observa-se que o voluntário 23 (Figura 31d) teve mais ativações cerebrais na área ocipital, assim como o voluntário 20 (Figura 31e). Já o voluntário 33 teve suas principais ativações cerebrais no hemisfério direito, provavelmente causada pelo processamento visuo-espacial (VILLAFAINA et al., 2019). 
A melhor classificação do voluntário 33 nessa questão pode estar ligado ao seu olhar direcionado à parte superior central e superior direita do tabuleiro, onde se encontram os bispos. Sua ativação cerebral foi principalmente relacionada ao processamento das informações visuais.

Já o olhar do voluntário 23 também pode explicar sua classificação inferior aos demais voluntários, já que esse voluntário visualizou toda a parte superior do tabuleiro. Essa ação é revelada em seu mapa cerebral, onde a ativação cerebral é concentrada no lobo ocipital, relacionado ao processamento primário da visão (MARTINI; TIMMONS; TALLITSCH, 2009; DE OLIVEIRA, 2001).

\subsubsection{Categoria 2: Reconhecimento de situações de xeque}

O objetivo das questões que pertencem à categoria 2 é verificar se o voluntário é capaz de identificar uma situação de xeque, em que o rei sofre ameaça de captura e existe a possibilidade de sair dessa situação (VOLKE et al., 2002). A Figura 32 mostra o desempenho de ambos os grupos com relação à quantidade de acertos e tempo médio de resposta.

A categoria 2 foi a que apresentou o maior número de respostas corretas dentre todas as categorias apresentas. De acordo com a Figura 32a, o grupo de maior proficiência teve apenas um erro na questão 50 e o grupo de menor proficiência variou a quantidade de acertos por questão com bom desempenho em todas elas. Analisando-se o tempo médio de resposta da Figura $32 \mathrm{~b}$, observa-se que o grupo mais proficiente respondeu todas as questões dessa categoria em menor tempo comparando-se com o grupo menos proficiente.

Baseado nas informações fornecidas na Figura 32, são gerados os hiperplanos de EEG e eye-tracking para a questão 23, única questão na qual todos os voluntários de ambos os grupos responderam corretamente. A Figura 33 exibe a comparação entre a classificação de Volke e hiperplano eye-tracking.

A Figura 33c mostra que a classificação de Volke ranqueou todos os voluntários de forma que não houve confusão entre eles e os grupos aos quais pertencem, porém o voluntário 14 encontra-se mais próximo ao grupo não-proficiente do que o grupo proficiente, ao qual ele pertence. O hiperplano eye-tracking mostrado na Figura 33d, revela que a projeção dos voluntários estão sempre próximas aos seus respectivos grupos. Analisando-se a Figura 33b verifica-se que há uma correlação estatisticamente significativa $(0,851)$ em que os voluntário 
Figura 32 - Categoria 2.

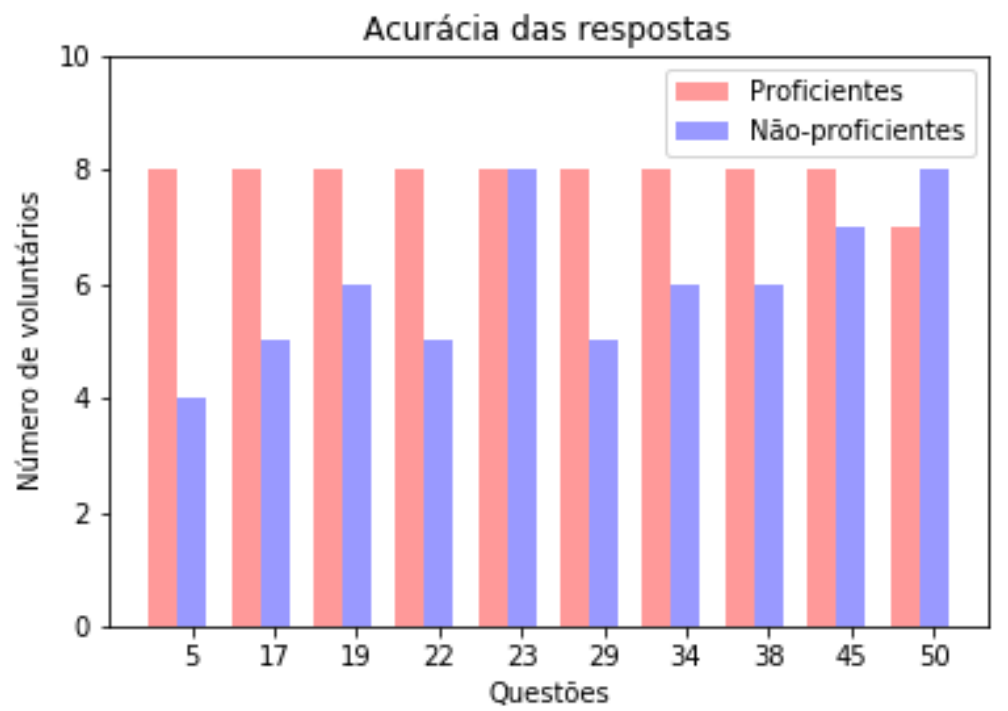

(a) Acurácia das respostas.

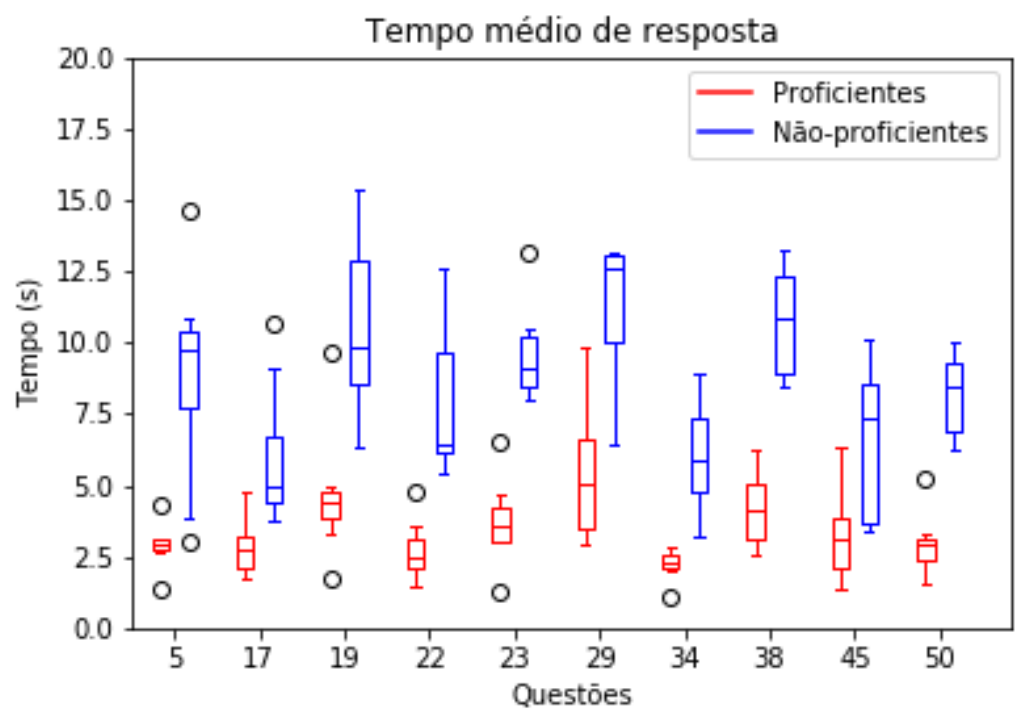

(b) Tempo médio de resposta.

Fonte: Autor

18, 20 e 27, pertencentes ao grupo não-proficiente, têm a mesma classificação em ambos os métodos de classificação.

Analogamente à análise feita entre a classificação de Volke e o hiperplano eye-traking, a Figura 34 exibe os resultados da comparação entre a classificação de Volke e hiperplano EEG.

De acordo com a Figura 34d, verifica-se que o hiperplano EEG não teve boa acurácia na separação dos voluntários. Com exceção do voluntário 20 , todos os outros voluntários pertencentes ao grupo não-proficiente foram projetados junto com os voluntários proficientes. Por 
Figura 33 - Classificação de Volke e eye-tracking para questão 23.

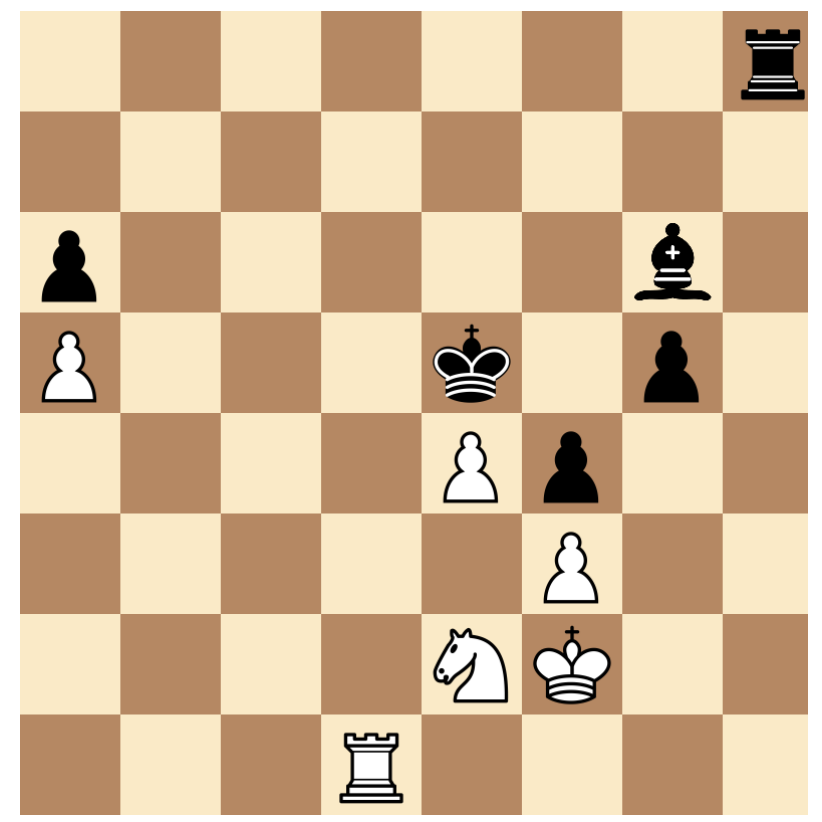

(a) Diagrama da questão 23 - O rei PRETO está em XEQUE? (Não).

Correlação de Spearman: 0.851

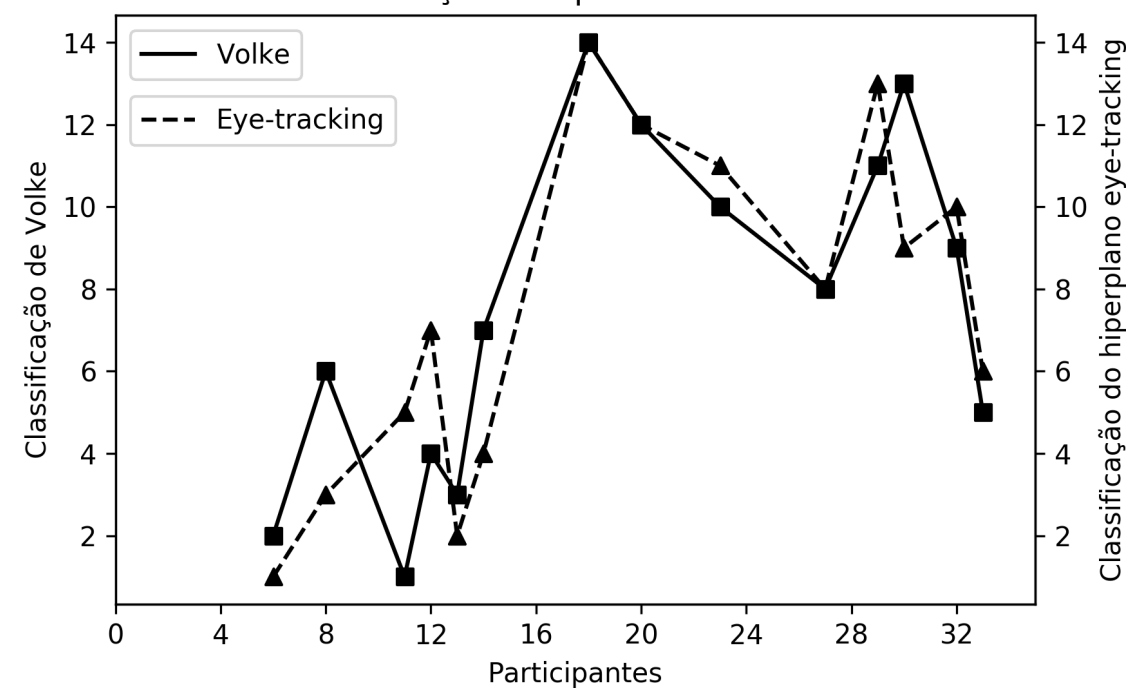

(b) Correlação de Spearman entre hiperplano eye-tracking e classificação de Volke.

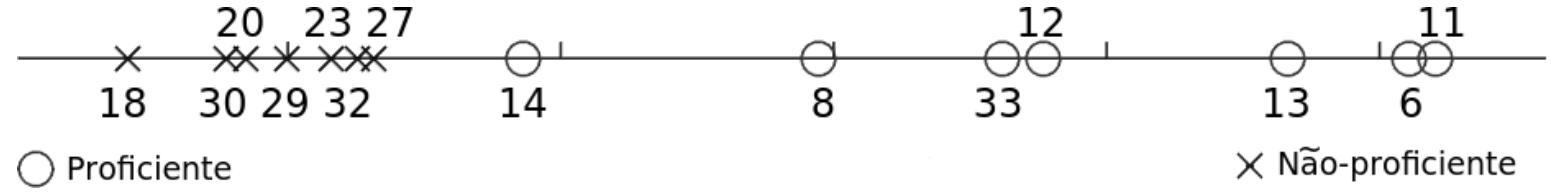

(c) Classificação de Volke.

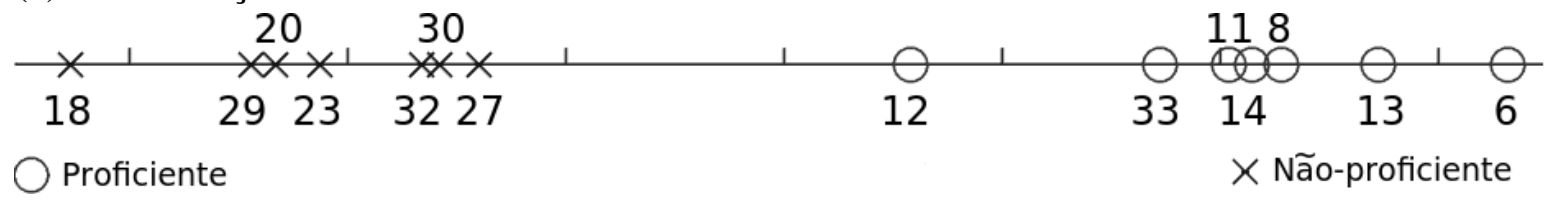

(d) Hiperplano eye-tracking.

Fonte: Autor. 
Figura 34 - Classificação de Volke e EEG para questão 23.

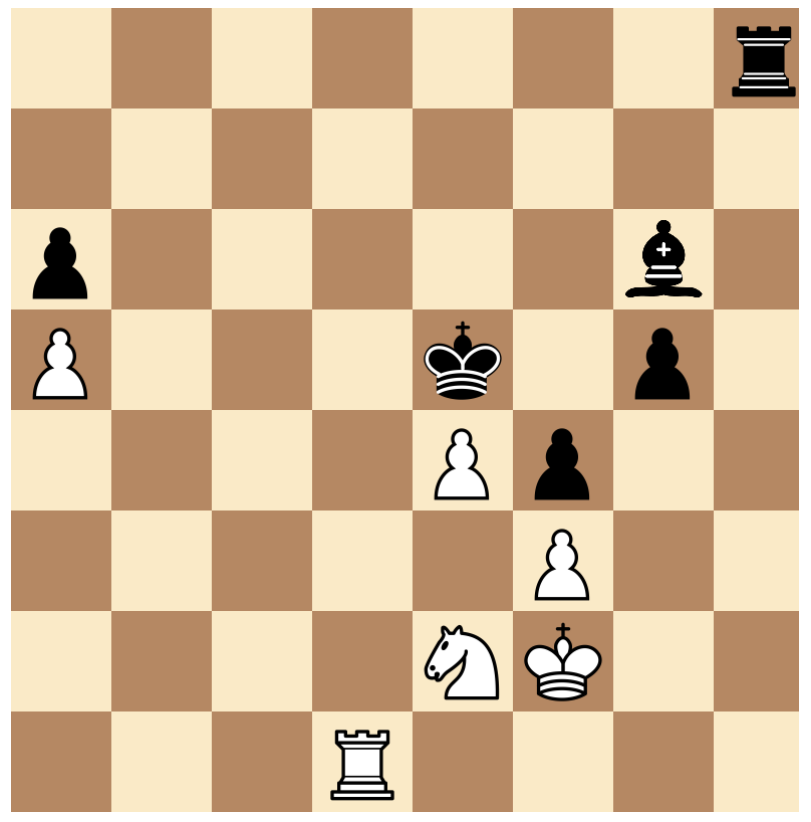

(a) Diagrama da questão 23 - O rei PRETO está em XEQUE? (Não).

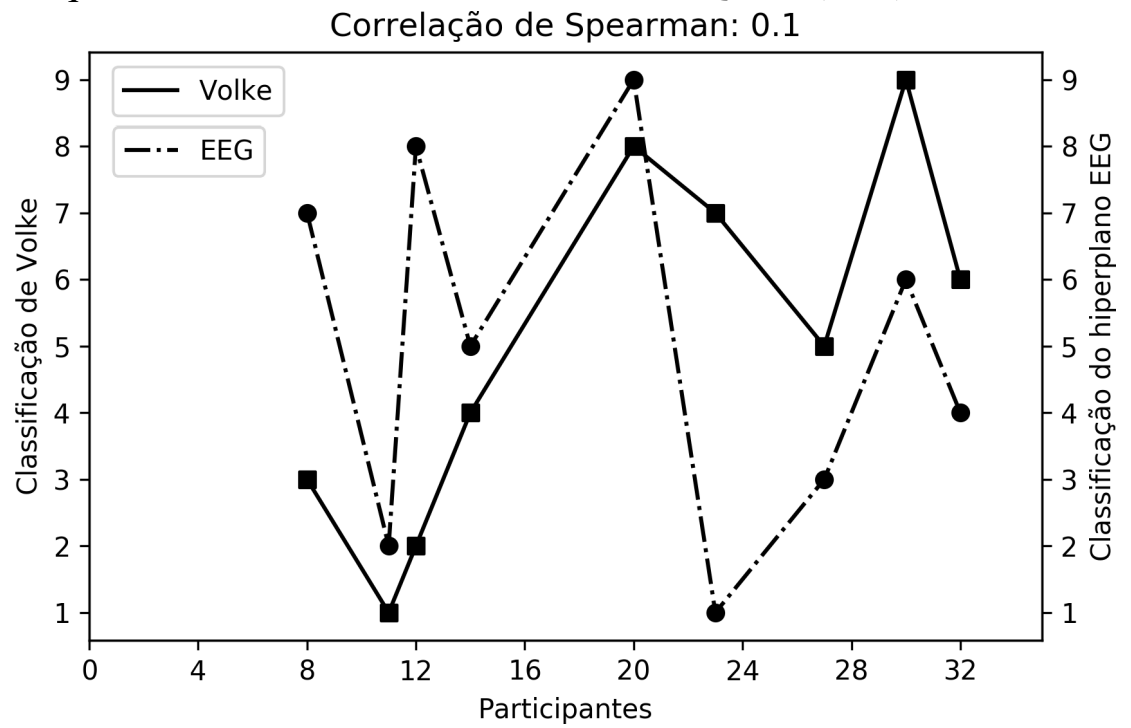

(b) Correlação de Spearman entre hiperplano EEG e classificação de Volke.

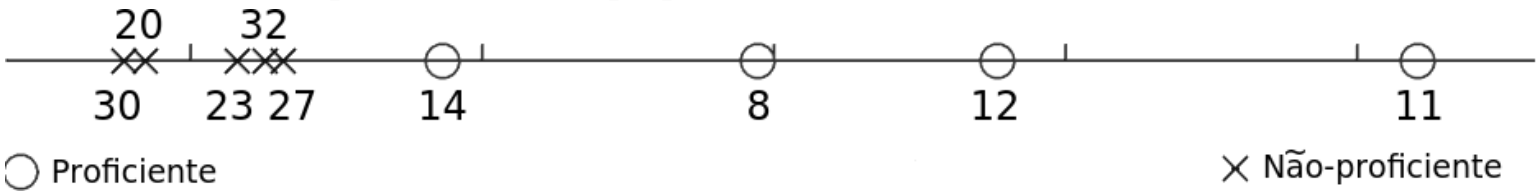

(c) Classificação de Volke.

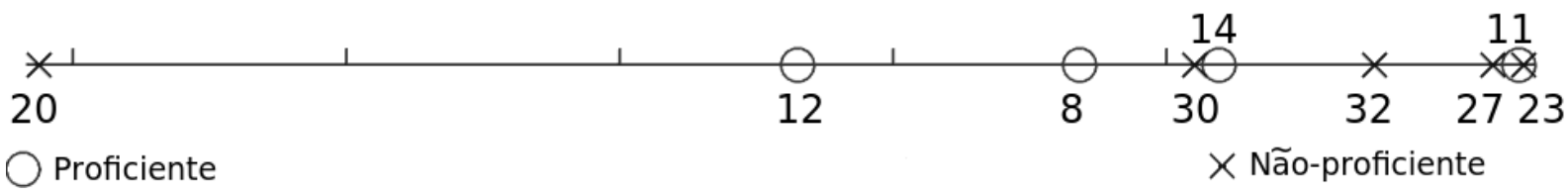

(d) Hiperplano EEG.

Fonte: Autor. 
esse motivo, a Figura 34b mostra que a correlação de Spearman entre os métodos foi baixa $(0,1)$.

A Figura 35 mostra a comparação entre o hiperplano eye-tracking e o hiperplano EEG com os voluntários que são comuns a ambos.

Comparando-se os voluntários que são comuns ao hiperplano eye-tracking (Figura 35c e ao hiperplano EEG (Figura 35d), nota-se que os voluntários 20 e 30, com o pior desempenho e o sexto melhor desempenho respectivamente, tiveram a mesmas posições em ambos os hiperplanos. A Figura 35b mostra a correlação de Spearman entre os hiperplanos, que apresenta valor que não é estatisticamente significante.

Como o hiperplano eye-tracking apresentou melhores resultados do que o hiperplano EEG, são gerados os heatmaps e mapas cerebrais dos voluntários 8, 12, 20, que se encontram nos extremos e no centro do hiperplano eye-tracking.

A Figura 36c mostra que o voluntário 8 olhou principalmente na área central e centralinferior do tabuleiro, em que se encontra a maioria das peças. O voluntário 12 teve sua atenção visual focada na área central do tabuleiro, conforme Figura 36b. Já a Figura 36a expõe o heatmap do voluntário 20, em que seus olhares focaram-se em sua maioria na área central do tabuleiro, área em que os voluntários 8 e 12 também focaram principalmente. Deve-se destacar que para responder à pergunta solicitada ( $\mathrm{O}$ rei preto encontra-se em xeque?) o olhar dos participantes deve necessariamente percorrer as casas onde se encontram as peças brancas.

O mapa cerebral do voluntário 8 exibido na Figura 36f revela ativações predominantemente na região dos eletrodos $\mathrm{T} 3, \mathrm{O} 2$ e $\mathrm{T} 4$, em que as ativações dos eletrodos $\mathrm{T} 3$ e $\mathrm{T} 4$ no momento anterior a tomada de decisão podem estar relacionadas à interpretação da pergunta em relação ao diagrama apresentado (VANLIERDE et al., 2003; BASTIAANSEN et al., 2002). Conforme Figura 36e, as principais atividades cerebrais do voluntário 12 ocorreram na área dos eletrodos $\mathrm{O} 1$ e O2, relacionadas ao processamento primário da visão e dos eletrodos T6 e T4 localizados no hemisfério direito do lobo temporal (MARTINI; TIMMONS; TALLITSCH, 2009; DE OLIVEIRA, 2001). A Figura 36d mostra que o voluntário 20 teve as principais ativações cerebrais nos eletrodos $\mathrm{O} 1$ e F4.

Nota-se, para o voluntário 20, apresentando o pior desempenho em ambos os hiperplanos, que seu heatmap está mais focado nas peças, enquanto que os outros voluntários também focaram nas áreas sem peças. Seu mapa cerebral se difere dos outros voluntários na área próxima ao eletrodo F7, onde ocorreu uma ativação cerebral mais baixa. 
Figura 35 - Classificação de eye-tracking e EEG para questão 23.

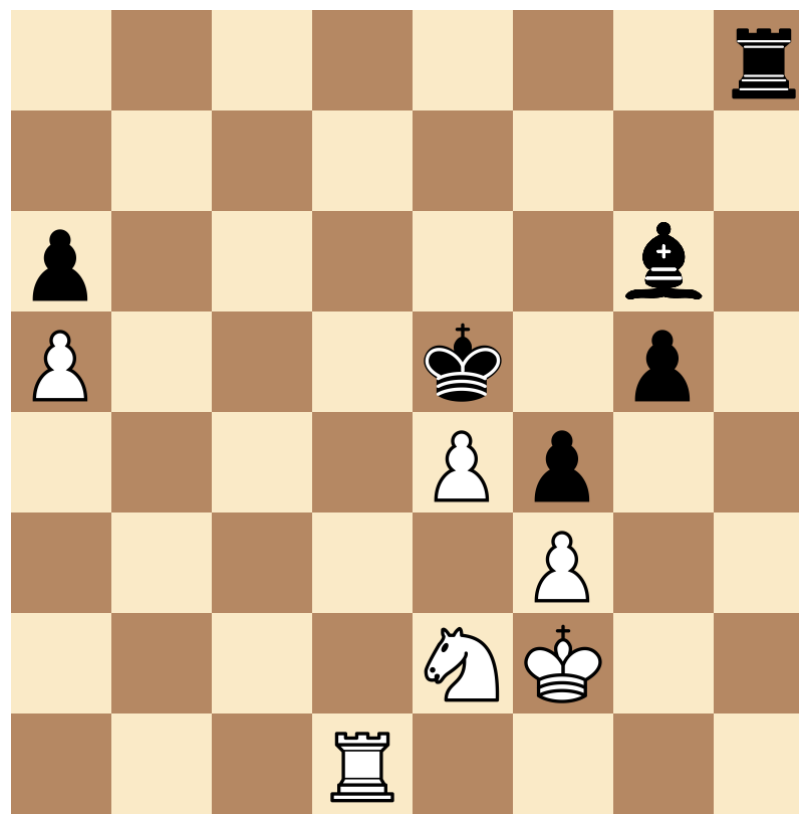

(a) Diagrama da questão 23 - O rei PRETO está em XEQUE? (Não).

Correlação de Spearman: -0.033

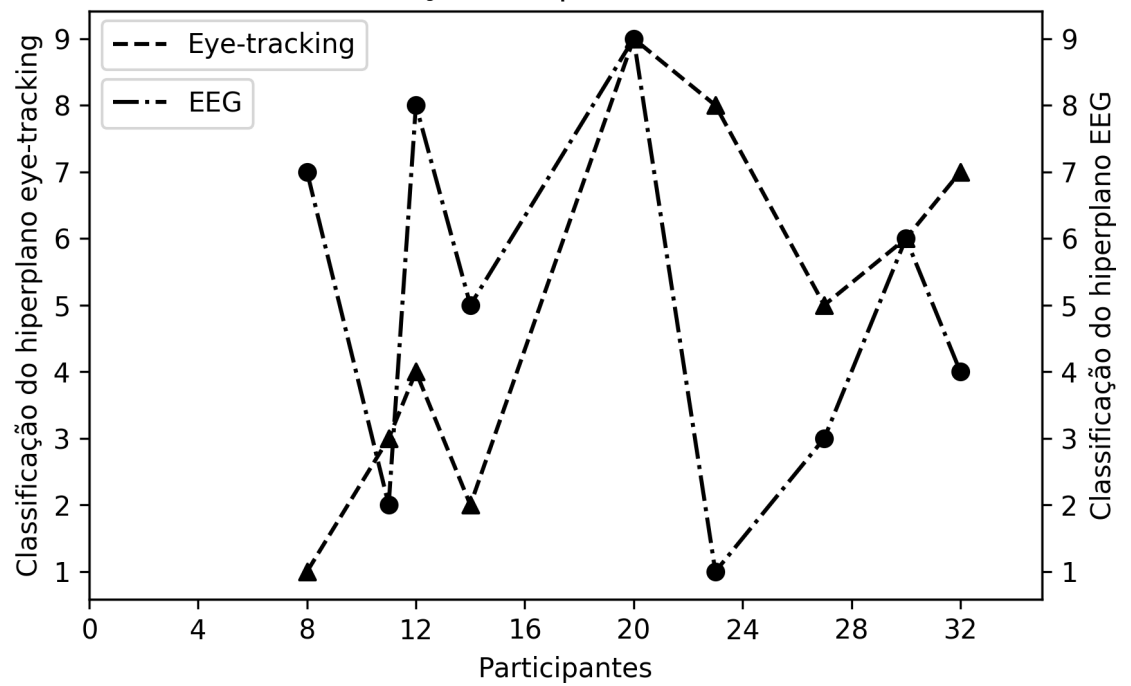

(b) Correlação de Spearman entre hiperplano eye-tracking e EEG.

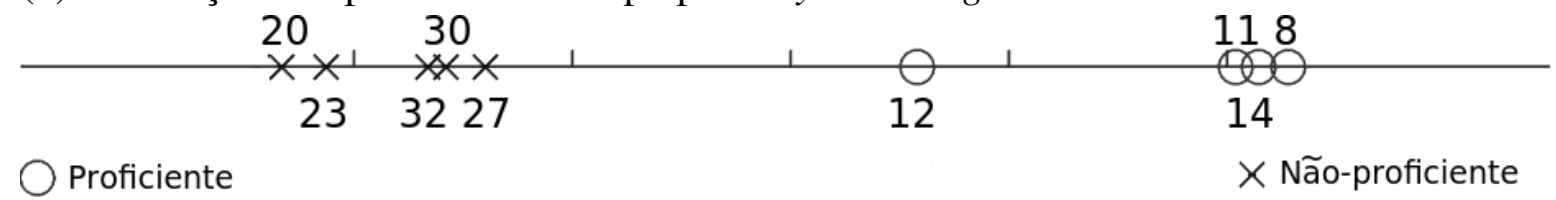

(c) Hiperplano eye-tracking.

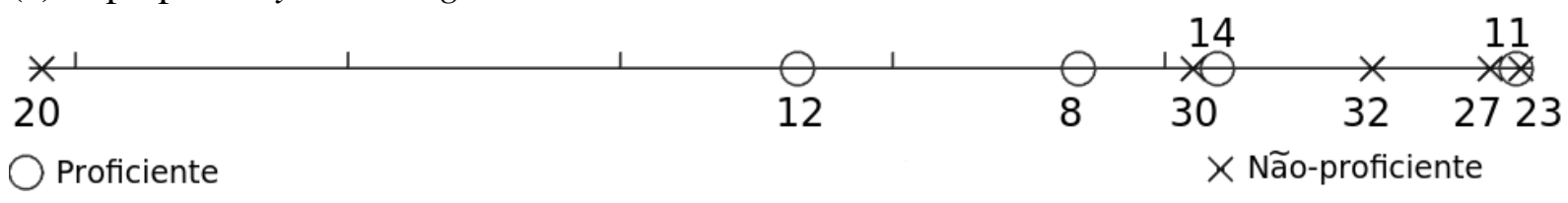

(d) Hiperplano EEG.

Fonte: Autor. 
Figura 36 - Heatmaps e mapas cerebrais para a questão 23.

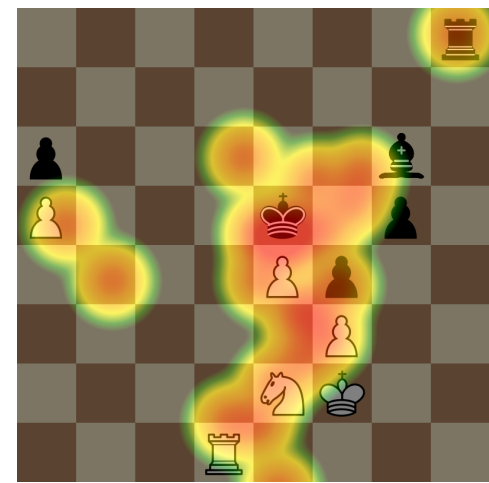

(a) Heatmap do voluntário 20.

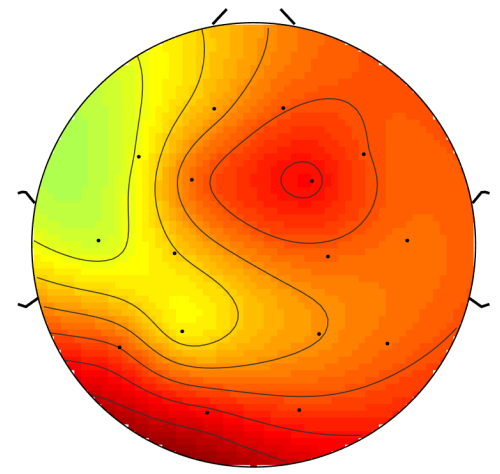

(d) Mapa cerebral do voluntário 20.

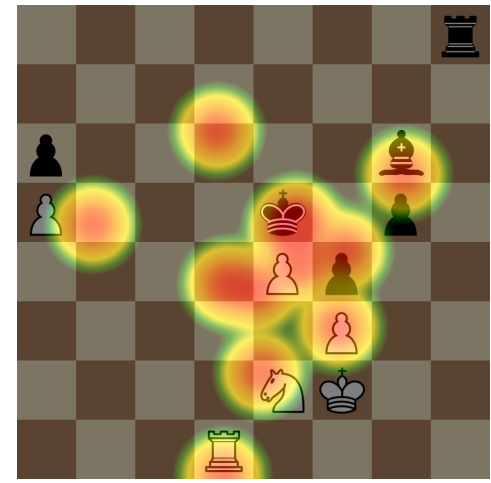

(b) Heatmap do voluntário 12.

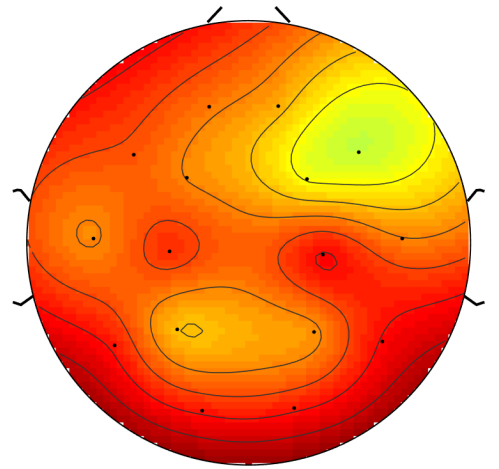

(e) Mapa cerebral do voluntário 12 .

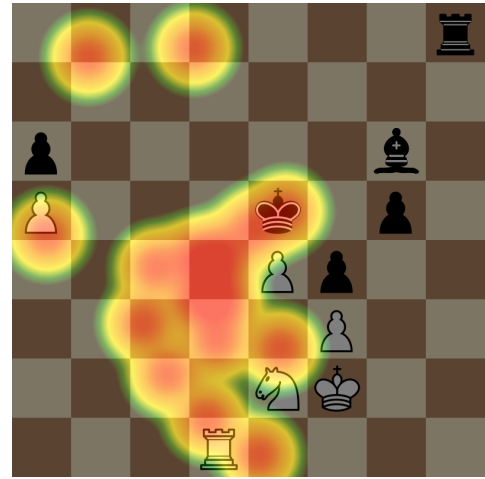

(c) Heatmap do voluntário 8.

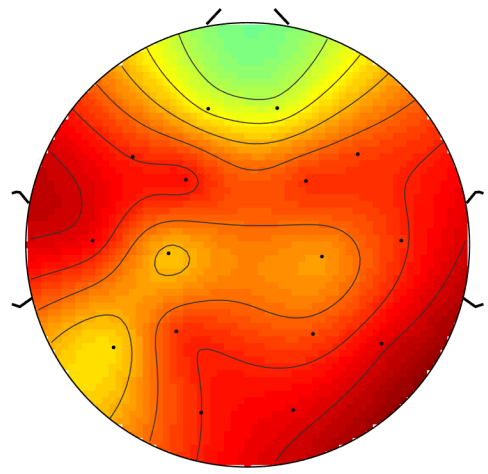

(f) Mapa cerebral do voluntário 8.

Fonte: Autor

\subsubsection{Categoria 3: Reconhecimento de situações de xeque-mate}

A categoria 3 apresenta questões em que o voluntário analisa situações de xeque-mate, em que o rei sofre ameaça de captura e não existe a possibilidade de sair dessa situação, encerrando-se, assim, uma partida de xadrez (VOLKE et al., 2002). A Figura 37 mostra o desempenho de ambos os grupos com relação à quantidade de acertos e tempo médio de resposta.

A Figura 37a mostra que os dois grupos obtiveram bom desempenho para essa categoria, sendo que o grupo mais proficiente teve mais acertos em quase todas as questões, exceto a questão 44, em que o grupo menos proficiente teve um acerto a mais. Comparando-se o tempo médio de resposta entre os dois grupos da Figura 37b, nota-se que o grupo com menor proficiência levou mais tempo para analisar as questões apresentadas e respondê-las, além da diferença entre o voluntário que respondeu mais rapidamente e o que levou mais tempo ser maior para o grupo menos proficiente. 
Figura 37 - Categoria 3.

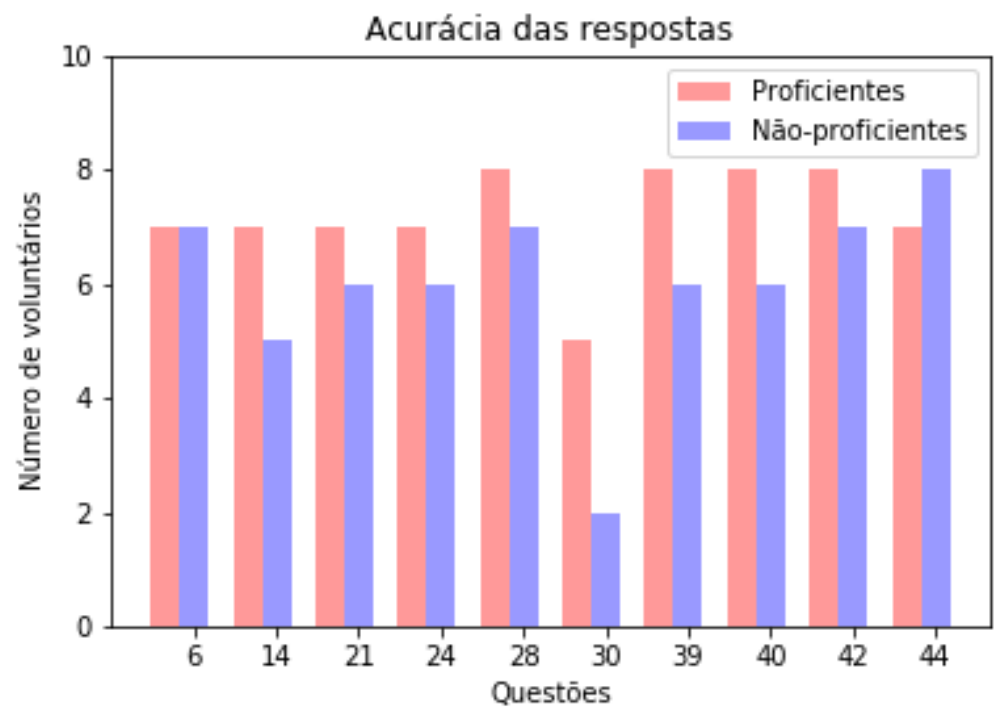

(a) Acurácia das respostas.

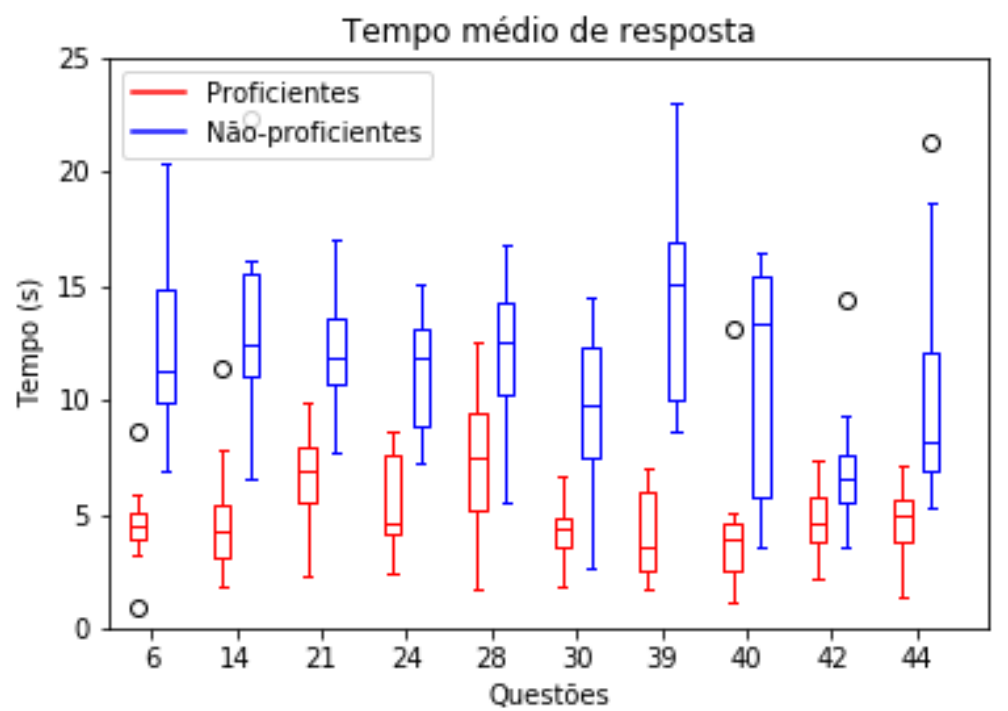

(b) Tempo médio de resposta.

Fonte: Autor

Baseado nas informações fornecidas na Figura 37a, são gerados os hiperplanos de EEG e eye-tracking para a questão 39, em que o grupo mais proficiente teve dois acertos a mais que o outro grupo. A Figura 38 exibe os resultados para essa questão.

Tanto na figura 38c (Classificação de Volke) quanto na Figura 38d (hiperplano eyetracking) observa-se que todos os voluntários foram classificados em seus respectivos grupos, em que não há confusão entre os mesmos. Já a Figura 38b, mostra que existe uma correlação estatisticamente significativa entre essas duas métricas, em que os voluntários 6, 13, 14 e 33, todos do grupo proficiente, tiveram a mesma posição. 
Figura 38 - Classificação de Volke e eye-tracking para questão 39.

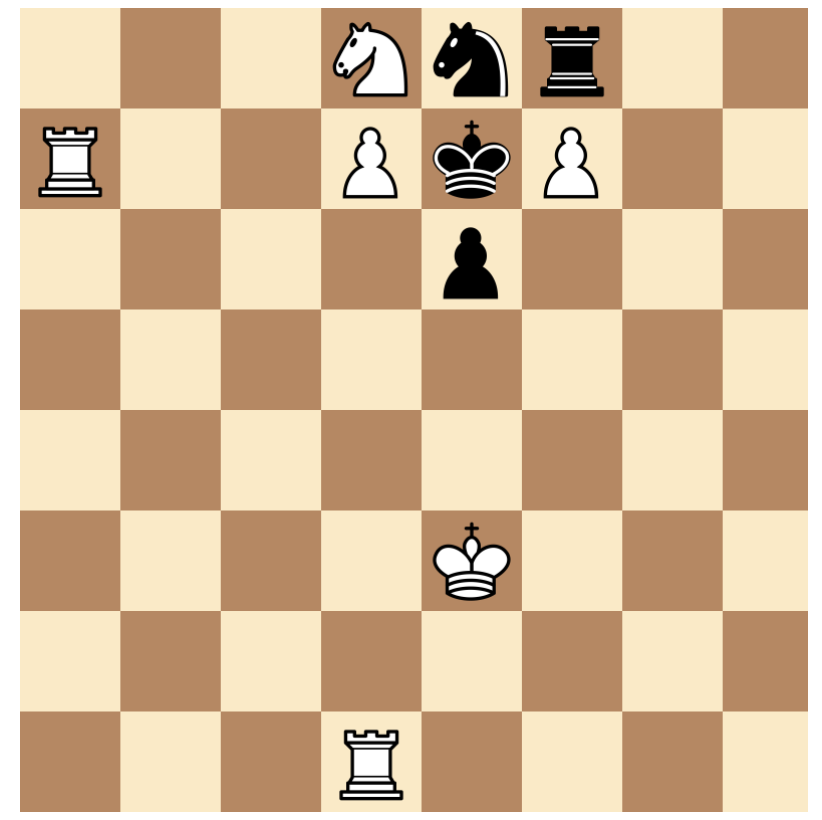

(a) Diagrama da questão 39 - O rei PRETO está em XEQUE-MATE? (Não).

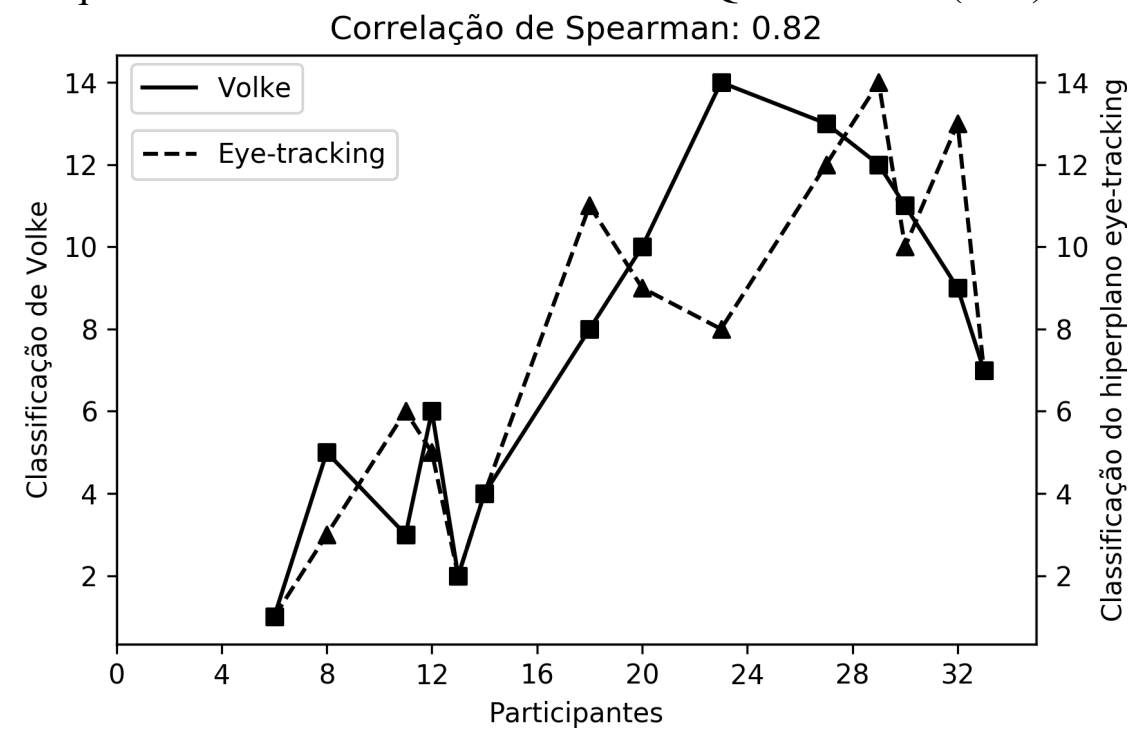

(b) Correlação de Spearman entre hiperplano eye-tracking e classificação de Volke.

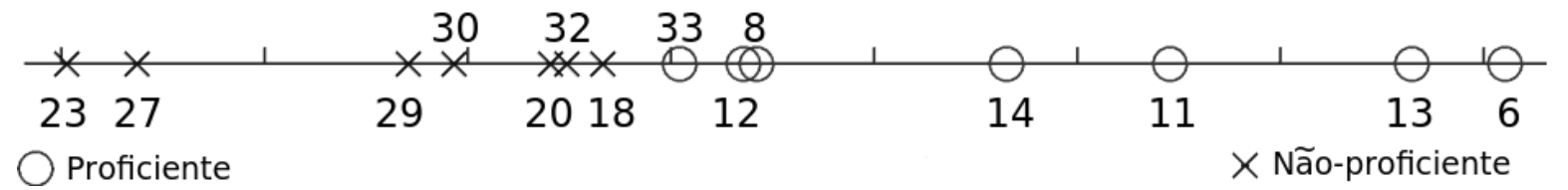

(c) Classificação de Volke.

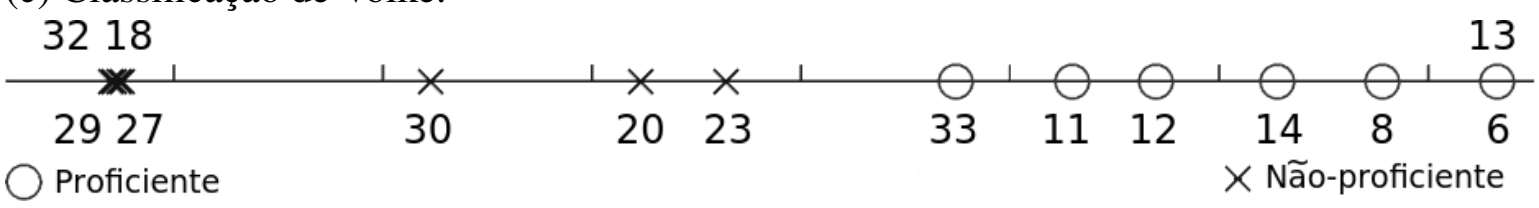

(d) Hiperplano eye-tracking.

Fonte: Autor. 
A Figura 39 exibe os resultados e comparações entre a classificação de Volke e hiperplano EEG.

Nota-se na Figura 39d que, com a exceção do voluntário 12, todos os voluntários foram projetados próximos uns dos outros, sendo assim, não há divisão clara entre os grupos. Como a classificação de Volke (Figura 39c) separou bem os grupos, nota-se na Figura 39b que a correlação entre os métodos é baixa $(0,267)$, apesar de ambos classificarem o voluntário 23 com a pior classificação.

A Figura 40 apresenta a comparação entre os hiperplanos eye-tracking e o hiperplano EEG por meio da correlação de Spearman entre os voluntários que são comuns a ambos.

A Figura 40b mostra que existe uma correlação negativa entre os hiperplano de eyetracking (Figura 40c) e o hiperplano EEG (Figura 40d). A única semelhança em relação à projeção de ambos os grupos é o voluntário 33, conforme exibido na Figura 40b.

De acordo com a projeção dos voluntários exibidas nas Figuras 40c e 40d, a Figura 41 revela os heatmaps e os mapas cerebrais dos voluntários 8, 12 e 27.

A Figura 41c exibe o heatmap do voluntário 8 que focou seus olhares na parte superior central do tabuleiro, canto superior esquerdo, onde se encontra uma torre. De acordo com a Figura 41b, o voluntário 12 também focou seus olhares na parte superior central do tabuleiro, porém não olhou para o canto superior esquerdo. Já na Figura 41a, nota-se que o voluntário 27 também teve a maior parte de seus olhares focados na parte superior do tabuleiro, porém focou em outras áreas. Do ponto de vista do jogo de xadrez, duas condições são necessárias para se checar se uma posição é de xeque-mate: (1) se o rei está ameaçado; e (2) se estiver ameaçado, não pode haver possibilidade de escapar do xeque. Dessa forma, a fixação nas casas que possibilitam fuga é perfeitamente razoável.

O mapa cerebral do voluntário 27 exibido na Figura 41d aponta ativações cerebrais com predominância na região do eletrodo O1, ligado ao córtex ocipital que, por sua vez, é relacionado ao processamento primário da visão (MARTINI; TIMMONS; TALLITSCH, 2009; DE OLIVEIRA, 2001). A Figura 41e revela fortes ativações cerebrais do voluntário 12 em quase todas as áreas, com exceção da região do eletrodo F8. Na Figura 41f nota-se que as principais ativações cerebrais encontram-se na região do eletrodo $\mathrm{O} 1$, assim como ocorreu com o voluntário 27, e do eletrodo T5, correlacionado à área de Brodmann 37, que relaciona-se à função da visão perceptual e função linguística auditiva (ARDILA; BERNAL; ROSSELLI, 2015; HOMAN, 1988). 
Figura 39 - Classificação de Volke e EEG para questão 39.

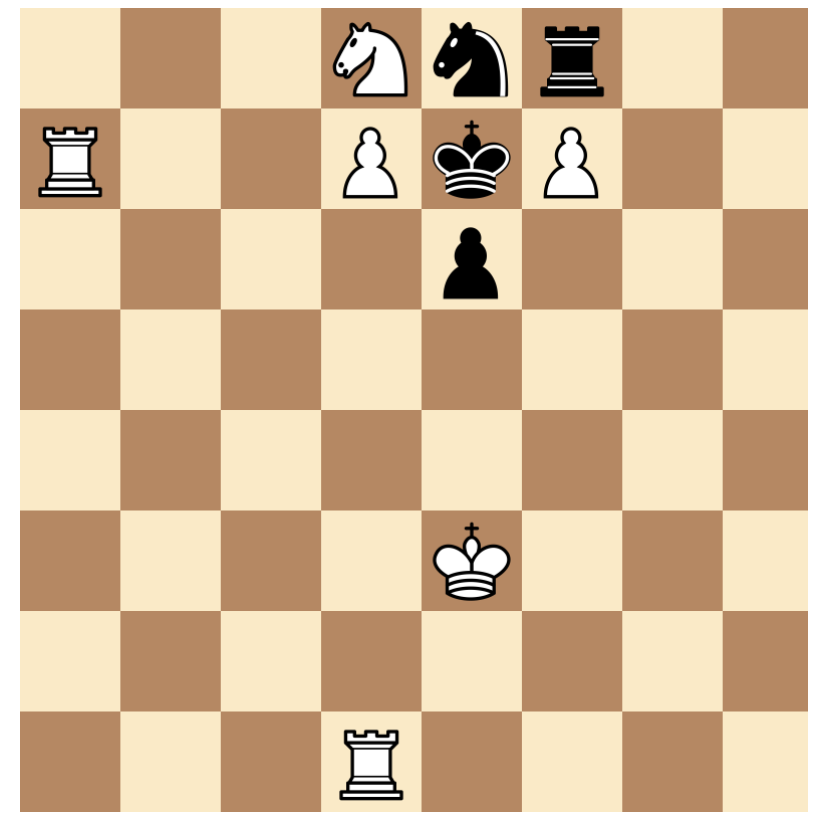

(a) Diagrama da questão 39 - O rei PRETO está em XEQUE-MATE? (Não).

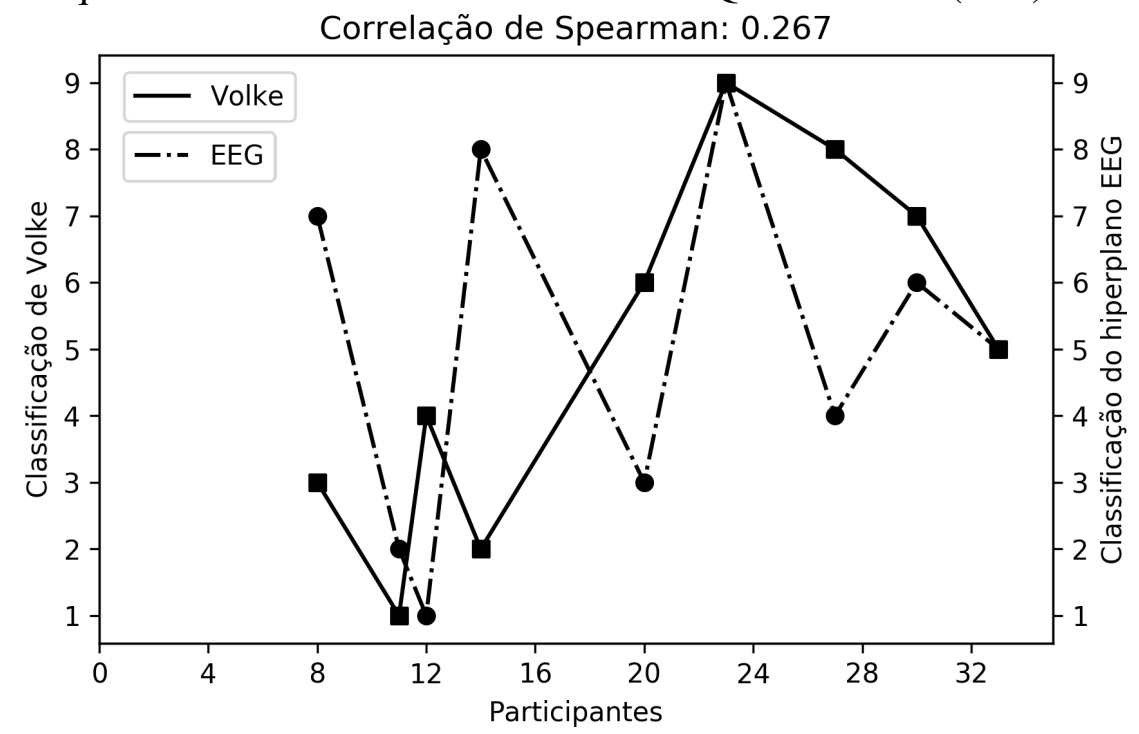

(b) Correlação de Spearman entre hiperplano EEG e classificação de Volke.

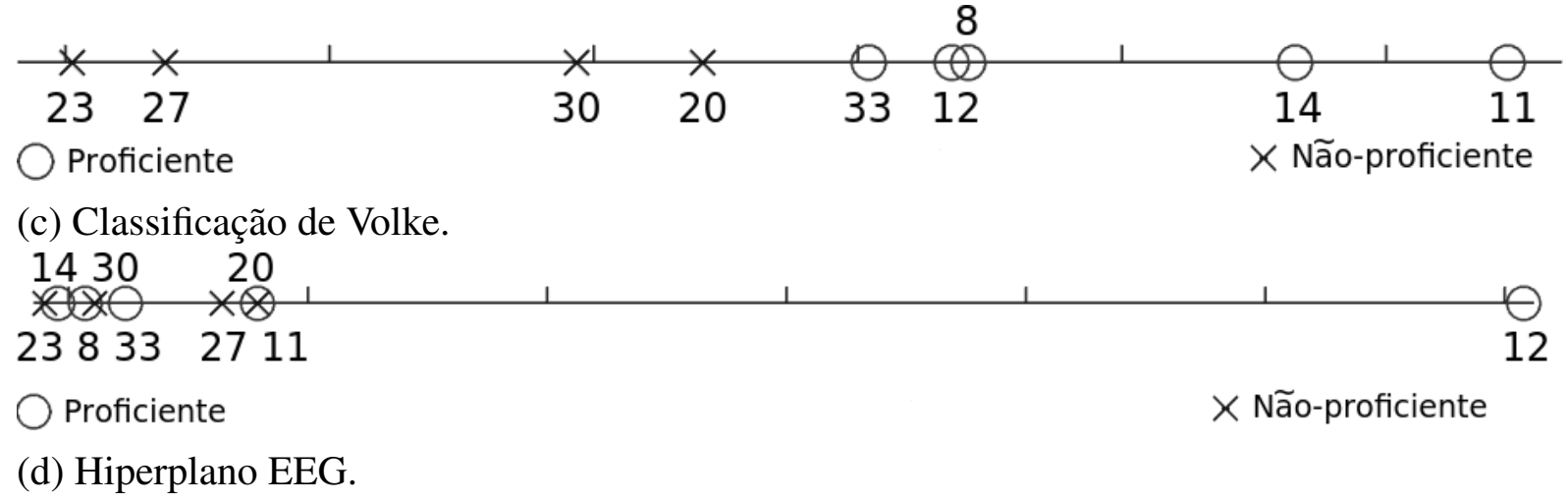

Fonte: Autor. 
Figura 40 - Classificação de eye-tracking e EEG para questão 39.

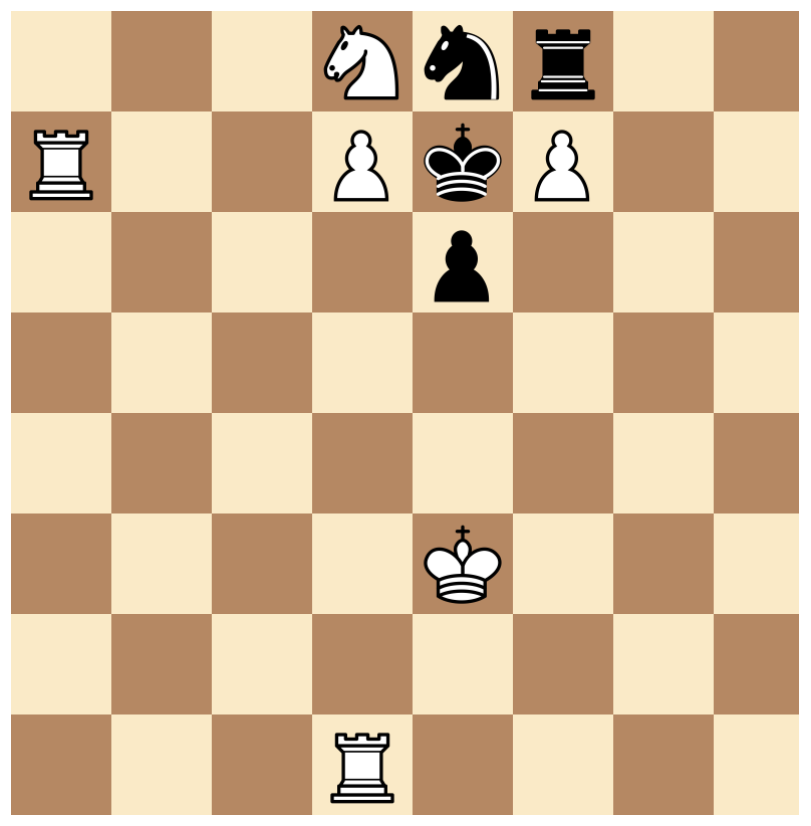

(a) Diagrama da questão 39 - O rei PRETO está em XEQUE-MATE? (Não).

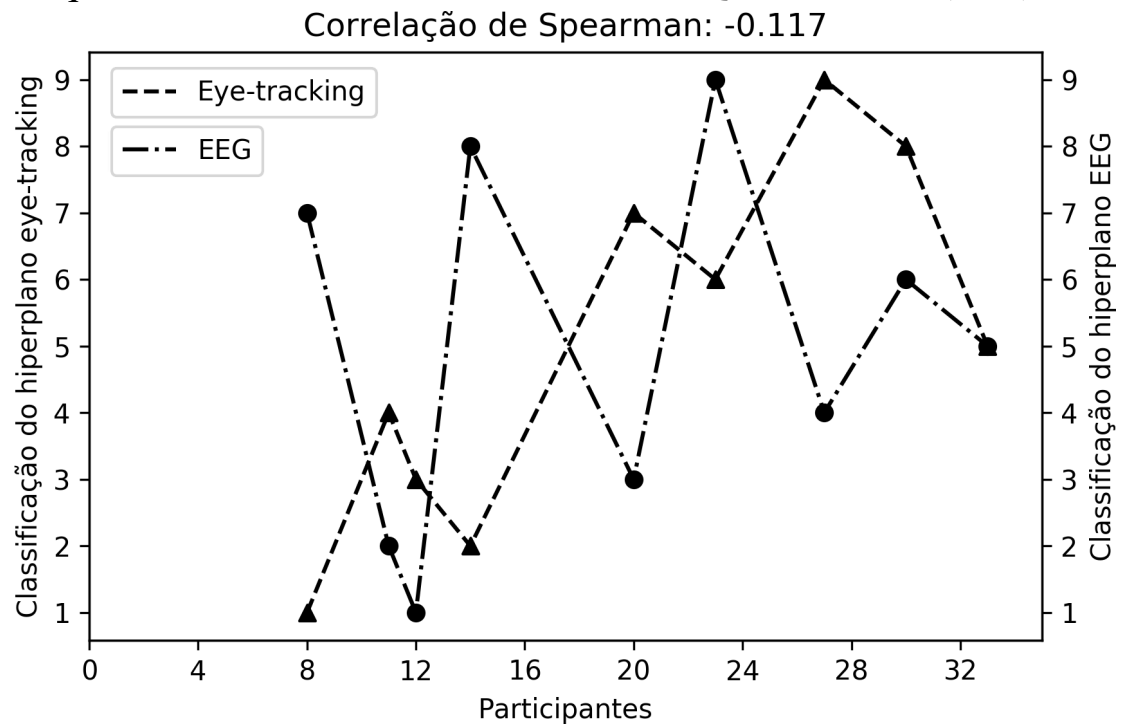

(b) Correlação de Spearman entre hiperplano eye-tracking e EEG.

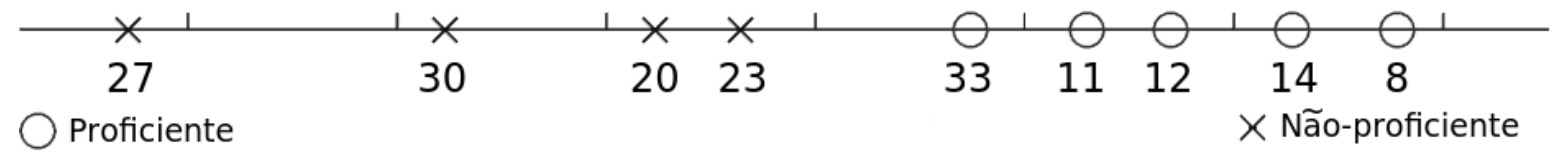

(c) Hiperplano eye-tracking.

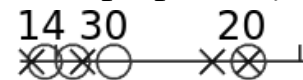

238332711

Proficiente

(d) Hiperplano EEG.

Fonte: Autor. 
Figura 41 - Heatmap e mapas cerebrais para a questão 39.

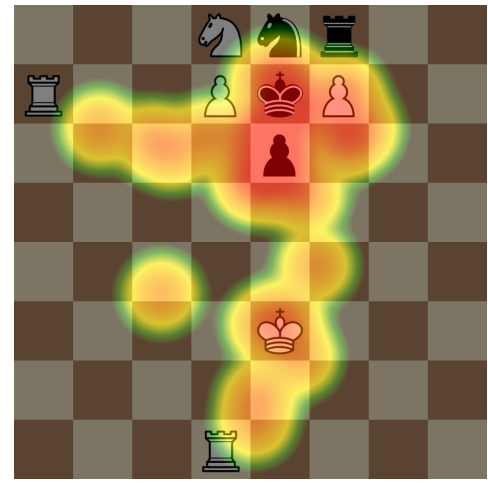

(a) Heatmap do voluntário 27.

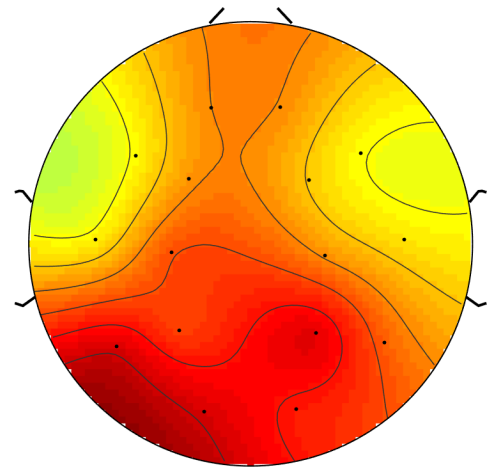

(d) Mapa cerebral do voluntário 27.

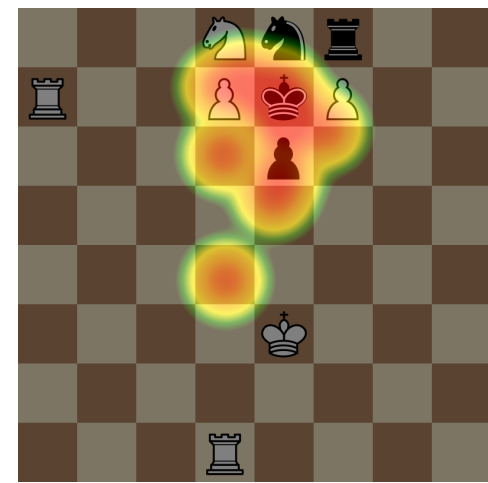

(b) Heatmap do voluntário 12.

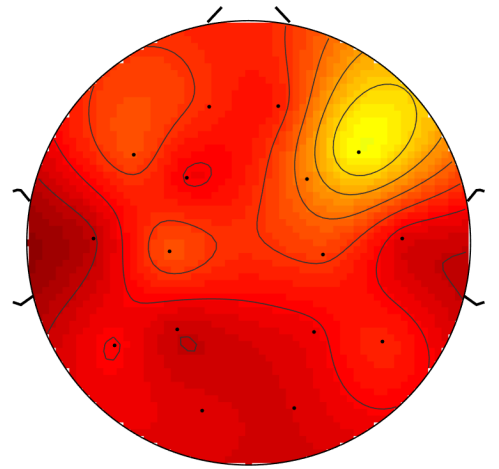

(e) Mapa cerebral do voluntário 12 .

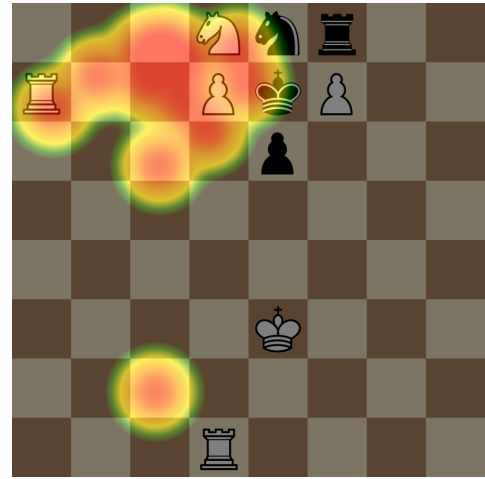

(c) Heatmap do voluntário 8.

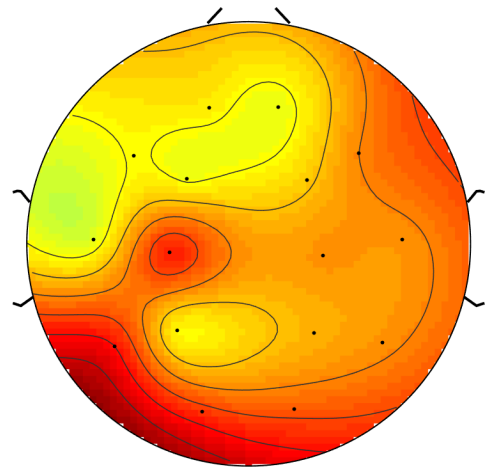

(f) Mapa cerebral do voluntário 8.

Fonte: Autor.

Semelhante à categoria 2 apresentada anteriormente, a categoria 3 é composta por questões que exigem que o voluntário conheça a regra de xeque-mate do jogo de xadrez e identifique se essa regra é aplicável para a situação específica apresentada. Na Figura 41 vemos que o mapa cerebral do voluntário 12 (Figura 41e), voluntário com melhor separação no hiperplano EEG, apresentou diferenças em relação aos demais e, apesar de seu heatmap ser similar ao do voluntário 8 (Figura 41f) sua classificação no hiperplano eye-tracking é inferior por não ter olhado o canto superior esquerdo.

\subsubsection{Categoria 4: Possibilidade de xeque-mate em um lance}

Essa categoria consiste em analisar o diagrama apresentado e verificar se uma peça pode realizar um único movimento que acarrete em uma jogada chamada de xeque-mate (VOLKE et al., 2002). A Figura 42 mostra o desempenho de ambos os grupos com relação à quantidade de acertos e tempo médio de resposta. 
Figura 42 - Categoria 4.

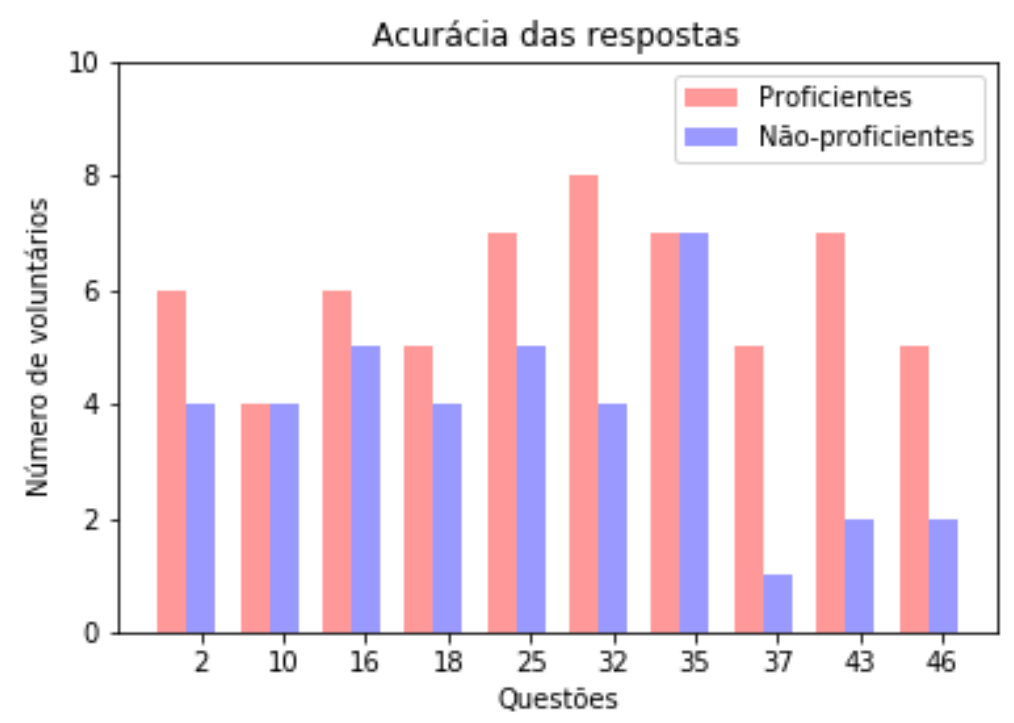

(a) Acurácia das respostas.

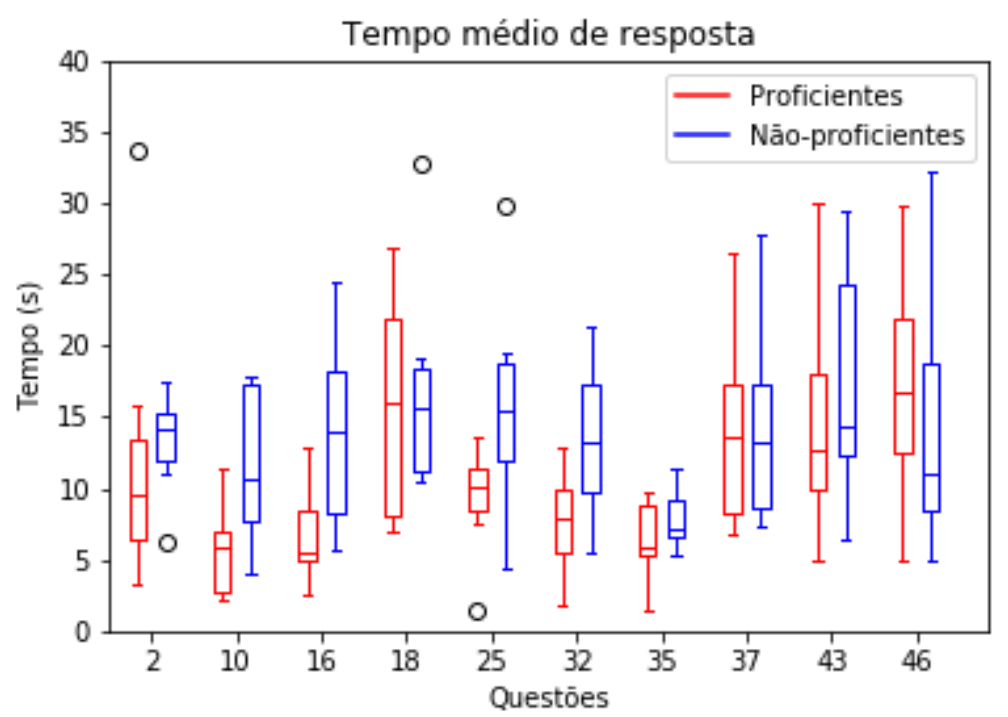

(b) Tempo médio de resposta.

Fonte: Autor

Essa categoria de questões é considerada a mais difícil dentre as categorias que foram selecionadas para realização dos experimentos. Os gráficos apresentados na Figura 42 retratam sua dificuldade, em que somente a questão 32 teve 100\% de acurácia do grupo de maior proficiência enquanto que o grupo de menor proficiência teve em sua maioria $50 \%$ ou menos de voluntários que responderam corretamente as questões, além do tempo médio de resposta ser maior que em todas as outras categorias, indicando que houve maior esforço dos voluntários para analisar as questões e solucioná-las. 
Baseado nas informações fornecidas na Figura 42, são gerados os hiperplanos de EEG e eye-tracking para a questão 37. Essa foi a questão que teve a menor acurácia dentre todas as questões do experimento. A Figura 43 exibe a comparação entre a classificação de Volke e hiperplano eye-tracking.

Para essa questão, o hiperplano eye-tracking (Figura 43c) separou todos os voluntários linearmente em dois grupos, porém a classificação de Volke considerou os voluntários 8, 11 e 12 (proficientes) como voluntários não-proficientes e o voluntário 30 (não-proficiente) como proficiente. Essa diferença entre os dois explica a baixa correlação mostrada na Figura 28b.

A Figura 44 exibe a comparação entre a classificação de Volke e o hiperplano EEG para a questão 37.

Assim como ocorreu com a classificação de Volke, o hiperplano EEG (Figura 44d) também apresentou confusão na classificação dos voluntários, em que os voluntários 6 e 8, que fazem parte do grupo proficiente, foram projetados entre os voluntários não-proficientes e o voluntário 11 teve a melhor classificação no hiperplano EEG e a pior classificação de Volke. Essa confusão entre ambas as métricas explica a baixa correlação entre elas, sendo, inclusive, negativa, conforme mostrado na Figura 34b.

A Figura 45 exibe a comparação entre o hiperplano eye-tracking e hiperplano EEG para a questão 37 relacionando os voluntários que são comuns a ambos.

Comparando-se os hiperplanos eye-tracking (Figura 45c) e o hiperplano EEG (Figura 45d) nota-se que não houve posições similares e que, mais do que isso, algumas posições são inversas. O voluntário 11 foi classificado com a melhor posição no hiperplano EEG e com a pior posição entre os voluntários proficientes no hiperplano eye-tracking. O voluntário 23 teve a pior classificação no hiperplano EEG e teve a melhor classificação entre os voluntários não-proficientes no hiperplano eye-tracking. Essas diferenças explicam a baixa correlação entre esses hiperplanos, conforme exibido na Figura 45b.

A Figura 46 mostra os mapas cerebrais e os heatmaps dos voluntários 8, 11 e 20 .

As Figuras 46a, 46b e 46c mostram heatmaps similares para os voluntários 20, 11 e 8 respectivamente, em que apenas o voluntário 20 focou seus olhares na parte central superior do diagrama. Os mapas cerebrais são distintos entre si. A Figura 46d mostra que o voluntário 20 teve suas principais ativações na área do eletrodo T3, associado à área de Brodmann 21, com a função de produzir palavras e sentenças (HOLODNY, 2018; HOMAN, 1988). O voluntário 11 (Figura 46e) teve ativações predominantemente na região ocipital, eletrodos $\mathrm{O} 1$ e O2, re- 
Figura 43 - Classificação de Volke e eye-tracking para questão 37.

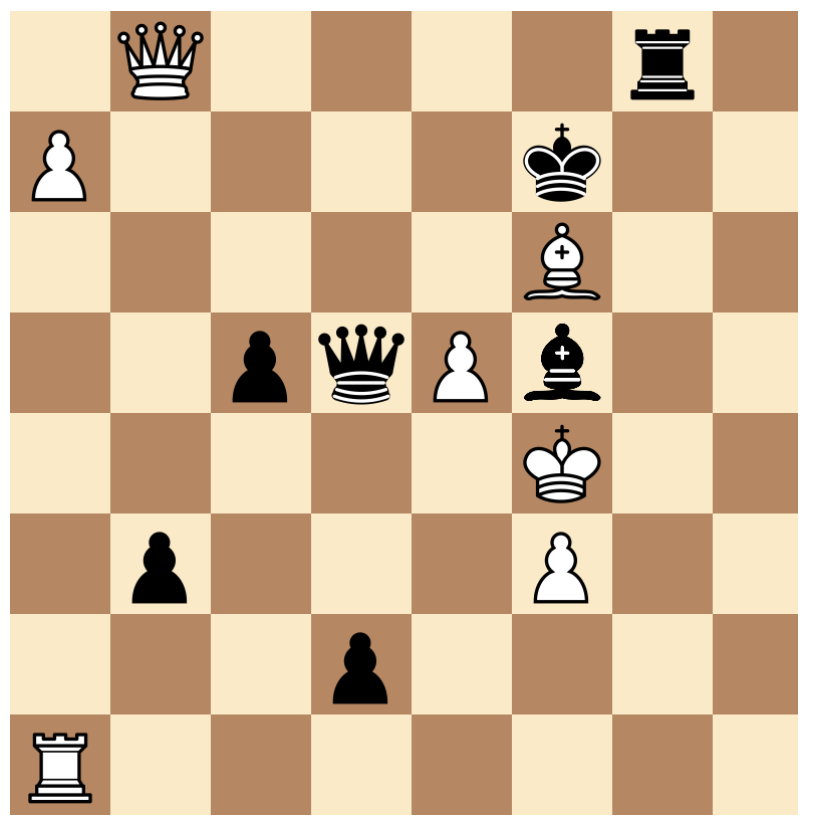

(a) Diagrama da questão 37 - A DAMA PRETA pode dar MATE em UMA jogada? (Não). Correlação de Spearman: 0.13

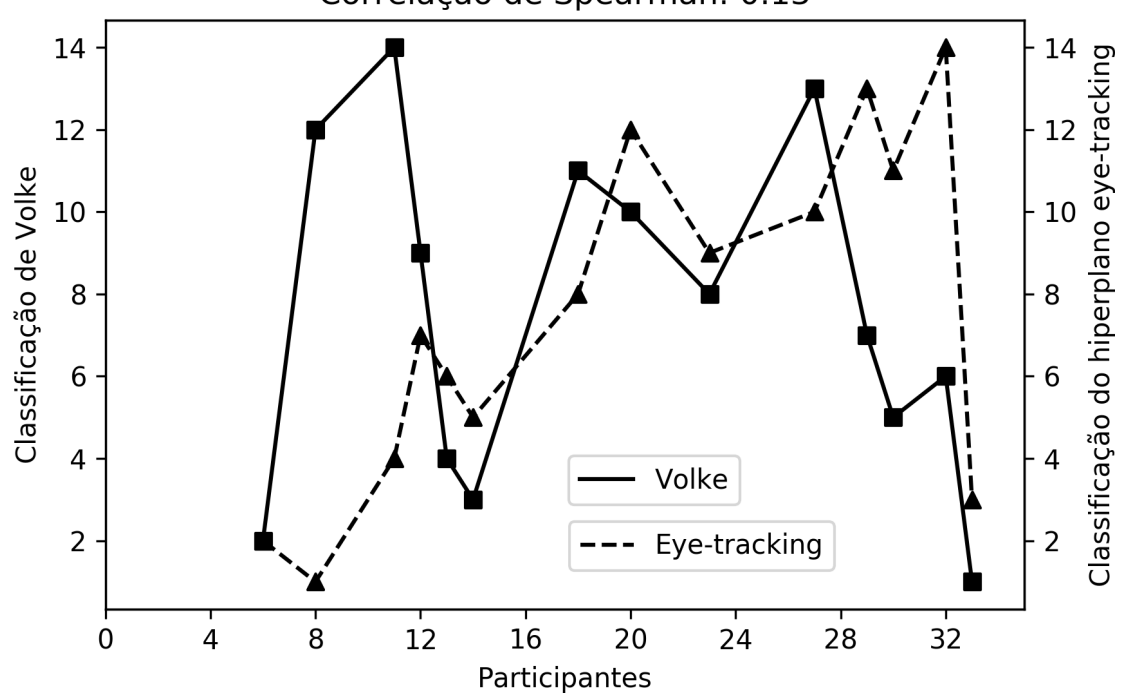

(b) Correlação de Spearman entre hiperplano eye-tracking e classificação de Volke.

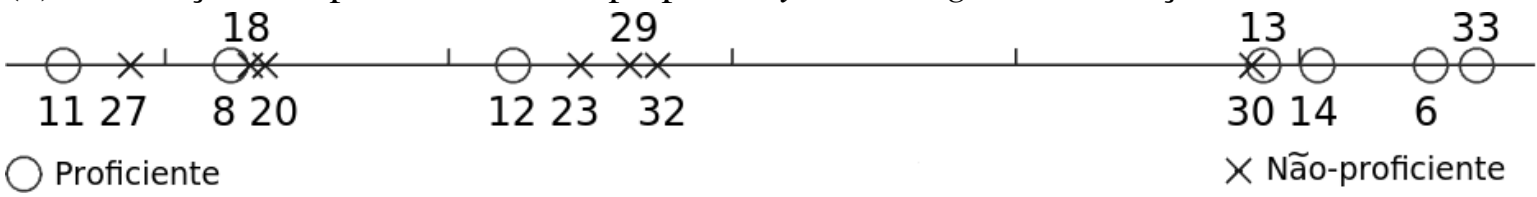

(c) Classificação de Volke.

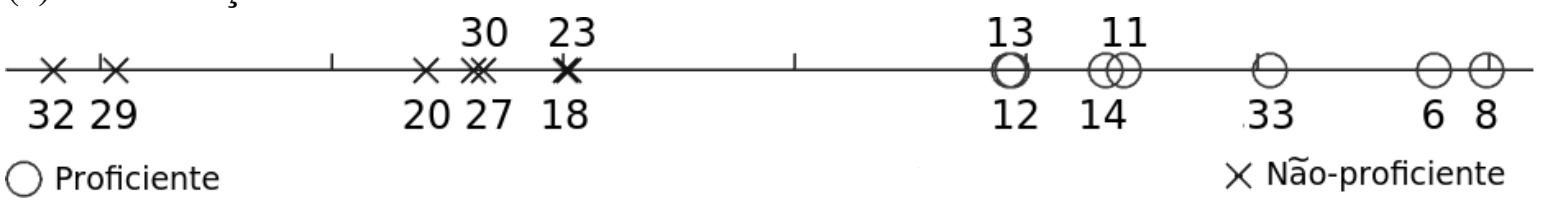

(d) Hiperplano eye-tracking.

Fonte: Autor. 
Figura 44 - Classificação de Volke e EEG para questão 37.

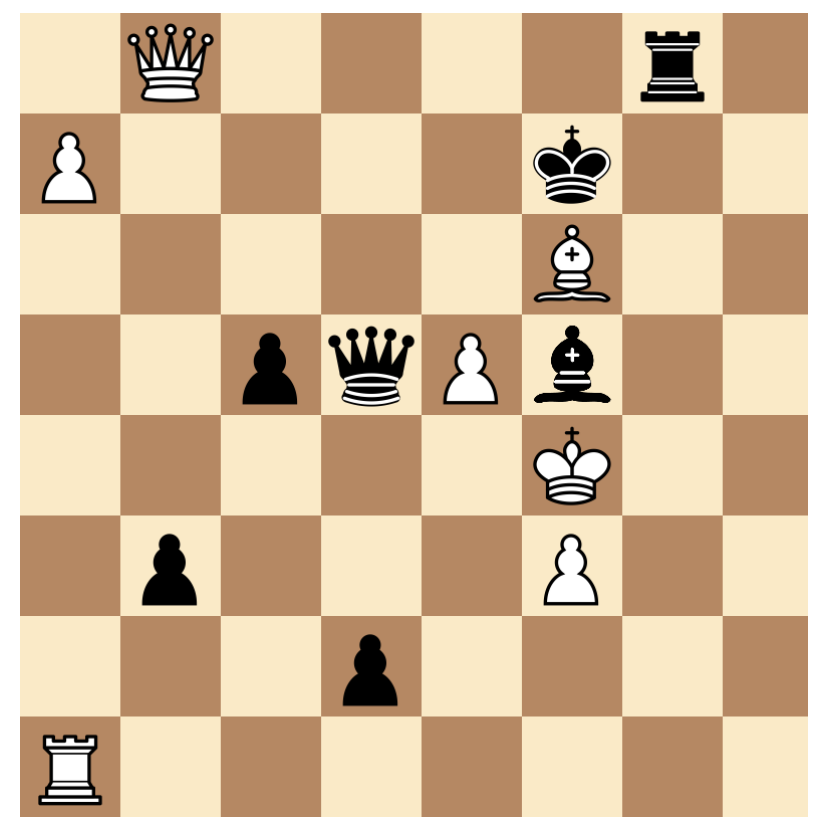

(a) Diagrama da questão 37 - A DAMA PRETA pode dar MATE em UMA jogada? (Não). Correlação de Spearman: -0.333

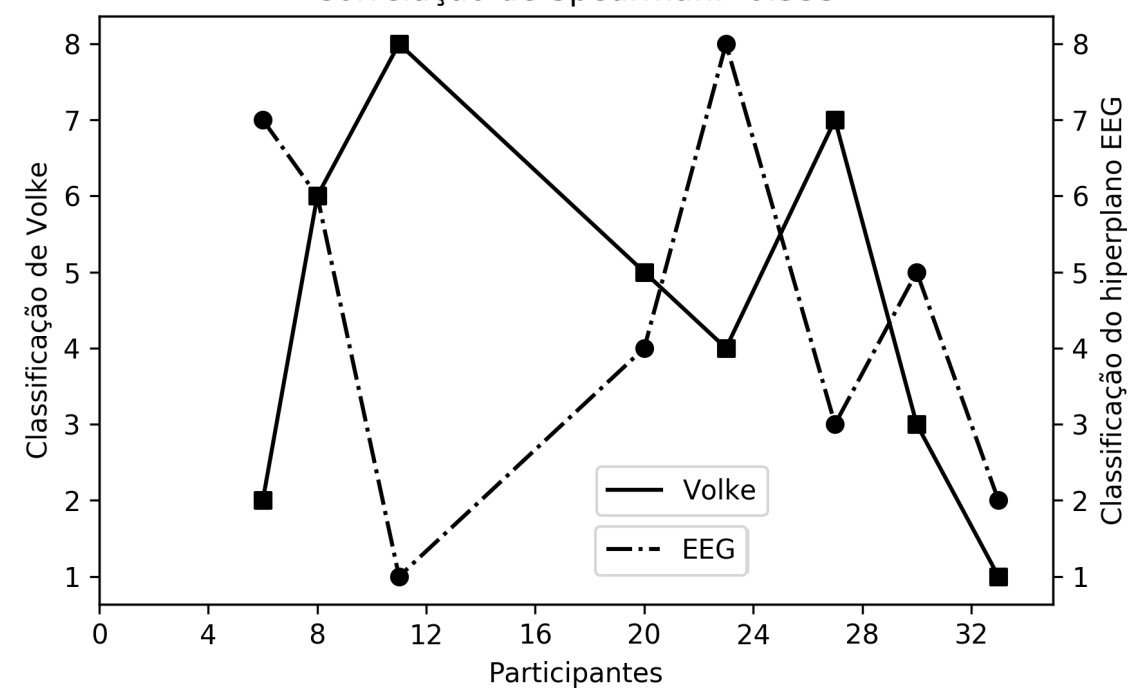

(b) Correlação de Spearman entre hiperplano EEG e classificação de Volke.

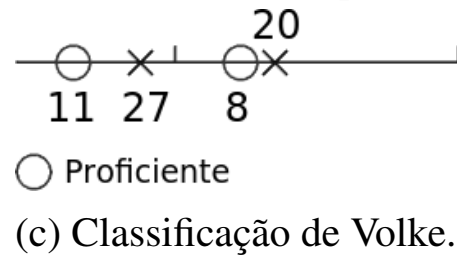

6

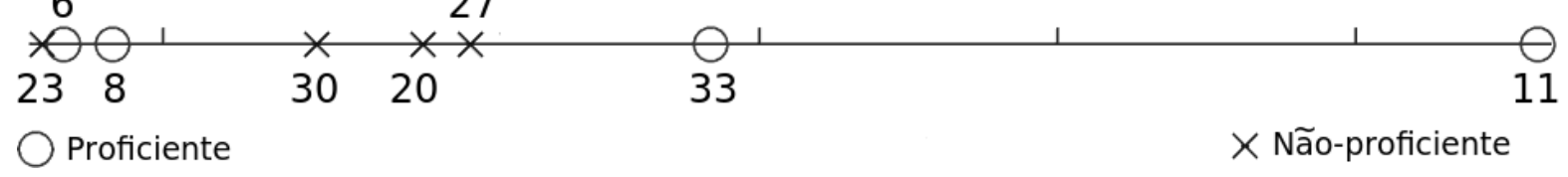

(d) Hiperplano EEG.

Fonte: Autor. 
Figura 45 - Classificação de eye-tracking e EEG para questão 37.

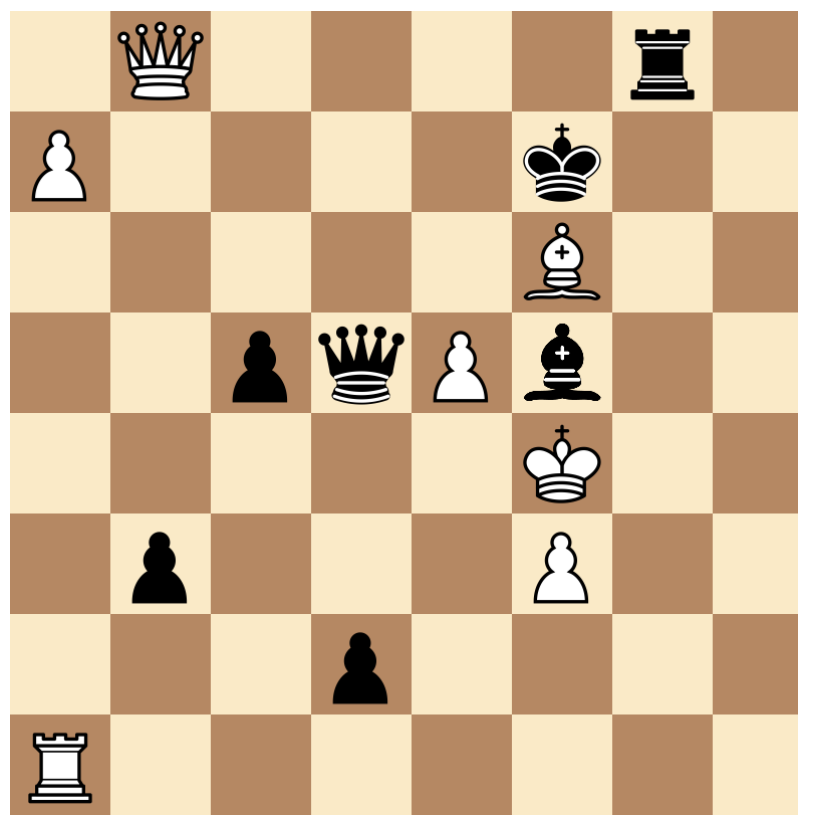

(a) Diagrama da questão 37 - A DAMA PRETA pode dar MATE em UMA jogada? (Não). Correlação de Spearman: -0.167

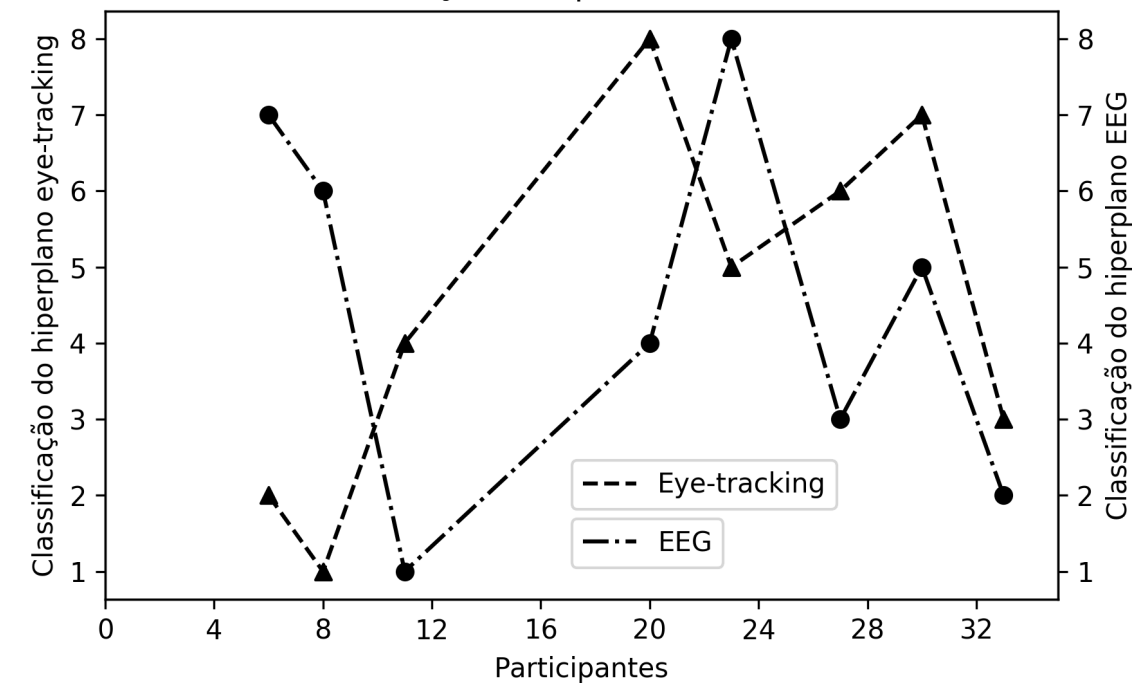

(b) Correlação de Spearman entre hiperplano eye-tracking e EEG.

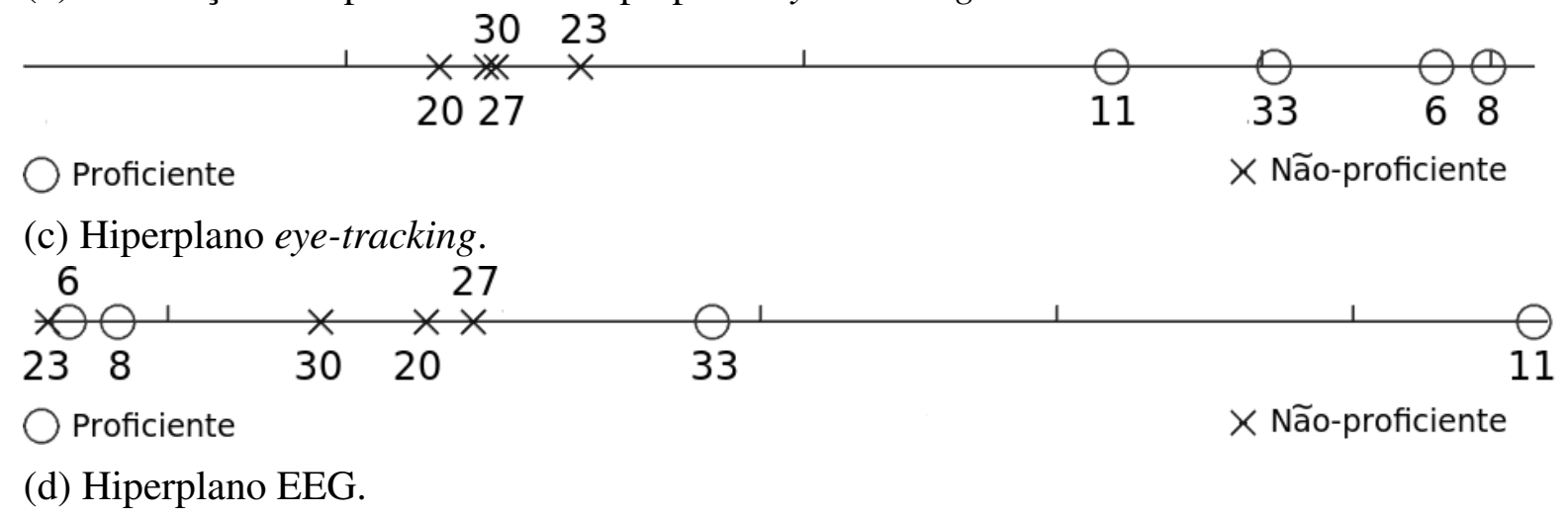

Fonte: Autor. 
Figura 46 - Heatmap e mapas cerebrais para a questão 37.

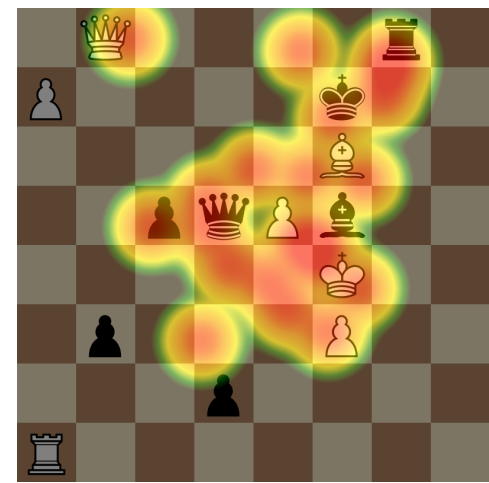

(a) Heatmap do voluntário 20.

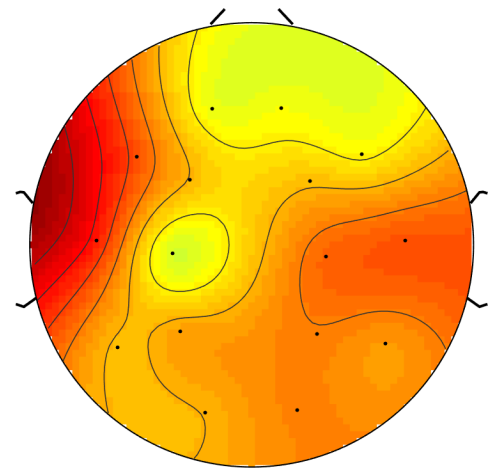

(d) Mapa cerebral do voluntário 20.

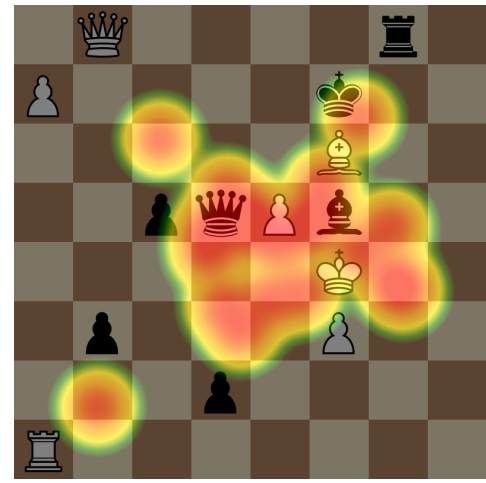

(b) Heatmap do voluntário 11.

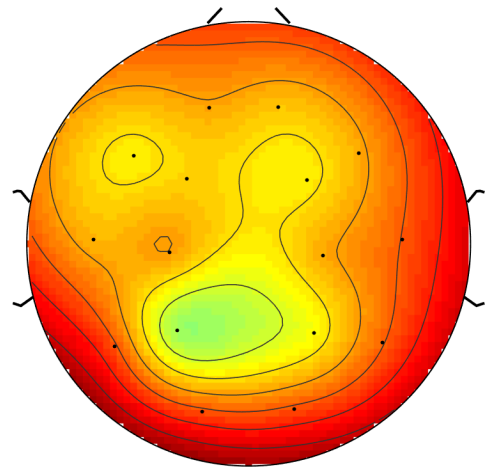

(e) Mapa cerebral do voluntário 11.

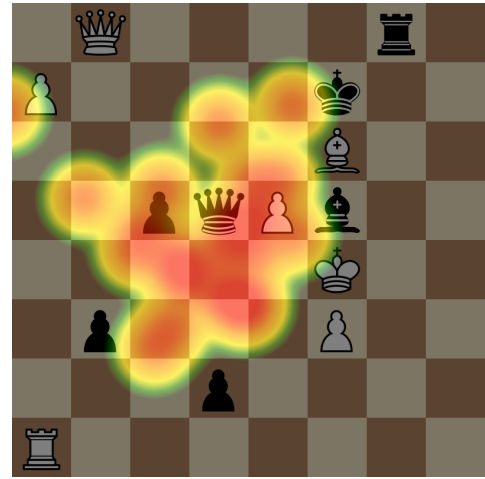

(c) Heatmap do voluntário 8.

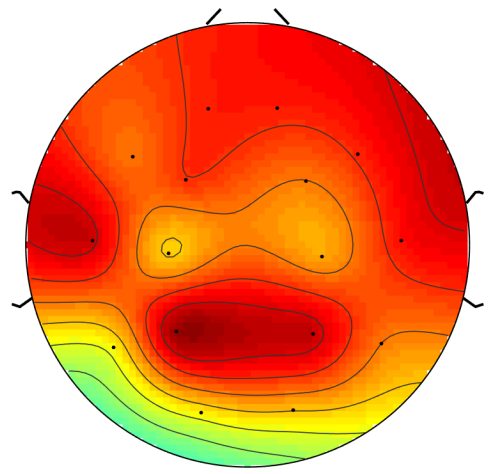

(f) Mapa cerebral do voluntário 8.

Fonte: Autor

lacionada ao processamento primário da visão e na área do eletrodo T6, aŕeas 19, 37 e 39 de Brodmann, que pode estar associado ao processamento de imagens (MARTINI; TIMMONS; TALLITSCH, 2009; DE OLIVEIRA, 2001; VANDENBERGHE et al., 1996; HOMAN, 1988). Já o voluntário 8 teve suas principais ativações próximas aos eletrodos P3, P4, T3 e T4, área chamada de parieto-temporal, relacionada ao armazenamento de localização de objetos e sinais que chamam atenção de uma pessoa (SANTANGELO; MACALUSO, 2013).

\subsubsection{Categoria 5: Conhecimento de jogadas e possibilidade de captura de peças}

A categoria 5 baseia-se no experimento realizado por Nichelli et al. (1994), em que o voluntário analisa um único movimento de uma única peça e responde se esse movimento é possível de ser realizado ou não. A Figura 47 mostra o desempenho de ambos os grupos com relação à quantidade de acertos e tempo médio de resposta. 
Figura 47 - Categoria 5.

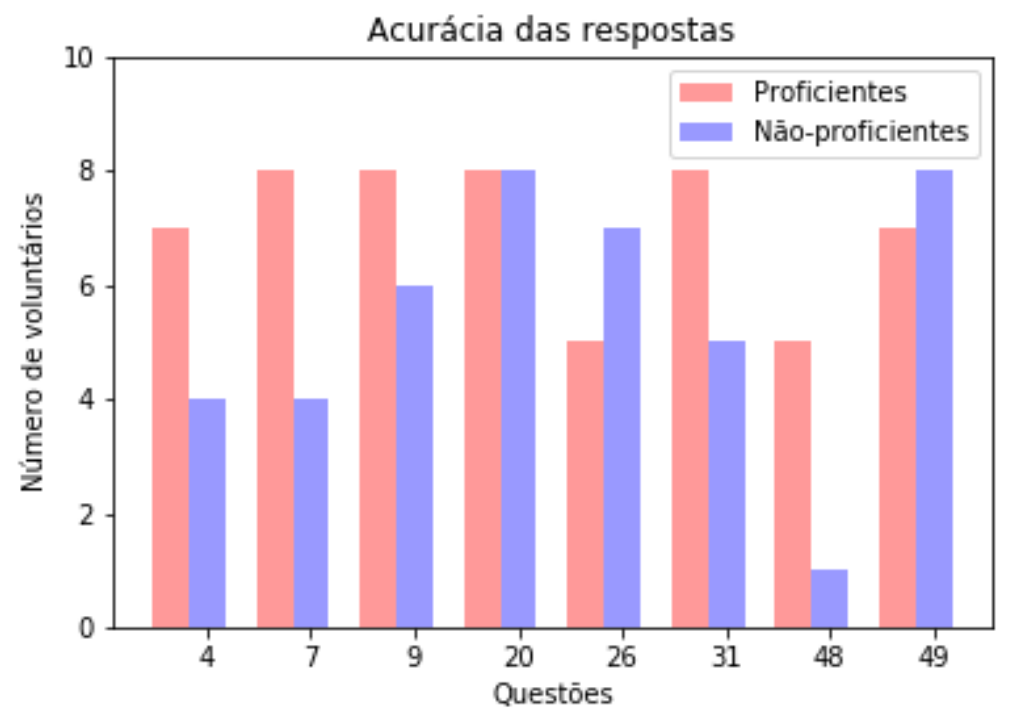

(a) Acurácia das respostas.

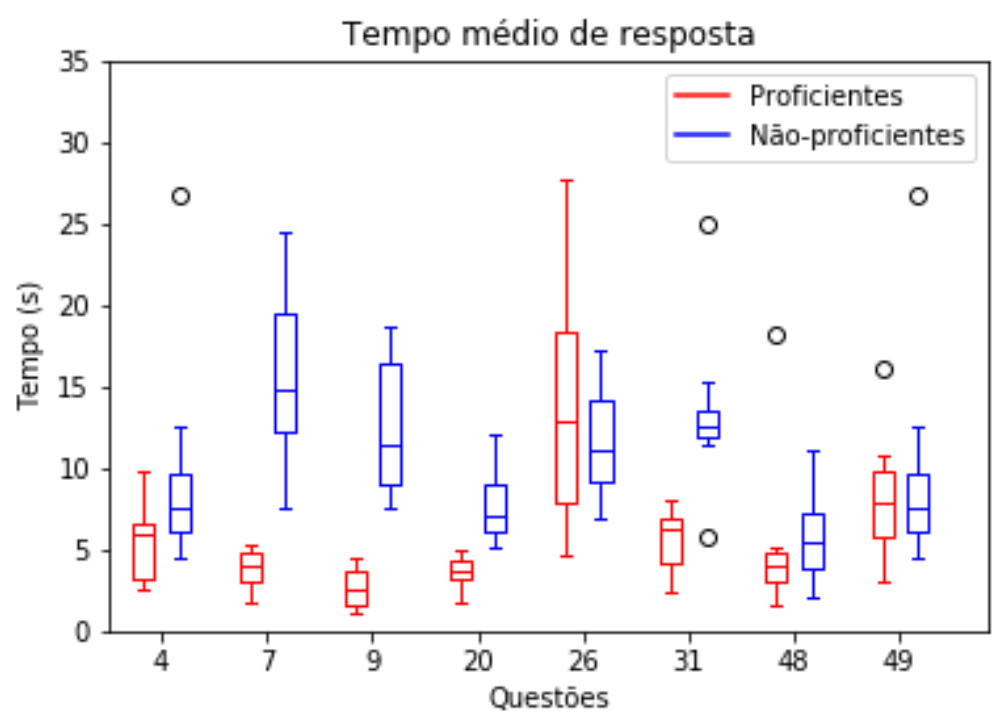

(b) Tempo médio de resposta.

Fonte: Autor

De acordo com a Figura 47a, verifica-se que, para a categoria 5, a quantidade de acertos por questão variou para os dois grupos e que, em sua maioria, o grupo mais proficiente teve melhor desempenho. Dentre as questões apresentadas, destacam-se as questões 4, 7, 31 e 48 pela diferença de acertos entre os grupos. Com relação ao tempo médio de resposta observado na Figura 47b, observa-se que o grupo mais proficiente demandou menos tempo para responder à maioria das questões, sendo que a exceção é a questão 26.

Baseado nas informações fornecidas na Figura 47, são gerados os hiperplanos de EEG e eye-tracking para a questão 48, na qual o grupo mais proficiente teve quatro acertos a mais que 
o outro grupo. A Figura 48 mostra o hiperplano de eye-tracking e classificação de Volke para essa questão.

Por meio da Figura 48b nota-se que a correlação de Spearman não é estatisticamente significante $(0,371)$. Para explicar essa baixa correlação, verifica-se na Figura 48c que os voluntários 12 e 33 (proficientes) foram classificados entre a maioria dos voluntários não-proficientes e o voluntário 27 (não-proficiente) entre os voluntários proficientes. Na Figura 48d, nota-se que todos voluntários proficientes foram projetados à direita do hiperplano e os não-proficientes à esquerda.

A comparação entre a classificação de Volke e o hiperplano EEG é exibida na Figura 49.

A Figura 49d mostra que os voluntários 11 e 14, proficientes, foram projetados no hiperplano EEG próximos aos voluntários não-proficientes. Comparando-se ambos os métodos, nota-se que a classificação de Volke (Figura 49c) classificou o voluntário 27 com o pior desempenho entre o grupo não-proficiente e o voluntário 14 com o melhor desempenho entre os voluntários proficientes. Para esses mesmos voluntários, a projeção do hiperplano EEG (Figura 49d) foi contrária, sendo que ambos os voluntários tiveram a pior classificação em seus respectivos grupos. Essas diferenças realçam a correlação de Spearman mostrada na Figura 49b.

Na Figura 50 são analisados e comparados os hiperplanos eye-tracking e hiperplano EEG entre si.

Assim como ocorreu na comparação de Volke e hiperplano EEG, o voluntário 14 foi projetado de forma contrária nos hiperplanos, em que a projeção no hiperplano EEG (Figura 50d) foi mais a esquerda e no hiperplano eye-tracking (Figura 50c) mais a direita. A única semelhança entre os hiperplanos é a projeção do voluntário 12, que teve a segunda melhor classificação. A diferença das classificações em ambos os hiperplanos para essa questão resulta em baixa correlação entre eles, conforme mostrado na Figura 50b.

A Figura 51 exibe os mapas cerebrais e os heatmaps dos voluntários 6, 14 e 23.

A Figura 51 mostra que mapas cerebrais são distintos entre si enquanto os heatmaps são semelhantes. Analisando-se os heatmaps, todos os voluntários focaram seus olhares na parte central do tabuleiro onde encontra-se a peça de xadrez referente à pergunta, a exceção é feita ao voluntário 23, que além focar no centro, focou também no canto esquerdo do tabuleiro (Figura 51a). Para essa questão, há 5 xeques diferentes com a dama: Dxe5; Dxf3; Dc4; Dd4; De4. As fixações nestas casas são importantes para responder à pergunta. A fixação na torre preta de g8 
Figura 48 - Classificação de Volke e eye-tracking para questão 48.

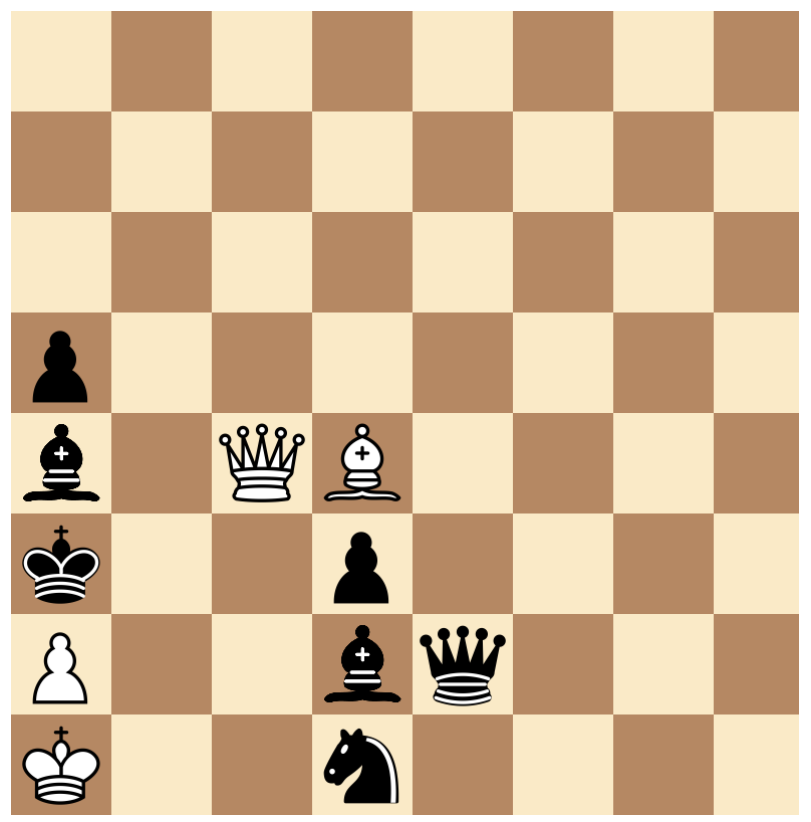

(a) Diagrama da questão 48 - O PEÃO PRETO consegue CAPTURAR a DAMA BRANCA? (Não).

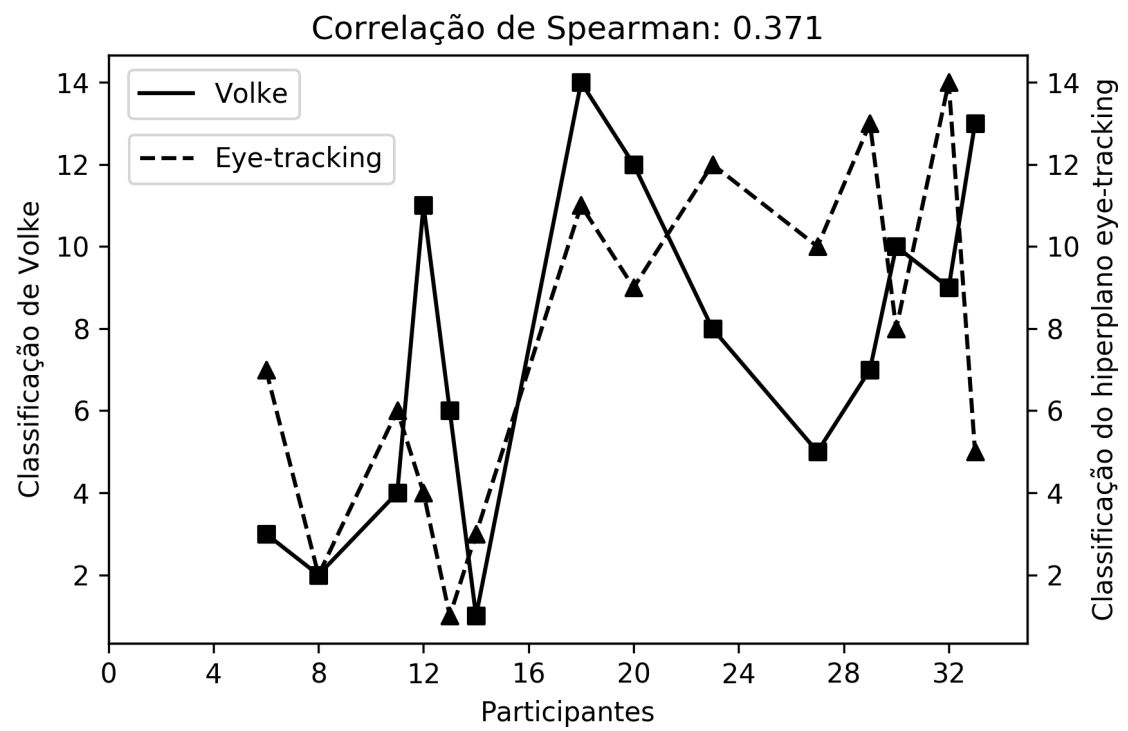

(b) Correlação de Spearman entre hiperplano eye-tracking e classificação de Volke.

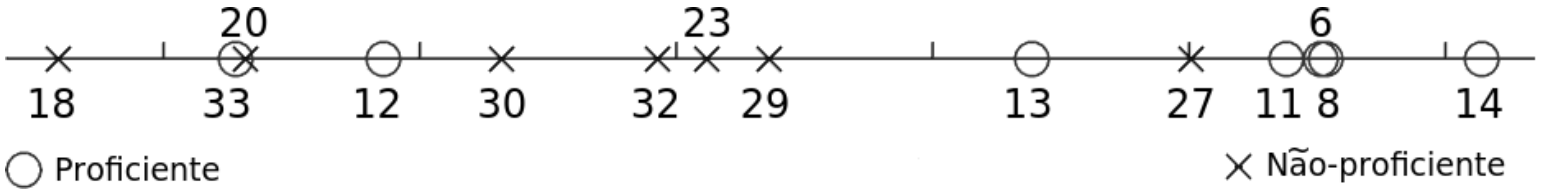

(c) Classificação de Volke.

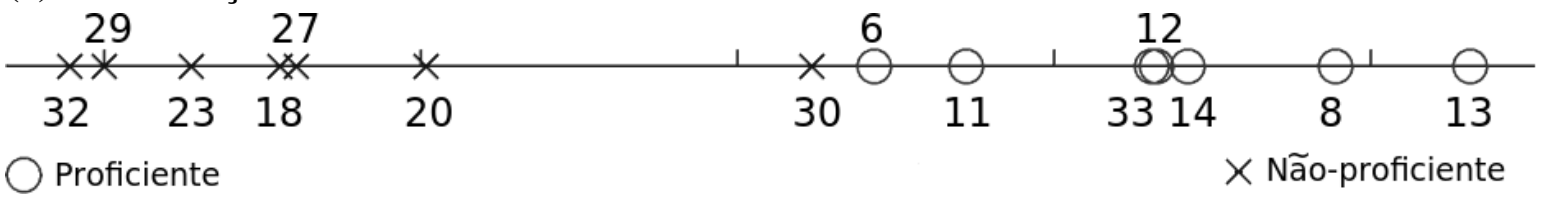

(d) Hiperplano eye-tracking.

Fonte: Autor 
Figura 49 - Classificação de Volke e EEG para questão 48.

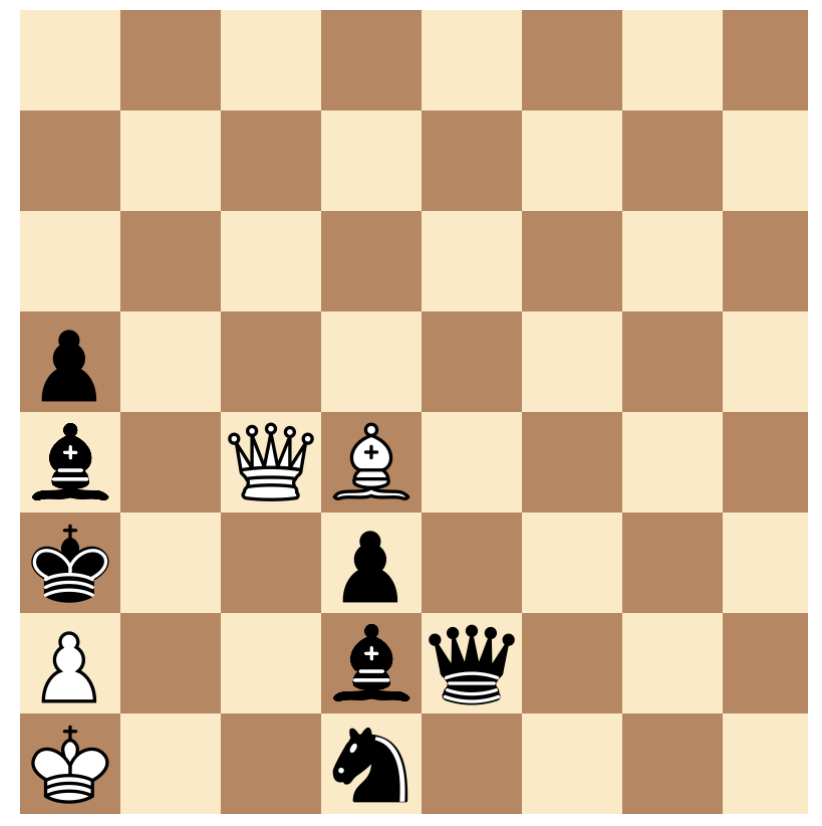

(a) Diagrama da questão 48 - O PEÃO PRETO consegue CAPTURAR a DAMA BRANCA? (Não).

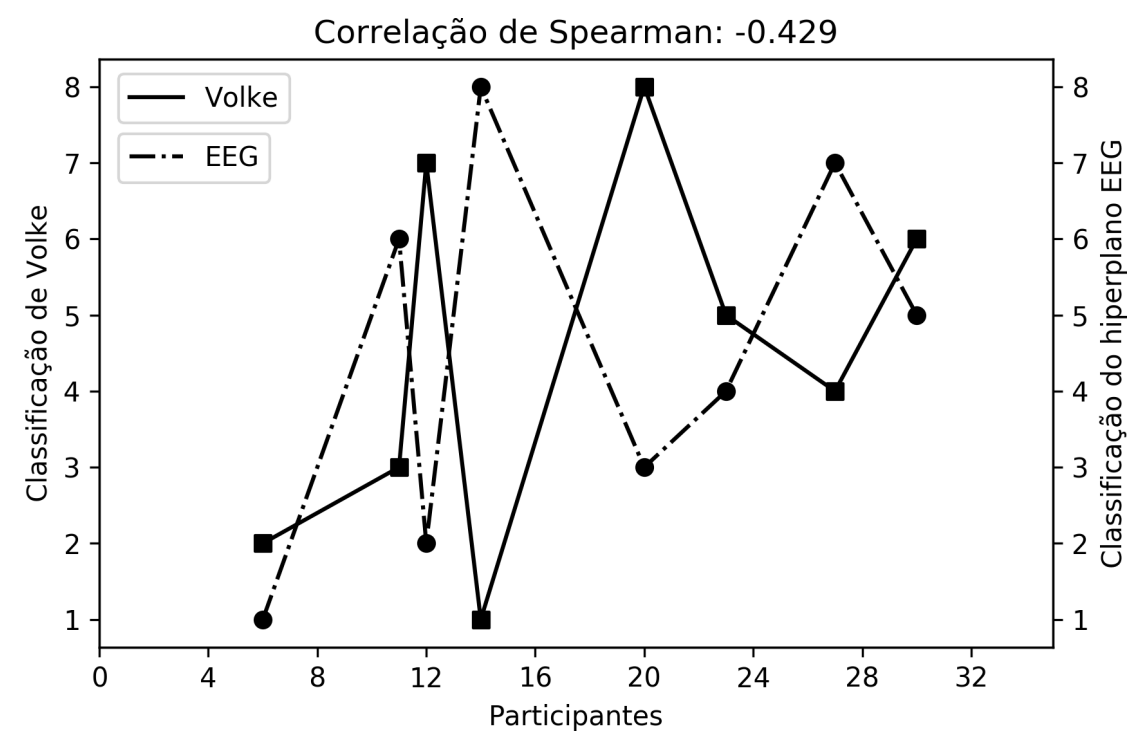

(b) Correlação de Spearman entre hiperplano EEG e classificação de Volke.

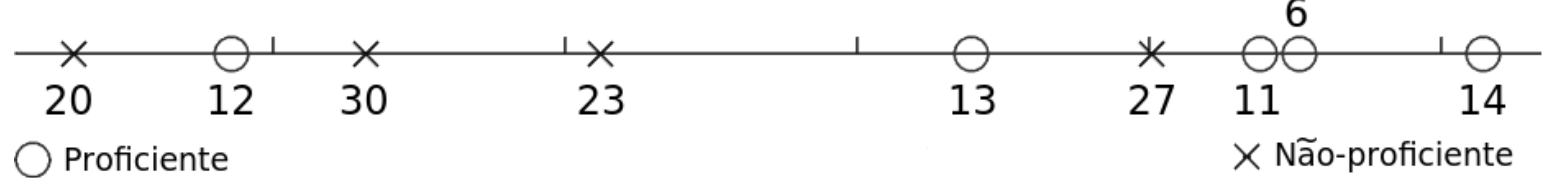

(c) Classificação de Volke.

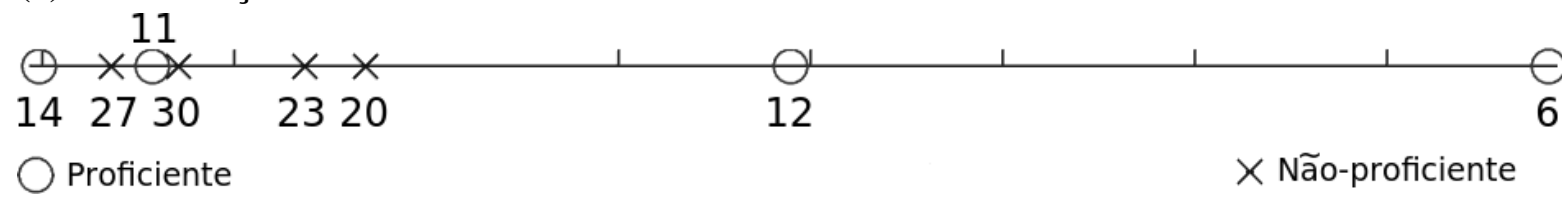

(d) Hiperplano EEG.

Fonte: Autor 
Figura 50 - Classificação de eye-tracking e EEG para questão 48.

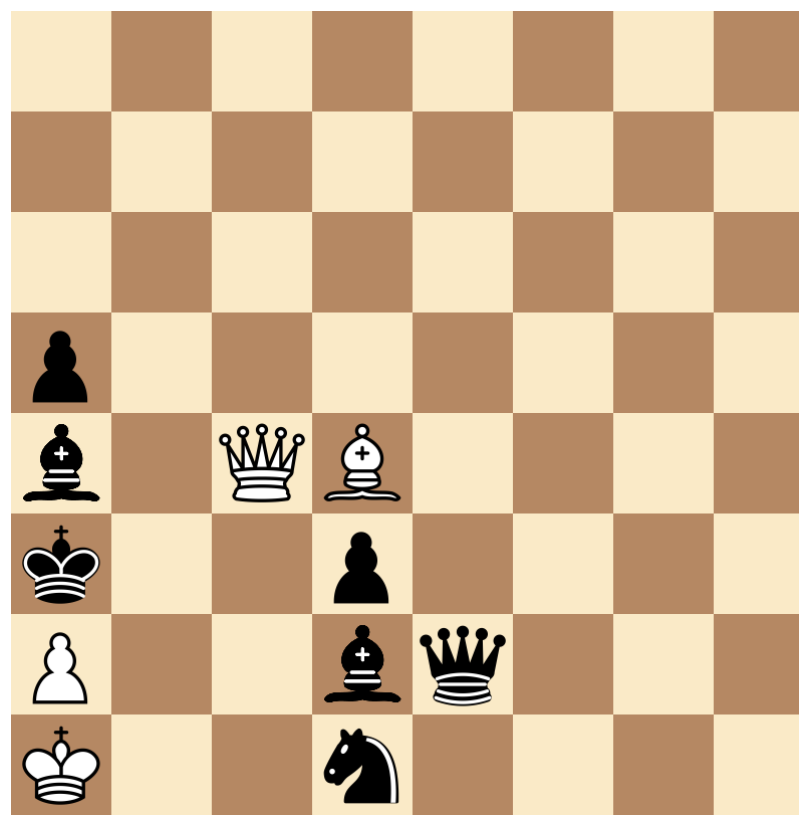

(a) Diagrama da questão 48 - O PEÃO PRETO consegue CAPTURAR a DAMA BRANCA? (Não).

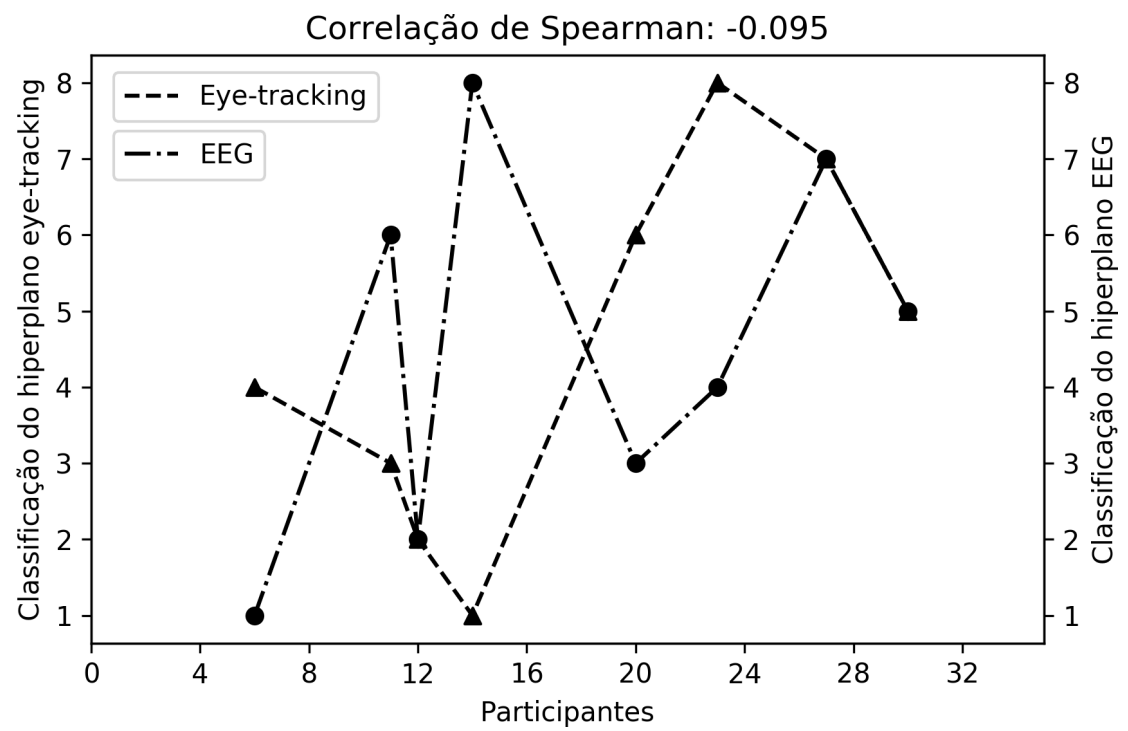

(b) Correlação de Spearman entre hiperplano eye-tracking e EEG.

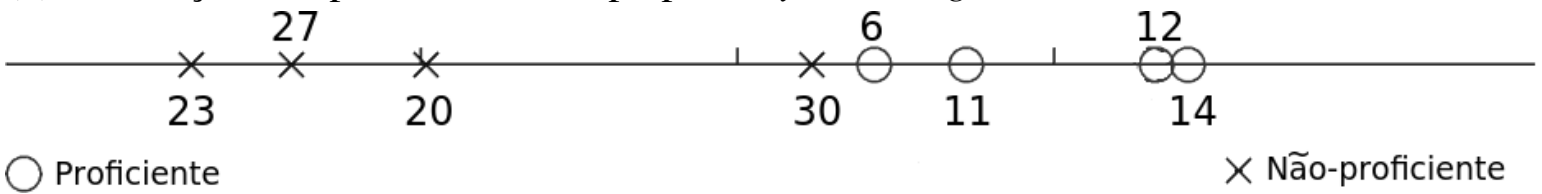

(c) Hiperplano eye-tracking.

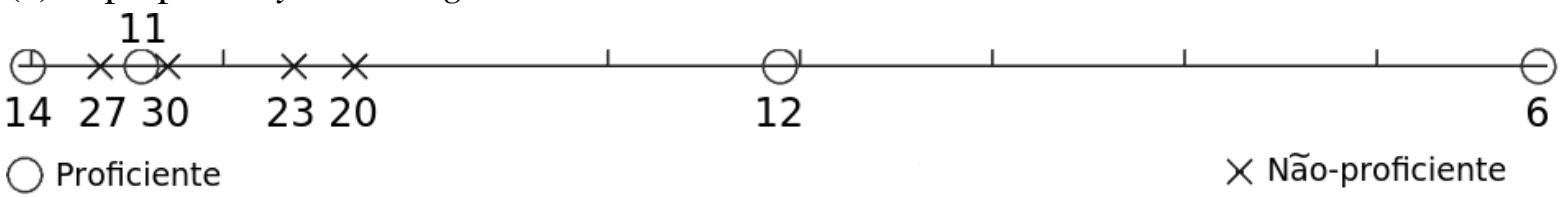

(d) Hiperplano EEG.

Fonte: Autor 
Figura 51 - Heatmaps e mapas cerebrais para a questão 48.

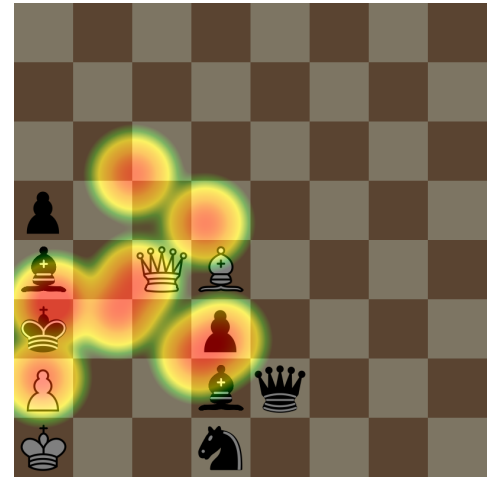

(a) Heatmap do voluntário 23.

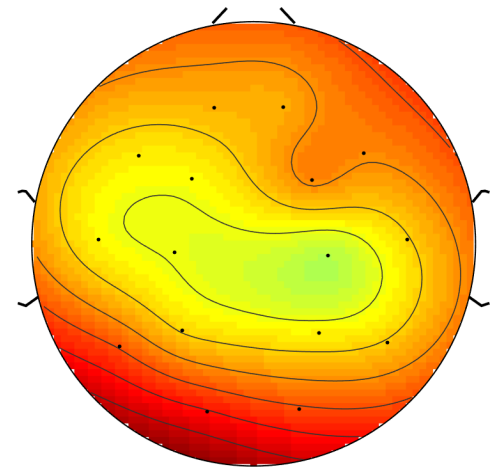

(d) Mapa cerebral do voluntário 23.

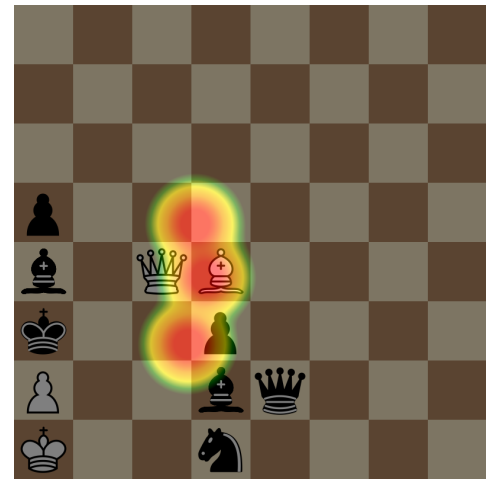

(b) Heatmap do voluntário 6.

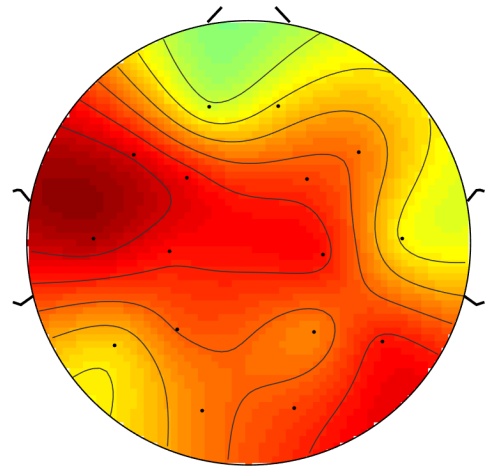

(e) Mapa cerebral do voluntário 6.

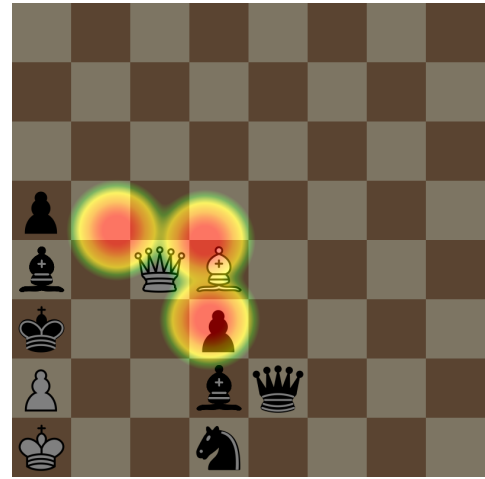

(c) Heatmap do voluntário 14.

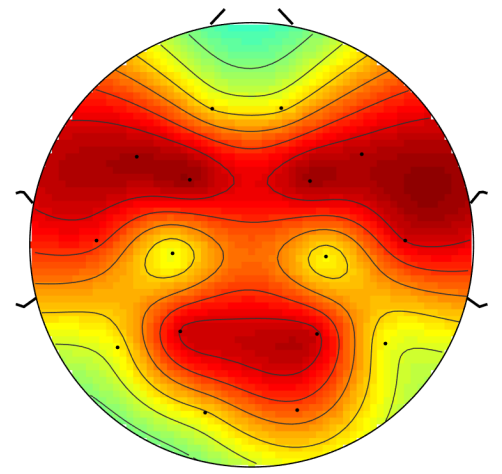

(f) Mapa cerebral do voluntário 14.

Fonte: Autor

é importante para perceber que o rei branco não pode se dirigir para às casas g3 e g5. Nota-se que o padrão de fixações do voluntário 8 (proficiente) não incluiu o rei branco, e para responder à questão deve-se também olhar o rei.

A Figura 51d revela que o voluntário 23 (pior desempenho geral de acordo com a métrica de acurácia e tempo de resposta) teve ativações principalmente na área dos eletrodos $\mathrm{O} 1$ e $\mathrm{O} 2$ relacionados ao processamento primário da visão e do eletrodo T5, correlacionado à área de Brodmann 37, que relaciona-se à função da visão perceptual e função linguística auditiva (MARTINI; TIMMONS; TALLITSCH, 2009; DE OLIVEIRA, 2001; ARDILA; BERNAL; ROSSELLI, 2015; HOMAN, 1988). O voluntário 6, conforme Figura 51e, teve as principais ativações na área do eletrodo T5, assim como ocorreu com o voluntário 23 e do eletrodo F7, relacionado à área de Brodmann 45, que realiza operações relacionadas à recuperação de palavras semânticas (KOESSLER et al., 2009; BUCKNER, 1996). Já o voluntário 14 teve ativações predominantemente no lobo parietal (eletrodos P3 e P4) relacionado com a percepção do tato, dor, vibração, pressão, temperatura, paladar, lobo frontal (F3, F4, F7 e F8), que tem participação 
na movimentação dos músculos responsáveis pelos movimentos oculares e de outros músculos do corpo de forma voluntária, desempenha funções no aprendizado, memória a curto prazo e raciocínio e ativações próximas aos eletrodos T3 e T4, área importante para o reconhecimento e interpretação da palavra (MARTIN, 2014; MARTINI; TIMMONS; TALLITSCH, 2009; KAY; TASMAN; LIEBERMAN, 2002; DE OLIVEIRA, 2001). 



\section{DISCUSSÃO}

Os resultados dos experimentos mostraram que é possível encontrar padrões cognitivos que diferem enxadristas proficientes e não-proficientes. Em sua maioria, os hiperplanos eye-tracking separam melhor os grupos de voluntários do que os hiperplanos EEG. Esse melhor desempenho pode ser atribuído às questões que foram apresentadas, pois, em sua maioria, demandavam rastreamento ocular específico para solução correta em menor tempo.

Mais especificamente, na Categoria 1 (reconhecimento de peças e posicionamento), verifica-se que o grupo menos proficiente demandou mais tempo para solucionar as questões apresentadas. A questão 36 exemplificada anteriormente evidenciou que o hiperplano eyetracking separou melhor os grupos de voluntários do que o hiperplano EEG. Esse resultado já era esperado, pois a questão exige do voluntário a contagem de peças solicitadas, algo que requer esforço visual essencialmente. Além disso, a correlação entre os hiperplanos foi maior que a correlação entre cada hiperplano com a classificação de Volke, indicando que, para esse exemplo, os sinais cognitivos são mais discriminantes para classificar proficiência do que somente acurácia e tempo de resposta.

Para a Categoria 2 (reconhecimento de situações de xeque), observou-se um desempenho superior do grupo mais proficiente, tanto na acurácia quanto no tempo para solucionar os problemas. Semelhante ao resultado apresentado na questão 36, a questão 23 exemplificada também apresentou melhor desempenho para o hiperplano eye-tracking. O hiperplano EEG pode ter tido desempenho inferior ao hiperplano eye-tracking por causa das ativações similares que ocorreram na área ocipital, fazendo com que houvesse confusão na projeção dos voluntários no hiperplano.

A Categoria 3 (reconhecimento de situações de xeque-mate) apresentou resultados semelhantes aos encontrados na Categoria 2 em relação ao tempo médio de resposta e acurácia, situação prevista devido à similaridade entre essas categorias. Na questão que foi analisada, é interessante notar como o mapa cerebral do voluntário 12 foi diferente dos demais a ponto de sua ativação cerebral ocorrer em praticamente todas as áreas, podendo indicar que ele teve um esforço cognitivo maior que os demais voluntários. Analisando-se os heatmaps, verifica-se que o voluntário 27 teve mais pontos de fixação que os demais voluntários e que o heatmap do voluntário 12 é mais conciso, focando no que realmente importa para a resposta da pergunta. 
Os resultados encontrados na Categoria 4 (possibilidade de xeque-mate em um lance) na questão 37 exemplificada não obtiveram correlação de Spearman estatisticamente significativa $(\rho<0.7)$ em nenhum dos hiperplanos. Resultados anteriores de Silva Junior et al. (2018) mostraram que há diferenças significativas na ativação cerebral entre os grupos proficientes e não-proficientes. Esperava-se mais ativações no lobo frontal, área responsável pelo raciocínio lógico, e, consequentemente, melhor desempenho do hiperplano EEG. Já o resultado do hiperplano eye-tracking era esperado, pois as questões dessa categoria demandam menos rastreamento ocular do que planejamento e análise das questões.

Embora essa seja a categoria considerada como a mais difícil dentre todas as apresentadas, não foi possível perceber diferenças significativas em relação ao tempo médio de resposta e, considerando que os voluntários receberam instruções verbalizadas de que o tempo de resposta era um parâmetro importante para os experimentos, é possível que o grupo menos proficiente tenha respondido a várias perguntas de maneira aleatória devido à dificuldade das mesmas, objetivando alcançar um melhor desempenho em questões menos difíceis sem comprometer o tempo de resposta total.

$\mathrm{Na}$ Categoria 5 (conhecimento de jogadas e possibilidade de captura de peças), observase que, assim como nas demais categorias, o hiperplano eye-tracking apresenta melhor desempenho na correlação que o hiperplano EEG. Para a questão 48 exemplificada anteriormente nota-se que há correlação negativa entre as comparações envolvendo os sinais de EEG. Isso pode ser explicado devido à similaridade da ativação cerebral entre principalmente os voluntários não proficientes.

Os resultados encontrados são consistentes com o estado da arte listado no Capítulo 3, em que jogadores proficientes focam seus olhares da parte central do tabuleiro, têm menos fixações quando comparados com jogadores menos proficientes e suas fixações são concentradas entre peças (REINGOLD et al., 2001; CHARNESS et al., 2001; REINGOLD; CHARNESS, 2005; BILALIĆ et al., 2010). Já as ativações cerebrais foram encontradas em diversas áreas do lobo cerebral dependendo do esforço cognitivo realizado pelos voluntários e de acordo com a tarefa proposta. Assim como nos trabalhos de Atherton et al. (2003) e Bilalić et al. (2010), essas ativações em diversas áreas mostram a complexidade encontrada em jogadas de xadrez e como a interpretação desses sinais pode ajudar a entender esse mecanismo de abstração mental. 


\section{CONCLUSÃO}

A revisão bibliográfica e o estado da arte detalhados aqui indicaram a base científica na qual esta tese se fundamenta: uma pesquisa voltada para aquisição e processamento de sinais elétricos do cérebro e dos movimentos oculares de voluntários durante jogadas de xadrez para analisar a proficiência dos mesmos neste ambiente cognitivamente estimulante.

Nos experimentos realizados, foram utilizadas técnicas computacionais de aquisição, pré-processamento e processamento desses sinais adquiridos. Após esse processamento, o método estatístico MLDA foi proposto e utilizado para interpretar, analisar e classificar os sinais cognitivos. Como resultado final, foram gerados hiperplanos discriminantes para separar e classificar jogadores de xadrez de acordo com níveis de proficiência por meio de seus sinais cerebrais e movimentos oculares durante jogadas específicas de xadrez. Além disso, essas métricas cognitivas foram comparadas ao método de ranqueamento baseado em acurácia e tempo de resposta utilizado na literatura afim como alternativa para o Rating Elo.

De maneira geral, os resultados dos experimentos mostraram diferenças significativas nos padrões de movimento ocular entre jogadores com maior e menor proficiência. Os jogadores menos proficientes levaram mais tempo para responder às questões apresentadas, o que pode ser reflexo da fixação dos olhares em um espaço maior, adquirindo-se mais informações a respeito dos diagramas e processando-se mais dados. O conhecimento prévio do xadrez que os mais proficientes têm também é responsável por esse padrão de fixações, pois o conhecimento prévio estrutura e organiza a visão, no sentido do que olhar, do que é relevante numa determinada posição.

Já para os sinais das atividades cerebrais, notou-se poucas diferenças entre os voluntários. A razão para isso pode estar ligada aos voluntários que participaram deste experimento, que em sua grande maioria não eram profissionais, consequentemente, não foi possível separálos com maior acurácia. Outro ponto são as tarefas apresentadas nos experimentos, questões que não exigiram dos voluntários ter conhecimento profundo sobre o jogo.

Analisando-se os biossinais de ativação cerebral e movimento ocular, nota-se que tais informações são complementares para entender o mecanismo humano complexo de abstração mental (conhecimento implícito) nesse processo de aprendizagem e codificação de informação relevante (reconhecimento de padrões). Por meio dos resultados encontrados nesse trabalho, 
pode-se assumir que o jogo de xadrez é baseado em reconhecimento de padrões, em que o processamento da visão é um elemento chave para atingir-se melhor desempenho.

Os resultados também mostram que a métrica tradicional de quantificação de proficiência tem uma acurácia média de até $73,3 \%$, enquanto que as métricas cognitivas baseadas nos sinais de EEG e movimentos oculares têm acurácia média de até 87,5\% e 98\%, respectivamente. Isso indica que as métricas cognitivas aqui propostas são mais discriminantes que a métrica tradicional e têm potencial para traduzir e compreender melhor proficiência em xadrez.

A partir deste trabalho, são vislumbradas possibilidades de pesquisas futuras. Uma delas é predizer o nível de proficiência de enxadristas analisando-se apenas seus sinais cerebrais e de movimentos oculares. Além da análise de proficiência, é possível utilizar essa métrica para aprimorar o ensino de xadrez, já que, a partir dos resultados aqui obtidos, é possível verificar quais são os padrões de ativações cerebrais e de movimentos oculares para alcançar melhor desempenho no jogo.

Como os resultados obtidos a partir dos movimentos oculares mostraram-se mais discriminantes que os resultados a partir das ativações cerebrais, é interessante analisar o scanpath dos participantes, ou seja, não somente o tempo de exposição em cada região do tabuleiro, mas também a sequência de cada uma das fixações. Ainda vislumbrando-se trabalhos envolvendo o olhar humano, a análise da variação pupilar juntamente com a análise do scanpath pode revelar revelar novas informações a respeito da cognição humana, já que a variação pupilar é associada à variação do esforço cognitivo, em que quanto maior o diâmetro da pupila, maior o esforço cognitivo.

Do ponto de vista das ativações cerebrais, como os principais resultados mostram que áreas cerebrais voltadas para o processamento da visão são importantes para solução das tarefas, futuras análises podem ser realizadas com enxadristas com problemas de visão, os quais não possam visualizar o tabuleiro, ou mesmo com enxadristas que jogam com olhos vendados, prática comum entre enxadristas profissionais. Essa análise pode desvendar ativações cerebrais em diferentes áreas do cérebro para uma tarefa cognitiva complexa.

Além disso, as métricas cognitivas aqui estudadas podem ser utilizadas fora do domínio do xadrez. Entender como proficientes em outras áreas do conhecimento humano pensam e observam o ambiente ao redor deles e conseguem obter melhor desempenho que outras pessoas pode ajudar a entender o mecanismo humano complexo de abstração mental (conhecimento implícito). Um exemplo é a área médica, em que existe profissionais capazes de olhar um 
exame e, logo em seguida, dar um diagnóstico preciso baseado em sua análise, ao passo que outros profissionais da mesma área não conseguem ter o mesmo desempenho. 



\section{REFERÊNCIAS}

AMIDZIC, Ognjen; RIEHLE, Hartmut J; ELBERT, Thomas. Toward a psychophysiology of expertise: Focal magnetic gamma bursts as a signature of memory chunks and the aptitude of chess players. Journal of Psychophysiology, Hogrefe \& Huber Publishers, v. 20, n. 4, p. 253-258, 2006.

AMIDZIC, Ognjen et al. Pattern of focal $\gamma$-bursts in chess players. Nature, Nature Publishing Group, v. 412, n. 6847, p. 603-603, 2001.

ARDILA, Alfredo; BERNAL, Byron; ROSSELLI, Monica. Language and visual perception associations: meta-analytic connectivity modeling of Brodmann area 37. Behavioural neurology, Hindawi Publishing Corporation, 2015.

ATHERTON, Michael et al. A functional MRI study of high-level cognition. I. The game of chess. Cognitive Brain Research, Elsevier, v. 16, n. 1, p. 26-31, 2003.

BASTIAANSEN, Marcel CM et al. Event-related alpha and theta responses in a visuo-spatial working memory task. Clinical neurophysiology, Elsevier, v. 113, n. 12, p. 1882-1893, 2002.

BILALIĆ, Merim et al. It takes two-skilled recognition of objects engages lateral areas in both hemispheres. PLoS One, Public Library of Science, v. 6, n. 1, e16202, 2011.

BILALIĆ, Merim et al. Many faces of expertise: fusiform face area in chess experts and novices. The Journal of Neuroscience, Soc Neuroscience, v. 31, n. 28, p. 10206-10214, 2011.

BILALIĆ, Merim et al. Mechanisms and neural basis of object and pattern recognition: a study with chess experts. Journal of Experimental Psychology: General, American Psychological Association, v. 139, n. 4, p. 728, 2010.

BLIGNAUT, Pieter J; BEELDERS, Tanya René; SO, CY. The visual span of chess players. In: EYE TRACKING RESEARCH \& APPLICATIONS, 28., 2008, Savannah. Eye tracking research \& applications. New York: ACM, 2008.

BRODMANN, Korbinian. Vergleichende Lokalisationslehre der Grosshirnrinde in ihren Prinzipien dargestellt auf Grund des Zellenbaues. [S.1.]: Barth, 1909.

BUCKNER, Randy L. Beyond HERA: Contributions of specific prefrontal brain areas to long-term memory retrieval. Psychonomic Bulletin \& Review, Springer, v. 3, n. 2, p. 149-158, 1996.

BURGOYNE, Alexander P et al. The relationship between cognitive ability and chess skill: A comprehensive meta-analysis. Intelligence, Elsevier, v. 59, 2016.

CAMPITELLI, Guillermo; GOBET, Fernand; PARKER, Amanda. Structure and stimulus familiarity: a study of memory in chess-players with functional magnetic resonance imaging. The Spanish journal of psychology, Cambridge Univ Press, v. 8, n. 02, p. 238-245, 2005. 
CAMPITELLI, Guillermo et al. Brain localization of memory chunks in chessplayers.

International Journal of Neuroscience, Taylor \& Francis, v. 117, n. 12, p. 1641-1659, 2007.

CASSON, Alexander J. Wearable EEG and beyond. Biomedical Engineering Letters, jan. 2019.

CESAR, Fábio Henrique Gonçalves. Aquisição e processamento de sinais de rastreamento ocular em jogadas de xadrez. 2016. Dissertação(Mestrado em Engenharia Elétrica) - Centro Universitário da FEI, São Bernardo do Campo, 2016.

CESAR, Fábio Henrique Gonçalves; ROCHA, Fabio Theoto.; THOMAZ, Carlos Eduardo. CHESSLAB: Um arcabouço computacional para aquisição e processamento de sinais de rastreamento ocular em jogadas de xadrez. In: SIBGRAPI CONFERENCE ON GRAPHICS, PATTERNS AND IMAGES, 28., 2015, Salvador. Proceedings of the... New York: IEEE, 2015.

CHABRIS, Christopher F; HAMILTON, Sania E. Hemispheric specialization for skilled perceptual organization by chessmasters. Neuropsychologia, Elsevier, v. 30, n. 1, p. 47-57, 1992.

CHARNESS, Neil. The impact of chess research on cognitive science. Psychological research, Springer, v. 54, n. 1, p. 4-9, 1992.

CHARNESS, Neil et al. The perceptual aspect of skilled performance in chess: Evidence from eye movements. Memory \& cognition, Springer, v. 29, n. 8, p. 1146-1152, 2001.

CHASE, William G; SIMON, Herbert A. The mind's eye in chess. Elsevier, p. 215-281, 1973.

CHEN, Shun-yu. Multivariate statistical analysis. [S.1.]: Taipei: Hwatai Books Co, 2005.

CHENNAMMA, HR; YUAN, Xiaohui. A survey on eye-gaze tracking techniques. Indian Journal of Computer Science and Engineering, Indian Society for Education e Environment, v. 4, n. 5, p. 388-393, 2013.

DE GROOT, Adriaan D. Thought and choice in chess (Vol. 4). Mouton De Gruyter, 1978.

DE OLIVEIRA, MARIA APARECIDA DOMINGUES. Neurofisiologia Do

Comportamento. Rio Grande do Sul: ULBRA, 2001.

DINIZ, Paulo SR; SILVA, Eduardo AB da; NETTO, Sergio L. Processamento Digital de

Sinais-: Projeto e Análise de Sistemas. [S.1.]: Bookman Editora, 2014.

DUAN, Xujun et al. Functional organization of intrinsic connectivity networks in Chinese-chess experts. Brain research, Elsevier, v. 1558, p. 33-43, 2014.

DUAN, Xujun et al. Large-scale brain networks in board game experts: insights from a domain-related task and task-free resting state. PloS one, Public Library of Science, v. 7, n. 3, e32532, 2012b. 
DUAN, Xujun et al. Reduced caudate volume and enhanced striatal-DMN integration in chess experts. Neuroimage, Elsevier, v. 60, n. 2, p. 1280-1286, 2012a.

DUCHOWSKI, Andrew. Eye tracking methodology: Theory and practice. New York: Springer Science \& Business Media, 2017. v. 373.

DUCHOWSKI, Andrew T. A breadth-first survey of eye-tracking applications. Behavior Research Methods, Instruments, \& Computers, Springer, v. 34, n. 4, p. 455-470, 2002.

EGGERT, Thomas. Eye movement recordings: methods. Neuro-Ophthalmology, Karger, v. 40, n. 1, p. 15-34, 2007.

ELO, Arpad E. The rating of chessplayers, past and present. [S.1.]: Arco Pub., 1978.

ERICSSON, K. Anders et al. The Cambridge Handbook of Expertise and Expert

Performance. 2nd Edition. [S.1.]: Cambridge University Press, 2018. ((Cambridge Handbooks in Psychology)). ISBN 9781107137554. Disponível em:

<http://gen.lib.rus.ec/book/index.php?md5=2d4567cf8d781010c867cd5d506c00b2>.

FONTES, Sissy Veloso; FUKUJIMA, Marcia Maiumi; CARDEAL, José Osmar. Fisioterapia neurofuncional: fundamentos para a prática. São Paulo: Atheneu, 2007.

FUENTES, Juan P et al. Use of biotechnological devices in the quantification of psychophysiological workload of professional chess players. Journal of Medical Systems, Springer, v. 42, n. 3, p. 40, 2018.

FUENTES-GARCÍA, Juan Pedro et al. Chess Players Increase the Theta Power Spectrum When the Difficulty of the Opponent Increases: An EEG Study. International Journal of Environmental Research and Public Health, Multidisciplinary Digital Publishing Institute, v. 17, n. 1, p. 46, 2020.

FUENTES-GARCÍA, Juan Pedro et al. Heart and Brain Responses to Real Versus Simulated Chess Games in Trained Chess Players: A Quantitative EEG and HRV Study. International Journal of Environmental Research and Public Health, Multidisciplinary Digital Publishing Institute, v. 16, n. 24, p. 5021, 2019.

FUKUNAGA, Keinosuke. Introduction to statistical pattern recognition. [S.1.]: Elsevier, 2013.

GANANÇA, Maurício Malavasi; CAOVILLA, Heloísa Helena;

GANANÇA, Fernando Freitas. Electronystagmography versus videonystagmography. Brazilian journal of otorhinolaryngology, SciELO Brasil, v. 76, n. 3, p. 399-403, 2010.

GAUR, Rohit P; JARIWALA, Krupa N. A survey on methods and models of eye tracking, head pose and gaze estimation. Journal of Emerging Technologies and Innovative Research, JETIR, v. 1, n. 5, p. 265-273, 2014.

GAZZANIGA, M.S.; IVRY, R.B.; MANGUN, G.R. Cognitive Neuroscience: The Biology of the Mind. New York: Norton, 2009. 
GOBET, Fernand. Expert memory: A comparison of four theories. Cognition, Elsevier, v. 66, n. 2, p. 115-152, 1998.

GONZALEZ, Rafael C.; WOODS, Richard E. Digital image processing. Upper Saddle River, N.J.: Prentice Hall, 2008.

GUYTON, Arthur Clifton; HALL, John E; GUYTON, Arthur C. Tratado de fisiologia médica. 12 ed. São Paulo: Elsevier Brasil, 2006.

HÄNGGI, Jürgen et al. The architecture of the chess player s brain. Neuropsychologia, Elsevier, v. 62, p. 152-162, 2014.

HENNEMANN, Ana Lucia. Neurociências em beneficio da educação!: Você consegue guardar segredos? Disponível em: <https://goo.gl/TFqARi>. Acesso em: 01 fev. 2017. 2012.

HOLMQVIST, Kenneth et al. Eye tracking: a comprehensive guide to methods and measures. Oxford: OUP Oxford, 2011.

HOLODNY, Andrei I. Right Brain Language Function and Academic Honesty. Brain connectivity, Mary Ann Liebert, Inc. 140 Huguenot Street, 3rd Floor New Rochelle, NY 10801 USA, v. 8, n. 6, p. 319-320, 2018.

HOMAN, Richard W. The 10-20 electrode system and cerebral location. American Journal of EEG Technology, Taylor \& Francis, v. 28, n. 4, p. 269-279, 1988.

JASPER, Herbert Henri. The ten twenty electrode system of the international federation. Electroencephalography and clinical neurophysiology, v. 10, p. 371-375, 1958.

JUNIOR, Laercio R. Silva; THOMAZ, Carlos E. Visual Perception Ranking of Chess Players. In: CAMPILHO, Aurélio; KARRAY, Fakhri; WANG, Zhou (Ed.). Image Analysis and Recognition. Cham: Springer International Publishing, 2020. P. 307-315. ISBN 978-3-030-50347-5.

KANDEL, E. et al. Princípios de neurociências. 5 ed. Porto Alegre: AMGH, 2014.

KAY, Jerald; TASMAN, Allan; LIEBERMAN, Jeffrey A. Psiquiatria. São Paulo: Manole, 2002.

KAZEMI, Farhad; YEKTAYAR, Mozafar; ABAD, Ali Mohammadi Bolban. Investigation the impact of chess play on developing meta-cognitive ability and math problem-solving power of students at different levels of education. Procedia-Social and Behavioral Sciences, Elsevier, v. 32, p. 372-379, 2012.

KOESSLER, Laurent et al. Automated cortical projection of EEG sensors: anatomical correlation via the international 10-10 system. Neuroimage, Elsevier, v. 46, n. 1, p. 64-72, 2009.

KRAWCZYK, Daniel C et al. The neural organization of perception in chess experts.

Neuroscience letters, Elsevier, v. 499, n. 2, p. 64-69, 2011. 
LI, Kaiming et al. A multimodal MRI dataset of professional chess players. Scientific data, Nature Publishing Group, v. 2, p. 150044, 2015.

LOUEDEC, Justin Le et al. Deep learning investigation for chess player attention prediction using eye-tracking and game data. In: PROCEEDINGS of the 11th ACM Symposium on Eye Tracking Research \& Applications. [S.1.: s.n.], 2019. P. 1-9.

MACHADO, Angelo Barbosa Monteiro; CAMPOS, Gilberto Belisario. Neuroanatomia funcional. 2 ed. Belo Horizonte: Atheneu Belo Horizonte, 2005.

MARTIN, J.H. Neuroanatomia: Texto e Atlas. 4 ed. Porto Alegre: AMGH, 2014.

MARTINI, F.H.; TIMMONS, M.J.; TALLITSCH, R.B. Anatomia Humana. 6 ed. Porto Alegre: Artmed, 2009. (Coleção Martini).

MAYELI, Mahsa; RAHMANI, Farzaneh; AARABI, Mohammad Hadi. Comprehensive investigation of white matter tracts in professional chess players and relation to expertise: Region of Interest and DMRI connectometry. Frontiers in neuroscience, Frontiers Media SA, v. 12, 2018.

MÜLLER-PUTZ, Gernot R; RIEDL, René; C WRIESSNEGGER, Selina et al. Electroencephalography (EEG) as a research tool in the information systems discipline: Foundations, measurement, and applications. Communications of the Association for Information Systems, v. 37, n. 1, p. 46, 2015.

NICHELLI, Paolo et al. Brain activity in chess playing. Nature, Nature Publishing Group, v. 369, n. 1, p. 191, 1994.

ONOFRJ, M et al. Non-dominant dorsal-prefrontal activation during chess problem solution evidenced by single photon emission computerized tomography (SPECT). Neuroscience letters, Elsevier, v. 198, n. 3, p. 169-172, 1995.

OPENBCI - Open Source Biosense Tools (EEG, EMG, EKGn and more). 2013. Disponível em: <http://www.openbci.com/>. Acesso em: 01 fev. 2019. OpenBCI.

OUELLETTE, David J et al. Cortical thickness and functional connectivity changes in Chinese chess experts. Plos one, Public Library of Science San Francisco, CA USA, v. 15, n. 10, e0239822, 2020.

PEREIRA, Telmo et al. Dynamics of the Prefrontal Cortex during Chess-Based Problem-Solving Tasks in Competition-Experienced Chess Players: An fNIR Study. Sensors, Multidisciplinary Digital Publishing Institute, v. 20, n. 14, p. 3917, 2020.

PICTON, TW et al. Guidelines for using human event-related potentials to study cognition: recording standards and publication criteria. Psychophysiology, Cambridge, v. 37, n. 02, p. $127-152,2000$. 
PINTO DA COSTA, Joaquim; SOARES, Carlos. A weighted rank measure of correlation. Australian \& New Zealand Journal of Statistics, Wiley Online Library, v. 47, n. 4, p. 515-529, 2005.

PORTERFIELD, William. A treatise on the eye, the manner and phaenomena of vision. In two volumes. [S.1.]: G. Hamilton e J. Balfour, 1759.

PRO, Tobii. Tobii Pro - Envision human behavior. 2014. Disponível em:

$<$ http://www.tobiipro.com/>. Acesso em: 01 fev. 2019. Tobii Pro.

PURVES, D. Neuroscience. Connecticut: Sinauer Associates Incorporated, 2004.

REINGOLD, Eyal M; CHARNESS, Neil. Perception in chess: Evidence from eye movements. Cognitive processes in eye guidance, Oxford: Oxford University Press, p. 325-354, 2005.

REINGOLD, Eyal M; SHERIDAN, Heather. Eye movements and visual expertise in chess and medicine. Oxford handbook on eye movements, Oxford University Press Oxford, UK, v. 29, n. 1, p. 528-550, 2011.

REINGOLD, Eyal M et al. Visual span in expert chess players: Evidence from eye movements. Psychological Science, SAGE, v. 12, n. 1, p. 48-55, 2001.

RENNIG, Johannes et al. The temporo-parietal junction contributes to global gestalt perception-evidence from studies in chess experts. Frontiers in human neuroscience, Frontiers, v. 7, p. 513, 2013.

ROCHA, Armando Freitas da et al. A Practical Guide to Brain Data Analysis. [S.1.]: World Scientific, 2017.

ROCHA, Fabio et al. Brain mappings of the arithmetic processing in children and adults. Cognitive Brain Research, Elsevier, v. 22, n. 3, p. 359-372, 2005.

ROCHA, Fabio et al. EEG acquisition and processing for cognitive brain mapping during chess problem solving. IEEE Latin America Transactions, IEEE, v. 14, n. 3, p. 1129-1134, 2016.

SAARILUOMA, Pertti. Chess players' thinking: a cognitive psychological approach. United Kingdom: Psychology, 1995.

SALVUCCI, Dario D; GOLDBERG, Joseph H. Identifying fixations and saccades in eye-tracking protocols. In: 20., 2000, Palm Beach Gardens. PROCEEDINGS of the... New York: ACM, 2000.

SANEI, Saeid; CHAMBERS, Jonathon A. EEG signal processing. Nova Jersey: John Wiley \& Sons, 2013.

SANTANGELO, Valerio; MACALUSO, Emiliano. Visual salience improves spatial working memory via enhanced parieto-temporal functional connectivity. Journal of Neuroscience, Soc Neuroscience, v. 33, n. 9, p. 4110-4117, 2013. 
SHANNON, Claude E. Communication theory of secrecy systems. Bell system technical journal, Wiley Online Library, v. 28, n. 4, p. 656-715, 1949.

SHERIDAN, Heather; REINGOLD, Eyal M. Expert vs. novice differences in the detection of relevant information during a chess game: evidence from eye movements. Psychological perspectives on expertise, Frontiers Media, p. 11, 2015.

SILVA, Wilson da et al. Raciocinio logico e o jogo de xadrez= em busca de relações. [sn], 2010.

SILVA JUNIOR, Laercio Ribeiro da et al. A Combined Eye-tracking and EEG Analysis on Chess Moves. IEEE Latin America Transactions, IEEE, v. 16, n. 5, p. 1288-1297, 2018.

SÖRNMO, Leif; LAGUNA, Pablo. Bioelectrical signal processing in cardiac and neurological applications. [S.1.]: Academic Press, 2005. v. 8.

SUBHA, D Puthankattil et al. EEG signal analysis: a survey. Journal of medical systems, Springer, v. 34, n. 2, p. 195-212, 2010.

TEPLAN, Michal. Fundamentals of EEG measurement. Measurement science review, v. 2, n. 2, p. 1-11, 2002.

THOMAZ, Carlos Eduardo; KITANI, Edson Caoru; GILLIES, Duncan Fyfe. A Maximum Uncertainty LDA-based approach for Limited Sample Size problems-with application to Face Recognition. Journal of the Brazilian Computer Society, SciELO Brasil, v. 12, n. 2, p. 7-18, 2006.

TIKHOMIROV, OK; POZNYANSKAYA, ED. An investigation of visual search as a means of analyzing heuristics. Soviet Psychology, Taylor \& Francis, v. 5, n. 2, p. 3-15, 1966.

UNDE, Sukhada A; SHRIRAM, Revati. Coherence analysis of EEG signal using power spectral density. In: PROCEEDINGS of the 2014 Fourth International Conference on Communication Systems and Network Technologies. [S.1.: s.n.], 2014. P. 871-874.

VANDENBERGHE, Rik et al. Functional anatomy of a common semantic system for words and pictures. Nature, Nature Publishing Group, v. 383, n. 6597, p. 254-256, 1996.

VANLIERDE, Annick et al. Occipito-parietal cortex activation during visuo-spatial imagery in early blind humans. Neuroimage, Elsevier, v. 19, n. 3, p. 698-709, 2003.

VILLAFAINA, Santos et al. Electroencephalographic response of chess players in decision-making processes under time pressure. Physiology \& behavior, Elsevier, v. 198, p. 140-143, 2019.

VOLKE, H-J et al. On-coupling and off-coupling of neocortical areas in chess experts and novices as revealed by evoked EEG coherence measures and factor-based topological analysis-a pilot study. Journal of Psychophysiology, Hogrefe \& Huber, v. 16, n. 1, p. 23, 2002. 
WADE, Nicholas; TATLER, Benjamin W. The moving tablet of the eye: the origins of modern eye movement research. Oxford: Oxford University, 2005.

WRIGHT, Michael $\mathrm{J}$ et al. ERP to chess stimuli reveal expert-novice differences in the amplitudes of N2 and P3 components. Psychophysiology, Wiley Online Library, v. 50, n. 10, p. 1023-1033, 2013.

WUKOVITS, J.F. Vince Lombardi. New York: Chelsea House, 1997.

XEQUE \& Mate - CAMPEORNATO PAULISTA DE XADREZ ESCOLAR. 2011. Disponível em: <https://goo.gl/ARqrKn>. Acesso em: 01 fev. 2019. Xeque \& Mate.

ZHANG, Chi et al. Automatic artifact removal from electroencephalogram data based on a priori artifact information. BioMed research international, Hindawi, v. 2015, 2015. 